\title{
Rethinking economic growth and structural change
}

\author{
Citation for published version (APA):
}

Guillard, C. (2019). Rethinking economic growth and structural change: the role of boundaries and linkages between industries. [Doctoral Thesis, Maastricht University]. Universitaire Pers Maastricht. https://doi.org/10.26481/dis.20191127cg

Document status and date:

Published: 01/01/2019

DOI:

$10.26481 /$ dis.20191127cg

Document Version:

Publisher's PDF, also known as Version of record

\section{Please check the document version of this publication:}

- A submitted manuscript is the version of the article upon submission and before peer-review. There can be important differences between the submitted version and the official published version of record.

People interested in the research are advised to contact the author for the final version of the publication, or visit the DOI to the publisher's website.

- The final author version and the galley proof are versions of the publication after peer review.

- The final published version features the final layout of the paper including the volume, issue and page numbers.

Link to publication

\footnotetext{
General rights rights.

- You may freely distribute the URL identifying the publication in the public portal. please follow below link for the End User Agreement:

www.umlib.nl/taverne-license

Take down policy

If you believe that this document breaches copyright please contact us at:

repository@maastrichtuniversity.nl

providing details and we will investigate your claim.
}

Copyright and moral rights for the publications made accessible in the public portal are retained by the authors and/or other copyright owners and it is a condition of accessing publications that users recognise and abide by the legal requirements associated with these

- Users may download and print one copy of any publication from the public portal for the purpose of private study or research.

- You may not further distribute the material or use it for any profit-making activity or commercial gain

If the publication is distributed under the terms of Article $25 \mathrm{fa}$ of the Dutch Copyright Act, indicated by the "Taverne" license above, 







\section{Rethinking economic growth and structural change}

The role of boundaries and linkages between industries 
(C) Copyright Charlotte Guillard, Maastricht, 2019

Universitaire Pers Maastricht

ISBN 9789463805865 


\section{Rethinking economic growth and structural change}

The role of boundaries and linkages between industries

\section{DISSERTATION}

to obtain the degree of Doctor at Maastricht University, on the authority Prof. Dr. Rianne M. Letschert, rector magnificus,

in accordance with the decision of the Board of Deans, to be defended in public on

Wednesday 27 November 2019, at 12.00 hours

by

Charlotte Guillard

This thesis was written under the jointly supervised degree program of Strasbourg University and Maastricht University. 


\section{Supervisors}

Prof. Dr. Robin Cowan

Prof. Dr. Pierre Mohnen

\section{Assessment Committee}

Prof. Dr. Bart Verpagen (Chair)

Dr. Swati Dhingra (London School of Economics)

Prof. Dr. Koen Frenken (Utrecht University)

Prof. Dr. Patrick Llerena (Strasbourg University) 


\section{Summary}

Economic development is associated with changes in production and export structures. Each country masters a set of capabilities, i.e. a set of tasks and knowledge necessary for the realization of some products. Mastering additional capabilities allows countries to produce more complex products or technologies. Understanding economic development involves understanding how countries can add new products to their production and export basket and develop particular industries. Each industry has specific characteristics in terms of capabilities, technologies and knowledge and in terms of the nature of their production. In this thesis, I provide empirical evidence of the importance of both boundaries and linkages between industries to understand structural change and the dynamics of economic growth.

Chapter 2 proposes a new methodology for identifying patterns of organization of industries and their evolution over time. To do this, I analyze the cluster structure of the product network built from export data. Results show that products cluster according to different factors: their complexity and technological domains, the abundance of low-skilled labor or of natural resources they require, as well as global value chains and vertical integration of their production process. Moreover, I find that technological domains and boundaries between industries are not always clear-cut and can evolve over time.

In chapter 3 , I study the dynamics of economic growth by examining the characteristics and determinants of transitions between different medium-term growth regimes (rapid growth, slow growth and recession) using a semi-Markov framework. Results indicate that the effect of the manufacturing sector on economic growth is far from uniform and that the measure of economic structure also matters. In addition, clusters with similar technological intensity play a different role in the dynamics of growth, and, global value chains (GVCs) may explain some of these differences. Furthermore, although the textile industry is often seen as a stepping stone to industrialization, in this study the effect of this cluster is negative in many cases. Finally, this analysis highlights the presence of "recesion traps", which are largely driven by a greater specialization natural resources-based manufacturing 
clusters.

Differences between industries affect not only the growth process through productivity gaps, but also the stimulation they provide to the rest of the economy through upstream and downstream linkages. Chapter 4 examines the impact of inter-industry interconnections on economic performance, focusing on demand dynamics (i.e. backward linkages). I relax two strong assumptions associated with the traditional calculation of the output multiplier, which makes it possible to estimate the degree of response to demand shocks from the supplying industries. Results show that there are significant differences across industries and countries. Manufacturing industries, and in particular final consumer goods ones, tend to be less responsive to shocks in demand relative to services. Significant differences are also observed between countries since manufacturing industries in developed countries tend to be less sensitive to demand shocks than in developing countries. 
À mes parents 



\section{Acknowledgements}

It is hard to express on paper the extent of my happiness to have finalized this thesis, and along the way, to have had such a rewarding experience. I was lucky to meet extraordinary people throughout this process that have directly or indirectly contributed to this book.

I am deeply grateful to Prof. Robin Cowan for his challenging comments, his patience and precious support. Prof. Pierre Mohnen was essential to this work as well in providing an additional perspective and very helpful comments and advice. I would also like to thank Bart Verspagen, Swati Dhingra, Koen Frenken and Patrick Llerena for accepting to be part of the reading committee and for taking the time to read this thesis and provide insightful comments on it.

My research has taken me to the most beautiful and unexpected places. Each and everyone of them has contributed to make my experience more gratifying. In Strasbourg, I owe a sincere thank you to the BETA at Strasbourg University for achieving the difficult balance of granting me a great amount of flexibility while making me comply with my deadlines. Bertrand Koebel, Julien Penin, Danielle and Geraldine were of great assistance in facilitating this. I am also lucky to have met such great colleagues. Thank you Marie, Narimene, Mischael, Prosper and Yankou for making my stays in Strasbourg more enjoyable.

In Maastricht, I am extremely thankful to the staff of UNU-MERIT and especially to Ad, Eric, Mourik-Jan, Herman, Howard, and of course, Eveline for their excellent work in providing me with the support and assistance I needed. UNU-MERIT and Maastricht were also amazing places to meet friends and interact with different cultures. I am deeply grateful to Andi, Dani, Fernando, Julieta, Lorena and Simone for making this experience so smooth and entertaining. I would also like to extend thanks to Josy and Lila for sharing great moments, both at home and abroad. I am happy to have crossed path with Agustin, Alison, Alejandro, Andres, 
Carmen, Daniel, Elisa, Francesca, Francois, Giorgio, Iman, Jennifer and Tashmia, who greatly contributed to making Maastricht more fun.

In Seville, I owe a huge debt of gratitude to Alicia, Chipi, Magdalena, Matias, Ricardo and Dr Martin.

In Washington D.C., I have learned a lot about innovation and development challenges in Latin America, working at the Inter-American Development Bank, thanks to Jose Miguel Benavente, Gustavo Crespi, Matteo Grazzi, Jordi Jaumandreu, Carlo Pietrobelli and Monica Salazar. Many thanks go to Carlos, Diego, Kayla and Pauline as well for lightening the mood during my breaks.

In London, I am particularly grateful to Ralf Martin, who gave me the opportunity to work with the great team of the Watson project at Imperial College. Thank you Dennis and Jennifer for being such enthusiastic colleagues and friends. Thank you Cleo, Lin, Mara and Esma for making my lunches more pleasant. I was also lucky to enjoy the good company of Claire, Damien, Ksenia, Mattia and Solene during my free time. I would also like to thank Nicola Venini for taking the time to make the cover of this book.

Because the knowledge process is cumulative, I wish to acknowledge the French education system and its invaluable teachers. Without them this thesis might not have seen the light, they have largely contributed to build a strong knowledge basis for this research project. I am also indebted to the R, Stackoverflow and Wikipedia communities. They have been a precious source of information for my research progress.

In every place and state, some people were always present. Thank you Nelson for being such an amazing friend throughout the years. A great deal of gratitude goes to Christian, for being the best partner one could wish for. Your continuous encouragement, patience and love were essential for the completion of this work. I would also like to extend my thanks to the Vanoni family for being so welcoming during my stays in Italy. Special thanks go to the people who have always been a source of great joy and motivation. I am thankful to have had such generous and loving grand-parents. I am also lucky to have grown up alongside Antoine, Evelyne and Marine and to have shared such memorable moments with them. Finally, I wish to thank my parents, Charles and Elisabeth, for their unconditional love and support, and for the way they let me discover the world. Because words would not suffice to express the extent of my gratitude, this book is dedicated to them. 


\section{Contents}

\begin{tabular}{lll}
\hline 1 & Introduction & 1
\end{tabular}

2 Mapping industrial patterns and structural change in exports $\quad 13$

2.1 Introduction . . . . . . . . . . . . . . . . . . . 13

2.2 Background and literature review . . . . . . . . . . . . . . . 15

2.3 Methodology . . . . . . . . . . . . . . . . . 22

$2.3 .1 \quad$ Network construction and data . . . . . . . . . . . . . . . . 22

2.3.1.1 The export network and the product space . . . . . 22

2.3 .1 .2 Data . . . . . . . . . . . . . . . 26

2.3 .2 The backbone of the product space . . . . . . . . . . . . 26

2.3 .3 The community structure of the product space . . . . . . . . 31

2.4 Results . . . . . . . . . . . . . . . . . . . . . . . . 32

2.5 Discussion: export patterns, structural change and factors of production .......................... 41

2.6 Conclusion and limitations . . . . . . . . . . . . . . . . . . 46

3 Breaking down the effect of manufacturing on the dynamics of $\begin{array}{ll}\text { economic growth } & 49\end{array}$

3.1 Introduction . . . . . . . . . . . . . . . . . . . . . . . 49

3.2 Manufacturing and economic growth: a review of the literature . . . 50

3.3 Growth patterns and economic specialization: data and stylized facts 57

3.3.1 Development patterns and dynamics: definitions and stylized facts . . . . . . . . . . . . . . . 57

3.3.2 Measuring economic structure in manufacturing exports . . . 61

3.4 A semi-Markov model for analyzing transitions between growth states 63

3.5 Results . . . . . . . . . . . . . . . . . . . . 70

3.5.1 The characteristics of growth transitions . . . . . . . . . . . 70

3.5.2 The effect of the economic structure on growth transitions . . 73



4 The extent of demand ripple effects on economic growth 81

4.1 Introduction . . . . . . . . . . . . . . . . . . 81

4.2 Literature review . . . . . . . . . . . . . . . . . . . . . 82

4.3 Methodology . . . . . . . . . . . . . . . . . 87 
4.3.1 Measuring the transmission of demand shocks by industry . . 87 4.3 .1 .1 Estimation method . . . . . . . . . . . . 990

4.3 .2 The determinants of the response to demand shocks . . . . . 92

4.3 .3 Data . . . . . . . . . . . . . . . . . . . . 93

4.4 Results. . . . . . . . . . . . . . . . . . . . . . . . . . . . . . . . . . 93

$4.4 .1 \quad$ Measuring the transmission of demand shocks by industry . . 93

\begin{tabular}{lll}
\hline 4.4 .2 & The determinants of the response to demand shocks $\ldots . .9$ & 95
\end{tabular}

4.5 Conclusion $\ldots \ldots \ldots \ldots \ldots$

$\begin{array}{lll}5 \text { Conclusion } & 103\end{array}$

\begin{tabular}{ll}
\hline References & 109
\end{tabular}



A.1 Serrano et al. (2009)'s network reduction method . . . . . . . . . 117

A.2 The Infomap algorithm . . . . . . . . . . . . . . . . . . . . . 119

A.3 Results. . . . . . . . . . . . . . . . . . . . . . . . 122

A.4 Robustness checks . . . . . . . . . . . . . . . . . . . . 140

A.4.1 Network reduction method . . . . . . . . . . . . . . . . 140

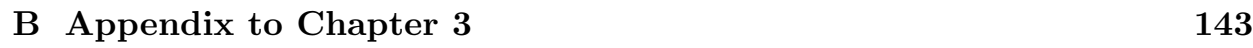

B.1 Dataset . . . . . . . . . . . . . . . . . . . . 143

B.2 Static community structure of the manufacturing exports . . . . . 143

B.3 Collinearity Diagnostics . . . . . . . . . . . . . . . . 147

B.4 Tests for the choice of the model . . . . . . . . . . . . . . . . . . 148

B.4.1 Testing the distribution of the hazard rate of waiting times . 148

B.4.2 Testing the number of the lag of the economic structure variables . . . . . . . . . . . . . . . . . . 149



C.1 Measuring weight disparity . . . . . . . . . . . . . . . 151

C.2 IOT data . . . . . . . . . . . . . . . . . 153

\begin{tabular}{ll}
\hline Valorization & 159
\end{tabular}

\begin{tabular}{ll}
\hline About the author & 163
\end{tabular} 


\section{List of Tables}

$2.1 \quad$ Size and density of common networks and snapshots of the product



2.2 Network statistics of each snapshot of the product space reduced using a global threshold on weights . . . . . . . . . . . . . . . . . 29

2.3 Network statistics of snapshots of the product space reduced using Serrano (2009)'s multiscale backbone technique . . . . . . . . . . . . 31

$3.1 \quad$ Descriptive statistics of the transitions and waiting time observed . . 61

3.2 Descriptive statistics of the transitions and waiting time observed (without Sudan) . . . . . . . . . . . . . . . 65

3.3 Estimated parameters of the hazard rate of waiting time and of

\begin{tabular}{|c|}
\hline the Markov chain (transition probabilities) for each transition $h j$ \\
\hline
\end{tabular}
(unrestricted model) . . . . . . . . . . . . . . 72

3.4 Estimated parameters of the hazard rate of waiting time and of the Markov chain (transition probabilities) for each transition $h j$ (restricted model) . . . . . . . . . . . . . . 72

$3.5 \quad$ Estimated coefficient parameters of the export value variables . . . . 77

3.6 Estimated coefficient parameters of the export diversity variables . . 78

$4.1 \quad$ Determinants of the response to demand shocks . . . . . . . . . . 100

A.1 Evolution of the number of countries and product in the international trade network . . . . . . . . . . . . . . . . 113

A.2 Correlation between the similarity measures . . . . . . . . . . . . . . 113

A.3 Interquartile range of each similarity measures . . . . . . . . . . . . 113

A.4 Definition of the set of industries in terms of SITC Revision 2 at 2 digits. . . . . . . . . . . . . . . . . 122

A.5 Leamer (1984) classification (pp. 62-63) . . . . . . . . . . . . . . . . 139

A.6 Lall (2000) classification . . . . . . . . . . . . . . . . . . . . 140

B.1 Variables . . . . . . . . . . . . . . . . . . . . . . . 143

B.2 Network statistics of the product space aggregate (1962-2000) reduced using Serrano (2009)'s multiscale backbone technique . . . . . 144

B.3 Results of the static community structure: number of products in each community by SITC . . . . . . . . . . . . . . . . . . 145 
B.4 Results of the static community structure: number of products in each community by SITC . . . . . . . . . . . . . . . . . . 146

B.5 Variance inflation factor tests . . . . . . . . . . . . . . . . . . . 148

B.6 Likelihood-ratio tests for different number of lags of the economic structure variables . . . . . . . . . . . . . . . . . . . . . . . 149

B.7 $\quad$ AIC for different number of lags of the economic structure variables 149

C.1 IOT country list . . . . . . . . . . . . . . . . . . . 153

C.2 IOT industry list . . . . . . . . . . . . . . . . . . . 154 


\section{List of Figures}

3.1 Distribution of GDP per capita growth from 1950 to 2006 . . . . . . 58

3.2 Share of observations corresponding to episodes of rapid growth, \begin{tabular}{|l}
\hline slow growth and recession from 1950 to 2006 \\
\hline
\end{tabular} . . . . . . . . . 59

3.3 Distribution of the fit of the estimation of GDP per capita growth



$3.4 \quad$ Relationship between export value versus export diversity in differ-



3.5 The three states model used for growth evolution . . . . . . . . . . 64

3.6 Survival rate of waiting time, hazard rate of waiting time and hazard rate of the semi-Markov process for each transition . . . . . . . . 73

4.1 Optimal value of $\alpha$ by industry and country $\ldots \ldots \ldots$. . . . . 96

$4.2 \quad$ Distribution of $\alpha$ over countries, by industry $\ldots \ldots \ldots \ldots . \ldots 97$

4.3 Distribution of $\alpha$ over industries, by country . . . . . . . . . . . 99

A.1 Weight distribution of the snapshots for each similarity measure . . 114

A.2 Simulation of two specific cases in which similarity measures differ . 115

A.3 Weight distribution of the snapshots of the product space . . . . . 116

A.4 The disparity filter and graph connectedness. . . . . . . . . . . . . 119

A.5 Huffman coding. . . . . . . . . . . . . . . . . . . 120

A.6 Share of products from each industry across communities (in \%) . . 123

A.12 Alluvial diagram of the evolution of the communities linked to the electronics industry . . . . . . . . . . . . . . . . . . 129

A.13 Alluvial diagram of the evolution of the communities linked to the machinery industry . . . . . . . . . . . . . . 130

A.14 Alluvial diagram of the evolution of the communities linked to the textile industry . . . . . . . . . . . . . . . 131

A.15 Alluvial diagram of the evolution of the communities linked to the petroleum industry . . . . . . . . . . . . . . . . 132

A.16 Alluvial diagram of the evolution of the communities linked to the wood, paper and metals industries . . . . . . . . . . . . . 133

A.17 Product overlap between communities across time (in \%) . . . . . . 134

A.22 Entropy of industry shares across communities . . . . . . . . 139 
B.1 Correlation coefficients . . . . . . . . . . . . . . . . . 147

C.1 Distribution of the normalized disparity of the demand for intermediate consumption, by industry . . . . . . . . . . . . . . 152

C.2 Distribution of the share of output of industry $i$ that is used as intermediate consumption, by industry . . . . . . . . . . . . 155

C.3 Share of output of industry $i$ in total output, by industry and country 156

C.4 Coefficient $\alpha^{k}$ in the revised Leontief matrix, $\tilde{L}$, for different values

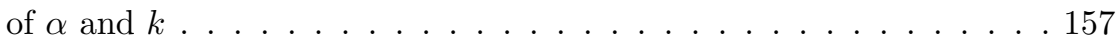




\section{Chapter 1}

\section{Introduction}

Economic growth is pursued by most countries as it is believed to be the main root of wealth and development. Since the industrial revolution, several countries have experienced sustained periods of rapid growth driven by changes in their economic structure, that is structural change. In particular, their economic resources have shifted from a traditional to a modern sector. Each sector and industry has a particular effect on growth dynamics because it differs from others in terms of productivity, technological opportunities and the nature of the production process. Past growth experiences show that the economic structure of countries and its dynamics are at the center of the growth process. Yet, several questions remain relative to the way elements of the economic system interact, in particular industries, the mechanisms of structural change and its effects on growth dynamics. In particular, what differences and interdependencies between industries lead to the emergence of important export and production patterns and which of these prevail in instigating structural change? How do these differences and interdependencies affect growth dynamics? This thesis aims at addressing these questions using a network approach and paying particular attention to the dynamics embedded in the economic system of countries.

Countries' economic growth experiences vary because the composition of their economic systems differ as each possesses a different set of capabilities. Capabilities are the skills that enable a country to make, and in a context of growing internationalization of production and commercialization of products, to export a given set of products. Products also differ in the combination of capabilities they require to be made (Weitzman, 1998, Arthur, 2009). Some products are more complex in that they entail a larger and more diverse set of capabilities that only a few countries possess. Products can also be distinguished by their technological domain Arthur, 2009): that is they are part of a cluster of technologies that rely on one or several common phenomena. For instance, electronic products rely on the phenomena associated with the electron. Other capabilities, such as those necessary for natural resource extraction, marketing, the quality of infrastructure and of institutions as 
well as policies to have just a few are also crucial for the economic performance of countries. All these dimensions constitute the capabilities that enable an economy to produce and export different types of products and to be more or less competitive in a given set of industries. In sum, the mix of capabilities a country possesses both reflects and determines many aspects of its performance. This leaves us with an important question: how are products related to each other and how does this affect structural change, and ultimately growth dynamics?

Most classical and trade models consider a continuous sequence of goods from low to high-tech, in which adjacent goods differ only slightly in their technologies. This implies that countries have one possible path to development, that is from low to high-tech, and that it does not become easier or harder to move towards the export of products of higher technological value along the path since the difference between adjacent goods is minimal. In contrast, one could consider that products are related to each other not as a continuum but as a network. In this setting, different products share common capabilities. Therefore, it is easier for countries to add products that have capabilities in common with what they already export. The product space is the first attempt to empirically represent the relationship between products as a network (Hidalgo et al. 2007, Hausmann and Hidalgo, 2011). In this network, the relationship between two products is measured by the number of times they are both found in the export basket of countries. This measure accounts for how common each good is in the export basket of countries in general. This measures the extent to which products are related in terms of the capabilities they require, assuming that the set of products a country exports defines well what it can produce and that products that are exported together require a similar set of capabilities. Let's imagine that a product A shares common capabilities with three other products B, C and D. In this context, a country able to produce A would have several options to add new products to its basket $(\{B, C, D\},\{B, C\},\{B, D\}$, $\{C, D\},\{B\},\{C\},\{D\})$ and it would have to acquire the missing capabilities in order to add any of these similar products. Acquiring the missing capabilities may implies more or less effort from the country depending on two things: (i) what it can already do, and (ii) the extent of additional skills that are required to make the newly added product. For instance, if a country is making shirts, it will be easier to start making pants than computers. This is because the production of shirts and pants involves similar capabilities, which are shared by firms within the textile industry. We know that firms tend to share common capabilities within 
industries (Malerba, 2002). But, what defines industries and what role do they play in economic development?

Industries consist in a set of firms that have similar characteristics. Industries differ in terms of $(i)$ the type of knowledge and technology they use and generate, (ii) the nature of the products they make, and (iii) the type of production process involved. On the one hand, depending on the industry, knowledge has different degrees of cumulativeness, tacitness, specific knowledge, technological opportunities and knowledge domain (that is the type of phenomena they rely on) (Nelson and Winter, 1982, Dosi, 1982, Malerba, 2002 and Arthur, 2009). Note that the association of a product or an industry to specific technological domains can also evolve with time. While cameras used to rely on chemical principles, most of them now are made using electronic and digital technologies. This change in technology domain is hereafter referred to as "redomaining". On the other hand, industries differ in terms of the technological complexity of the products they make, whether the production process is continuous or discontinuous, as well as the physical aspects of the products. The physical aspects of products are important in this context because they influence the ease of transporting them. This in turn affects the easiness to fragment the production process (Lall, 2000). Why do these differences between industries and products matter for structural change and economic growth?

These differences engender boundaries and interdependencies between industries that affect the way structural change takes place. Boundaries between industries can emerge because production processes within an industry tend to be associated to a specific set of capabilities, and in particular of knowledge and technologies. The extent to which a firm from industry A can access knowledge from another industry B depends on the degree of cumulativeness, tacitness, specificity of the knowledge from industry B. The importance of boundaries between industries draws into question the validity of the general assumption according to which the knowledge stock is freely available (Arrow, 1962b and Arrow, 1962a). On the other hand, the potential of fragmenting the production process in some industries creates pathways between otherwise unrelated industries. This emergent phenomenon tends to blur the boundaries between low and high-tech industries and generates opportunities for countries to catch up by integrating global value chains (GVC). For instance, the production process of the electronics industry is highly fragmented between developed and developing countries (in particular in 
East Asia). In this context, the level of technological capabilities of countries is no longer reflected by the industry but by the stage of the production process of their activities. In the example of the electronics industry, the production process involves a variety of tasks, from the most complex ones, such as product design, to the least complex ones, such as assembly. Typically, developing countries enter this industry by doing low-skill assembly work, and work their way up the value chain by acquiring new capabilities at each step.

Furthermore, interdependencies emerge in the economic system due to the presence of complementarities and input-output relations between industries. Complementarity can arise in different ways. First, investment has complementary effects, both direct and indirect. In the indirect case, when an industry invests it increases its production capacity and its economic outcome. This increase, in turn, translates into higher investments elsewhere in the economy. This mechanism is known as the induced investment. As for the direct case, investments in one industry create the need for additional investments in another or several other industries (Hirschman, 1958). For instance, investments in transport services call for additional investments in infrastructure (to expand, maintain or renew the infrastructure).

Furthermore, technical complementarities can also exist and operate through two different channels. The presence of economies of scale can induce complementarities such that the increase in the output of an industry leads to a decrease in marginal cost in another industry. This occurs under two scenarios: (i) if the products from the two industries are related through input-output links and the input is produced under increasing returns to scale, or, (ii) if they are complementary inputs in the production of a third good and are both produced under increasing returns to scale. Another type of technical complementarity can arise when the increased use of one product indirectly leads to an increase in demand of another (Hirschman, 1958). This does not refer to the case of derived demand in which two products are complementary inputs in the production process of a third product, where an increase in the use of the third product would be the triggering factor. Instead, this corresponds to a more indirect complementarity in use where the demand for one product triggers the need for other products that are not directly involved in its production process. For example, the construction of a new airport can indirectly lead to an increase in demand for transport services, office furniture, new residential buildings and car parks around the airport and so on.

Because of the presence of complementarity effects and input-output interlinkages between industries, an initial change in output in one industry can have a 
much greater final impact on the aggregate output of the whole economy through a multiplier effect. In other words, it quantifies the extent to which shocks in industry B diffuse to the whole economy. Two different inducement mechanisms can arise, one from the demand side, backward linkages, and another from the supply side, forward linkages. On the one hand, backward linkages represent the links from user to supplier industries. Because of the presence of these links, an increase in demand in industry $\mathrm{A}$ is likely to trigger an increase in demand in its supplier industries due to the presence of investment and technical complementarities. This is because industry A will require more inputs to produce more output and will request its suppliers to provide these additional inputs. This can only occur if the firms operate under decreasing or constant returns to scale. For instance, to make twice as much orange marmalade, you will need twice as much oranges and sugar. If the demand for this marmalade increases, the demand for oranges and sugar will also rise. On the other hand, forward linkages correspond to the diffusion of shocks from supplier to user industries. In this case, an increase in productivity of a supplier industry leads to a reduction in the price of its products. Because these products are inputs in other industries, this shock further results in a decrease in the marginal costs of the industries using these inputs and an increase of their profitability. This of course depends on the pressure firms in the supplier industry have to reduce their prices, and in particular on the concentration of the market in which they operate.

Industry linkages go beyond input-output relationships at the intermediate consumption level. Industries are also related through the technologies they exchange. The existence of technological complementarities constitutes an additional triggering factor to the development of technologies and industries Rosenberg, 1976 and Rosenberg, 1979). They are likely to cause technological interdependencies between apparently unrelated processes and industries. Technological progress within a technological regime often relies on the improvement of major components $\mathrm{Nel}-$ son and Winter, 1982 and Arthur, 2009). The introduction of an improved component into a technology, also called internal replacement, creates a technological imbalance. This imbalance needs to be corrected for the whole to work in coordination and for the technology to be used efficiently. Thereby, the problem stimulates the demand and search for new solutions within the system of interdependent components in order to improve the internal structure. This is in line with the concept of technological regimes or paradigms, for which the definition of 
the "relevant" problems determines the direction of the search for new technological alternatives. Complementarities between industries are key to explaining the technological backwardness of some countries. In particular, in many developed countries, the agricultural sector has benefited greatly from advances in other industries such as machinery and chemical industries (Rosenberg, 1976). Advances in these supplier industries have allowed for an increased mechanization of production processes and the use of fertilizers. The absence of these complementary industries in developing countries has amplified the technological gap with developed countries in this sector. Overall, industries differ not only in terms of their productivity but also in terms of the stimulus they provide to the rest of the economy through backward and forward linkages.

The existence of linkages between industries is the basis of unbalanced growth theories. In this case, the net input of externalities of each investment project ${ }^{1}$ generated by the multiplier effect can vary. In addition, the extent of these externalities is not necessarily linked to their size (Hirschman, 1958). As a result, economies benefit from following an unbalanced growth path focused on industries with important positive externalities. Furthermore, particular attention should be paid to the structure of the connections between industries because the difference between industries in the strength and asymmetry of their linkages has several important consequences. First, following Lucas (1977), economists tend to discard the existence of industry linkages or assume that they are symmetric. In either case, micro shocks on individual industries average out rapidly and have no effect on the aggregate outcome. However, Acemoglu et al. (2012) show that the way micro shocks are transmitted at a more aggregate level is strongly dependent on the structure of these connections. In particular, micro shocks have an important role in generating aggregate fluctuations when the relationships between industries are asymmetric. Second, the order in which industries develop is important as it involves different types of cumulative effects. In this context, present investments influence the profitability of subsequent projects. Because the structure of industrial linkages differs between countries, the efficient sequence of investment should also vary between them.

As a result, the presence of interdependencies and complementarities can reinforce and limit boundaries between industries. The formation and development of an industry is strongly affected by the environment in which it evolves through

\footnotetext{
${ }^{1}$ The net input of externalities of an investment project corresponds to the difference between the externalities it creates and the ones it benefits from
} 
linkages, complementarities and spillovers.

In most countries, intermediate consumption represents a large part of total production. The exchange of intermediate consumption between industries is often informed by input-output transactions. For this reason, input-output linkages between industries are key to the performance of industries and the economy as a whole. In particular, the analysis of input-output networks enables us to better understand how shocks at the industry level (both from domestic and foreign sources) are transmitted throughout the economy. Several authors have focused on the empirical measurement of backward linkages. While Chenery and Watanabe (1958) only account for direct linkages, Rasmussen (1956) uses the input-output matrix, which quantifies the input-output linkages, to derive the extent of direct and indirect backward linkages between industries ("power of dispersion"). This measure accounts for three types of effects: $(i)$ the initial effect, $(i i)$ the direct effect and ( $i i i)$ the indirect effect. The initial effect corresponds to the rise in output of industry $A$ needed to fulfill a change in its final demand. The increase in output of its direct suppliers is the direct effect. And the increase in output of the suppliers of the direct suppliers of industry A corresponds to the indirect effect. However, these measures have strong assumptions. They assume that as long as there is an input-output link, the shock is transmitted and that a direct shock is as important as an indirect one. The measure of the output multiplier and backward linkages is an important tool to identify industries that generate greater externalities for the growth of an economy through demand and production dynamics. Mis-estimating them is likely to lead to unfit industrial policies. Moreover, traditional measures of backward linkages overlook the mechanisms that influence the size of the linkage effects and the identification of industries acting as obstacles in the transmission process of demand and supply shocks.

In this context, identifying key differences between industries matter because they affect the way the economic structure of countries changes, and therefore, their potential for economic growth. In particular, the presence of boundaries and interdependencies between firms, industries and countries explains the existence of discontinuities between production capabilities and path dependence.

Chapter 2 proposes a new methodology to identify industrial patterns and their evolution over time by analyzing the community structure of the product space and its evolution over time. As in Hidalgo et al., 2007, I assume that the set of products 
a country exports defines well what it can produce, and that products that are exported together require a similar set of capabilities to be made. The community structure of a network is used to detect the presence of clusters of nodes (in this case, products) tightly connected to each other and less to the rest of the network. If the product space measures the extent to which products are related in terms of the set of capabilities they require; then its community structure enables us to draw a better picture on the set of products that tend to be exported together and so that share similar skills ${ }^{2}$ In addition, the evolution of the community structure provides information on the way structural changes take place and export patterns transform. Here, the evolution in the community structure refers to the merging and splitting of communities and the change in their composition. The merger of two communities indicates that there have been some changes in the export and production structure of a number of countries. The skills and technologies associated to the two communities were similar enough for countries to be able to make this change.

Results from this exercise provide information on the linkages between products and industries. First, results show that the product space is highly modular. Second, according to the results, that there are industrial differences Malerba, 2002 at a global level but also that the boundaries between industries are not always clear-cut. This reveals the importance of industry linkages. I find that a community can correspond to a single industry, in some cases, and in several industries or even groups of industries, in others. The products of the same industry are also sometimes found in several communities. By analyzing the composition of the communities detected, I identify several common characteristics that are potential determinants for the emergence of several clusters. In particular, technological complexity and domains are associated to the formation of several clusters of medium and high-tech products. In addition, I find evidence that technological domains are not immutable. The merger of several groups of products (photographic equipment, optical goods and watches) with the electronics cluster reflects the evolution of technologies and their "redomaining" towards electronics over time. In other words, the production of photographic equipment, optical goods and watches have converged to rely more and more on the use of electronic technologies. I also find that the abundance of low skilled labor, on the one hand, and of natural resources, on the other, is at the source of the formation of several clusters. Yet, the structure and evolution of the product space show that the factors explaining

\footnotetext{
${ }^{2}$ I make no a priori assumption on the type of capabilities leading to the emergence and the evolution of these clusters.
} 
industrial patterns and structural change are more complex than the traditional divide between low-tech and medium to high-tech industries. Overall, value chains and vertical integration seem to be an overwhelmingly important and growing determinant of export patterns and structural transformation. For instance, changes in the composition of the electronics community show evidence of an acceleration of the international fragmentation of the production process from the 1980s onwards. This analysis also provides information on the export profile of countries that have succeeded to enter this GVC. Their export basket is strongly focused on the low-end of the textile industry, characterized by cheap low-skilled labor. This reflects the main objective of such delocalization processes, which consist in reducing production costs. These differences are fundamental aspects explaining the structure and evolution of the globalized economy, which directly affect growth dynamics.

It has a long been argue that the structure of the economy has an important role in economic growth dynamics. I look at this in more details in chapters 3 and 4 . In these two studies I pay special attention to industries boundaries and interlinkages.

In chapter 3, I study economic growth dynamics by examining the characteristics and determinants of transitions between different medium-run growth regimes (rapid growth, slow growth and recession). More precisely, I use a semi-Markov framework to estimate the behavior of each potential transition between these previously defined growth regimes. I also investigate the effect of the economic structure on these growth transitions. Regarding the determinants, I focus on the role played by the economic structure within the manufacturing sector. The economic structure is defined endogenously by identifying different patterns of manufacturing exports using the methodology of chapter 2 but focusing on manufacturing exports. I use two instruments of measurement of the economic structure: specialization and diversification. Results offer important insights on growth dynamics and on the role the economic structure plays. Results indicate that the effect of the manufacturing sector on economic growth is far from being uniform. Moreover, I find that cluster with similar technological intensity can play a different role on growth dynamics. For instance, both the electronics and chemicals clusters have positive effects on the growth process, but some differences in their effect are worth noting. Distinguishing between the intensive and extensive margin also matters. It is the case of the effect of the participation in the chemicals cluster, among other examples. Countries that are more diversified in the chemicals cluster are more likely to attain rapid growth while the ones that are more specialized in this cluster have more 
chances of going out of a recession state. Regarding electronics, countries with a greater participation in this cluster (both in terms of specialization and diversification) are likely to improve their growth rate when in recession. In addition, those that become more involved in this cluster have higher chances of escaping a growth slow down. For this to happen, they ought to be more diversified when they are in a rapid growth regime and more specialized when they experience slow growth. Conversely, the machinery cluster pushes countries towards slow growth, whether they experience rapid growth or recession. Thus, to some extent, these results point to the differences between industries with regards to the establishment of GVCs. On the one hand, the low ratio between weight and value of electronic products has facilitated the international organization of the production process. On the other, the products of the automotive industry are characterized by heavy components that are difficult to transport, which makes GVCs less widespread in this industry. In addition, the effect of the electronics cluster is probably closely related to the integration of developing countries into low technology activities since they tend to grow more rapidly in the catch-up process. Despite the fact that the textile industry is often seen as the stepping-stone towards industrialization, the effect of this cluster is negative in several cases. Indeed, a greater participation in this cluster increases the risk of falling into a recession regime (both specialization and diversification variables are significant). Additionally, for countries experiencing rapid growth, increasing their diversification in this cluster is likely to lead to a lower growth rate (i.e. transition to slow growth regime). Finally, this analysis shows evidence of a recession trap, largely fed by a greater specialization in the export of several clusters composed mainly of natural-resources manufacturing. Overall, the argument that there is no unique path to growth (Rodrik, 2008) seems to also apply to the economic structure.

Differences between industries not only affect the growth process through productivity differentials but also in terms of the stimulus they provide to the rest of the economy through backward and forward linkages. Chapter 4 studies the incidence of industries' inter-linkages on economic performance. I focus here on demand dynamics linked to intermediate consumption (i.e. backward linkages). Backward linkages consist in ripple effects on the production of downstream industries (or output multiplier) generated by an increase in the output of industries upstream of the production chain, following a demand shock. The traditional calculation of the production multiplier is often measured using the inverse of the 
Leontief matrix. I relax the two assumptions associated with the traditional calculation of the output multiplier. This enables to test whether backward linkages are overestimated by traditional measures (Rasmussen, 1956). I use a modified version of the Leontief inverse to predict output variation for different degrees of response to demand shocks from supplier industries. In this estimation, I take into account the variation in demand and technology. I then evaluate the strength of the response of each supplier industry to final demand shocks in its user industries. This evaluation is done by comparing the variations of the predicted and actual production values for each industry and country between 1995 and 2011. Results show that there are important differences in this response between industries and countries. In particular, manufacturing industries tend to have a lower response to demand shocks relative to services. Within the manufacturing sector, final good industries benefit less from potential backward linkages than others, in particular the electronics, other machinery, automotive industries. Furthermore, the response to final demand shocks tends to be more elastic in industries at the bottom of the value chain such as low-tech and especially raw material industries. Important differences are also found between countries. Manufacturing supplier industries in developed countries tend to be less responsive to demand shocks relative to developing ones. This can be explained by the fact that developed economies produce more complex goods involving a larger set of intermediaries, which implies a reduced adjustment margin. Results from the linear regression corroborates these arguments. In addition, it shows that the type of fixed costs an industry is facing also matters. Overall, these results show that the response to demand shocks is widely heterogenous across both industries and countries. This justifies the need for industrial policies tailored to the input-output patterns of each country. 


\section{Chapter 2}

\section{Mapping industrial patterns and structural change in exports}

\section{$2.1 \quad$ Introduction}

In a globalized environment, export patterns and their evolution play a central role in countries' economic development. What you export matters, not only because some products are associated with higher productivity levels than others but also because they open the way to greater opportunities. Countries differ in the set of capabilities they have and products differ in the set of capabilities they require to be made. Assuming that the set of products a country has a comparative advantage in defines well what it can produce, looking at export data gives an indication of the set of capabilities a country has through the types of products it exports. Furthermore, one way in which products are related is through the type of capabilities they share. Because knowledge is cumulative, countries build on existing knowledge and capabilities and economic development is strongly path dependent (Weitzman, 1998, Arthur, 2009). It is therefore easier to start exporting new products that have capabilities in common with products already being produced in the economy so that fewer new capabilities have to be mastered.

How do we measure product relatedness? Export data can be used to construct a bipartite network linking countries to products they have a comparative advantage in. This network can be projected onto a network of products where, roughly speaking, two products are linked if they are both exported by the same country. Assume that products that are often exported together require a similar set of capabilities in production. In that case, this product network, otherwise called the product space, provides a measure of the relatedness between products in terms of the set of capabilities they require (Hidalgo et al. 2007). A country's "location" in the product space is defined by the set of products it exports. Structural change, then, can be seen as a movement through the product space. In principle, a country 
can move from anywhere to anywhere in the space. In practice, however, movement to nearby products will be simpler because of the way products are related to each other in the product space through the capabilities they require.

Existing literature suggests that products tend cluster around a specific set of capabilities and form industries and sectors. These clusters reflect important differences in terms of knowledge and production processes (Pavitt, 1984, Malerba, 2002, Lall et al., 2004, Arthur, 2009). However, they are not completely isolated as each firm is associated to specific complementary activities and linkages with other firms within and between industries. The presence of industry interlinkages implies that the development of specific industries can act as bottlenecks or opportunities for the industrial prospects of countries. In addition, the boundaries between industries evolves over time for several reasons. First, because the technologies and knowledge industries use is constantly recombined. For instance, watches went from being mechanical to relying on electronics as they became powered by a battery. Second, the acceleration of trade exchanges has redefined the boundaries between industries and emphasized their differences in terms of the divisibility of the production process and of their participation in global value chains (GVC).

Industry taxonomies have several shortcomings. First, Pavitt (1984)'s classification focuses on developed countries and innovative firms. Second, product classifications are often ad-hoc, which makes them subjective and hardly reproducible (Leamer, 1984, Lall et al., 2004). Finally, existing classifications are often static and so do not account for the evolution in the relationships between products and between industries.

In this chapter, I present a new dynamic product classification based on the temporal network structure of the product space. I rely on a tool of network analysis called "community detection" to find this product classification. In network analysis, a community is a group of densely connected nodes that are also only loosely connected to the rest of the network. In the context of the product space, I assume that a community of products would be products that are tightly related to each other in terms of capabilities and less to the rest of the network. There exist several algorithms to detect the community structure of a given network. I apply the Infomap algorithm (Rosvall and Bergstrom, 2008, 2010, 2011) on 5-year snapshots of the product space from 1975 to 2000. This exercise enables me to identify different clusters of related products and to follow their evolution over time. I find that the product space is highly modular, that is it contains well delimited clusters of products. The community structure and its evolution show that the factors 
explaining industrial patterns and structural change are more complex than the traditional divide between low, medium and high-tech industries. In analyzing the results, I identify several common drivers that explain the emergence and evolution of different communities. These factors include the experience in a technological domain, factor abundance, scale economies and vertical integration. In addition, I find that the community structure is fairly stable over time and tends to stabilize even more from 1990 onwards.

This chapter is organized as follows. In the first section, I review the literature on the modular structure of the economy and industry idiosyncrasies. In the second section, I describe the data and the construction of the temporal network. In the third section, I detail the methodological steps to uncover the community structure of the product space. In the fourth section, I analyze the results of the dynamic community structure. Finally, I conclude in the last section.

\subsection{Background and literature review}

Relying on an evolutionary framework, Malerba (2002) highlights the importance of accounting for the modular structure of the economy by introducing the concept of sectoral systems of innovation. He argues that the nature of the innovation process varies across industries, which explains the fact that firms experience different innovation and productivity dynamics depending on the industry they belong to. Knowledge differs in several dimensions, including the degree of appropriability, tacitness, complementarity, technological opportunity and cumulativeness, along with the ease of access to complementary knowledge (both internal and external to the sector). These characteristics are central to explaining differences between industries as they influence the way knowledge is created, combined and spreads.

As presented in Nelson and Winter (1982), by sharing a common set of knowledge bases, firms in the same industry have common learning processes, technologies and production processes. They also share the same types of complementarities with other knowledge (internal or external to the industry), and similar relationships with other actors. The nature of the learning process depends on technological opportunity, cumulativeness, the degree of tacitness and the appropriability of knowledge, which are fundamental characteristics of knowledge. Nelson and Win- 
ter (1982) and Dosi et al. (1995) explain that because the search process delimited by technological paradigms relies heavily on the knowledge base of individuals and organizations, the potential to exploit natural trajectories and thereby benefit from technological opportunities greatly differs across industries and firms (incumbents versus entrants for example). This, in turn, affects their potential for technological progress. Furthermore, Winter (1984) argues that the characteristics associated with the technology and knowledge set of an industry, and in particular its degree of cumulativeness, tacitness and specificity, influences the ease of entry to a given market. The greater the need to build on an existing knowledge base that is not easily accessible from external sources, the harder it is for entrants to be competitive. As a result, first mover advantage, leading to industrial concentration, tends to prevail in such configurations. In addition, cumulativeness also occurs through positive feedback from the market. In this case, cumulativeness creates a virtuous cycle, in which innovation leads to more profit that becomes available for investing in R\&D (Research \& Development), enabling a higher probability to innovate. This effect also strongly depends on the level of appropriability of innovation rewards. Any lack of appropriability leads to spillovers inducing cumulativeness at the sectoral level.

Differences across industries are also expressed in the nature and the extent of their linkages with other industries. The existence of technological complementarities constitutes a triggering factor to the development of technologies and industries (Hirschman, 1958, Rosenberg, 1976 and Rosenberg, 1979). These complementarities are likely to cause technological interdependences between apparently unrelated processes and industries ${ }^{1}$ Technological progress within a technological regime often relies on the improvement of major components (Nelson and Winter, 1982), which take the form of internal replacement and structural deepening Arthur, 2009). Internal replacement consists in the introduction or replacement of improved components into a technology (or a body of technologies), which leads to a increase in the complexity of its overall structure, otherwise called structural deepening. Internal replacement and structural deepening are likely to create a technological imbalance that needs to be corrected for the different parts of the technology to work in coordination and the whole to be used efficiently. Thereby, the problem stimulates the demand and the search (and its direction) for new solutions to improve the internal structure (Rosenberg, 1976, Arthur, 2009).

\footnotetext{
${ }^{1}$ Technological interdependences have been otherwise named technological interrelatedness or technological networks.
} 
Technological imbalance can originate from the need to improve a product or a production process in the same industry or another (Rosenberg, 1976). In such conditions, technological development is the result of the interplay between industries. The presence of complementarities between industries is central to explaining economic development and its direction in some countries as well as further technological backwardness in others. Rosenberg (1976) argues that in many developed countries, the agricultural sector has benefited greatly from advances in other industries such as machinery and chemical industries, allowing for an increased mechanization of production processes and the use of fertilizers. The absence of these complementary industries in developing countries has amplified the technological gap with developed countries in this sector.

Without focusing solely on technological development, Hirschman (1958) affirms that the existence of backward and forward linkages between industries provides a stimulus for the development of related economic activities. On the one hand, he argues that domestic production of inputs is accompanied by an active stimulus for their use by local producers, that is they will attempt to create forward linkages with potential demand. On the other hand, the development of economic activities depends on the availability of inputs on the domestic market. Although imports are a possibility, getting supplies on the international market requires additional skills and is riskier due to exchange rate variations. In addition, setting up new economic activities automatically leads to the creation of potential new domestic markets by incentivizing the supply of domestic inputs. This mechanism gives rise to backward linkages. However, the growing role played by global value chains in the last decades shows that these linkages can be distorted. It is therefore important to consider industries' idiosyncrasies in the potential fragmentation of their production processes. Lall et al. (2004) highlights the differences in fragmentation intensity across industries. One important aspect of fragmentation is that it can only be realized when technical divisibility of production processes and components in terms of scale, skills and technological needs is high. Since it is particularly low in the chemical industry for example, most production processes are likely to take place in industrialized countries. But the divisibility of the production process is not a sufficient condition for firms to reallocate their production to access low-skilled labor at lower cost. Establishing a global value chain is beneficial when $(i)$ the production process is labor intensive (for labor cost reductions to compensate for the cost associated with the reallocation in terms of transport and coordination), (ii) the tasks involved are relatively simple, and ( $i i i)$ the goods to be produced are 
characterized by a high value to weight ratio to limit transport costs.

Several authors have analyzed the structure of industries and products (exports) in order to classify industrial goods into homogenous groups according to their technological content. Pavitt (1984) is one of the first to empirically study innovative firms' differences across industries. He focuses on three important differences: $(i)$ the source of the technology used in the production of goods, $(i i)$ the users' profile (whether they are sensitive to price or performance) and (iii) the appropriability conditions of knowledge. This classification contains four groups of innovative firms: supplier-dominated; scale-intensive; specialized suppliers; and science-based. Supplier-dominated firms are traditional firms mainly relying on external innovation as in textile and agriculture industries. Scale-intensive firms mostly consist of large firms leaning on both internal and external knowledge with a moderate level of appropriability. The main areas of production of this category are basic material and consumer durable such as the automotive industry. Specialized suppliers are small and highly specialized in high-technology industries (machinery and instruments). Their main activity consists in creating knowledge to be sold to other firms, relying on its tacit nature and thus high appropriability. Finally, science-based firms include high-tech firms that rely on both internal and external knowledge from academic research to innovate through the introduction of new products and processes. The high appropriability of the knowledge they create relies on different mechanisms including patenting, secrecy and tacit knowhow. Pharmaceutical and electronics companies are the main components of this group.

Although Pavitt (1984)'s classification provides rich information on the differences between firms and industries, only innovative firms are considered. In the present study, we are interested in both innovative and non-innovative firms. For this reason, I rather focuses on the classifications of Leamer (1984) and Lall (2000). These two classifications rely on the measurement product relatedness using export data, covering a wider part of the economy, to identify non-overlapping groups. On the one hand, Leamer (1984)'s classification is based on a endogenous method of aggregation of trade data at the two digits level of the SITC, which contains 61 product classes. Products are classified according to the cross-country correlations of net export data in 1958 and 1975. According to Leamer (1984), if two products are highly correlated across countries in terms of their net exports, it is reasonable to argue that they have similar export features. The groups are formed through a 
combination of two different methods of aggregation. The first method applies an algorithm (which is not detailed) to the correlation matrix while the second consists in a set of cross-section regressions of the net exports on several resources. Finally, this technique contains a certain amount of "fiddling" in order for the results to make sense. The presence of clusters in trade data is explained in this work by input-output relations among products.

On the other hand, Lall (2000) uses export data in order to construct a detailed classification of products relying on the results of the literature on different existing product classifications (Pavitt, 1984 and OECD, 1994), on the capability approach and on his "own judgement". Primary products are classified in one group but not analyzed further as they are not part of the manufacturing sector. Within the manufacturing sector, Lall (2000) considers four groups of products, for which characteristics are detailed as follows. (i) Resource-based products are classified together. This group is sub-divided into several categories. One group includes agriculture-based goods, which are labor intensive, and the other corresponds to products based on capital accumulation as well as scale and skill intensive technologies. (ii) Products with a low technology content are grouped together. A distinction is made between the textile (including garment and footwear) cluster and other products. The first sub-group relies heavily on technology embodied in machines and unskilled labor while the second sub-group relies more on complex technology and skilled labor, although not reaching the level of complexity and qualification of medium and high technology products. (iii) Medium technology goods are characterized by complex technologies, qualified labor and important investments in R\&D. In this group the author identifies three sub-groups. Automotive products are highly linkage-intensive given that they require a high level of interaction between firms in order to reach technical efficiency ${ }^{2}$ Process industries, such as chemical and basic metal goods, are characterized by large-scale plants and innovative activities focused on the improvement of equipment and complex processes. Finally, in the case of engineering products, innovation focuses primarily on products. In this industry, the production process can be broken down according to the complexity of the tasks, from product design to assembly. This industry also relies on firms interactions and on an extensive supplier network. (iv) High-technology firms evolve in a dynamic technological environment and firms' competitiveness rests on important investments in R\&D, infrastructure, advanced skills and strong links with other firms and research institutions. This group con-

\footnotetext{
${ }^{2}$ It is important to note that the products included in this group are mostly final goods. The intermediate products needed in the automative industry can be found in the engineering group.
} 
tains electronics and electrical products on the one hand and other products such as generating equipment, aircrafts, precision instruments and pharmaceuticals on the other hand. The first sub-group has the particularity of having a production system can be broken down between product design and assembly. According to Lall (2000), all products need technology upgrading in order to keep a comparative advantage but the intensity of the technological effort and the type of capabilities to do so are different. That is in essence what this classification is aiming to capture.

Both of these methods rely on a certain amount of ad-hoc adjustments, in particular in Lall (2000). In addition, the lack of details on the algorithm applied in Leamer (1984) makes this method impossible to reproduce. For these reasons, I propose a new methodology that can reproduced on any disaggregated export data and does not rely on any ad-hoc adjustments.

Countries differ in the set of capabilities they possess and products differ in the set of capabilities they require to be made. The production of a good is the result of a combination of capabilities (Weitzman, 1998, Arthur, 2009). Some products are more complex in that they require a larger and more diverse set of capabilities that only a few countries possess in totality. Products also differ in terms of their technological domain (Arthur, 2009). A technological domain consists in a cluster of technologies that are associated to a similar phenomenon or family of phenomena. As an example, the production of cars relies on the principle of the ideal gas law, according to which raising the temperature of a gas increases the pressure that makes the gas want to expand. In internal combustion engines, this principle is used to create a motion that makes wheels turn. Importantly, the domains a technology belongs to can evolve over time. Keeping the same example, cars have undergone a series of "redomainings" as their development has relied increasingly on electric, electronic and digital technologies. Electric cars do not rely on the ideal gas law anymore but on electricity to power the motor and set the wheels in motion. Cameras have also experienced an important "redomaining" first relying on chemical technologies and then on electronics and digital ones.

Furthermore, different products can share similar capabilities, and in that way they can be related. Most classical and new trade models consider products as being organized in a continuous sequence in which adjacent ones are fairly similar but the extremes (i.e., very low-tech relative to very high-tech) are very different. The position of products on this continuous sequence depends on their technology level. 
This representation has several implications. First, products are related according to one dimension only (technology). Second, since the sequence is continuous, there is no discontinuity in the effort of countries to introduce new products to their basket. Third, a country should add products according to the sequence and cannot start exporting products that are not directly linked to products already in its basket. As a consequence, according to this representation, there is one unique path to development, that is from low to high-tech products.

Conversely, one could imagine that products are related through a network and that their links is define according to many dimensions, not only technology. The product space is the first empirical attempt to represent products' relationships as a network and not as a continuum (Hidalgo et al. (2007)). This network is derived from a network of exports where countries are linked to products they have a comparative advantage in. It is assumed that the set of products a country has a comparative advantage in defines well what it can produce, and indirectly, the extent of its capabilities. In other words, the export network gives an idea of the set of capabilities a country has through the products it exports. Further, one can assume that if two products are often found together in the export basket of countries, their production is likely to involve common capabilities. Based on this assumption, we can derive a network of products: the product space. In this network, the similarity between products $p$ and $p^{\prime}$ is measured by the number of countries that are exporting both products divided by the number of countries exporting the most common product of the pair. In that representation, a given set capabilities is not unique to a product but is shared among several products. For instance, unit process (such as filtration or distillation) and unit operations (such as crystallization, evaporation or polymerization) are core competencies for the production of a wide range of chemicals goods. Computer simulation is also an important core competency in the chemical industry as well as in many other manufacturing industries, although each industry has specific tools and methods. Furthermore, in this framework, capabilities correspond to different dimensions of product relatedness including inputs, markets to which products are exported, their R\&D intensity, institutions and infrastructures required for the goods to be exported. The focus is not on any particular aspect of products' similarity but rather on a general feature accounting for a set of dimensions that make products close to each other.

The position of a country in the product space provides information on the extent and nature of its capabilities, which determine its possibilities for present 
and future growth. Therefore, the empirical estimation of products' relatedness provides important information for studying countries' development patterns and their evolution. In other words, whether or not a country can introduce a new product to its production and export basket depends on the capabilities present in the country because these determine the set of missing capabilities to be added.

In this chapter, I focus on the analysis of country differences in terms of export structure to understand differences in economic development between countries. I assume that a country has a relative comparative advantage in a product if at least one of its domestic firms does. According to the National Innovation Systems literature (in particular Lundvall, 1992), firms in the same country share a common institutional and cultural environment along with geographical proximity that facilitates flows (and spillovers) of knowledge and technologies across actors. In line with this literature, I assume that it is easier for a firm to build on the set of capabilities within the country where it is located, with other conditions remaining the same. Jaffe et al. (1993) provide empirical evidence of the local nature of knowledge diffusion showing that patents tend to be more cited by people from the same country (and from the same region) as the inventor.

In the next section, I describe the methodology developed to empirically analyze the modular structure of the economic system and its evolution using export data.

\subsection{Methodology}

\subsubsection{Network construction and data}

\subsubsection{The export network and the product space}

Countries have a unique set of capabilities. Each product demands certain capabilities to be produced. If a country exports a good, this provides evidence that the country possesses the necessary capabilities. Following Hidalgo et al. (2007), I exploit this country-product relationship in export data to measure product relatedness in terms of capabilities. Export data linking countries to products can be interpreted as a weighted, undirected bipartite network. The weight of each link measures the export value of product $p$ by country $c$ at time $t$. The corresponding 
incidence matrix is called $W_{c p}^{t}$. As in Hidalgo et al. (2007), this weighted network is turned into an unweighted one based on the revealed comparative advantage (RCA) index developed by Balassa (1965) ${ }^{3}$ The link between product $p$ and country $c$ is set to one when country $c$ has a revealed comparative advantage in product $p$, i.e. $R C A_{c p}^{t}>1$. The link is removed otherwise. The unweighted incidence matrix is defined by $M_{c p}^{t}$ as:

$$
M_{c p}^{t}= \begin{cases}1, & \text { if } R C A_{c p}^{t}>1 \\ 0, & \text { otherwise. }\end{cases}
$$

The RCA index corresponds to the ratio of the export value of product $p$ in country $c$ over its export value in the global economy at time $t$.

$$
R C A_{c p}^{t}=\frac{W_{c p}^{t} / \sum_{p} W_{c p}^{t}}{\sum_{c} W_{c p}^{t} / \sum_{c p} W_{c p}^{t}}
$$

The incidence matrix of the unweighted undirected bipartite network $M_{c p}^{t}$ is used to derive a weighted one-mode network of products. Network theory offers a wide range of methodologies to measure the similarity between elements in a system based on the structure of their interactions. The standard way to do a one-mode projection would simply be to say that two products are directly connected if they are both exported by at least one country. A weighted version of that projection would be to state that the weight of the link between two products is a count of the number of countries that export both. This measure corresponds to structural

\footnotetext{
${ }^{3}$ Keeping the weights and all the links would result in a very dense bipartite network and product space, making it more difficult to capture the most important features of the data.
} 
equivalence. 4

$$
S E_{p p^{\prime}}^{t}=\sum_{c} M_{c p}^{t} M_{c p^{\prime}}^{t}
$$

This is a very simple measure of structural equivalence, but it suffers from a bias in favor of commonly exported products. That is commonly exported products will tend to have edges with higher weights. The several proposed solutions differ in the correction of this bias. I focus on three common measures of similarity for which values range between 0 and 1, namely the cosine similarity, the Jaccard index and the "proximity index" introduced in Hidalgo et al. (2007) respectively defined as follows:

$$
\begin{gathered}
\cos _{p p^{\prime}}^{t}=\frac{\sum_{c} M_{c p}^{t} M_{c p^{\prime}}^{t}}{\sqrt{\sum_{c}\left(M_{c p}^{t}{ }^{2}\right)} \sqrt{\sum_{c}\left(M_{c p^{\prime}}^{t}\right)}} \\
j a c_{p p^{\prime}}^{t}=\frac{\sum_{c} M_{c p}^{t} M_{c p^{\prime}}^{t}}{\sum_{c} M_{c p}^{t}+\sum_{c} M_{c p^{\prime}}^{t}-\sum_{c} M_{c p^{t}}^{t} M_{c p^{\prime}}^{t}} \\
P_{p p^{\prime}}^{t}=\frac{\sum_{c} M_{c p^{t}}^{t} M_{c p^{\prime}}^{t}}{\max \left\{\sum_{c} M_{c p}^{t}, \sum_{c} M_{c p^{\prime}}^{t}\right\}}
\end{gathered}
$$

The cosine index corrects for this bias by dividing by the geometric mean of the degrees of the two products (i.e., the number of countries that export each product). The denominator of Jacquard index used to correct for this bias corresponds

\footnotetext{
${ }^{4}$ There exists another measure of structural similarity: regular equivalence. Two products are regularly equivalent if the set countries that export them are themselves regularly equivalent. This measure is particularly relevant for disconnected networks and when analyzing the different functional roles in a network since it focuses on the symmetry of the structure of relationships. Leicht et al. (2006) show that the measure of regular equivalence is a generalization of the one of structural equivalence since the former accounts for paths of all length between nodes while the later only considers paths of length two. In the framework of this analysis, this would mean that two products are structurally equivalent if they are related to the same set of countries while they are regularly equivalent if they are related to the countries that have the same structure of interactions. This implies that a pair of products can be considered similar even though they have no countries in common. While the measure of regular equivalence is interesting, I prefer to discard it in this analysis. The main reason is that defining product similarity accounting for paths of all length is likely to lead to a highly dense network. The measure of structural equivalence, which is a stricter measure of similarity, already leads to the construction of a very dense network requiring the use of network reduction techniques to study modular structure.
} 
to the total number of countries that export each product (i.e. the cardinality of the union of the two sets of countries exporting each product). Finally, in the proximity index, the bias is corrected by dividing by the maximum number of countries associated with any of the products of the pair.

The three measures are highly correlated as correlation between any pair of the three measures is always superior to 0.94 (Table A.2. In addition, in all snapshots of the network, there is little difference in the dispersion of the weights. The interquartile range is the highest with the cosine index, the lowest with Jaccard index and the proximity index is in the middle.

Despite this, in two specific cases, there are important differences between the measures.

- In the first case, the set of countries exporting product $A$ is a subset of countries exporting product $B$. As an example, imagine that we are interested in the similarity between two products: product $A$ is exported by 16 countries and product $B$ by countries that also export product $A$ (Figure A.2a). Let's consider a situation in which the number of countries exporting product $B$ increases and any country adding product $B$ to its export basket always export product $A$. In other words, the set of countries exporting $B$ is a subset of the set of countries exporting $A$. When using the proximity and Jaccard indexes, the similarity between the two products will grow linearly with the set of countries exporting product $B$. Conversely, the similarity derived from the Cosine index will increase at a decreasing rate when an increasing number of countries export product $B$. Yet, there is no reason to believe that this relationship should be concave.

- In the second case, the two products are exported by the same number of countries, but not necessarily the same set. For example, imagine that we want to measure the similarity between two products that are each exported by 12 countries (Figure A.2b). When measured with the cosine or the proximity indexes, the similarity between the two products will increase linearly with the number of countries the pair of products has in common. Conversely, this relationship is convex when using the Jaccard index. This means that the similarity will increase with the number of countries the two products have in common and at an increasing rate. Here again, there is no reason to 
believe that this relationship should be convex.

For these reasons, I use the proximity index as a measure of similarity between products.

\subsubsection{Data}

The networks described above are constructed using gross export data from COMTRADE cleaned by Feenstra et al. (2005). These data are disaggregated at the 4-digits level for the period 1962 to 2000 and include 108 to 134 countries depending on the year. For the sake of comparison across time, I only use data from 1975 to 2000 and the 111 countries that are present throughout the period of analysis. Details on the dataset are provided in Table A.1. As highlighted by Lall (2000), export performance is key to economic development for several reasons. On the one hand, countries can benefit from economies of scale and specialization through exports. On the other hand, the increased competitivity of the globalized world makes export performance a good indicator of the productive efficiency of countries in the manufacturing sector. Although it is an imperfect and partial representation of economic activities and their interdependencies across nations, trade values remain the most complete and disaggregated empirical measure in terms of time and space.

I assume that when a country exports a good $p$, it has the capabilities to produce it. When a large number of countries export two goods $p$ and $p^{\prime}$, we can infer that the competences underlying their production are related. Identifying pairs of related products is fairly straightforward but when it comes to uncovering a larger set of related products it becomes more complicated. Community detection is used to identify groups of similar products. In network theory, a community consists of a group nodes tightly connected to each other and less connected to the rest network.

\subsubsection{The backbone of the product space}

As shown in Table 2.1, the snapshots of the product space at different periods in time are very dense (between $83.55 \%$ and $91.65 \%$ of the potential links are actual links). The density of these networks is tightly linked to their construction. In particular, ubiquitous products are connected to most other products even though 
the weights attached to them are extremely low due to the normalization. However, we are interested in the capabilities that help countries develop. If all countries have capabilities $X$, associated with the production of product $P$, then clearly $X$ is not the capability that distinguishes development potential from lack thereof. Even if $X$ is necessary for development, it is other capabilities that make the difference. For this reason, it is important to downplay $X$, hence the need to filter out some of the links in the product space. At the same time, the presence of edges with extremely low weights makes it complicated to discern the most significant connections and analyze their structure to identify important capabilities. Community detection algorithms are constructed for and tested on low-density networks since the density of most observed networks ranges between almost $0 \%$ to roughly $7 \%$. The high density of our product space results in an unreasonable community structure when applying most algorithms to the raw network, giving product groups that contrast sharply with most industrial classifications. One solution to this problem is to reduce the number of links by uncovering the most important connections between products and so lowering the density of the network. But it is important that the network reduction method keeps the relevant structural features of the original network. The weights of the snapshots of the product space follow a lognormal distribution (see Figure A.3, which behaves similarly to a power-law indicating the presence of a core-periphery structure. In the present study, the network reduction method should preserve this property of the networks. 
Table 2.1: Size and density of common networks and snapshots of the product space

\begin{tabular}{lccc}
\hline Real network & Number of nodes & Number of edges & Density (\%) \\
\hline Zachary's club & 34 & 78 & 6.7474 \\
Dolphins & 62 & 159 & 4.1363 \\
Football & 115 & 613 & 4.6352 \\
UK commuting & 10608 & 1220337 & 1.0845 \\
C. elegans & 453 & 2025 & 0.9868 \\
Word association & 7207 & 31784 & 0.0612 \\
Live Journal & 4846609 & 42851237 & 0.02 \\
www. uk & 18484117 & 292244462 & 0.01 \\
US airports 2009 (jan) & 448 & 7659 & 3.8161 \\
US airports 2009 (mar) & 456 & 8491 & 4.0835 \\
US airports 2009 (jun) & 453 & 8480 & 4.1324 \\
US airports 2009 (sep) & 452 & 7870 & 3.8521 \\
\hline Product space snapshots & & & 83.55 \\
\hline 1975-1979 & 769 & 246710 & 90.29 \\
1980-1984 & 783 & 276431 & 89.90 \\
1985-1989 & 783 & 275234 & 89.73 \\
1990-1994 & 783 & 274707 & 89.79 \\
1995-1999 & 781 & 273477 & 91.65 \\
2000 & 769 & 270628 & \\
\hline
\end{tabular}

There are two main network reduction methods. The first, called coarsegraining, consists in considering groups of similar nodes as a single node, inducing a new representation of the system at a more aggregated scale. This makes sense when the network has self-similarity properties (recursiveness, fractals). The second method, filtering or pruning, entails keeping the same scale but discarding a part of the information in the network. In the case of weighted networks, two filtering methods can be used: the minimum (or maximum) spanning tree and the application of a global threshold on the weights. A minimum spanning tree is the shortest length (minimum sum of the weights in the case of a weighted network) tree subgraph that contains all the nodes. The main drawback of this method is that it implies removing local cycles and clustering hierarchies and as a consequence erasing the modular structure of a network. The second filtering method involves withdrawing the edges of the network for which the weight is below a global threshold. This method performs very poorly when applied to networks with weights and strength following heavy tailed distributions (i.e. networks in which links and weights are not distributed normally) since it systematically discards nodes with low strength. With this method, one can only look at the information present at a higher aggregation level (which are arbitrarily defined by the threshold). This problem is amplified when weights are correlated locally leading to a network with groups of isolated nodes. This correlation is high when 
dealing with core-periphery networks such as the snapshots of the product space. And indeed, using this method leads to the isolation of a large proportion of the nodes even when using a low threshold, as revealed in Table 2.2. The reason is that the median of the distribution of the maximum weight of each node is around 0.6 in these networks. Therefore, for any threshold of 0.6 or higher, at least half of the nodes in the networks become isolated.

Table 2.2: Network statistics of each snapshot of the product space reduced using a global threshold on weights

\begin{tabular}{|c|c|c|c|c|c|c|}
\hline Period & $\alpha$ & TW (\%) & $\mathrm{N}(\%)$ & $\mathrm{E}(\%)$ & $\mathrm{D}(\%)$ & $\mathrm{C}$ \\
\hline \multirow{6}{*}{ 1975-1979 } & 0 & 100 & 100 & 100 & 83.55 & 1 \\
\hline & 0.2 & 68.33 & 100 & 43.28 & 36.16 & 1 \\
\hline & 0.4 & 19.85 & 98.44 & 8.04 & 6.72 & 14 \\
\hline & 0.6 & 2.42 & 54.10 & 0.63 & 0.53 & 385 \\
\hline & 0.8 & 0.98 & 14.82 & 0.20 & 0.17 & 680 \\
\hline & 1 & 0.85 & 5.33 & 0.17 & 0.14 & 735 \\
\hline \multirow{6}{*}{ 1980-1984 } & 0 & 100 & 100 & 100 & 90.29 & 1 \\
\hline & 0.2 & 73.36 & 100 & 49.71 & 44.88 & 1 \\
\hline & 0.4 & 22.88 & 98.72 & 10.32 & 9.32 & 11 \\
\hline & 0.6 & 2.06 & 57.47 & 0.66 & 0.60 & 364 \\
\hline & 0.8 & 0.09 & 9.07 & 0.02 & 0.02 & 732 \\
\hline & 1 & 0 & 0 & 0 & 0 & 783 \\
\hline \multirow{6}{*}{ 1985-1989 } & 0 & 100 & 100 & 100 & 89.90 & 1 \\
\hline & 0.2 & 70.23 & 100 & 46.21 & 41.54 & 1 \\
\hline & 0.4 & 20.41 & 98.47 & 8.82 & 7.92 & 13 \\
\hline & 0.6 & 2.03 & 55.17 & 0.62 & 0.56 & 392 \\
\hline & 0.8 & 0.15 & 9.45 & 0.04 & 0.03 & 724 \\
\hline & 1 & 0 & 0 & 0 & 0 & 783 \\
\hline \multirow{6}{*}{ 1990-1994 } & 0 & 100 & 100 & 100 & 89.73 & 1 \\
\hline & 0.2 & 68.62 & 100 & 44.35 & 39.79 & 1 \\
\hline & 0.4 & 18.54 & 98.85 & 7.79 & 6.99 & 11 \\
\hline & 0.6 & 1.74 & 53.51 & 0.52 & 0.47 & 404 \\
\hline & 0.8 & 0.08 & 7.41 & 0.02 & 0.02 & 741 \\
\hline & 1 & 0 & 0 & 0 & 0 & 783 \\
\hline \multirow{6}{*}{ 1995-1999 } & 0 & 100 & 100 & 100 & 89.79 & 1 \\
\hline & 0.2 & 68.87 & 99.87 & 44.71 & 40.14 & 2 \\
\hline & 0.4 & 18.39 & 97.82 & 7.77 & 6.98 & 18 \\
\hline & 0.6 & 1.54 & 54.29 & 0.46 & 0.41 & 399 \\
\hline & 0.8 & 0.11 & 6.91 & 0.03 & 0.02 & 741 \\
\hline & 1 & 0 & 0.26 & 0 & 0 & 780 \\
\hline \multirow{6}{*}{2000} & 0 & 100 & 100 & 100 & 91.65 & 1 \\
\hline & 0.2 & 70 & 100 & 46.69 & 42.79 & 1 \\
\hline & 0.4 & 17.39 & 98.05 & 7.56 & 6.93 & 17 \\
\hline & 0.6 & 1.17 & 49.41 & 0.36 & 0.33 & 424 \\
\hline & 0.8 & 0.07 & 5.98 & 0.02 & 0.01 & 736 \\
\hline & 1 & 0 & 0.26 & 0 & 0 & 768 \\
\hline
\end{tabular}

Edge removed if weight $<\alpha$; TW (\%), the percentage of total weights left; $\mathrm{N}(\%)$, the percentage of nodes left; E (\%), the percentage of edges left; D, the density of the network; $\mathrm{C}$, the number of components.

To circumvent the problems of traditional network reduction methods, Serrano 
et al. (2009) construct a threshold considering weight heterogeneity at the node level. This method selects the most significant links in a network as determined by a disparity filter. This filter is a p-value representing the probability of observing a normalized weight larger or equal to the weight under the null hypothesis. In the null hypothesis, normalized weights are defined using a random model which accounts for the degree of each node. This probability is defined for a given edge attached to a given node and depends on the degree of the node and the normalized weight of the edge. A homogeneous significance level is chosen to filter out edges for which the p-value is above the significance level. Every edge involves two nodes, and so has two p-values. The edge is kept if it is significant for at least one of the two associated nodes. As one reduces the significance level, more edges are filtered out. However, below a critical level, the graph becomes disconnected. I redefine the condition under which edges are kept using the lower bound of the significance level. Further details on this method and the definition of lower bound of the significance level are provided in Appendix A.1.

The density of the network is significantly reduced when applying this multiscale backbone technique while the network stays entirely connected with $\alpha \geq \alpha_{L B}$ (Table B.2). I consider the significance level generating the network with the lowest density and for which all nodes stay connected so as to be able to apply a community detection algorithm 5 The significance levels of each network snapshot, $\alpha_{L B}$, are presented in Table B.2. The reduced networks have a density ranging from $3.40 \%$ to $4.39 \%$ as shown in Table B.2. which is considerably lower than that of the original networks.

\footnotetext{
${ }^{5}$ This method has some limitations discussed in the appendix of this chapter.
} 
Table 2.3: Network statistics of snapshots of the product space reduced using Serrano (2009)'s multiscale backbone technique

\begin{tabular}{lcccccc}
\hline & $\alpha_{L B}$ & $\% \mathrm{TW}$ & $\% \mathrm{~N}$ & $\% \mathrm{E}$ & $\mathrm{D}(\%)$ & $\mathrm{C}$ \\
\hline \multirow{2}{*}{$1975-1979$} & 1 & 100 & 100 & 100 & 83.54 & 1 \\
& 0.09176 & 12.10 & 100 & 4.96 & 4.14 & 1 \\
\hline \multirow{2}{*}{$1980-1984$} & 1 & 100 & 100 & 100 & 90.29 & 1 \\
& 0.10233 & 8.20 & 100 & 3.76 & 3.40 & 1 \\
\hline \multirow{2}{*}{$1985-1989$} & 1 & 100 & 100 & 100 & 90.11 & 1 \\
& 0.09698 & 9.22 & 100 & 4.06 & 3.66 & 1 \\
\hline \multirow{2}{*}{$1990-1994$} & 1 & 100 & 100 & 100 & 91.35 & 1 \\
& 0.11161 & 10.98 & 100 & 4.80 & 4.39 & 1 \\
\multirow{2}{*}{$1995-1999$} & 1 & 100 & 100 & 100 & 91.48 & 1 \\
& 0.10272 & 10.13 & 100 & 4.43 & 4.05 & 1 \\
\hline \multirow{2}{*}{2000} & 1 & 100 & 100 & 100 & 93 & 1 \\
& 0.09995 & 8.47 & 100 & 3.81 & 3.54 & 1 \\
\hline
\end{tabular}

Edge removed if weight $<\alpha_{L B} ; \mathrm{TW}(\%)$, the percentage of total weights left; $\mathrm{N}$ (\%), the percentage of nodes left; $\mathrm{E}(\%)$, the percentage of edges left; D, the density of the network; $\mathrm{C}$, the number of components.

\subsubsection{The community structure of the product space}

In the product space, links between products reflect some similarity in terms of capabilities and knowledge. In addition, I argue that products are likely to be clustered according to a common set of capabilities they share. In network analysis, community detection algorithms enable to identify these clusters. A community or cluster is defined as a group of nodes more tightly connected together than with the rest of the network.

A wide range of methods have been developed in the last years to detect the community structure of networks 6 Many of those are based on a community quality function called modularity (Newman and Girvan, 2004). The modularity function compares the fraction of edges inside the communities of the real network relative to the fraction of edges inside the communities of a random version of that network. The maximization of this function enables one to find the community structure of a network. However, the maximization of this function suffers from several important drawbacks. First, it is assumed that a random network does not have any community structure. If this assumption fails to be true, then the modularity function is no longer a good measure to evaluate the quality of the community structure. However, it has been shown that random networks may have a community structure (Guimerà et al., 2004, Reichardt and Bornholdt, 2006). Second, it has a resolution limit (Fortunato and Barthélemy, 2007). This means

\footnotetext{
${ }^{6}$ For an extensive review of community detection algorithms see Fortunato 2010
} 
that it does not detect clusters that are small with respect to the network, even when they are well defined communities (cliques). The reason is that under the null model, it is assumed that each node can interact with any other node of the network. However, in practice, nodes have a limited horizon. The third limitation has to do with the fact that the modularity function has many local optima near the global optimum and these lead to very different partitions (Good et al. 2010).

I use the Infomap algorithm (Rosvall and Bergstrom, 2008; 2010; 2011) because it does not have these drawbacks. In particular, compared to other algorithms, it performs very well when it comes to detecting small communities (Lancichinetti and Fortunato, 2009). This method is based on random walks on the network and information theory. It is that assumed that when a random walker enters a cluster, it will spend a long period of time inside before leaving since nodes inside a true cluster are more densely connected. The quality function is called the map equation and corresponds to the length of the code that describes the path of the random worker on a given network. This code is composed of the codename of the cluster and the codename of the vertex in which the random walker is. When the random walker changes cluster, the code indicates the codename of the cluster the random walker is leaving, the codename of the cluster it is entering and the codename of the new vertex. The strongest community structure corresponds to the one for which the code length is minimized. If the community structure is not well defined, then the random walker will often go in and out of the defined clusters, which will lead to a longer code length. There is a trade off between having a few community codenames along with longer node codenames and many community codenames conjointly with short node codenames 7

\subsection{Results}

The evolution of the community structure of the product space from 1975 to 2000 reveals several export patterns linked to different sets of industries. In particular, this exercise shows the presence of modern development patterns including global value chains and vertical integration 8 as well as other traditional ones such

\footnotetext{
${ }^{7}$ Further details on the Infomap algorithm can be found in the Appendix A.2 In addition, an interactive explanation of the algorithm is available at the address: http://www.mapequation.org/apps/MapDemo.html.

${ }^{8} \mathrm{I}$ always refer to vertical integration at the country level and not at the firm level.
} 
as factor abundance (Heckscher-Ohlin theorem) and technology (Ricardo, 1817).

The main patterns of evolution in the composition of communities are represented with alluvial diagrams in Figures A.12 to A.16. In addition to these figures, the interpretation of the results requires quantitative measures to identify communities in terms of the types of products they contain. We can describe the constitution of a community by reference to the industries of the products it contains. That is the content of a community is identified by observing the share of products from each industry it contains as displayed in Figure A.6. The set of industries are defined according to the aggregation of goods from the SITC at 2 digits in terms of the industry and of the stage of production (whenever the information is available at such a disaggregated level). For example, textile fibers (SITC 26), textile material manufacturing (SITC 65) and textile manufacturing (SITC 83, 84, 85) are part of the textile industry but belong to three different stages of production. The details on the aggregation are presented in Table A.4. Communities are hereafter labelled according to the set of industries strongly present in them.

The composition of communities also evolves over time as individual communities split into several modules or merge with others. The community structure is identified for each snapshot of the produce space (each 5-year period) and so we do not have at this stage information on the correspondence between clusters across the different periods of time. To analyze the evolution of the composition of communities, I measure the extent of product overlap between two communities at time $t$ and $t+1$ using the Jaccard index as suggested in Lancichinetti and Fortunato 2012). The Jaccard index is calculated as follows:

$$
J_{q_{t}, q_{(t+1)}^{\prime}}=\frac{\left|S_{q_{t}} \cup S_{q_{t+1}^{\prime}}\right|}{\left|S_{q_{t}} \cap S_{q_{t+1}^{\prime}}\right|}
$$

with $S_{q_{t}}$ corresponding to the set of products in community $q$ at time $t$.

When the overlap is large, many products are in both cluster $q$ at time $t$ and cluster $q^{\prime}$ at time $t+1$. This index enables us to find the correspondence between clusters from one period to the next. In addition, the extent of the overlap provides information on the continuity of a community throughout time as well as changes in its composition. A relatively high overlap between one community at time $t$ and several communities at time $t+1$ indicates a split into several modules while a 
significant overlap of several communities at time $t$ with one module at time $t+1$ reveals a merger. Figure A.17 displays heatmaps of the overlap between communities across time.

\section{The electronics community}

More than $50 \%$ of electronics products are grouped into one community. This module also includes on average more than $50 \%$ of goods from photographic apparatus, optical goods and watches manufacturing industries (SITC 88). This association is not surprising given the growing importance of electronics in the making of such products, indicating that internal replacement and structural deepening is taking place in such technologies. The relationship between the electronics and machinery industries is limited and decreasing over time as depicted in the alluvial diagram in Figure A.12 and A.13 According to Figure A.6, the share of electronics products located in the machinery community 9 goes from $32 \%$ in $1975-1979$ to $21 \%$ in 2000. In addition, the ties between the electronics and machinery communities are weak as the product overlap between them over the period of analysis is almost inexistent (Figure A.17). The use of disaggregated data at the industry level is therefore crucial to better grasp the different patterns of structural change within the manufacturing sector.

As shown in Figure A.17, this module is relatively stable over the period of analysis (1975-2000) with an average product overlap between one period to the next being close to $53 \%$. However, the electronics community experiences two important changes over the period studied. While it is almost exclusively composed of medium to high-tech products during the period 1975-1979, the alluvial diagram in Figure A.12 shows that, from 1980 onwards, it incorporates crude and manufactured materials for the textile industry (textile fibers - SITC 26 and textile yarns and fabrics - SITC 65) as well as low-tech manufacturing (SITC 89). This merge is also noticeable in the heatmap in Figure A.17 as the product overlap between the electronics community in the 1975-1979 period and the metal and textile manufactures in the 1980-1984 period amounts to $10 \%$. This evolution provides evidence for the acceleration of the fragmentation of the production process in the electronics industry during the 1980s. This representation also shows that countries that have entered the electronics global value chain were for the most part little developed in the textile industry as textile manufacturing products (SITC 84, 85,

\footnotetext{
${ }^{9}$ During periods 1975-1979 and 1985-1989, the machinery industry corresponds to several communities.
} 
86) are not part of the electronics community and the product overlap between the two communities over time is never above 3\% (Figure A.17). The presence of the least complex stages of production in the textile industry within the electronics community can be explained by the fact that the fragmentation of the production process in the electronics industry implies the delocalization of labor intensive and low skill tasks (such as assembly) to countries where wages are particularly low in the interest of reducing costs.

The share of products from low-tech industries grows until 1995-1999, after which the community splits into two modules in 2000. The electronics community in the period 1995-1999 has an important product overlap with two communities in the next period (2000) as shown in Figure A.17. While the electronics community remains strong with 59\% of products overlapping between 1995-1999 and 2000, it also has a strong overlap (20\% of the products) with a newly formed community composed of textile materials and metal manufactures. Figure A.6 provides information on the composition of the two modules. The largest one includes mostly medium to high-tech products as well as some products from low-tech manufacturing industries while the second one is composed of the least complex industries (crude and material manufacturing for the textile industry). Such an evolution can reflect different events. Some countries previously dedicated to low value-added stages of the production process have upgraded their export basket by focusing on the electronics industry. This period also follows the Asian crisis of 1997, which has significantly affected economies and thereby exports within the region.

Finally, there is a noticeable difference between medium and high-tech industries (SITC 75, 76, 77 and 88) relative to low-tech industries (SITC 26, 65 and 89) in terms of the concentration of industries across communities as measured by the entropy of industry shares across communities (Figure A.22. While products from the former are highly concentrated into few communities with an average entropy of 0.35 , products from the later are much more spread as entropy is close to 0.6 on average. In other words, countries associated these low-tech industries have different export patterns and having a comparative advantage in these industries is not a sufficient condition to take part in the electronics GVC.

\section{The machinery community}

The machinery community is composed of machinery products, most products from the controlling instruments industry (SITC 87) as well as chemicals goods, especially plastics (SITC 5 and 58). Chemical products associated with the machinery 
industry consist mainly of plastics (SITC 58) and some organic chemicals (SITC 51), dyeing and coloring materials (SITC 53) as well as chemical materials and products (SITC 59). The presence of controlling instruments and chemicals in the machinery module means that countries with a comparative advantage in machinery also have a comparative advantage in those two industries. Despite the fact that these industries are associated with different technological domains, they have common features explaining their co-occurrence in the export basket of countries. The production and export of goods from these industries involves complex processes and requires a great amount of resources to dedicate to $R \& D$, which explains the predominance of industrialized countries in this community. Furthermore, vertical integration also partially explains the high occurrence of both machinery and chemical products in the export basket of countries. According to input-output data from Timmer et al. (2015), in 1995, almost $80 \%$ of the production from the chemical industry consists of intermediate consumption used in other industries and a large share is connected to the machinery industry. It is also worth noting that there are important differences between chemical products (ISIC 24) and plastic and rubber products (ISIC 25). While the machinery industry is an important source of income for the plastics and rubber industry as it absorbs close to $20 \%$ of its production of inputs, it is limited for the chemical industry (consuming less that $4 \%$ of its production of inputs). This explains the preponderance of plastic products within the chemical industry present in the machinery community.

The machinery industry is split into several communities at the first period of analysis (1975-1979) but merges into fewer communities over time as shown in Figure A.13. Towards the last three periods of analysis, a large share of products from the chemical industry move to the machinery community (60\% in 1990-1994, $49 \%$ in 1995-1999 and $41 \%$ in 2000). The composition of the machinery community is also affected by an increase of the share of metal manufacturing products (SITC 67, 68 and 69) over time. As it is the case for the plastic industry, input-output data from Timmer et al. (2015) point to important linkages between the machinery and metal industries. In 1995, basic and fabricated metals amount to $20 \%$ of intermediary consumption used in the production of machinery goods. The machinery industry 10 also represents the largest source of income for the industries of basic and fabricated metals (21\%) during the same year. Another common feature highlighted by Pavitt (1984) is that these two industries are both scale-intensive. The appearance of metal manufactured products within the machinery community can

\footnotetext{
${ }^{10}$ The machinery industry consists of groups 29,24 and 35 from the ISIC (Revision 3.1 ) and the chemical industry includes groups 24 and 25 .
} 
be induced by the change in the composition of the export basket of countries exporting a large number of products from the industries attached to this community or by the upgrade of the export basket of countries with a comparative advantage in metal industries. Although the results from this analysis cannot provide a detailed explanation for this evolution, the overwhelming presence of industrialized economies among the set of countries with a comparative advantage in at least two metal manufacturing products within the machinery community suggests that vertical integration, rather than a fragmentation of the production process, better explains these trends ${ }^{11}$ This is in line with the characteristics of the machinery and chemicals industries described in Lall et al. (2004). The fragmentation of the production process is limited by the high value to weight ratio of products and parts in the machinery industry and by the limited divisibility of production processes in the chemical industry. Indeed, on average more than $70 \%$ of parts and components from the machinery industry are in the machinery community.

The machinery community also sees its share of textile materials and fibers grow from 1990-1994. Much like for the metal manufacturing industries, this change is unlikely to be linked to a fragmentation of the production process within the machinery industry as it is the case for the electronics industry since industrialized countries have the highest level of export diversity in textile products present in the machinery community 12

\section{The textile and food community}

A large share of products from textile and food industries form a community during most of the period of analysis. The strong co-occurrence of products from these two industries can be attributed to the fact that they share common characteristics as they are both labor intensive Lall et al. 2004 and supplier-dominated (Pavitt, 1984). Some degree of vertical integration seems to take place in the textile industry as products ranging from crude textile materials (animal skins - SITC 21 and textile fibers - SITC 26), to manufactured textile materials (leather - SITC 61 and textile yarns and fabrics - SITC 65) and to textile manufactures (SITC 84, 85 and 86) are present in the same community. In other words, countries that have a comparative advantage in textile will likely be exporting products from several levels of the

\footnotetext{
${ }^{11} 63 \%$ of countries with a comparative advantage in at least two metal manufacturing products within the machinery community during the period 1985-1989 and 65\% in 2000.

${ }^{12}$ During the period 1990-1994, more than $60 \%$ of countries with a comparative advantage in at least two textile products located in the machinery community are industrialized countries against less than $25 \%$ in the electronics community during the same period.
} 
value chain. This module is the most stable over time as its average product overlap across time is close to $70 \%$ (Figure A.17).

There is one noticeable change during the period 1980-1984, where the textile and food as well as the textile manufacturing communities merge (Figure A.17 and A.14. While during the period 1975-1979, the textile industry within this module is mainly represented by crude and material textile products, the module concentrating most of the textile manufacturing industry merges with the textile and food community from 1980 onwards. This merge can have several explanations. One possibility is an upgrade of the export basket of countries with a strong focus on agro-based products (including textile materials and fibers) towards textile manufacturing. Another potential explanation is a diversification of textile manufacturing exporters with the incorporation of agro-based products. A more detailed analysis would be required to understand the causes of this merge. Despite the important structural change occurring during the period 1975-1979, the high and increasing overlap of the set of products belonging to this module from one period to the next indicates its growing stability over time. As shown in Figure A.17, it is always over $50 \%$ and increases with time reaching $79 \%$ between 1995 1999 and 2000. The increased cohesion of this community over time reflects the static composition of the basket of exporters associated with this community, which translates into an increased resistance to structural change towards modernization.

Finally, there are some notable differences between the industries present in this module in term of their dispersion across communities as illustrated in Figure A.22. While products from the textile manufacturing industry are mostly concentrated in the food and textile community (entropy is 0.23 on average), products from the food industry, textile fibers industry and especially textile materials industry are much more spread across communities (their average entropy is respectively 0.53 , 0.56 and 0.61$)$.

\section{The petroleum community}

The petroleum community is identified in most of the periods of analysis and regroups most products from the petroleum industry. The presence of inorganic chemicals within this community shows that some petroleum exporters have upgraded their exports through vertical integration. Indeed, crude and refined petroleum is at the bottom of the chemical value chain, directly followed by basic chemicals (inorganic) and polymers. However, results also show that this integration is limited as polymers, which would require greater knowledge and infrastructure, are 
almost inexistent from the petroleum community ${ }^{13}$

According to the results depicted in Figure A.17, the product content of this community becomes more and more stable over time as the overlap between product sets from one period to the next increases and reaches $66 \%$ between period 1995 1999 and 2000 14 As depicted in Figure A.15, the community is broken down into several modules only during the years following the second oil crisis of 1979 (1980-1984), which is likely to have disturbed export flows in this industry.

The low level and limited variability of the entropy of shares of petroleum products across communities ( 0.21 on average) confirm the concentration of petroleum products in one or a few communities (Figure A.22). Overall, this outcome makes the petroleum industry rather peculiar relative to other resource-based industries, for which products are often dispersed across communities and unstable over time.

\section{The wood and paper communities}

The wood community mostly consists of crude wood and wood manufacturing, indicating some degree of vertical integration from countries with abundant wood resources. The wood community is maintained over the period of analysis as evidenced by its relatively high product overlap from one period to the next, shown in Figure A.17 (close to 45\%) ${ }^{15}$

Some exporters of wood manufacture focus solely on wood while others diversify into resource-based manufactures such as metal and paper or into textile and food manufacture. The export pattern relating wood and other resource-based manufacture only holds for two periods as the community related to resource-based products is discontinued from the period 1985-1989 onwards. The presence of wood manufacturing in the textile and food community decreases from $18 \%$ during the period $1975-1979$ to $9 \%$ during the rest of the periods of analysi: 16 .

Crude wood products have similar export patterns with wood manufactures

\footnotetext{
${ }^{13}$ Only 1 is found during 1985-1989, 3 during 1990-1994, 1 during 1995-1999 and 2 during 2000.

${ }^{14}$ During 1990-1994, the petroleum community merges with the one of iron and steel. Note that over this period, many communities tend to merge.

${ }^{15}$ The wood community is broken down during the period 1990-1994 with most products shifting to the textile and food community. However, there is tendency for communities to merge during this period, which is likely to be linked to a change in the data rather than a relevant evolution of export patterns. In addition, most products shift back to the wood community from 1995 onwards.

${ }^{16}$ With the exception of period $1990-1994$, which is subject likely to be subject to irregularity in the data
} 
but some important differences are worth mentioning. Contrasting with wood manufacturing, crude wood products are concentrated into a fewer communities as indicated by the lower level of entropy in Figure A.22. Furthermore, there is a shift of crude wood products from communities including wood manufacturing products (wood module and textile and food module) towards the paper community. The share of crude wood products located in the paper community increases over time from $11 \%$ during the period $1975-1979$ to $33 \%$ in 2000 .

Vertical integration in the paper industry ranges from crude wood to pulp wood and to paper products as all these products are present in the same community. The paper community is sustained over the period of analysis with a product overlap of above $30 \%$ on average (Figure A.17). The entropy of shares across communities depicted in Figure A.22 provides evidence of the high uniformity of export patterns within this industry and increasingly so towards the high-end of the value chain (paper products) ${ }^{17}$

A pattern of diversification is identified from period 1990-1994 onwards as the metal and paper modules merge into one community. Figure A.17 shows that this newly formed community is stable over time as the products' overlap is over $40 \%$ between periods from 1990 onwards.

These results contrast with Leamer (1984), where the paper and wood industries are in the same product class. The present study reveals the boundaries present in most countries between the wood and paper industries, especially at the manufacturing level.

\section{The metal communities}

There exist differences within the metal industry regarding the type of metal and the stage of production. Crude metal products tend to be less dispersed across communities than metal manufacturing products as evidenced by its lowest entropy of shares across communities reported in Figure A.22 Natural resources are characterized by export concentration in a limited set of countries. Crude and metal manufacturing exports (SITC 28 and 68) are often found in the same communities, attesting to the limited upgrade of crude metal exporters.

Iron and steel products are regrouped in one community that can be identified

\footnotetext{
${ }^{17}$ The set of paper products is the most concentrated across communities with an average entropy of shares slightly above 0.15. Backward industries producing the inputs for the paper industries (pulp wood and crude) are also concentrated within a few communities over the period of analysis relative to other resource-based products.
} 
in each period of analysis while other metal products are found in a relatively wide range of communities. That is, we can expect a greater degree of specialization in the export of iron and steel than other metals. Nonetheless, the product overlap from one period to the next in the iron and steel community is on average relatively low (31\%) and variable, ranging from 20 to 40\%, as presented in Figure A.17, which means that some change in the composition of the basket of iron and steel exporters occurs 18 The alluvial diagrams in Figure A.16 and Figure A.6 show that from 1985 onwards, around $20 \%$ of the products from the iron and steel industry shift to machinery communities on average 19 A common feature of industries related to the manufacture of metal is their increasing presence in machinery communities. By 2000 , above $25 \%$ of products relative to metal manufacturing industries (SITC 67 , 68 and 69 ) are located in the machinery community. The share of goods relative to manufacturing metal products (SITC 69) has experienced the greatest increase as it has been multiplied by almost 5 from 1975 to 2000 while iron and steel products remain the predominant metals within the machinery communities. This evolution is likely to be due to the use of metals, especially iron and steel, as inputs in this industry. Local value chains linking metal and machinery products exclude crude metals because those require the abundance of such resources in the country and involve much less complex or no manufacturing process.

Another evidence of structural change is worth mentioning. During the period 1990-1994, the merge between the metal and paper communities results in the formation of a new community. Although part of the metal products (both crude and worked) leave this community to form a new one almost exclusively composed of metal goods during the period 1995-1999, the module associating metal and paper products remains until 2000 with an average product overlap of $44 \%$ from one period to the next (Figure A.17).

\subsection{Discussion: export patterns, structural change and factors of production}

Overall, the community structure and its evolution show that the factors explaining industrial patterns and structural change are more complex than the tradi-

\footnotetext{
${ }^{18} \mathrm{As}$ it is the case of many communities during the period 1990-1994, a merge occurs between the iron and steel module and the petroleum one.

${ }^{19}$ In the period 2000, iron and steel products are found in two communities with a predominance of machinery goods.
} 
tional divide between low-tech and medium to high-tech industries. Below I examine the community structures that emerge and identify a set of potential common drivers that explain the emergence and evolution of communities 20 Clusters can form due to $(i)$ the experience in a technological domain, (ii) the abundance in production factors, (iii) the need for large scale economies and (iv) vertical integration.

The community corresponding to electronics products (SITC 75, 76, 77) and photographic equipment, optical and watches (SITC 88) forms around their experience in a technological domain, which corresponds to the one associated with the phenomenon of the electron. In addition, this association reveals the growing importance of electronics in the making of photographic equipment, optical goods and watches, indicating that internal replacement and structural deepening taking place in such technologies.

Also, the electronics and machinery industries are associated with an experience in different technological domains. Their location in distinct communities (Figure A.12 and A.13 illustrates the importance of accounting for heterogeneity within the manufacturing sector. Moreover, the relationship between the electronics and machinery industries is limited and decreasing over time as depicted in the alluvial diagram in Figure A.17.

The relative abundance in production factors also influences the structure of communities. The results reveal the importance of several factors. Natural resources are a determinant driver in several cases. There exists a community associated with petroleum products, one regrouping iron and steel goods, several with a predominance in metal exports and another focused on the export of wood products. The community corresponding to textile and food products appears due to the abundance of low-skilled labor (Lall et al. 2004) ${ }^{21}$ The formation of the machinery community characterized by a high concentration and predominance of high to medium-tech industries (machinery, controlling instruments and chemicals) is likely to be associated with important technological capabilities and financial resources as they involve knowledge intensive and complex processes and require a great amount of R\&D.

\footnotetext{
${ }^{20} \mathrm{~A}$ more detailed analysis of the results is presented in section ??.

${ }^{21}$ Another common characteristic shared by these two industries is that they are supplierdominated (Pavitt, 1984).
} 
Furthermore, vertical integration seems to be a fundamental determinant in the community structure and its evolution during the period of analysis. We can observe several cases of vertical integration within countries.

Some degree of vertical integration within countries is noticeable and deepening around the machinery industry with several industries involved: chemicals, iron and steel and metal. The association of machinery and metal products could also be driven by the need for large scale economies.

Vertical integration at the local level is also present in industries involving less complex processes. The set of chemicals (mostly inorganic) present in the petroleum community increases over time, indicating that some petroleum exporters have upgraded their exports through vertical integration. However, this integration is limited as polymers are are almost nonexistent in this community. This can be explained by the fact that polymers are at the high end of the value chain and so their production would require greater knowledge, technology and infrastructure.

There exist two integrated value chains associated with the export of wood, which evolves over time. One community groups most wood products including crude and manufacturing wood while another represents the paper industry as it comprises crude wood, pulp wood and paper products. The composition of these two communities evolves as crude wood products tend to shift from the wood towards the paper community.

From 1980 onwards, the electronics industry and other low-tech industries are merged into a single community, indicating the presence of vertical integration at the global level. This evolution provides evidence for the acceleration of the fragmentation of the production process in the electronics industry during the 1980s. This representation also shows that countries that have entered the electronics global value chain were for the most part little developed in the textile industry as textile manufacturing products are not part of the electronics community and the product overlap between the two communities over time is never above $3 \%$ (Figure A.17). The presence of the least complex stages of production in the textile industry within the electronics community can be explained by the main objectives of the fragmentation of the production process: reducing costs. For this reason, the fragmentation of production implies the delocalization of labor-intensive and low skill tasks (such as assembly) to countries where wages are particularly low. This community splits again in 2000 to form two modules, one including mostly 
medium to high-tech industries and another composed of low-tech industries. Such an evolution can reflect different events. Some countries previously dedicated to low value-added stages of the production process may have upgraded their export basket by focusing on the electronics industry. This period also follows the Asian crisis of 1997, which significantly affected economies and thereby exports within the region. However, a deeper analysis would be needed to shed light on the causes of this evolution.

By contrast, there is no evidence of fragmentation of the production process in the community associated with the machinery, controlling instruments and chemical industries. This result is in line with the characteristics of the machinery and chemicals industries described in Lall et al. (2004). The fragmentation of the production process is limited by the high value to weight ratio of products and parts in the machinery industry and by the limited divisibility of production processes in the chemical industry. Indeed, on average more than $70 \%$ of parts and components from the machinery industry are in the machinery community. However, this result should be taken with caution as the sample excludes Eastern Europe countries, which is where a large part of the global value chain (GVC) in the machinery industry has taken place after 1989.

Finally, I have argued that firms cluster into industries according to a set of common capabilities, technologies and knowledge. However, these boundaries are likely to differ across industries. Recall that a community is defined here as a set of products that are likely to be exported together, which I assume provides information on their relatedness in terms of the capabilities they require. An industry refers to a group of products derived from a traditional and ad-hoc classification: the SITC (see details in Table A.4). I look at the dispersion of products from each industry across communities to test the strength of the boundaries between industries. If products from one industry are clustered into one community, then it is likely that this industry has fairly strong boundaries. The reason for this is that the countries exporting them are likely to export other products from the same industry (according to the definition of the cluster). Conversely, if products from one industry are spread across several communities, then this industry has softer boundaries. A high dispersion of the products of a given industry can also be a sign that the capabilities required within a industry are heterogeneous. In other words, the capabilities required to make one product can be different from the ones to make another product from the same industry. In what follows, I describe the 
tools used in the analysis of the results.

Results show that while some industries are represented by one or two communities, others have their products distributed across a wide range of communities. I calculate the entropy of shares of products from industry $i$ across $q$ communities to quantify the dispersion of an industry's products across a set of communities as follows:

$$
H_{q}^{i}=\frac{1}{Q} \sum_{q=1}^{Q} s_{q}^{i} \ln s_{q}^{i}
$$

with $s_{q}^{i}=\frac{x_{q}^{i}}{\sum_{q=1}^{Q} x_{q}^{i}}$

This measure provides an indication on the strength of the boundaries of each industry. The results are presented in a heatmap in Figure A.22. When $H_{q}^{i}$ is low, the products of the industry are found in one or a few communities and exporters within this industry are characterized by relatively uniform export patterns. This industry displays strong boundaries, suggesting that it would not be straightforward for countries to start exporting products from this industry if they do not have any in their existing export basket.

The degree of uniformity of export patterns differs between low-tech relative to medium and high-tech industries. This is to be expected as low-tech industries require a less diverse set of capabilities. As a consequence, it is easier to start exporting products from these industries even when the export basket of countries does not contain any of their products. Low-tech industries such as textile, wood, paper and furniture tend to be characterized by a wide range of export patterns. Figure A.22 shows that the entropy is often high in these low-tech industries, meaning that products are distributed across a large number of communities. Conversely, the entropy of medium to high-tech industries such as machinery, controlling instruments, electronics, optical goods and plastics (4 out of 6 periods) is much lower in general, with the exception of chemicals. These results indicate that such industries tend to exhibit a relatively homogenous export patterns. In other words, countries exporting products from these industries are likely to focus on them. Low entropy is also found in most resource-based industries including petroleum, coal, wood and pulp wood, metal and, in half of the periods, iron and steel. The general high uniformity of exports found in these industries is not surprising as the large majority of countries abundant in natural resources find it difficult to develop and diversify their production and export basket. Overall, these patterns are relatively constant over the period of analysis. 


\subsection{Conclusion and limitations}

Uncovering the community structure of the product space and its evolution enables us to identify potential paths for structural change by providing information on the linkages between products and industries. This exercise enables us to map several industries and groups of industries according to common characteristics, thereby reinforcing the empirical evidence of the importance of industry differences (Malerba, 2002) at a global level. Technological development is an important determinant of export patterns as medium to high-tech products tend to be grouped together, as evidenced by the community comprising machinery goods, controlling instruments and chemicals and the electronics community. Results also indicate that the structure of export patterns also depends on bounds defined by domains of knowledge and technology, partly explaining the location of medium to high-tech products in different communities. The machinery and electronics are found in two different clusters with a limited product overlap over time.

The merge of photographic equipment, optical goods and watches with the electronics community provides empirical evidence of the evolution of these technologies. The evolution of these technologies consisting in internal replacement and structural deepening has translated into their "redomaining" as the technological family of their sub-parts has shifted towards electronics over time. Arthur (2009) points out that technological domains are never clearly defined as their content is not constant over time and space.

Furthermore, according to the results, industry differences cannot be solely explained by technological complexity and domains but also by factor abundance and vertical integration at the local and global levels.

On the one hand, the abundance of low skilled labor in some countries is at the source of the formation of a community regrouping the food and textile industries. In addition, several modules are characterized by products associated with a certain number of natural resources. This is the case of the petroleum, iron and steel, metals, wood and paper communities that are identified and persist throughout most of the period of analysis. On the other hand, most communities gather products associated with the same value chains indicating the manifestation of vertical integration, which tends to intensify with time. This is true for all industries, inde- 
pendently of their technology intensity, as value chains are found in the machinery, petroleum, wood and paper communities. While in these cases, vertical integration is likely to take place within the country, the presence and composition of the electronics community shows evidence of an acceleration of the fragmentation of the production process within the industry from the 1980s onwards. This analysis also provides information on the export profile of countries that have succeeded to enter this global value chain. Their export basket is strongly focused on the low end of the textile industry, characterized by cheap low-skilled labor. This reflects the main objective of such delocalization processes, which consists in reducing production costs. The results presented here indicate that industries also differ in the nature of their production process, that is whether it is divisible or continuous and whether tasks are all complex or not, along with products' characteristics (especially the weight). These differences are fundamental aspects explaining the structure and evolution of the globalized economy.

Finally, the analysis presented here provides evidence of the relatively high heterogeneity of export patterns within some industries, especially low-tech ones, such as those of textile and food.

Several limitations are worth noting. Gross export data comprise important measurement errors including double counting and does not account for product quality. In addition, the level of disaggregation of this data does not allow to distinguish between parts and components and final products. Countries' capabilities are thereby imperfectly estimated, and by consequence, some of the links between industries are biased. This bias could be limited by looking at the value added share of exports data. However, these data should be available at a high level of product disaggregation and cover a wide range of countries and years.

Lastly, although this analysis has enabled us to identify important factors explaining export patterns and their evolution, further work is needed to shed light on countries' export trajectory to explain changes in the community structure over time. For instance, it is important to explain the causes of the incorporation of metal products within the machinery community. Is this change the result of an upgrade of the export basket of metal exporters or of a diversification of industrialized countries? 


\section{Chapter 3}

\section{Breaking down the effect of manufacturing on the dynamics of economic growth}

\subsection{Introduction}

Economic growth is pursued by most countries as it is believed to be the main root of wealth and development. Since the industrial revolution, some countries have experienced periods of rapid growth driven by the shift of economic resources from a traditional to a modern sector, that is, structural change.

Most studies on the effect of structural change on economic growth focus on the differences between sectors, that is between agriculture, services and manufacturing. Results often show that the effect of manufacturing is unclear or weak. In addition, most studies consider that the growth process is a linear process and do not account for the volatility of output, which tends to be especially high in developing countries.

In this chapter, I focus on medium-term growth (8-year periods) following Pritchett (2000) and Hausmann et al. (2005), and identify three growth patterns: rapid growth, slow growth and recession. I use this typology to estimate a semiMarkov model in which the probability for a country to remain in a given state of growth depends on the state it is in and the time spent in this state. This model also allows explanatory variables to influence the speed and the trajectory of the growth process (by making the probability to transition between states depend on them).

The first part of the analysis consists in estimating the probability of transition between the different states of growth. I find that the transition behavior between growth states is heterogeneous. With the exception of the transition from slow to 
rapid growth, changes from one growth regime depends on the time spent in the former. For example, for countries experiencing rapid growth, the propensity to fall into a state of slow growth decreases with time. The opposite behavior is found for the transition from recession to slow growth. Namely that as countries remain in either slow growth or recession, their chances to leave this state increase with time.

The second part of the analysis consists in estimating the effect of the economic structure of countries on the probability to transition between different states of growth. I focus on the manufacturing sector and uncover several clusters of products based on the structure of the product space using export data from 1962 to 2000. I study the effect of two dimensions of the economic structure by looking at the intensive and extensive margin. The intensive margin reflects the intensity of the export of countries in a given cluster, while the extensive margin corresponds to the export diversity of countries in a cluster. This analysis provides evidence to the argument that there is no unique path to growth (Rodrik, 2008) and on the role played by different clusters at different stages of the growth process. Moreover, clusters of similar technological intensity, such as electronics, machinery and chemicals, have very different effects. Furthermore, I find evidence of a recession trap, which is strongly linked to an increased specialization in the export of several manufacturing export clusters composed mainly of natural-resources manufacturing.

The structure of this chapter is as follows. In the first section, I review the growth literature focusing on the structuralist view. In the second section, I present the data and variables I use in the estimations. In particular, I identify different growth patterns and I present a methodology to measure different dimensions of economic structure. In the third section, I study the characteristics and determinants of transitions between different states of growth. Finally, I conclude in the last section.

\subsection{Manufacturing and economic growth: a re- view of the literature}

Structural change, that is a change in the sectoral composition of output, can foster growth through a variety of channels on both the demand and supply sides. 
On the one hand, the rate of technological progress is heterogeneous across sectors. As a consequence, a reshuffling of resources into activities with higher potential for technological advance, such as the manufacturing sector, can foster economic growth (Salter, 1960). In addition, the manufacturing sector is characterized by dynamic scale economies (learning by doing) and important backward linkages to other sectors (Cornwall, 1977). The prices of manufacturing goods are also less prone to external shocks and they are less affected by a degradation of the terms of trade relative to agricultural products and commodities, limiting the risk of falling into a low-development trap (Prebisch, 1950 and Singer, 1950).

On the other hand, a productivity increase can lead to demand saturation, which create opportunities for a reallocation of newly available resources towards more productive sectors, for which demand elasticity is also lower. According to Pasinetti (1981), this mechanism explains the "structural change bonus".

Several empirical studies find that the role played by the manufacturing sector as an engine of economic growth is unclear. Fagerberg and Verspagen (1999) analyze the effect of the growth rate of manufacturing value added on growth for the period 1973 to 1989 in 67 countries. They demonstrate that the manufacturing sector still plays a role as an engine of growth in the developing world but that its effect has faded in industrialized economies. Using a sample of 88 countries from 1950 to 2005, Szirmai and Verspagen (2015) find that the share of manufacturing value-added in GDP has a positive effect on growth. However, when including the education and catch-up level in interaction with the manufacturing variable, the direct effect of manufacturing on growth is no longer significant (when breaking down the sample into 5-year periods, the direct effect is significant only for the period 1970-1990).

Structural transformation often focuses on the distinction between a traditional sector, agriculture, and a modern sector, manufacturing (Lewis, 1954). Yet, nowadays the productive structure of countries is much more complex than it used to be. Each sector is made up of a wide variety of industries with specific characteristics in terms of knowledge creation and diffusion, technologies and capabilities, among others. Using a sample of 39 countries and 24 industries (rather than sectors) from the UNIDO database between 1973 and 1990, Fagerberg (2000) decomposes productivity growth into three components: $(i)$ structural change (change in productivity due to labor reallocation between industries), (ii) productivity change within industries, (iii) the interaction of the two effects. In this decomposition, productivity variation within industries is the main cause of productivity growth while structural change has almost no effect. Furthermore, electrical machinery 
stands out as it is associated with the highest average productivity growth over the period. In order to better understand the role of this industry in productivity dynamics, Fagerberg (2000) regresses the share of electrical machinery in total employment on productivity growth. His results show that aggregate productivity growth can be attributed to productivity growth variation within the electrical machinery industry and to spillovers from this industry to others.

Also departing from the idea of the existence of a dual economy, Saviotti and Frenken 2008) argue that economic growth can be driven not only by structural changes but also by qualitative change. The latter includes changes at different levels of aggregation of the productive structure (sectors, industries and products). They quantify this by using the Shannon entropy index, which has the property of being decomposable at different levels of aggregation. At the highest level of aggregation is unrelated variety, which consists in the variety of shares between sectors. It reflects the extent of structural changes in the economy of a country. At the lowest level of aggregation, the average variety of shares within sectors measures the degree of related variety inside a country's economy. This dimension is ignored in most studies on structural change. Saviotti and Frenken (2008) argue that unrelated and related variety growth have different effects on growth and are in fact complementary (Frenken et al. 2007). On the one hand, the existence of a large unrelated variety of exports leads to Jacobs externalities. According to Jacobs (1969), the most important sources of knowledge spillovers are external to the firm or the industry. The presence of a wide variety of different but complementary industries encourages the exchange of knowledge and capabilities leading to knowledge recombination and the application of knowledge to new domains. They note, though, that this effect is limited to sectors that are complementary and involves sets of knowledge that are not too far from each other for their recombination to be feasible. Unrelated variety is also a risk-sharing tool to assimilate sectorspecific shocks. On the other hand, related variety, that is specializing in similar products, has different effects. It may lead to Marshallian externalities. These generate agglomeration economies due to spillovers within sectors through labor market pooling, the creation of specialized suppliers, and knowledge spillovers. In particular, it is often argued that the textile industry has laid the foundations for the development of other industries (possibly with greater value-added and learning potential) by inducing learning by doing, knowledge spillovers, agglomeration effects and local linkages, such as business support networks. Results show that related variety leads to short term growth while unrelated variety has positive effects 
in the long term (Saviotti and Frenken, 2008). They argue that while unrelated variety generates radical and product innovations, related variety is more likely to steer incremental and process innovation inducing productivity rises.

However, increasing variety implies productivity growth only if the transfer of resources is realized towards a sector for which the potential rate of technological change is higher. Therefore, the set of sectors or industries used to compute variety matters. The different measures of variety used in (Saviotti and Frenken, 2008) do not account for the differences in the complexity of embodied knowledge between products and thereby sectors. A complex product involves a complex production process that requires to combine an advanced set of knowledge, technologies and capabilities that only a few countries possess. This set is advanced because it builds on many more simple knowledge, technologies and capabilities, that had to be mastered beforehand. Because of the difference in the complexity of the products in the economic system, its composition is of great importance. It is not because a country diversifies or specializes that it will grow more: the composition of that diversification matters. And so the keys to economic development goes beyond the idea of economic variety. In fact, in the study of Saviotti and Frenken (2008), the sample includes a few developed countries that have a fairly homogenous productive structure. But if one wishes to include a larger sample of countries with a more heterogenous productive structure, using the entropy index amounts to comparing quantities that are not comparable because products are not linearly related to each other.

As argued in the previous Chapter, countries differ in the set of capabilities they master, and products, in the combination of capabilities they require to be made. Some capabilities are shared across several products. In that way products are related. The nature of products relatedness leads to path dependence in the production structure of countries. That is economies tend to extend their export basket by adding products that are closely related to their current basket. This is because their current basket determines the extent of their "tool box" to develop new products (new to the country). The "further" the product is from the existing basket, the more the new knowledge and new capabilities a country would need to accumulate in order to produce it. Path dependence in the process of economic development and in the economic structure stems, in part, from the nature of knowledge production. The creation of new knowledge and appropriation of existing knowledge derive from the recombination of existing knowledge follow- 
ing a combinatorial process (Schumpeter, 1934, Weitzman, 1998, Olsson, 2005 and Arthur, 2009), making "nearby" innovations easier in some sense than distant ones.

The product space formalizes the network of similarities between products dalgo et al. 2007). In this network, the distance between products is proportional to the number of countries exporting both products, controlling for the fact that some products are relatively more common. This measure has two important underlying assumptions: (i) the products a country has a comparative advantage in is a good indication of what it can produce, and, (ii) products that are often exported together share common capabilities. Chapter II shows that the product space is characterized by a modular structure. In other words, some groups of products are more densely connected among themselves than to the rest of the products. As argued before, products that are exported together share common capabilities, and the more often they are exported together, the larger this set of common capabilities is. The fact that we find different clusters of products reveals two important patterns. First, products within each cluster tend to be exported together by a given set of countries. This set of countries relies on a common set of capabilities. Second, products in different clusters rely on different building blocks. This highlights the fact that there are boundaries between products in different clusters. A country that does not export any product from a given cluster does not possess the required building blocks and so it will find it difficult to start exporting any products from this cluster. As a consequence, the localization of a country on this space, that is the clusters in which it exports products, matters and influences its opportunities for future development paths (that is its future location on this space). Chapter II also shows that the clusters are composed of one or several industries. This can be explained by the fact that knowledge and technological characteristics differ across sectors, industries and firms both in terms of the complexity and type of knowledge. These differences also imply the rate of technological progress and the stimulus of a particular industry on the rest of the economy is heterogenous across industries. Given that, the localization of countries on the product space and the way it evolves affect the growth process. In addition, the effect on growth of increasing variety in related and unrelated products depends on the initial composition of the basket. For instance, unrelated variety growth is likely to have a greater effect on growth when the current basket contains mainly low complexity products (assuming new unrelated products are associated to a productivity growth potential higher than the average productivity growth potential of the current products). 
In general, GDP per capita growth is characterized by high levels of volatility, that is, in many cases growth not sustained over time. Most interesting from the perspective of long term economic development are growth episodes that are sustained for long periods. It is thus worth understanding the turning points leading a country to follow a sustainable growth path. Estimating the effects of regressors on the growth of GDP per capita from one year to the next using conventional panel methods is likely to capture uninteresting growth determinants (Pritchett, 2000 and Hausmann et al. 2005). In such estimations, the effect of explanatory variables captures any variation in the growth rate and not in the transition from one growth regime to another and thereby picks up the uninteresting determinants. To address this issue, Pritchett (2000) focuses on the analysis of patterns of growth around the most significant structural break in the economic growth of countries between 1960 and 1992. He identifies several patterns of growth based on the detection of a unique structural break in the economic growth of each of the 111 countries in the sample from 1960 to 1992: steady-state growth (hills and steep hills), rapid growth followed by slow growth (plateaus), rapid growth followed by decline (mountains) or catastrophic fall (cliffs), long term slow growth (plains) and steady decline (valleys). He also shows that developing countries display important instability and volatility in economic growth, which makes the analysis of growth using high-frequency panel data inadequate. Hausmann et al. (2005) propose a new methodology to identify the start of episodes of growth acceleration, lasting at least 8 years, both unsustained and sustained in the following period. They study the determinants of the probability of occurrence of these episodes between 1950 and 2000. Their results show that there are important differences in the determinants between unsustained (8 years) and sustained growth (beyond 8 years). The positive effect of trade shocks and financial liberalization is limited to unsustained growth accelerations while economic reforms and political change (democratization) increases the likelihood of sustained growth accelerations. Jerzmanowski (2006) adopts another approach by estimating a Markov-switching model in which the transition probabilities between states vary according to a country specific measure of institutional quality. He identifies four distinct growth regimes: stable growth, miracle catchup, slow growth and crisis and shows that institutional quality is a positive and significant determinant of the transition between these growth states. What about structural change? Do the changes in the economic structure of countries influence the probability of transition between different growth regimes? 
Several papers focus specifically on the effect of economic structural change on the occurrence of growth accelerations. Jones and Olken (2005) find that most growth transitions are explained by changes in total factor productivity. They propose several explanations for this. On the one hand, productivity gains through increased trade openness tends to favor growth accelerations. On the other hand, they find that growth collapses are associated with a decrease in the labor share in the manufacturing sector while during growth accelerations this share tends to increase. Using data from 1950 to 2005 on value added in Asia and Latin America (19 countries) with a sectoral breakdown, Timmer and de Vries (2009) find that growth accelerations are explained by productivity increases within sectors, not by reallocation of employment to more productive sectors.

In this chapter, I am interested in estimating the role of economic structure in growth dynamics. Economic growth has three main components: (i) the steadystate part corresponds to the growth rate of the steady-state level of output, (ii) the transitional dynamics are the changes in output to adjust to the steady-state level of output and (iii) the business cycle component corresponds the dynamics in actual output. Many growth studies that are interested in the effect of determinants that vary slowly over time such as education, institutional quality or structural change, use short-term panel data on to measure economic growth. Yet, a large part of the variation in short-term growth is linked to business cycles. For this reason, the use of high-frequency panel data is likely to lead to erroneous results by creating estimation problems, such as a lower power, measurement error, endogeneity bias and dynamic misspecification (Pritchett, 2000). In addition, these problems tend to be exacerbated when removing country-fixed effects, which has the effect removing the persistence component while preserving the volatility part associated to business cycles. With the aim to capture steady-state dynamics rather than the variance associated to business cycle, I focus on the analysis of medium-term growth. Rather than focusing on sector-level determinants of the transitions between different states of medium-term growth, I look at the effect of the specialization in different industries within the manufacturing sector. 


\subsection{Growth patterns and economic specialization: data and stylized facts}

In this section, I present the methodology to identify different levels mediumterm growth and the definition of different measures of economic specialization.

\subsubsection{Development patterns and dynamics: definitions and stylized facts}

Based on the methodologies developed in Pritchett (2000) and Hausmann et al. (2005), I define three growth levels:

- Rapid growth: $g_{t, t+7}>3.5$

- Slow growth: $0<g_{t, t+7} \leq 3.5$

- Recession: $g_{t, t+7} \leq 0$

$g_{t, t+7}$ corresponds to the annual growth rate of GDP per capita, in percentage, for each window of time $\tau$ from $t$ to $t+7 \cdot g_{t, t+7}$ is estimated by regressing GDP per capita on time using OLS using the observations for each country and for each window of time $\tau$ from $t$ to $t+7$.

$$
\ln y_{t+\tau}=\alpha_{\tau}+\beta_{\tau} *(t+\tau) \text { with } \tau=0, \ldots, 7
$$

Where $\hat{\beta_{\tau}}=g_{t, t+7}$ and $y_{t}$ is the GDP per capita at time $t$.

Using GDP per capita data from 1950 to 2010 for 111 countries (Maddison Project, 2013), I obtain medium-term growth rates. Their distribution is normal with a mode around $2 \%$ (Figure 3.1). While the occurrence of rapid growth episodes is comparable in industrialized and developing countries, they have diverging patterns when it comes to slow growth and especially recession. A developing country has one chance out of 4 to be in a recession episode, whereas recession almost never 
occurs in industrialized countries. Differences can be noted when it comes to the time period as well. The occurrence of rapid growth episodes increases in the 1950's and 1960's and strongly declines from 1970 to 2000. During this period recession episodes are also more likely to happen.

The advantage of this method relative to a simple average is that it provides additional information on the different growth regimes, including the level of volatility. The estimated growth rates exhibit heterogenous volatility (measured by the fit of the estimation) depending on the growth and development level. Figure 3.3 shows the distribution of the fit of the estimation of GDP per capita growth $\left(R^{2}\right)$ broken down by level of growth (rapid growth, slow growth and recession) and of development. A low fit of the model is a sign of high volatility of GDP per capita during the 8-year period. The distribution of the fit of the GDP per capita growth estimation shows that GDP per capita is less volatile when countries experience an episode of rapid growth as almost all observations correspond to a $R^{2}$ of at least 0.9. The figure also reveals the high volatility in the data when focusing on slow growth and especially recession. When looking at slow growth episodes, slightly more than $50 \%$ of observations correspond to a $R^{2}$ superior to 0.8 . When it comes to recession episodes, GDP per capita is extremely volatile as less than $25 \%$ of observations correspond to a $R^{2}$ greater than 0.8 .

There is also a difference between developing and industrialized countries. While slow growth tends to be more volatile in developing countries, recession is more strained in industrialized countries where more than $75 \%$ of observations on recession are associated to a $R^{2}$ lower than 0.4 .

Figure 3.1: Distribution of GDP per capita growth from 1950 to 2006



Note: GDP per capita growth is calculated following the methodology presented in section 3.3.1 
Figure 3.2: Share of observations corresponding to episodes of rapid growth, slow growth and recession from 1950 to 2006

(a) By development level

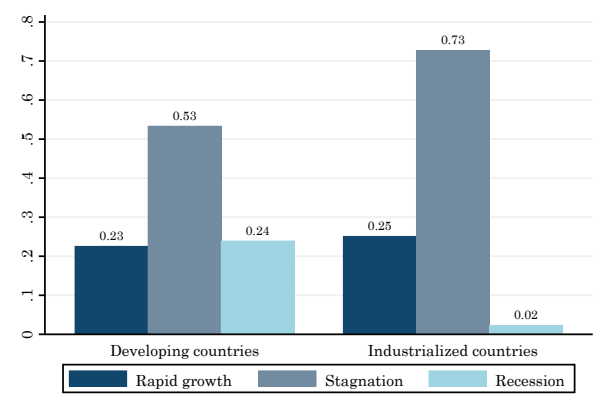

(b) By time period



Note: Growth episodes are defined according to the medium-run GDP per capita growth rate calculated according to the methodology presented in section 3.3 .1

Figure 3.3: Distribution of the fit of the estimation of GDP per capita growth $\left(R^{2}\right)$

(a) All countries

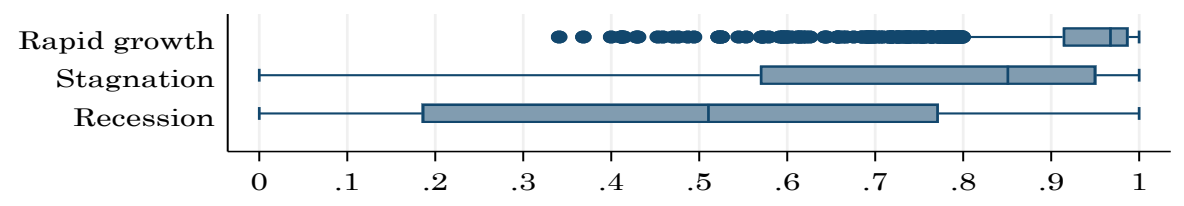

(b) Industrialized countries

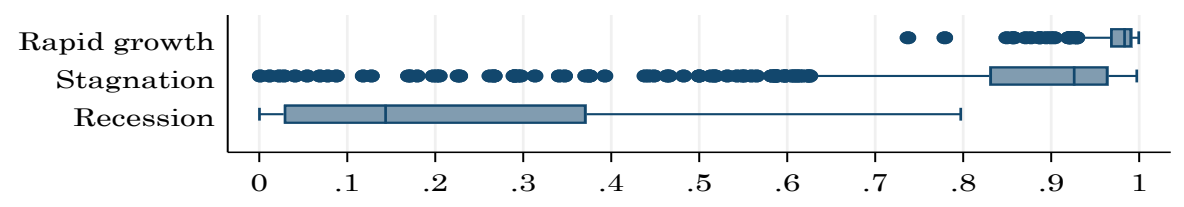

(c) Developing countries

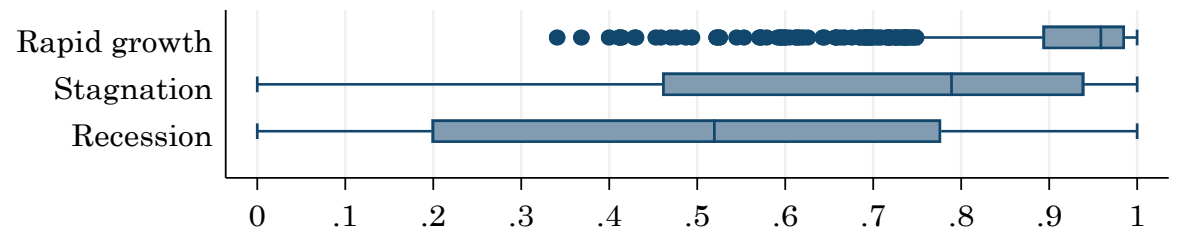

Note: I calculate the medium-run GDP per capita growth rate following the methodology presented in section 3.3.1 I estimate the trend of GDP per capita growth over 8-period windows. The fit of these estimations provides information on the volatility of growth. For each country sample (a), (b) and (c), the distribution of the fit $\left(R^{2}\right)$ is plotted by growth regime. That is, the $R^{2}$ is divided into 3 subsamples corresponding to observations of rapid growth, slow growth and recession. 
Looking at descriptive statistics on the transition between growth states provides some interesting insights on growth dynamics. Transitions resulting in the improvement of the economic situation of countries (from slow to rapid growth and from recession to slow growth) tend to occur slightly more often than those where the growth rate decreases (from rapid to slow growth and from slow growth to recession) during the period of analysis (Table 3.1). However, transitions between rapid growth and recession rarely occur. This shows that the process of growth regime shifts is gradual, as transitions between extreme states (rapid growth and recession) are extremely rare. Descriptive statistics also show that there is a symmetry in the frequency of transitions between states. A transition from rapid growth to slow growth is as likely to occur as a transition from slow to rapid growth. The same is true for transitions between slow growth and recession.

The time a country remains in state $h$, or waiting time in state $h$, (independently of the subsequent state $j$ ) shows that countries tend to stay longer in a state of recession than in a state of slow or rapid growth, thereby hinting to the existence of a development trap. However, waiting time is the most dispersed when countries are in a state of slow growth. Also, it is worth noting that three industrialized countries do not change state during the period of observation. Australia, Denmark and the USA remain in a slow growth regime during the years of observation. 
Table 3.1: Descriptive statistics of the transitions and waiting time observed

\begin{tabular}{|c|c|c|c|c|c|c|}
\hline \multirow[t]{2}{*}{ State $h$} & \multirow[t]{2}{*}{ State $j$} & \multirow{2}{*}{$\begin{array}{l}\text { Number } \\
\text { of } \\
\text { transitions }\end{array}$} & \multirow{2}{*}{$\begin{array}{l}\text { Share of } \\
\text { transitions } \\
(\%)\end{array}$} & \multirow{2}{*}{$\begin{array}{l}\text { Median } \\
\text { waiting } \\
\text { time }\end{array}$} & \multicolumn{2}{|c|}{$\begin{array}{l}\text { Waiting time } \\
\text { in state } h\end{array}$} \\
\hline & & & & & Median & IQR \\
\hline \multirow{3}{*}{1} & $1^{*}$ & 33 & 5.66 & 4 & \multirow{3}{*}{4} & \multirow{3}{*}{3} \\
\hline & 2 & 125 & 21.44 & 4 & & \\
\hline & 3 & 0 & 0 & - & & \\
\hline \multirow{3}{*}{2} & 1 & 116 & 19.90 & 4 & \multirow{3}{*}{4} & \multirow{3}{*}{8} \\
\hline & $2^{*}$ & 63 & 10.81 & 10 & & \\
\hline & 3 & 118 & 20.24 & 3.5 & & \\
\hline \multirow{3}{*}{3} & 1 & 1 & 0.17 & 15 & \multirow{3}{*}{5.5} & \multirow{3}{*}{7} \\
\hline & 2 & 121 & 20.75 & 5 & & \\
\hline & $3^{*}$ & 6 & 1.03 & 8.5 & & \\
\hline Total & & 583 & 100 & & 4 & \\
\hline
\end{tabular}

Notes: Transitions are from state $h$ (column 1) to state $j$ (column 2). State 1 corresponds to rapid growth, 2 to slow growth and 3 to recession. * stands for censored waiting times. The last waiting time is right-censored when the last duration and the last arrival state are unknown and if the process does not enter an absorbing state (see section 3.4 for details on the treatment of right-censored data). IQR stands for interquartile range.

\subsubsection{Measuring economic structure in manufacturing ex- ports}

To recall from the previous chapter, we can define a "product community" (or product cluster) as a group of products that are often seen together in the export basket of countries. These groups are representative of common product mix countries specialize in. As argued in the previous chapter, it is reasonable to think that if several countries tend to export a particular set of products, these products are relatively similar (in terms of capabilities they require to be made, technological domain and so on). Because of the way it is created, the SITC has the feature that many industry classes cover products that are likely to have different characteristics and effects on economic growth. This is the case of machinery and electronics products, for example, which are under the same group, or plastics and organic chemicals, which are grouped together along with other chemicals. Additionally, multicollinearity is also a problem when introducing industry-level variables to growth regression. Suppose that part of the products from industry $A$ is likely to be exported with the products from industry $B$. When focusing on industries rather than communities, we are likely to introduce highly correlated variables in the regressions and to obtain biased coefficients. To address these issues, instead of using SITC industry classes, I identify a static community structure of a subset 
of the product space corresponding to manufacturing products (see details of the methodology and results in section B.2. Community-level variables do not eliminate the multicollinearity problem fully but reduces it because products inside each community represent the export patterns of a particular group of countries. Note that when studying the economic structure at a more disaggregated level implies more correlation between the different groups of products because some countries will overlap several export patterns. This is due to the fact that some countries export a very wide range of export products, especially middle income countries Klinger and Lederman, 2004 and Cadot et al. 2011) 1 I obtain 17 communities of which 9 contain at least 10 products, community id 1 to 8 (Table B.4). I analyze the effect of the economic structure associated to these 8 communities (470 products), which correspond to more than $90 \%$ of the total of manufacturing products. I label each community according to the type of product they include, based on SITC, (Table B.3).

I use two different sets of variables to calculate the economic structure, that is specialization of country $c$ in community $q$ :

1. Share of country $c$ 's export value in community $q$ in its total export value: $\frac{\sum_{p \in q} x_{c p}}{\sum_{p} x_{c p}}$

2. Share of products exported by country $c$ from community $q$ relative to the total number of products in community $q^{2} \frac{\sum_{p \in q} M_{c p}}{\sum p \in q}$

While the first index measures the intensive margin, the second measures the extensive margin. Figure 3.4 shows the relationship between the export value (intensive margin) and export diversity (extensive margin). It shows that the correlation between the intensive and extensive margin varies widely across communities. In the electronics community, countries with a high extensive margin tend to have a low intensive margin. In the machinery community, countries with a low intensive margin have a very heterogenous profile when it comes to extensive margin. In the textile community, there is no correlation between the extensive and intensive margins.

\footnotetext{
${ }^{1}$ The diversity variables are sometimes highly correlated (Figure B.1b but this does not seem to lead to multicollinearity problems according to the variance inflation factor test (Table B.5.

${ }^{2}$ For instance, according to the community structure derived from the export behavior of the countries of the sample, 90 products form the electronics community in 2000. During the same year, South Korea exports 42 products from this cluster, which corresponds to around $46.67 \%$ of the products belonging to the electronics community.
} 
Figure 3.4: Relationship between export value versus export diversity in different communities

(a) Machinery community



(c) Textile community



(b) Electronics community

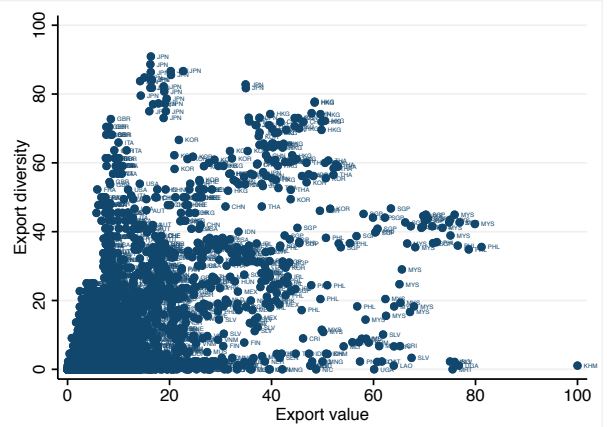

(d) Natural resource-based manufacturing community



Notes: The x-axis corresponds to a country's export value share in a community relative to its total export value. The y-axis corresponds to a country's share of products in a community relative to the total number of product in this community.

\subsection{A semi-Markov model for analyzing transi- tions between growth states}

To study the behavior of growth transitions and their potential determinants, I adopt a Markov framework. In simple Markov models, it is assumed that the probability of transition from one state to another only depends on the current state the country is in and that the expected time to transition between states is always the same. This is a rather strong hypothesis and in the context of this 
analysis, it amounts to discarding transition dynamics in the growth process. Instead, I estimate a semi-Markov model with an embedded homogenous Markov chain. In such a model, the time of entry in a state (or growth regime in this case) does not have any effect on the transition probabilities but the duration time a country stays in a state can have an effect. I estimate the model with three states representing: rapid growth, slow growth and recession. According to the data, the transitions between these states can occur between rapid growth and slow growth and between slow growth and recession but not between rapid growth and recession as illustrated in Figure 3.5. Note that, in the dataset, only one transition from recession to rapid growth is observed (in Sudan) and none from rapid growth to recession. I remove the observations associated to Sudan, to be able to estimate the semi-Markov model. The estimation of a model in which all transitions are possible leads to estimation convergence problems and to unreliable estimates. If we were to include Sudan, the extremely low or null probability of transition between states of rapid growth and recession results in the estimation of parameters with extremely high values for these transitions, or induces convergence problems, in particular with the inversion of the Hessian matrix. As shown in Table 3.2 the descriptive statistics after this modification are almost unchanged.

Figure 3.5: The three states model used for growth evolution




Table 3.2: Descriptive statistics of the transitions and waiting time observed (without Sudan)

\begin{tabular}{|c|c|c|c|c|c|c|}
\hline \multirow[t]{2}{*}{ State $h$} & \multirow[t]{2}{*}{ State $j$} & \multirow{2}{*}{$\begin{array}{l}\text { Number } \\
\text { of } \\
\text { transitions }\end{array}$} & \multirow{2}{*}{$\begin{array}{l}\text { Share of } \\
\text { transitions } \\
(\%)\end{array}$} & \multirow{2}{*}{$\begin{array}{l}\text { Median } \\
\text { waiting } \\
\text { time }\end{array}$} & \multicolumn{2}{|c|}{$\begin{array}{c}\text { Waiting time } \\
\text { in state } h\end{array}$} \\
\hline & & & & & Median & IQR \\
\hline \multirow{3}{*}{1} & $1^{*}$ & 32 & 5.55 & 4 & \multirow{3}{*}{4} & \multirow{3}{*}{3} \\
\hline & 2 & 124 & 21.49 & 4 & & \\
\hline & 3 & 0 & 0 & - & & \\
\hline \multirow{3}{*}{2} & 1 & 115 & 19.93 & 4 & \multirow{3}{*}{4} & \multirow{3}{*}{8} \\
\hline & $2^{*}$ & 63 & 10.92 & 10 & & \\
\hline & 3 & 117 & 20.28 & 4 & & \\
\hline \multirow{3}{*}{3} & 1 & 0 & 0 & - & \multirow{3}{*}{5.5} & \multirow{3}{*}{6.75} \\
\hline & 2 & 120 & 20.80 & 5 & & \\
\hline & $3^{*}$ & 6 & 1.04 & 8.5 & & \\
\hline Total & & 577 & 100 & & 4 & \\
\hline
\end{tabular}

Notes: Transitions are from state $h$ (column 1) to state $j$ (column 2). State 1 corresponds to rapid growth, 2 to slow growth and 3 to recession. ${ }^{*}$ stands for censored waiting times. The last waiting time is right-censored when the last duration and the last arrival state are unknown and if the process does not enter an absorbing state (see section 3.4 for details on the treatment of right-censored data). IQR stands for interquartile range.

I now turn to the presentation of the semi-Markov model (Foucher et al., 2005) estimated in this chapter.

Consider the random process $\left(J_{n}, T_{n}\right)$, with $n \in \mathbb{N}$, in which $T_{0}, T_{1}, \ldots, T_{n}$ represent the time of entry to growth states $J_{0}, J_{1}, \ldots, J_{n}$ with $J_{n} \neq J_{n+1}$. In this setting, $J_{n}$ is an embedded homogenous Markov chain taking its values in a discrete finite state space $E$ (here $E=3$ since there are 3 states) and with transition probabilities $p_{h j}$ given by:

$$
p_{h j}=P\left(J_{n+1}=j \mid J_{n}=h\right)
$$

with the constraint $\sum_{j} p_{i j}=1$.

The Markov renewal process $\left(J_{n}, T_{n}\right)$ is semi-Markovian if the distribution of waiting times, $W_{n+1}$, satisfies the following Markov kernel, $Q_{h j}(d)$ :

$$
\begin{aligned}
Q_{h j}(d) & =P\left(J_{n+1}=j, W_{n+1} \leq d \mid J_{0}, J_{1}, \ldots, J_{n}\right) \\
& =P\left(J_{n+1}=j, W_{n+1} \leq d \mid J_{n}=h\right)
\end{aligned}
$$

where $W_{n+1}=T_{n+1}-T_{n} \forall n \in \mathbb{N}^{*}$ is a continuous variable corresponding to the duration time spent in state $J_{n}, d \in \mathbb{R}_{+}$and $(h, j) \in E \times E$. 
The time a country spends in a state $h$ before transitioning to another state $j$ (otherwise called waiting time), is defined by a density probability function given by:

$$
f_{h j}(d)=\lim _{\triangle d \rightarrow 0} \frac{P\left(d<W_{n+1} \leq d+\triangle d \mid J_{n}=h, J_{n+1}=j\right)}{\triangle d}
$$

The associated cumulative density function of the waiting time is written as:

$$
F_{h j}(d)=P\left(W_{n+1} \leq d \mid J_{n}=h, J_{n+1}=j\right)
$$

The hazard rate of waiting time at duration time $d, \alpha_{h j}(d)$, represents the conditional probability that a transition from state $h$ to state $j$ is observed given that no transition occurs until duration time $d$ :

$$
\alpha_{h j}(d)=\lim _{\triangle d \rightarrow 0} \frac{P\left(d<W_{n+1} \leq d+\triangle d \mid J_{n}=h, J_{n+1}=j, W_{n+1}>d\right)}{\triangle d}
$$

$\alpha_{h j}(d)$ is related to the probability density function, $f_{h j}(d)$, and the survival function of waiting times, $G_{h j}(d)$, in the following way:

$$
\alpha_{h j}(d)=\frac{f_{h j}(d)}{G_{h j}(d)}
$$

Following Foucher et al. (2005), I assume that the distribution of waiting times is parametric and transition specific. I consider the following distributions to describe the hazard rate of waiting time, $\alpha_{h j}$ :

- the exponential distribution, $\alpha_{h j}=\frac{1}{\sigma_{h j}}, \forall d \geq 0$, corresponds to the Markov case where the distribution is constant over time.

- the Weibull distribution, $\alpha_{h j}(d)=\frac{\nu_{h j}}{\sigma_{h j}}\left(\frac{d}{\sigma_{h j}}\right)^{\nu_{h j}-1}, \forall d \geq 0$, which allows the distribution of waiting time to vary according to the time spent in a state.

$\sigma$ and $\nu$ corresponds respectively to the scale and shape parameter of the distribution.

The hazard rate of the semi-Markov process, $\lambda_{h j}(d)$, depends on the hazard rate of waiting time, the survival functions of waiting time and the transition probabilities. It can be calculated as follows:

$$
\lambda_{h j}(d)= \begin{cases}\frac{p_{h j} f_{h j}(d)}{G_{h .}(d)}=\frac{p_{h j} G_{h j}(d) \alpha_{h j}(d)}{G_{h .}(d)}, & \forall h \neq j \\ -\lambda_{h j}(d), & \forall h=j\end{cases}
$$


where $G_{h} .(d)$ corresponds to the survival function of the waiting time in state $h$, which depends on the transition probabilities, $p_{h j}$, and on the cumulative density function of the waiting time, $F_{h j}$. It is defined as:

$$
G_{h .}(d)=\sum_{j \in E} p_{h j}\left(1-F_{h j}(d)\right)
$$

The hazard rate of the semi-Markov process corresponds to the probability of transition to state $j$ between time $d$ and $d+\triangle d$ given that the process is in state $h$ for a duration $d$. Note that the hazard rate of the semi-Markov process is equivalent to the hazard rate of waiting time when the latter follows an exponential distribution. In this case, both hazards are independent of time, i.e. constant.

In addition, to analyze the characteristics of transitions between states, one can study the effect of a set of variables on the hazard rate of waiting time and on the semi-Markov process. Following the Cox proportional regression model (Cox, 1972), I introduce a set of $s_{h j}$ economic structure variables $Z_{h j}=\left(z_{h j}^{1}, z_{h j}^{2}, \ldots, z_{h j}^{s_{h j}}\right)$, which are likely to have an effect on the hazard rate of waiting time associated to the transition from state $h$ to state $j$. In this model, the set of explanatory variables and their effect are transition specific. This implies that the effect of each variable is allowed to vary according to the type of transition. The set of $s_{h j}$ explanatory variables also depends on the type of transition. The hazard rate of waiting time corresponding to transition from state $h$ to state $j$ becomes:

$$
\alpha_{h j}\left(d \mid \boldsymbol{Z}_{h j}\right)=\alpha_{h j 0}(d) \exp \left(\boldsymbol{\beta}_{h j}^{T} \boldsymbol{Z}_{h j}\right), d \geq 0, h, j \in E, h \neq j
$$

where $\boldsymbol{\beta}_{h j}=\left(\beta_{h j}^{1}, \beta_{h j}^{2}, \ldots, \beta_{h j}^{s_{h j}}\right), Z_{h j}=\left(Z_{h j}^{1}, Z_{h j}^{2}, \ldots, Z_{h j}^{s_{h j}}\right)$ and $\alpha_{h j 0}$ is the baseline hazard rate as defined in equation 3.7 .

The explanatory variables influence the hazard rate of the Semi-Markov process, $\lambda_{h j}$, indirectly, through the waiting time distribution. The resulting hazard rate of waiting time in the context of the Cox model can be interpreted as a relative risk for a unit increase in the explanatory variable. This relative risk corresponds to the ratio of two probabilities: $(i)$ the probability that a transition to state $j$ occurs after $d$ years spent in state $h$ when a unit increase in the explanatory variable is observed, over, $(i i)$ the probability that a transition to state $j$ occurs after $d$ years spent in state $h$ occurs when no increase in the explanatory variable is observed. 
The parameters of the distribution of waiting time, the transition probabilities and the coefficients of the explanatory variables are estimated simultaneously by maximizing the following Likelihood function:

$$
L=\prod_{i} L_{i}=\prod_{i}\left[\prod_{n=1}^{N_{i}}\left(p_{J_{n-1}^{i} J_{n}^{i}} f_{J_{n-1}^{i} J_{n}^{i}}\left(W_{i, n}\right)\right) G_{J_{N_{i}}^{i}}\left(U_{i}\right)\right]
$$

The likelihood function corresponds to the different transitions countries can take. For each country $i$, it is the product of the likelihoods of each observed transition. Each of these likelihoods is a function of the probability of transition and on the probability density function, $f$, which depends on the hazard rate of waiting time, $\alpha . N_{i}$ represents the total number of transitions from two distinct states in country $i, U_{i}$ is the duration between the time of the last observation and the time of the end of the study $T_{N_{i}}\left(U_{i}=T_{N_{i}}-T_{N_{i}-1}\right)$. When the last waiting time is right-censored, the last arrival state and the duration are unknown. For instance, imagine a country is in a state of slow growth at the last time of observation $t$. In this case, we do not know whether this country remain in this state and for how long or whether it changes state after $t$. To model the time spent in the last state, the (marginal) survival function in the last state $J_{N}^{i}, G_{J_{N}^{i}}$ is used.

The estimation of the semi-Markov model enables one to answer two important questions:

( $i$ ) Does the number of years a country spends in a growth regime $h$ affect its chances to leave this regime to transition to another growth regime $j$ ?

(ii) Does the transition from growth regime $h$ to growth regime $j$ depend on the economic structure?

To answer $(i)$, I test the functional form of the distribution of waiting times (using the hazard rate). When assuming an exponential distribution of waiting time, the hazard rate for the transition from state $h$ to $j$ is constant over time while it varies with time when assuming a Weibull distribution. Because these two distributions are nested, the Wald test ${ }^{3}$ can be used to assess the distribution that best fits the data. To answer $(i i)$, I estimate a semi-Markov model in which the hazard rate of waiting time for the transition from state $h$ to state $j, \alpha_{h j}$, depends on a set of explanatory variables (the set of explanatory variable is allowed to vary across transitions). The coefficients associated to these explanatory variables are

\footnotetext{
${ }^{3}$ In the null hypothesis, the shape parameter is equal to one (exponential distribution), and in the alternative one the shape parameter is different from one (Weibull distribution).
} 
estimated using the Cox proportional regression model described above. In sum, I estimate in two steps three different sets of parameters for each type of transition (from state $h$ to state $j$ ):

- the parameters associated to the distribution of waiting times, $\sigma_{h j}$ and $\nu_{h j}$,

- the transition probabilities, $p_{h j}$,

- the coefficients, $\beta_{h j}^{s_{h j}}$, associated to each explanatory variable, $z_{h j}^{s_{h j}}$, affecting the hazard rate of waiting time for any transition.

Because of the large number of covariates considered here, the estimation of this model is realized in two steps described as follows $4^{4}$

- The first step consists in estimating the parameters of distribution of waiting times $\left(\sigma_{h j}\right.$ and $\left.\nu_{h j}\right)$ and the transition probabilities $\left(p_{h j}\right)$ for each transition in a model without covariates. In this stage, I first estimate a model assuming a Weibull distribution for the hazard rate of the each of the four transitions. If the shape parameter, $\nu_{h j}$, of any of the transitions is not significant, I estimate a model assuming an exponential distribution for the transition for which the shape parameter is not significant and Weibull distribution for the rest. I then select a model based on the results of a Likelihood ratio test (LR test) used to comparing the different models. In this LR test, the null hypothesis consists in the restricted model (with less parameters) and the alternative hypothesis is the model with all parameters, that is corresponding to the Weibull distribution for all transitions (unrestricted model).

- The second step consists in estimating the coefficients associated to the covariates $\left(\beta_{h j}^{s_{h j}}\right)$ for each transition, given the value of the distribution of waiting times and transition probability parameters estimated in the first step. I test the number of lags using the Akaike Information Criterion (AIC).

\footnotetext{
${ }^{4} \mathrm{I}$ adapt the code of the package SemiMarkov in $\mathrm{R}$ in order to estimate the model in two steps instead of simultaneously.
} 


\subsection{Results}

\subsubsection{The characteristics of growth transitions}

I look at the characteristics of growth transitions by estimating the distribution and transition probability parameters of a semi-Markov model. I first estimate the most general model, in which a Weibull distribution of the waiting times is assumed for all the transitions. Results for this model show that the shape parameters, $\nu_{h j}$, are significantly different from 1 for all transitions except for the one from slow to rapid growth (Table 3.3). In this case, the shape parameter is not significantly different from 1 according to the estimation results and so the data are better represented by a constant hazard rate of waiting times, i.e. modeled using an exponential distribution. Results from the LR test confirms that the best model is the one with an exponential distribution for the transition from slow to rapid growth and a Weibull distribution for the rest of the transitions 5 In what follows, I describe the results of the selected model (Table 3.4.

The parameters of the hazard rate of waiting times offers several insights on the behavior of each transition over time. First, the scale parameter, $\sigma$, provides information on the magnitude of the risk to transition to another growth regime. The higher it is, the lower the risk of transition. Given that this parameter is particularly high for the transition from rapid to slow growth $(\sigma \approx 24)$, countries experiencing rapid growth are likely to remain in this growth regime. The hazard rate oscillates around 0.1 , depending on the duration time in this growth regime. The scale parameter, however, is much lower for the remaining transitions (around 7). In these cases, countries experiencing slow growth or recession are more unstable as they have a higher risk to transition to another potential growth regime (to rapid growth or recession when in a slow growth regime or to slow growth when in recession). As shown in Figure 3.6c this translate into a hazard rate between 0.1 and 0.3. Second, the shape parameter, $\nu$, also provides an indication of whether the chance to transition from growth regime $h$ to $j$ increases $(\nu>1)$ or decreases $(\nu<1)$ with the time spent in $h$. The propensity to transition of countries in a rapid growth regime decreases with time since the shape parameter is lower than 1. However, the shape parameter is greater than 1 for the transitions between slow

\footnotetext{
${ }^{5}$ The null hypothesis of this test is the model assuming an exponential distribution for the transition from slow to rapid growth and the alternative, the model assuming a Weibull distribution for the rest. The LR statistics is equal to -0.375 and the p-value to 1 so that the null hypothesis cannot be rejected.
} 
growth and recession. In other words, their propensity to transition from state $h$ to state $j$ given that no transition occurs for a time duration $d, \alpha_{h j}(d)$, increases with the time.

I now turn to the hazard rate of the semi-Markov process, which provides more complete information on the transition process between the three growth regimes. Indeed, this hazard rate accounts in particular for the hazard rate of waiting times and the transition probability of the Markov chain. According to the results on the estimated transition probabilities $\left(\hat{h}_{\hat{h} j}\right)$, countries that are experiencing slow growth are almost equally likely to shift to a rapid growth regime than to recession (Table 3.4). The transition probabilities associated to rapid growth and recession are set to 1 , as data show that there is no evidence of an alternative transition from these two growth regimes other than slow growth. In other words, the countries in state of rapid growth or in a state of recession have only one possibility of transition: slow growth. Figure 3.6d represents the evolution of the hazard rate of the semi-Markov process for each transition relative to the time spent in the departure state $h$. The hazard of the semi-Markov process can be interpreted as the propensity of transition to state $j$ given that country $c$ is in state $h$ until a time duration $d$. This measure is particularly interesting to analyze more in-depth the behavior of the transitions from a slow growth regime, which offers two possibilities of transition: rapid growth or recession.

In this case, the hazard of the semi-Markov process shows that the risk of transition to a state of recession increases during the first few years of experiencing slow growth. After being in a state of slow growth for more than 9 years, the risk of falling into recession decreases as countries sustain a slow growth. Conversely, countries experiencing slow growth are more and more likely to see their economic situation improve as they maintain their growth rate. Moreover, countries that remain in a state of slow growth for more than 15 years become more and more likely to transition to a state of rapid growth than a state of recession. Overall, as expected, countries experiencing recession have the highest chance to transition. This results also reflects the high volatility in the output of such countries as seen in section 3.3.1. In contrast, countries that benefitting from rapid growth have the lowest risk to see their economic situation worsen and this risk decreases with time. 
Table 3.3: Estimated parameters of the hazard rate of waiting time and of the Markov chain (transition probabilities) for each transition $h j$ (unrestricted model)

\begin{tabular}{|c|c|c|c|c|c|c|c|c|}
\hline \multirow[b]{2}{*}{$h j$} & \multicolumn{6}{|c|}{ Hazard rate of waiting times $\alpha_{h j}$} & \multicolumn{2}{|c|}{ Markov chain } \\
\hline & $\hat{\sigma}_{h j}$ & SD & $\mathrm{p}$-value & $\hat{\nu}_{h j}$ & $\mathrm{SD}$ & p-value & $\hat{p}_{h j}$ & SD \\
\hline $1 \rightarrow 2$ & 24.358 & 1.45 & 0 & 0.606 & 0.05 & 0 & 1.000 & - \\
\hline $2 \rightarrow 1$ & 8.544 & 0.90 & 0 & 1.027 & 0.08 & 0.74 & 0.527 & 0.03 \\
\hline $2 \rightarrow 3$ & 7.243 & 0.66 & 0 & 1.213 & 0.08 & 0.011 & 0.473 & 0.001 \\
\hline $3 \rightarrow 2$ & 7.624 & 0.56 & 0 & 1.357 & 0.09 & 0 & 1.000 & - \\
\hline
\end{tabular}

Notes: SD stands for standard deviation. Parameters are estimated assuming a Weibull distribution of waiting times for all transitions.

Table 3.4: Estimated parameters of the hazard rate of waiting time and of the Markov chain (transition probabilities) for each transition $h j$ (restricted model)

\begin{tabular}{|c|c|c|c|c|c|c|c|c|}
\hline \multirow[b]{2}{*}{$h j$} & \multicolumn{6}{|c|}{ Hazard rate of waiting times $\alpha_{h j}$} & \multicolumn{2}{|c|}{ Markov chain } \\
\hline & $\hat{\sigma}_{h j}$ & $\mathrm{SD}$ & p-value & $\hat{\nu}_{h j}$ & $\mathrm{SD}$ & p-value & $\hat{p}_{h j}$ & SD \\
\hline $1 \rightarrow 2$ & 24.315 & 1.47 & 0 & 0.596 & 0.05 & 0 & 1.000 & - \\
\hline $2 \rightarrow 1$ & 8.429 & 1.05 & 0 & - & - & - & 0.482 & 0.03 \\
\hline $2 \rightarrow 3$ & 7.451 & 0.65 & 0 & 1.214 & 0.08 & 0.011 & 0.518 & 0.001 \\
\hline $3 \rightarrow 2$ & 7.514 & 0.56 & 0 & 1.350 & 0.09 & 0 & 1.000 & - \\
\hline
\end{tabular}

Notes: SD stands for standard deviation. Parameters are estimated assuming an exponential distribution of waiting times for the transition from slow to rapid growth $(2 \rightarrow 1)$ and a Weibull distribution for the remaining transitions. 
Figure 3.6: Survival rate of waiting time, hazard rate of waiting time and hazard rate of the semi-Markov process for each transition

(a) Survival rate of waiting time



(c) Hazard rate of waiting time



$1 \rightarrow 2 \rightarrow 2 \rightarrow 1$ (b) Survival rate of waiting time in state $h$

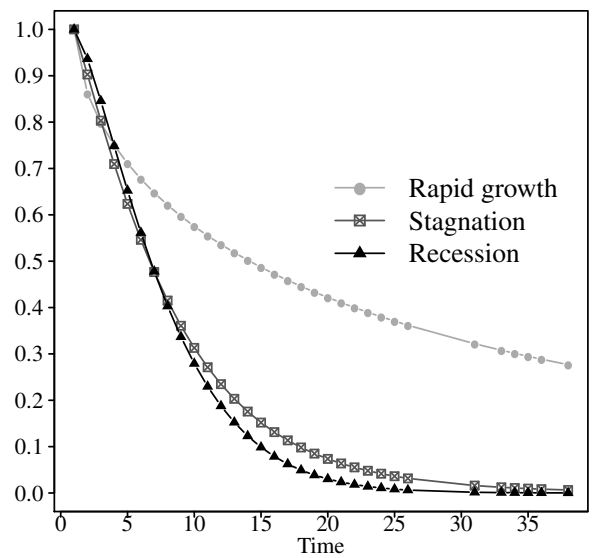

(d) Hazard rate of the semi-Markov process



$2 \rightarrow 3 \rightarrow 3 \rightarrow 2$

\subsubsection{The effect of the economic structure on growth tran- sitions}

I now turn to the second stage of the estimation, which looks at the role of economic structure variables in influencing each transition. I use two measures 
for the economic structure: export value and export diversity (defined in section 3.3.2. I estimate two models, one focusing on export value measures and the other one on export diversity measures, for two reasons. First, because including all economic structure variables in one model would imply estimating a large number of parameters (64 parameters), which is not recommended in this type of model. Second, because the two measures for the same product cluster are in some cases highly correlated. The results are presented in Tables 3.5 and 3.6 respectively. I hereafter refer to specialization when countries increase their export value in a given cluster and diversification when they increase their export diversity.

Beforehand, I test the number of lags for the explanatory variables that best fits the data (I test one, two and and three-year lags) using Akaike Information Criterion (AIC). This criterion evaluates the trade-off between goodness of fit according to the maximum of likelihood function and overfitting of the model given by the number of parameters estimated. According to the results, in both cases the model with 3-year lag better explains the data (Table B.6). In what follows, I describe the results of the selected models, i.e. with explanatory variables with 3-year lag 6

Two preliminary observations can be made when looking at the results. First, results differ when looking at export value and export diversity as a measure of economic structure. Second, the effects of different clusters within the manufacturing sector are widely heterogeneous. There are also notable differences between clusters of similar technological intensity, that is machinery, electronics and chemicals. For instance, the machinery cluster tends to drive countries that are specializing and diversifying in it towards a slow growth regime. A greater specialization into this cluster tends to affect countries that are experiencing rapid growth, while a greater diversification in it limit countries with slow growth from falling into recession. Note that the pool of countries in the slow growth regime is heterogenous, since it includes many of the advanced countries as well as developing countries. So, this result could be driven by the growth dynamics of advanced countries, which tend to sustain a slow growth during many years and are more specialized and diversified into the machinery cluster than developing ones. The machinery cluster is mainly composed of medium-tech goods and so structural change in this direction does not provide sufficient drivers to continue towards a sustainable rapid growth path. In addition, the machinery cluster is made of industries that fit less easily into global

\footnotetext{
${ }^{6}$ Note that there are no major changes in the value and significance of the different parameters when using different lags.
} 
value chains (GVC) than others, such as electronics, because of the prevalence of high-weight components. Therefore, the participation in this cluster of developing countries, exhibiting higher growth rates due to a catch-up process, is much more limited.

The results on the machinery cluster contrast with the ones on the chemicals and electronics clusters that tend to lead to an amelioration of growth or avoiding its deterioration. In the case of chemicals, an increased participation in this cluster improves growth levels of countries whether they are in a state of slow growth or recession. Having said that, there are differences when looking at increase in specialization or diversification in this cluster. An increased specialization in chemicals in countries experiencing recession tends to raise their propensity to transition to a state of slow growth. However, for this cluster to have a positive effect on growth at higher growth levels (i.e. transitioning from slow to rapid growth), countries need a increased diversification of their exports within this cluster. In latter instance, countries experiencing slow growth, in order to accelerate their growth process, might engage in a vertical integration strategy, which is a pattern that has been observed in the previous chapter. The diversification in the range of chemical products could also have rippling effects. For instance, the chemical industry can create forwards linkages inducing productivity increases in other sectors and industries through the development of agro-chemicals. Since it is made of medium to high-tech products, the chemical cluster also exhibits relatively high levels of technological change and productivity.

Likewise, the increased presence in the electronics cluster (whether through increase specialization or diversification) of countries experiencing recession increases their chances to see their economic situation improve. Yet, in comparison to the chemicals cluster, in most case, a greater participation in the electronics cluster tends to limit the risk of countries to reduce their growth prospects, rather than improving growth rates, whether they are experiencing slow or rapid growth. And, similarly to the chemicals cluster, some differences can be noted relative to the measure of economic structure. An increased specialization in this cluster diminishes the risk of countries with slow growth to undergo recession. This result is likely to be associated with the integration of developing countries into GVC. Furthermore, countries benefiting from rapid growth need to increase their diversification in this cluster in order to avoid transitioning to a slow growth regime. While specialization is sufficient to avoid recession, it is not to sustain rapid growth. Instead, countries that adopt a diversification strategy, which could be resulting from an effort to go 
up the value chain and thereby adding more products to their export baskets, seem to succeed in maintain rapid growth.

In contrast with most high and medium-tech clusters, a greater participation in low-tech ones tends to drive countries towards lower growth regimes. These results show that industrialization can have perverse effects for countries that do not manage to go up the technology ladder. For instance, textile cluster is systematically associated to a transition to a lower growth regime. A greater participation in this cluster, both in terms of export value and diversity, leads to a higher risk for countries in a slow growth regime to fall into recession. For countries benefitting of a rapid growth are likely to undergo a transition to a slow growth regime if they extent their range of export products within the textile cluster.

Finally, the influence of natural resources-based manufacturing clusters is concentrated on the transition from recession to slow growth, which mainly concerns developing countries. More precisely, there is a clear evidence of a recession trap associated to a greater specialization in the iron and steel cluster as well as the natural resources-based manufacturing one. 
Table 3.5: Estimated coefficient parameters of the export value variables

\begin{tabular}{|c|c|c|c|c|}
\hline$h j$ & Variable $(Z)$ & $\hat{\beta}_{h i}^{Z}$ & SD & p-value \\
\hline \multirow{8}{*}{$1 \rightarrow 2$} & Machinery & $0.165^{*}$ & 0.09 & 0.058 \\
\hline & Electronics & -0.106 & 0.09 & 0.225 \\
\hline & Textile & 0.064 & 0.06 & 0.279 \\
\hline & Iron and steel & 0.070 & 0.08 & 0.354 \\
\hline & Natural resources & 0.038 & 0.13 & 0.764 \\
\hline & Chemicals & 0.152 & 0.12 & 0.204 \\
\hline & Machinery nes & 0.064 & 0.18 & 0.729 \\
\hline & Wood & -0.058 & 0.11 & 0.603 \\
\hline \multirow{8}{*}{$2 \rightarrow 1$} & Machinery & 0.130 & 0.11 & 0.216 \\
\hline & Electronics & -0.077 & 0.12 & 0.532 \\
\hline & Textile & -0.072 & 0.06 & 0.213 \\
\hline & Iron and steel & -0.040 & 0.12 & 0.740 \\
\hline & Natural resources & -0.035 & 0.23 & 0.887 \\
\hline & Chemicals & 0.247 & 0.19 & 0.195 \\
\hline & Machinery nes & -0.124 & 0.23 & 0.584 \\
\hline & Wood & 0.003 & 0.13 & 1.000 \\
\hline \multirow{8}{*}{$2 \rightarrow 3$} & Machinery & $\begin{array}{l}-0.037 \\
\end{array}$ & 0.10 & 0.718 \\
\hline & Electronics & $-0.626^{* * *}$ & 0.15 & 0.000 \\
\hline & Textile & $0.370^{* * *}$ & 0.07 & 0.000 \\
\hline & Iron and steel & -0.092 & 0.09 & 0.305 \\
\hline & Natural resources & 0.039 & 0.17 & 0.823 \\
\hline & Chemicals & -0.148 & 0.16 & 0.343 \\
\hline & Machinery nes & 0.027 & 0.23 & 0.920 \\
\hline & Wood & -0.166 & 0.13 & 0.218 \\
\hline \multirow{8}{*}{$3 \rightarrow 2$} & Machinery & -0.090 & 0.08 & 0.251 \\
\hline & Electronics & $0.202 *$ & 0.11 & 0.058 \\
\hline & Textile & -0.053 & 0.06 & 0.338 \\
\hline & Iron and steel & $-0.122^{*}$ & 0.07 & 0.062 \\
\hline & Natural resources & $-0.237^{* *}$ & 0.12 & 0.047 \\
\hline & Chemicals & $0.299^{* *}$ & 0.14 & 0.036 \\
\hline & Machinery nes & $0.358^{* *}$ & 0.14 & 0.011 \\
\hline & Wood & 0.062 & 0.09 & 0.498 \\
\hline
\end{tabular}


Table 3.6: Estimated coefficient parameters of the export diversity variables

\begin{tabular}{|c|c|c|c|c|}
\hline$h j$ & Variable $(Z)$ & $\hat{\beta}_{h j}^{Z}$ & $\mathrm{SD}$ & p-value \\
\hline \multirow{8}{*}{$1 \rightarrow 2$} & Machinery & 0.084 & 0.17 & 0.631 \\
\hline & Electronics & $-0.284^{* * *}$ & 0.12 & 0.015 \\
\hline & Textile & $0.230 * * *$ & 0.09 & 0.012 \\
\hline & Iron and steel & 0.032 & 0.11 & 0.777 \\
\hline & Natural resources & 0.151 & 0.13 & 0.249 \\
\hline & Chemicals & 0.014 & 0.10 & 0.887 \\
\hline & Machinery nes & -0.055 & 0.11 & 0.617 \\
\hline & Wood & 0.040 & 0.08 & 0.617 \\
\hline \multirow{8}{*}{$2 \rightarrow 1$} & Machinery & 0.146 & 0.22 & 0.512 \\
\hline & Electronics & -0.064 & 0.14 & 0.639 \\
\hline & Textile & -0.025 & 0.08 & 0.752 \\
\hline & Iron and steel & -0.075 & 0.12 & 0.543 \\
\hline & Natural resources & -0.183 & 0.14 & 0.207 \\
\hline & Chemicals & $0.215^{*}$ & 0.11 & 0.051 \\
\hline & Machinery nes & -0.024 & 0.13 & 0.863 \\
\hline & Wood & 0.013 & 0.09 & 0.887 \\
\hline \multirow{8}{*}{$2 \rightarrow 3$} & Machinery & $-0.436^{* *}$ & 0.21 & 0.040 \\
\hline & Electronics & 0.055 & 0.18 & 0.764 \\
\hline & Textile & $0.288^{* * *}$ & 0.10 & 0.005 \\
\hline & Iron and steel & 0.065 & 0.12 & 0.572 \\
\hline & Natural resources & -0.213 & 0.15 & 0.143 \\
\hline & Chemicals & -0.166 & 0.13 & 0.196 \\
\hline & Machinery nes & 0.105 & 0.13 & 0.435 \\
\hline & Wood & -0.166 & 0.13 & 0.185 \\
\hline \multirow{8}{*}{$3 \rightarrow 2$} & Machinery & 0.084 & 0.18 & 0.647 \\
\hline & Electronics & $0.303^{*}$ & 0.16 & 0.053 \\
\hline & Textile & -0.072 & 0.09 & 0.410 \\
\hline & Iron and steel & -0.142 & 0.09 & 0.129 \\
\hline & Natural resources & 0.004 & 0.10 & 1.000 \\
\hline & Chemicals & -0.020 & 0.11 & 0.863 \\
\hline & Machinery nes & 0.028 & 0.12 & 0.823 \\
\hline & Wood & -0.008 & 0.09 & 0.920 \\
\hline
\end{tabular}




\subsection{Conclusion}

In this chapter, I focus on characterizing the behavior of transitions between different growth regimes and on the role played on these by the economic structure within the manufacturing sector. I use a semi-Markov framework to estimate the parameter of each possible transition between three previously defined growth states: rapid growth, slow growth and recession, as well as the effect of the economic structure on them. I adopt two definitions of economic structure to proxy for a specialization at the intensive and extensive margin.

The results obtained offer important insights in the dynamics of growth and the role the economic structure plays in it. First, results on the estimation of the parameters of the distribution of waiting times indicate that while the transition between slow to rapid growth does not depend on the duration spent in the departure state (here, slow growth), it does for all the remaining transitions. Furthermore, the transitions between slow growth and recession are less and less stable over time. To put it another way, the more time countries stay in any of these growth regimes, the more likely they are to transition to the other regime. Conversely, countries that succeed in maintaining their rapid growth will be more likely to continue to do so in the future.

Second, results on the effect of the economic structure on growth transitions have two important implications. Firstly, they indicate that a distinction between the intensive and extensive margin is important. Secondly, there are important differences in the effects of clusters within the manufacturing sector, and even between clusters of similar technological intensity. For instance, we can note that there are notable differences among high-tech sectors and in particular between the machinery and electronics ones in the effect they have on growth dynamics. While a high specialization in the machinery can be a bottleneck for countries to remain in a state of rapid growth, a greater diversification in the electronics one is key for countries to remain in this state. The effect of the economic structure on the transition between rapid to slow growth is likely to be associated with differences between industries in the setting up of GVC. Indeed, this strategy has been an important growth driver during the last decades of the 20th century. Differences in adopting it arises because the light weight-to-value ratio of electronics products facilitated the global vertical organization of production relative to machinery products that are characterized by heavy and hard to transport components. However, the integration into GVC is not the only explanation. According to the results, 
in countries experiencing slow growth, a greater diversity in the chemicals cluster leads to better chances to transition to a rapid growth regime. As the chemical industry is less adapted to form global value chains due to a lesser divisibility of the production process, this result is likely to be explain by a vertical integration strategy within countries. This is in line with the results found in the previous chapter. These clusters also affect the transitions between slow growth and recession. On the one hand, the electronics and chemicals cluster affect positively the transition from recession to slow growth. On the other hand, a greater diversity in the machinery cluster enables countries in a state of slow growth to not collapse into a recession state.

While it is often believed that the textile industry is an important step in the industrialization process, it is shown here that it can also have perverse effects. Namely, a greater participation in this cluster can precipitate countries to a more disadvantageous growth regime, whether they are experiencing rapid or slow growth. Further, the results show evidence of a recession trap resulting from an increased specialization in export products of several clusters composed mainly of natural-resources manufacturing. Overall, the argument that there is no unique path to growth Rodrik, 2008) seems to also apply to the economic structure.

Finally, there are several potential enhancements of this study. One would be to introduce all the economic variables into one model and selecting them using Least Absolute Shrinkage and Selection Operator (LASSO) analysis in the second stage of the estimations, i.e. the Cox proportional hazard model. Another possible extension of this analysis is to estimate a non-homogeneous semi-Markov model, in which transition probabilities are also allowed to vary with time and to depend on economic structure variables. 


\section{Chapter 4}

\section{The extent of demand ripple effects on economic growth}

\section{Are backward linkages overestimated?}

\subsection{Introduction}

Intermediate consumption accounts for more than half of the value of total production in most countries 11 Furthermore, the last decades were marked by an increased division of tasks and globalization of their distribution in most economies of the world. This greater interconnection between industries within and across countries renders the study of input-output linkages all the more pertinent. In particular, it enables us to better understand how shocks at the industry level (both from domestic and foreign sources) are transmitted throughout the economy. This issue is partly addressed by studies on the output multiplier, which quantifies the transmission of final demand shocks throughout the economy. However, traditional measures have strong assumptions. In particular, they assume both that as long as there is an input-output link, the shock is transmitted, and that a direct shock is as important as an indirect one.

The measure of backward linkages is an important tool to identify industries that generate greater externalities for the growth of an economy through demand and production dynamics. And, over-estimating them is likely to lead to inappropriate industrial policies. Moreover, the literature often overlooks the identification of industries acting as obstacles in the transmission process of demand shocks. In this chapter, I relax the two assumptions associated with the calculation of the output multiplier and test whether backward linkages are overestimated by traditional measures. I use a modified version of the Leontief inverse to predict output variation for different degrees of response to demand shocks from supplier industries. In this model, I account for the variation in demand and technology. I then

\footnotetext{
${ }^{1}$ Between 1995 and 2011, intermediate consumption (including taxes) represent between 30\% and $70 \%$ of the output value according to input-output tables from the OECD.
} 
estimate the strength of the response of each supplier industry to final demand shocks in its user industries by comparing predicted and actual variation in output values by industry and country between 1995 and 2011.

Results show that there are important differences in response to final demand shocks between industries and countries. Manufacturing industries tend to have a lower response to demand shocks relative to services. Within the manufacturing sector, final good industries benefit less from potential backward linkages than others, in particular the electronics, other machinery, automotive industries. Furthermore, the response to final demand shocks tends to be more elastic in industries at the bottom of the value chain such as low-tech and especially raw material industries. Important differences are also found between countries. Manufacturing supplier industries in developed countries tend to be less responsive to demand shocks relative to those in developing countries. Developed countries produce more complex products involving a larger set of intermediaries, which implies a smaller margin of adjustment. Results from a linear regression corroborates these arguments. In addition, it shows that the type of fixed costs an industry is facing also matters.

The remainder of this chapter is organized as follows. In the first section, I describe the main developments in the literature on inter-industries linkages and their measurements. In the second section, I present a new methodology to measure the extent of the transmission of demand shocks by industry and country. I present the results in the third section. Finally, I conclude in the last section.

\subsection{Literature review}

Countries have complex internal structures and economic development is the result of the interaction between its parts (that is its different economic activities). More precisely, economic development is driven by a "multiplicity of causal relationships" in which the outputs of one economic activity become the input of others, and so on (Leontief, 1991). The economy can thus be viewed as a system in which economic activities are interdependent. The Leontief model is one of the first efforts to empirically model interdependences between industries as a central element of economic development, using input-output data. In this model, a product is characterized by the inputs it requires and the proportion of each input entering its production. The Leontief model is a demand-driven model in which sectoral 
output is directly linked to final demand.

Interdependencies arise due to the existence of complementarities between industries at the level of investment and production activities. Investment complementarities can be direct or indirect. In the direct case, additional investments in one industry leads to a higher outcome that can be re-invested in the economy. This is known as induced investment. In addition, Hirschman (1958) emphasizes the importance of the indirect effect of investment. In this case, the investment in one industry creates a need for investment in other industries. For instance, the investment in a cycle hire scheme calls for investments in bike maintenance and repair, in transport services but also in infrastructure (cycling paths), and so on. In other words, the investment in one industry creates a chain of investments in the whole economy.

When it comes to the production process, several technical or production complementarities play out through different channels. There exist production complementarities in the form of input-output relations, joint-products and by-products. Under specific conditions, such complementarities can give rise to economies of scale, that is the decrease in unit costs as output increases. As a result, the increase in output of a given industry $A$ can lead to a decrease in marginal costs in another industry $B$. This can take place in several specific situations: $(i)$ if the two industries are related through input-output exchanges and the input is produced under decreasing costs, or, $(i i)$ in presence of joint-products or by-products that are produced under decreasing costs. Technical complementarity can also take place through demand. In this case, the rise in demand for one product leads to an increased need for the use of another one. This does not refer to the case of derived demand in which two goods are complementary in the production of a third one. Instead, Hirschman (1958) points out that demand complementarity can also arise when two products are not in the same production process. For instance, the construction of a new train station indirectly stimulates the need for other activities such as restaurants, hotels, shops, and so on.

Due to complementarities between industries, a change in the production of one industry is transmitted to others through a multiplier effect. The chain of transmission can run from user to supplier industries (backward linkages) or from supplier to user industries (forward linkages). In the presence of backward linkages, a variation in final demand in one industry will induce a variation in the production of its supplier industries. For instance, if the demand for computers increases, the 
industry providing these goods will require from its suppliers more plastic parts and electronics components, among other things. The plastics industry will in turn require additional inputs to fulfill the requests of the electronics industry, and so on. In sum, the initial increase in the demand for computers will be transmitted to other industries through the input-output network. A similar inducement mechanism can take place from supplier to user industries through forward linkages. In this case, a shock in supply rather than demand is transmitted across the economic system. Dietzenbacher (1997) recommends interpreting the variation in supply in terms of variation in value of inputs rather than in quantities.

The presence of inter-linkages between industries is at the center of unbalanced growth theories. According to this theory, the growth of some industries should be favored over others at particular moments in time. The question is which industries, when and why? As we have seen in the previous chapter, industries differ in terms of their productivity level and the technological opportunities they can harness. In addition to this, the stimulus each industry engenders in the economic system is also heterogenous. As a consequence, countries benefit from focusing on industries that tend to have an important stimulus on the economy. Furthermore, the strength of this stimulus is tightly connected to the structure of the input-output linkages between industries. In particular, the presence of asymmetric linkages between industries is often overlooked as in Lucas (1977). When one assumes that industries are connected with each other in a symmetric way, then a shock in one industry does not affect the overall outcome because it averages out rapidly. However, as showed in Acemoglu et al. (2012), the diffusion of shocks from a micro to a macro level strongly depends on the structure of the interactions between industries. In particular, micro shocks tend to have an effect on the overall outcome when industries are asymmetrically connected. Finally, the order in which industries develop is important as it implies different types of cumulative effects. In such a context, present investments influence the profitability of subsequent projects. A similar idea is present in the theory of the roundaboutness of production of Eugen von Böhm-Bawerk. According to this theory, sometimes it is necessary to make a detour in the production of a product to be able later to produce it or improve the efficiency of the production process. The production detour involves investments in related activities. This leads to an additional stages in the production process but will ultimately facilitate the production. Because the structure of industrial linkages differs between countries and regions, the efficient sequence of investment should also vary between them. In sum, differences in 
the strength of backward and forward linkages across industries are likely to have important consequences on industrial and growth dynamics. How do we measure the strength of these economic spinoffs?

Several authors have focused on the empirical measurement of these linkages. Chenery and Watanabe (1958) compare the degree of interdependence between industries in terms of backward and forward linkages through purchases from other sectors and sales to other sectors, respectively. However, these measures only account for direct linkages. Rasmussen (1956) uses the inverse of the input-output matrix to derive the extent of direct and indirect backward linkages between industries ("power of dispersion") ${ }^{2}$ This measure accounts for three types of effects: ( $i)$ the initial effect, (ii) the direct effect, and, (iii) the indirect effect. Assume the final demand of the products of industry A increases. The increase in output in industry A to fulfill this change in demand is the initial effect. The increase in output of its direct suppliers is the direct effect. And the increase in output of the suppliers its suppliers corresponds to the indirect effect.

Once it is established that industry linkages are central to determining the path of industrial development, it is important to understand the mechanisms that influence the size of the linkage effects. Hirschman (1958) suggests that the potential importance of linkage effects induced by a given user industry industry $j$ depends on two key variables: $(i)$ the increase of potential net output created by the growth of existing industries or the emergence of new industries linked to industry $j$ and (ii) the probability that these industries emerge or grow, which depends on the strength of the stimulus. Hirschman (1958) argues that the strength of the stimulus depends on the minimum economic size of firms that could potentially provide these inputs. The minimum economic size is defined as the size enabling firms to have positive profit and to compete with foreign firms in the environment in which they operate. However, this variable plays an important role when the industry producing the needed inputs.

Hirschman (1958) distinguishes between two types of industries emerging or developing due to the presence of linkages. Satellite industries are those that are closely located to a master industry, that are strongly linked to this industry

\footnotetext{
${ }^{2}$ Formally, backward linkages are: $(I-A)^{-1}=I+A+A^{2}+A^{3}+\ldots$ where $A$ is the matrix of technical coefficients, I is the identity matrix and 1 is a row vector of ones which dimension corresponds to the dimensions $A$.
} 
through input-output relations and for which the minimum economic size is smaller than the master industry. They are likely to create a stimulus on other industries due to backward (forward) linkages but the importance of this stimulus is small, that is the net output is likely to be limited. Conversely, non-satellite industries are characterized by weaker input-output linkages with the potentially new industry, and the minimum economic size of the latter is likely to be larger. Because of this, non-satellite industries are less likely to produce a stimulus but if they do, the net output is large. When considered in isolation, non-satellite industries are associated to an extremely small probability of stimulating other industries and therefore their establishment is often disregarded. However, the joint linkage effect of several nonsatellite industries is likely to exceed the sum of individual linkages. The reason for this is that the joint probability will be larger than a given critical value and so the establishment of such industries is considered. This is a fundamental point in Hirschman's theory. It highlights the cumulative nature of development and the importance of considering the economic structure as a network of industries and not as a set of individual industries. In such a context, moving away from the equilibrium is an ideal pattern of development as a disequilibrium in one industry brings about disequilibrium in others, which in turn is transmitted throughout the economy. Such complementarities exist between industries because their activities require the production of goods in other industries.

Industries also differ in the type of relationship patterns they display (Chenery and Watanabe, 1958). On the one hand, some sets of industries display a oneway interdependence from primary industries to final manufacturing industries (for instance, raw cotton to textile fabrics to clothing). Taking the example of textile goods, raw cotton would be exclusively used as an input, textile fabrics to a lesser extent and clothing would be entirely dedicated to final consumption. The inputoutput matrix of countries specialized in these types of industry takes a triangular form and a hierarchy between industries can be found in terms of the proportion of their production used as an input. On the other hand, other industries are linked in a circular way. This pattern better characterizes intermediate manufacturing industries, such as chemicals, paper and fuels.

Despite these reflections on the differences in the linkages between industries, no measure presented in the literature captures the degree of response to backward or forward linkages received from other industries. In what follows, I present a methodology to estimate the response of supplier industries to demand shocks from users industries that they are directly or indirectly connected to. 


\subsection{Methodology}

\subsubsection{Measuring the transmission of demand shocks by in- dustry}

The Leontief matrix, $A$, characterizes the structure of the links between industries through which shocks in final demand are transmitted throughout the economy. In the static Leontief model, the output of industry $i, x_{i}$, depends on the demand for intermediate inputs, $z_{i j}$ from industries $j$, and for final goods, $f_{i}$.

$$
x_{i}=\sum_{j} z_{i j}+f_{i}=\sum_{j} a_{i j} x_{j}+f_{i}
$$

where $a_{i j}$ corresponds to the technical coefficients and $x_{j}$ the output of other industries supplied by industry $i$.

In matrix terms, we have:

$$
X=A X+F
$$

Leontief shows that a variation in the output of one industry, induced by a change in its final demand, affects all industries related to it through input-output exchanges both directly and indirectly. This transmission effect can be formalized through the Leontief inverse as follows:

$$
X=L F \text { with } L=(I-A)^{-1}=\left[l_{i j}\right] \text { and } l_{i j}=\frac{\delta x_{i}}{\delta f_{j}}
$$

As a result, the variation of output of industry $i$ depends on a variation of its final demand as well as on a variation of its direct or indirect user industries.

$$
x_{i}=\sum_{j} l_{i j} f_{j}
$$

This effect is often referred to as the output multiplier. However, using the traditional output multiplier presented above implies making three strong assumptions:

(i) A1: When an input-output link is present between supplier industry $i$ and user industry $j$, the shock from user industry $j$ is fully transmitted to its supplier industry $i$. As long as there is a link, there is a transmission of the shock. 
(ii) A2: The strength of the final demand shock from a user industry $j$ to its supplier industry $i$ depends exclusively on the importance of industry $i$ for industry $j$. Whether or not industry $j$ is an important user of industry $i$ 's products does not matter.

(iii) A3: Paths of any length have the same weight. In other words, a direct shock is considered to be as important as an indirect one.

A parallel can be made between the measure of backward linkages derived from the Leontief inverse (and its associated multiplier) and several centrality measures from social network analysis. From network analysis, $A$ can be analyzed as a directed weighted network, in which nodes correspond to industries and link weights to the associated technical coefficients. First, direct backward linkages of an industry correspond to its in-degree. Second, the total backward linkages (direct and indirect linkages) are closely linked to the generalized Katz centrality (Newman, 2018) defined as follows:

$$
x_{i}=\alpha \sum_{j} A_{i j} x_{j}+\beta_{i}
$$

In matrix terms, we have:

$$
X=\alpha A X+\boldsymbol{\beta}
$$

$A_{i j}$ is the adjacency matrix of technical coefficients representing linkages between domestic industries. $x_{j}$ is the output of the neighboring industries, $\alpha$, a constant parameter, and $\beta_{i}$, the final demand for the goods of industry $i$. The first right-hand side term measures the network contribution in the centrality measure and the second one captures the non-network contribution to this measure (in this case final demand of each industry). In the Katz centrality measure $\alpha$ is a scale parameter. However, for the purpose of this study, I use a more general measure in $\alpha$ is a vector parameter. The reason is that the response to demand shock is likely to vary across industry, as argued below. The measure of the output multiplier then becomes:

$$
X=(I-\boldsymbol{\alpha} I A)^{-1} \boldsymbol{\beta}=\tilde{L} \boldsymbol{\beta}
$$

where $I$ is the identity matrix with the same dimensions as $A$.

The revised Leontief inverse, $\tilde{L}$, includes a vector parameter, $\boldsymbol{\alpha} . \alpha_{i}$ represents the strength of the response of supplier industry $i$ to final demand shocks in its 
corresponding user industries. In what follows, the values of $\boldsymbol{\alpha}$ are bounded to the interval $[0,1[3]$ Traditionally, in input-output analysis, it is assumed that $\alpha$ is the same for all supplier industries and is equal to one. This implies that the final demand shocks are transmitted throughout the economy as long as there is a link (i.e. an input-output exchange) and that the direct and indirect effects have the same weight in the calculations (Rasmussen, 1956). The introduction of this attenuation factor, $\alpha_{i}$, in equation 4.6 enables to relax these two assumptions.

First, when $\alpha$ is less than 1 , the direct effect has a higher contribution to the multiplier than indirect effects $4^{4}$ In practice, one can expect that the length of the path through which a shock is passed on increases the likelihood to encounter obstacles along the way. At each obstacle, the strength of the response of the supplier industry decreases and so the transmitted shock to its user industries attenuates. For this reason, indirect effects should not have the same weight as direct effects when calculating the multiplier and the backward linkages. The lower the value of $\alpha$ is, the lower the weight of indirect effects in the total effect is.

Second, $\alpha_{i}$ measures the response of a supplier industry $i$ to demand shocks from its user industries. Because industries have different production characteristics (production capacity, position in the value chain, returns to scale), their capacity to respond to final demand shocks is likely to differ. There are several reasons explaining the fact that an industry partially captures the effects of a demand shock.

One can expect a low response to demand shocks in industries operating at full production capacity. As highlighted in Chamberlin's theory, only in the presence of monopolistic competition, firms are in excess capacity. In addition, in industries making tangible products where price competition prevails, to keep their prices low firms are less likely to keep large inventories. In particular, inventories can have a significant additional cost for heavy machinery goods and for goods that rapidly become obsolete, such as electronics. Keeping inventories is also not possible in industries producing mainly perishable products such as agriculture.

\footnotetext{
${ }^{3}$ For $\sum_{k=1}^{\infty}(\boldsymbol{\alpha} I A)^{k}$ converges to $(I-\boldsymbol{\alpha} I A)^{-1}$ as long as $\lambda_{1}<1$, where $\lambda_{1}$ is the largest eigenvalue of $(\boldsymbol{\alpha} I A)$.

${ }^{4}$ To see this, let's assume for a moment that the response to demand shock is the same for all supplier industries, i.e. $\alpha_{i}=\alpha$. In this case, we have an $\alpha$ parameter such that: $\tilde{L}=(I-\alpha A)^{-1}=$ $I+\alpha A+\alpha^{2} A^{2}+\ldots+\alpha^{k} A^{k}+\ldots$, where $k$ corresponds to the length of the path. According to this equation, when $\alpha$ is set to $1, \alpha^{k}$ is also 1 for any $k$. However, when $\alpha$ is less than 1 , paths of longer length have a lower weight (see Figure C.4.
} 
Furthermore, in industries where a large share of the cost is fixed, a significant increase in demand implies large additional costs and slow adjustments (a new plant, new machines, new infrastructure). This is the case of capital intensive industries that require significant investments in machinery and infrastructures such as automotive manufacturing, oil production and refining, steel production as well as telecommunications and transportation services. Some high-tech industries also involve large fixed costs in R\&D. Even if these costs are not directly necessary to increase output of existing products, there is a trade-off in the allocation of resources between production and R\&D. Firms in some industries need to invest a large share of their resources in $\mathrm{R} \& \mathrm{D}$ to remain competitive and these resources cannot be immediately made available for production. Spacecraft, scientific R\&D, software publishing, pharmaceuticals and electronics are some of the most most R\&D intensive sectors (Galindo-Rueda and Verger, Galindo-Rueda and Verger). Furthermore, in industries requiring a large input of skilled labor, the adjustment is likely to also be slower.

Moreover, location in the value chain of the industry and the country makes it more or less susceptible to shocks. Industries delivering mostly final goods are less sensitive to final demand shocks from other industries. In particular, according to the Bullwhip effect, forecasting errors amplify as one moves further up the supply chain leading to excess supply and larger inventories (Forrester, 1961). The manufacturing sector tends to cater a smaller share of its production to intermediate consumption relative to other sectors (Figure C.2). There are several exceptions in the services sector: trade, hotels and restaurants, and real estate.

Finally, specialization patterns are likely to affect the response to demand shocks. An industry is more likely to respond to demand shocks in a country where its production accounts for a large share of output.

\subsubsection{Estimation method}

The methodology to estimate the transmission of demand shocks between industries relies on the estimation of the output variation of each industry. There are several ways to do that. Dietzenbacher and Los (1998) analyze different decompositions of output variation and find that the one described as follows is acceptable. In this case, the variation in output in industry $i$ at year $t$ is explained by variations in final demand and technology (I drop the country subscript to simplify), such that: 


$$
\begin{aligned}
\Delta \hat{x}_{i ; t}(\boldsymbol{\alpha}) & =\frac{1}{2}\left[\sum_{j}\left(l_{i, j ; t-1}(\boldsymbol{\alpha})+l_{i, j ; t}(\boldsymbol{\alpha})\right) \Delta f_{j ; t}\right] \\
& +\frac{1}{2}\left[\sum_{j} \Delta l_{i, j ; t}(\boldsymbol{\alpha})\left(f_{j ; t-1}+f_{j ; t}\right)\right]
\end{aligned}
$$

with $\Delta y_{i, j ; t}\left(\alpha_{i}\right)=y_{i, j ; t}-y_{i, j ; t-1}$ for any variable $y$, and,

$$
\begin{aligned}
l_{i, j ; t}(\boldsymbol{\alpha}) & =\left[(I-\boldsymbol{\alpha} \otimes A)^{-1} \boldsymbol{\beta}\right]_{i, j ; t} \\
& =1+\alpha_{i} a_{i, j ; t}+\alpha_{i} \sum_{k} \alpha_{k} a_{i, k ; t} a_{k, j ; t}+\alpha_{i} \sum_{k, l} \alpha_{k} \alpha_{l} a_{i, k ; t} a_{k, l ; t} a_{l, j ; t}+\ldots
\end{aligned}
$$

In equation 4.8, output variation in supplier industry $i$ between time $t-1$ and $t$ is the result of the average of $(i)$ the sum of the variations in output due to variations in final demand of its user industries $j$ and $(i i)$ the sum of the variations in output due to variations in the production technology of its user industries $j$. The production technology is measured using the revised Leontief matrix. Finally, the Leontief matrix used to calculate the variation in output induced by these changes is the average of the Leontief matrices in time $t-1$ and $t$.

In this setting, the transmission of demand shocks from one industry to another depends on the response to these shocks of all the industries through the parameter vector $\boldsymbol{\alpha}$. Because of this, the output variations must be jointly determined and no industry can be treated in isolation. The output variation of all supplier industries $\left(\Delta x_{i ; t}\right)$ are defined as a nonlinear system of equations:

$$
\left\{\begin{aligned}
\Delta \hat{x}_{1 ; t}(\boldsymbol{\alpha}) & =\frac{1}{2}\left[\sum_{j}\left(l_{1, j ; t-1}(\boldsymbol{\alpha})+l_{1, j ; t}(\boldsymbol{\alpha})\right) \Delta f_{j ; t}\right]+\frac{1}{2}\left[\sum_{j} \Delta l_{1, j ; t}(\boldsymbol{\alpha})\left(f_{j ; t-1}+f_{j ; t}\right)\right. \\
\Delta \hat{x}_{2 ; t}(\boldsymbol{\alpha}) & =\frac{1}{2}\left[\sum_{j}\left(l_{2, j ; t-1}(\boldsymbol{\alpha})+l_{2, j ; t}(\boldsymbol{\alpha})\right) \Delta f_{j ; t}\right]+\frac{1}{2}\left[\sum_{j} \Delta l_{2, j ; t}(\boldsymbol{\alpha})\left(f_{j ; t-1}+f_{j ; t}\right)\right] \\
& \vdots \\
\Delta \hat{x_{N ; t}}(\boldsymbol{\alpha}) & =\frac{1}{2}\left[\sum_{j}\left(l_{N, j ; t-1}(\boldsymbol{\alpha})+l_{N, j ; t}(\boldsymbol{\alpha})\right) \Delta f_{j ; t}\right]+\frac{1}{2}\left[\sum_{j} \Delta l_{N, j ; t}(\boldsymbol{\alpha})\left(f_{j ; t-1}+f_{j ; t}\right)\right]
\end{aligned}\right.
$$

For each country, I estimate simultaneously the value of the total response to shocks in final demand of all industries, $\boldsymbol{\alpha}$, by minimizing the objective function over supplier industries $i$ and time $t$ as follows:

$$
\min _{\boldsymbol{\alpha}}\left\{\sum_{i, t}\left(\Delta x_{i ; t}-\Delta \hat{x}_{i ; t}(\boldsymbol{\alpha})\right)^{2}\right\}
$$


where $\Delta x_{i ; t}$ is the actual value of output variation at time $t$ and $\Delta \hat{x}_{i ; t}\left(\alpha_{i}\right)$ the corresponding predicted value. The calculation of the predicted value is based on the vector parameter $\boldsymbol{\alpha}$ estimated by solving the system of equations $4.10^{5}$ As a result of this exercise, I obtain an $\alpha$ for each industry and each country.

Classical input-output theory assumes this $\boldsymbol{\alpha}$ is a unit vector, but as results show, this is far from reality (see section 4.4.1 for details on the results). An interesting question is why different industries have different values of $\alpha$. I turn to this now.

\subsubsection{The determinants of the response to demand shocks}

I estimate a pooled linear model to analyze the potential determinants of the response of industry $i$ in country $c$ to demand shocks. The model is described as follows:

$$
\begin{aligned}
\hat{\alpha}_{i, c} & =\beta_{0}+\beta_{1} \text { spec }_{i, c}+\beta_{2} I C_{i, c}+\beta_{3} \text { kint }_{i, c}+\beta_{4} \text { RDint }_{i, c} \\
& +\beta_{6} d_{i, c}^{\text {out }}+\beta_{8} \tilde{d i s p}_{i, c}^{\text {out }}+\epsilon_{i, c}
\end{aligned}
$$

The set of explanatory variables represent different characteristics of industry $i$ in country $c . \hat{\alpha}_{i, c}$ is the estimated response to demand shocks, $I C_{i, c}$ the share of its output used as intermediate consumption, spec $_{i, c}$ the share of its production in total output, $k i n t_{i, c}$ the capital intensity, $R \operatorname{Dint}_{i, c}$, the R\&D intensity, $d_{i, c}^{\text {out }}$, the number industries it supplies, disp out the disparity of its supply of intermediate consumption across user industries and $\epsilon_{i, c}$ the error term $[6$ All variables are averaged over the period 1995-2011, except for $k i n t_{i, c}$ which is averaged over the period 1995-2009.

The capital intensity variable corresponds to the share of Gross Fixed Capital Formation relative to total production 7 Because of lack of data at the industry level (and in particular for the ISIC Revision 3), R\&D intensity is measured as follows:

$$
\begin{gathered}
\operatorname{RDint}_{i, c}=\text { RDint }_{c} \text { if industry } i \in R, \\
=0 \text { otherwise. }
\end{gathered}
$$

\footnotetext{
${ }^{5}$ To solve this non-linear optimization problem, I use an extension of the BFGS method (Broyden, 1970, Fletcher 1970, Goldfarb, 1970 Shanno, 1970), which allows for an upper and lower constraint on each of the parameters to estimate (Byrd et al. 1995).

${ }^{6}$ The measures of disparity are detailed in section C.1

${ }^{7}$ I use investment instead of capital stock because the latter contains a large amount of missing data at the industry level (ISIC Revision 3). Investment averaged over almost 20 years gives an indication of the stock of capital that is required for production in an industry.
} 
Where $R$ Dint $_{c}$ corresponds to the R\&D expenses as a share of GDP in country $c$. The set of $\mathrm{R} \& \mathrm{D}$ intensive industries, $R$, includes other transports, $\mathrm{R} \& \mathrm{D}$, computer activities, chemicals and electronics.

\subsubsection{Data}

I use the OECD Input-Output Tables for the calculations (OECD, 2017). This dataset provides information on input-output flows between 33 industries and on total output and final demand by industry, country and year, in current USD 8 It covers 63 countries and the rest of the world for the period 1995 to 2011 9 Data on R\&D intensity and on gross fixed capital formation (GFCF) are from the OECD (OECD, 2019 and OECD, 2011, respectively) 11

\subsection{Results}

\subsubsection{Measuring the transmission of demand shocks by in- dustry}

Results show that most industries are strongly dependent on changes in final demand in other industries as in $75 \%$ of cases (countries and industries) the $\alpha$ parameter is larger than 0.7. However, there are important differences between industries and countries (Figure 4.1).

Manufacturing industries tend to have a lower response to demand shocks relative to services. This is likely due to the fact that services tend to be more flexible in terms of their capacity of production, which makes them more able to respond to demand shocks.

Within the manufacturing sector, medium to high-tech industries, such as electronics, other machinery and automotive industries, tend to have a lower response to demand shocks. The value of $\alpha$ in these industries is 0 in more than $45 \%$ of the countries. This can be explained by the fact that these industries are mostly selling final goods (Figure C.2). It matters because if the market opportunities of

\footnotetext{
$\varepsilon^{\text {Dietzenbacher and Temurshoev }(2012)}$ show that predicted effects using the output multiplier for Denmark were similar when using current or constant prices.

${ }^{9}$ The list of countries and industries are detailed in the appendix (section C.2

${ }^{10} \mathrm{I}$ exclude Brunei and Malta as the intermediate consumption in some of their industries is zero so that the sample analyzed is reduced to 61 countries.

${ }^{11}$ GFCF data at the industry level (ISIC Revision 3) are only available up to 2009.
} 
an industry rely mostly on final demand, it will have a lower pressure to respond to changes in demand from the productive sector. Other transports, electrical machinery and chemicals are an exception as they display, in most countries, a relatively high $\alpha$ (median of $0.84,0.84$ and 0.73 , respectively). Low-tech industries such as textile, other manufacturing and food tend to be more responsive to demand shocks since the median $\alpha$ is relatively higher (around 0.7). Furthermore, industries at the lower end of the value chain tend to have a more elastic response to final demand shocks. For instance, paper, petroleum, plastics, fabricated and basic metals industries display a larger $\alpha$ (higher than 0.7 in more than $75 \%$ of cases). This response is even more elastic when looking at industries selling raw materials such as mining and agriculture.

Supplier industries in the service sector seem to display the most elastic response to final demand shocks. The only exception is found in the trade as well as hotel and restaurant industries. This can be caused by the fact that these two industries require important fixed costs in terms of infrastructure. Conversely, the construction industry has the strongest response to demand shocks with an average $\alpha$ above 0.9 . Because the construction industry relies heavily on physical capital (machines), for which the quantity is not easily adjusted in the short-run, it is likely to be in excess capacity. This makes it more apt to respond to increases in demand. In addition, this industry often benefits from a flexible labor market, requiring mainly low-skilled labor.

There exist important heterogeneities between countries as well. Specialization patterns seems to have an incidence on industries' responsiveness to demand shocks. For instance, Asian countries tend to have a high $\alpha$ in the electronics industry relative to other countries. Manufacturing supplier industries in developed countries tend to be less responsive to demand shocks relative to developing ones, especially from Asia. The highest interquartile ranges are found in other manufacturing, textile, electronics and automotive industries (Figure 4.2). One possible explanation to this is that developing economies are relying on less intermediaries than developed ones, thereby easing adjustments. In addition, most of these industries are involved in global value chains. The position of a country in the value chain defines the level of complexity of tasks, which can potentially influence the flexibility in production adjustment. 


\subsubsection{The determinants of the response to demand shocks}

Results from the pooled linear regression provides some insights into the potential determinants of the responsiveness to demand shocks over the sample of industries and countries (Table 4.1). They show that industries in which a country is specialized and that are selling mainly intermediate goods tend to display a higher response to demand shocks. However, this response tends to be more limited in industries that supply most of their production of inputs to one or a few industries ${ }^{12}$ Imagine a situation in which the share of inputs a firm from a given industry provides to each of its user industries is concentrated on a only a few. In this case, the priority will be to satisfy the few. By contrast, since the other users have a marginal contribution to the total input, the response to their demand for more inputs is likely not to be the priority. However, for firms in which the supply of inputs is spread homogeneously across industries, not loosing these relationship is important. R\&D intensive industries also tend to not receive the full potential backward linkages from other industries. This could be due to the high fixed costs of such activities. It could also be linked to the fact that industries with higher technological intensity require a larger share of skilled labor, which is harder to find than unskilled labor. Finally, capital intensity seem to have a positive incidence on the responsiveness of supplier industries to demand shocks. According to this result, industries with high fixed costs are more responsive to demand shocks. However, this result has to be taken with caution because this variable has many missing data and so its inclusion leads to a significant decrease in the sample of observations.

\footnotetext{
${ }^{12}$ Note that the out-degree, representing the number of industries to which a given industry supplies inputs, is never significant. This is likely to be due to the fact that there is little differences between industries as the network is extremely dense, i.e. most industries are connected with the rest of the network.
} 
Figure 4.1: Optimal value of $\alpha$ by industry and country





Notes: The darker the color the lower the value of $\alpha$ is. The dendrogram represent hierarchical clusters of countries and industries according to the values of $\alpha$. The hierarchical clustering analysis is done as follows: "Initially, each object is assigned to its own cluster and then the algorithm proceeds iteratively, at each stage joining the two most similar clusters, continuing until there is just a single cluster. At each stage distances between clusters are recomputed by the Lance-Williams dissimilarity update formula according to the particular clustering method being used." (for more details see R function "hclust"). 
Figure 4.2: Distribution of $\alpha$ over countries, by industry



Notes: Within each industry, each observation corresponds to a country. The set of observations is described by the boxplot. 


\begin{tabular}{|c|c|c|c|}
\hline & $\begin{array}{r}\text { Share of countries } \\
\text { for which } \alpha=0\end{array}$ & Median & $\begin{array}{r}\text { Interquartile } \\
\text { range }\end{array}$ \\
\hline Agr. & 1.61 & 0.95 & 0.09 \\
\hline Mining & 4.84 & 0.94 & 0.21 \\
\hline Food & 12.90 & 0.74 & 0.49 \\
\hline Textile & 29.03 & 0.66 & 0.91 \\
\hline Wood & 3.23 & 0.94 & 0.22 \\
\hline Paper & 3.23 & 0.94 & 0.15 \\
\hline Petroleum & 16.13 & 0.83 & 0.54 \\
\hline Chemicals & 17.74 & 0.73 & 0.60 \\
\hline Plastics & 6.45 & 0.86 & 0.26 \\
\hline Non-metallic minerals & 1.61 & 0.96 & 0.09 \\
\hline Basic metals & 14.52 & 0.88 & 0.24 \\
\hline Fabricated metals & 0.00 & 0.84 & 0.26 \\
\hline Machinery, nec & 45.16 & 0.12 & 0.63 \\
\hline Electronics & 54.84 & 0.00 & 0.85 \\
\hline Electrical machinery & 11.29 & 0.84 & 0.50 \\
\hline Automotives & 53.23 & 0.00 & 0.76 \\
\hline Other transp. & 24.19 & 0.84 & 0.62 \\
\hline Manuf. nec & 33.87 & 0.73 & 1.00 \\
\hline EGW & 0.00 & 0.97 & 0.06 \\
\hline Construction & 0.00 & 0.98 & 0.05 \\
\hline Trade & 0.00 & 0.75 & 0.19 \\
\hline Hotels & 3.23 & 0.74 & 0.35 \\
\hline Transp. & 1.61 & 0.83 & 0.15 \\
\hline Post and telecoms. & 0.00 & 0.96 & 0.09 \\
\hline Finance & 0.00 & 0.94 & 0.07 \\
\hline Real estate & 0.00 & 0.96 & 0.08 \\
\hline Renting of machinery & 3.23 & 0.94 & 0.14 \\
\hline Computer acti. & 0.00 & 0.95 & 0.13 \\
\hline $\mathrm{R} \& \mathrm{D}$ & 0.00 & 0.95 & 0.08 \\
\hline Public admin. & 3.23 & 0.98 & 0.10 \\
\hline Education & 1.61 & 0.93 & 0.11 \\
\hline Health & 0.00 & 0.98 & 0.09 \\
\hline Others & 0.00 & 0.90 & 0.18 \\
\hline
\end{tabular}


Figure 4.3: Distribution of $\alpha$ over industries, by country



Notes: Within each country, each observation corresponds to an industry. The set of observations is described by the boxplot. 
Table 4.1: Determinants of the response to demand shocks

\begin{tabular}{lccc}
\hline & \multicolumn{3}{c}{$\alpha$} \\
\hline Intermediate consumption & $(1)$ & $(2)$ & $(3)$ \\
Specialization & $\left(0.057^{* * *}\right.$ & $0.075^{* * *}$ & $0.078^{* * *}$ \\
& $0.145^{* * *}$ & $(0.007)$ & $(0.011)$ \\
R\&D intensity & $(0.010)$ & $\left(0.156^{* * *}\right.$ & $0.124^{* * *}$ \\
& & $-0.050^{* * *}$ & $(0.019)$ \\
Capital intensity & & $(0.016)$ & $(0.020)$ \\
& & & $0.087^{* * *}$ \\
Out-degree & & & $(0.013)$ \\
& 0.019 & -0.015 & -0.031 \\
Out-disparity & $(0.016)$ & $(0.025)$ & $(0.050)$ \\
& $-0.054^{* * *}$ & $-0.065^{* * *}$ & $-0.043^{* * *}$ \\
Constant & $(0.009)$ & $(0.011)$ & $(0.016)$ \\
& $0.158^{* * *}$ & $0.215^{* * *}$ & 0.075 \\
Observations & $(0.049)$ & $(0.081)$ & $(0.173)$ \\
$\mathrm{R}^{2}$ & 2,046 & 1,386 & 798 \\
Adjusted $\mathrm{R}^{2}$ & 0.138 & 0.161 & 0.225 \\
\hline
\end{tabular}

Notes: ${ }^{*} \mathrm{p}<0.1 ;{ }^{* *} \mathrm{p}<0.05 ;{ }^{* *} \mathrm{p}<0.01$. Standard errors are in parenthesis. All variables are in log.

\subsection{Conclusion}

Traditional measures of the transmission of final demand shocks throughout the economy have strong assumptions. In particular, they assume that as long as there is an input-output link, the shock is transmitted and that a direct shock is as important as an indirect one. In this chapter, I relax these two assumptions and test whether they are reasonable. I modify the Leontief inverse to include an $\alpha$ vector parameter that measures the strength of the response of each supplier industry to final demand shocks in its user industries. In this setting, the transmission of demand shocks from one industry $i$ to the rest of the input-output network depends on the response of all the industries that are linked directly or indirectly to industry $i$. For this reason, the predicted output variation of industries is defined by a system of equations. In addition, output variation is described as weighted sum of the variations in demand and technology. For each country, I estimate simultaneously the response to demand shocks of each supplier industry by minimizing the objective function. The later quantifies the sum of squared residuals between the 
actual and predicted values of output variations over industries and time. Results show that there are important differences in this response between industries and countries.

Overall manufacturing industries tend to have a lower response to demand shocks relative to services. Within the manufacturing sector, as expected final good industries benefit less from potential backward linkages than others. In particular, the electronics, other machinery, automotive industries have extremely low $\alpha$. Low-tech industries also tend to adjust better to demand shocks (textile, food and other manufacturing industries). Furthermore, industries at the lower end of the value chain, such as paper, petroleum, plastics, fabricated and basic metals industries, tend to have a more elastic response to final demand shocks. This response is even more elastic when looking at industries selling raw material including mining and agriculture. Important differences are also found between countries. For instance, Asian countries tend to have a higher $\alpha$ in the electronics industry relative to other countries, which points to the incidence of specialization patterns on industries' responsiveness to demand shocks. Furthermore, manufacturing supplier industries in developed countries tend to be less responsive to demand shocks relative to developing ones, especially in Asia. This can be explained by the fact that the production of complex products involves relying on many intermediaries, making adjustments to demand shocks more difficult. In addition, most of these industries are involved in global value chains and the position of a country in the value chain defines the level of complexity of tasks. This can potentially influence the flexibility in production adjustment. Moreover, results from the linear regression show that industries in which a country is specialized, that are selling mainly intermediate goods and with an homogenous share of inputs supplied across user industries tend to display a higher response to demand shocks. The type of fixed costs an industry is facing also matters. R\&D intensity is negatively associated to the response to demand shocks while capital intensity seems to have a positive effect. However, it is important to note that the capital intensity variable has many missing data and so this result only holds for a very limited number of countries.

The measure of backward linkages is an important tool to identify industries that generate greater externalities for the growth of an economy through demand and production dynamics. The results presented in this chapter show that these backward linkages are often overestimated in some industries and countries. This can potentially lead to inadequate industrial policies. 
Next steps include realizing a more in-depth analysis of the determinants of the response to demand shocks and developing an improved methodology for calculating backward linkages accounting for these determinants. In addition, this analysis is limited to inputs that are consumed within a year, excluding investments in fixed capital. Including these fixed inputs in the analysis would provide additional insights in the role played by technology inter-linkages between industries in the transmission of demand shocks and in the growth process. Finally, it would be helpful to investigate whether positive and negative shocks in one industry have symmetric effects on the production of others. For instance, we would expect that negative shocks are only partially transmitted to the rest of the economy because of the lack of flexibility in the production process and of the presence of inventory stocks. 


\section{Chapter 5}

\section{Conclusion}

Recent growth spurs are tightly linked to the change in the economic structure of countries. Understanding the role structural change plays on growth dynamics requires a better grasp at the way industries are linked and transform. Moreover, the level of aggregation matters. As a consequence, overlooking the heterogeneity and evolution in the composition of sectors may hide important growth drivers and impediments, and ultimately lead to unsound policy implications and recommendations.

In chapter 2. I study the community structure of the product space and its evolution between 1962 and 2000. This analysis provides valuable information on the linkages between products and industries and enables us to identify important differences between and within industries. A better definition of these links matters greatly because they reveal potential paths for structural change. An analysis of the content of the clusters found suggests that they emerge as a result of differences between and within industries in terms of several factors: technological complexity, domain of knowledge, factor endowments (natural resources and labor), production processes (in particular their degree of fragmentation) and the stage of production. More importantly, results show that some industries display similar patterns for a large number of countries (such as electronics and part of textile industries) while different patterns were found within the same industry (including chemicals and textile industries). Boundaries between industries also evolve over time. For instance, photographic equipment, optical goods and watches merge with the electronics cluster over time. Furthermore, the importance of the internationalization of production processes emerges from the study of both export and production data. These new conditions blur the boundaries between industries and create new pathways for some parts of the world to catch-up and grow rapidly. Yet, the participation to GVC can also be associated to a growth slow down through demand dynamics, as results indicate in chapter 4

I study growth dynamics more in-depth in chapters 3 and 4 taking into consideration industries interlinkages and boundaries. These two chapters differ in that I adopt two distinct frameworks. Namely, in chapter 3 , I look at the supply side 
and the effect of the economic structure on growth dynamics, while, in chapter 4, I focus on rippling effects originating from the demand side affecting growth at the aggregate level. Results from this two chapters show that growth dynamics are complex and that industries interactions and characteristics are an important part of the explanation.

More precisely, in chapter 3 . I show that the growth process is gradual. In other words, countries never jump between extreme growth regimes (between rapid growth and recession) in the medium term. Furthermore, using a semi-Markov framework, I find evidence that transitions between growth regimes depend on the growth state a country is in and the time it has spent in it. Regimes with lower growth levels (slow growth and recession) display the lowest level of inertia in that they are less likely to be sustained over time and even less so as countries spend more time in these states. Conversely, as countries maintain a state of rapid growth, they become more and more likely to remain in this growth regime with time. The structure of the manufacturing sector also matters and the incidence of each industry depends on the growth regime a country is in along with the one it transitions to. I test two different measures of economic structure: export value and export diversity. Results show that the way the economic structure is measure matters, and a greater specialization in a cluster has different implications than a greater diversity in the same cluster. Moreover, there are notable differences among high and medium-tech clusters in the effect they have on growth dynamics. Namely, results reveal important differences between the machinery, chemicals and electronics clusters. While a diversification in the chemicals cluster leads to an improvement of the economic situation, a greater participation in the electronics cluster prevent countries from lowering their growth rate. Conversely, more presence in the machinery cluster pushes countries towards a slow growth regime, whether they are experiencing rapid growth or recession. The positive role of the electronics sector in promoting rapid growth is likely to be tightly linked to the development of global value chains (GVC) in developing countries, and in particular in Asia. In line with the relevant literature, I find that low-tech clusters are associated to the degradation of the economic situations. In addition, this analysis shows that these cluster play a role at different levels of growth. The textile cluster pushes countries towards a more unfavorable growth regime, whether they experience rapid or slow growth. By contrast, the clusters of iron and steel and natural resources-based manufacturing are associated to a recession trap. In other words, a greater specialization in these cluster leads to a lower chance to see their 
economic situation improve (i.e. transition to a slow growth regime). Overall, with regards to the incidence of the economic structure of countries, results corroborate the argument that there is no unique path to growth (Rodrik, 2008).

Complex dynamics in the growth process also arise from the demand side due to the existence of input-output interdependences between industries. In particular, the structure of the input-output network influences the transmission of final demand shocks throughout the economy and in turn alters growth dynamics. The traditional estimation of the output multiplier and backward linkages based on the Leontief inverse relies on two strong assumptions. First, it is assumed that as long as there is an input-output link, the shock is transmitted, and its strength is proportional to the technical coefficients. Second, a direct shock is considered as important as an indirect one. In chapter 4, I relax these assumptions and identify important differences between industries and countries in terms of the degree of their response to demand shocks. Manufacturing supplier industries in developed countries tend to be less responsive to demand shocks relative to developing ones. Developed countries produce more complex products involving a larger set of intermediaries, which implies a smaller margin of adjustment. Results from the linear regression corroborates these arguments. In addition, it shows that the type of fixed costs an industry is facing also matters.

The results of this thesis call for careful considerations with regard to trade and industrial policies. The economy behaves as an ecosystem, in which economic and technological conditions change as industries transform from within and boundaries between them evolve. Interdependences between industries play a crucial role on both supply and demand dynamics, which in turn alters growth dynamics. In addition, some evidence of path dependence is found when modelling the growth process as a semi-Markov model. Indeed, in most cases, the type of growth regime a country is in depends on its growth level in the past as well as the time it has maintained it. Moreover, the economic structure does play a role and the role played by each economic activity is tightly linked to the growth level a country is in. As a result, a successful growth strategy for one country at a given time does not necessarily works for another country or for the same country at a different period in time. Furthermore, the presence of strong interdependences within the economic system implies that a policy targeted at one industry will affect the whole system from both the supply and demand side. Countries should constantly review their growth strategy depending on their current situation and the evolution of economic and technological opportunities. 
Several limitations remain, suggesting several paths for further research. First, the level of disaggregation of the export data used in this work does not allow to account for product quality and distinguish between parts and components and final products. Countries' capabilities are thereby imperfectly estimated, and by consequence, some of the links between industries are biased. Future studies on the composition and evolution of industries would be enriched by using more disaggregated data that could capture these features. Furthermore, while this analysis has enabled to identify important factors explaining export patterns and their evolution, further work is needed to shed light on the countries' export trajectory to explain changes in the community structure over time. In addition, a deeper analysis on the determinants of these changes is necessary to identify the key capabilities that have enabled structural change to take place.

Second, I estimate the average effect of the economic structure of countries on growth dynamics over the period of analysis. Future work involves testing the stability of these coefficients over time to estimate the evolution of the role played by different export patterns on growth prospects. This can be done by estimating a non-homogeneous semi-Markov model, in which transition probabilities are also allowed to vary with time and to depend on economic structure variables.

Third, an important path for further research concerns the identification of determinants of the transmission of demand shocks between pairs of supplier-user industries. In this thesis, I have focused on demand shocks, but this framework is also helpful for studies on the transmission of productivity shocks throughout the economy. It could be useful in the future to extent the methodology developed here to study the rippling effects of productivity shocks. As argued by Dietzenbacher (1997), the supply-side model should be considered as a price rather than a quantity model. That is one assumes that variations reflect changes in prices or costs of primary inputs (quantities are fixed, while prices vary). In this setting, a decrease in the price of inputs could be explained by the fact that the supplier industry has a better production technology and thereby is able to offer inputs at a lower price. Furthermore, the same way the shocks in the demand driven model are limited by the capacity of production of supplier industries, productivity shocks in the supply driven model are limited by production technology of the user industries. A simultaneous change in the production technology of supplier and user firms makes it more difficult to identify the source of the shock. The decrease in the price of inputs could also be due to the fact that the production technology of the user industry is more efficient and thus requires less inputs. To better clarify 
the evolution of the production technology of industries and shed some clarity on this problem, it would be useful to complement input-output data with data on $\mathrm{R} \& \mathrm{D}$ and on fixed capital investments (both tangible and intangible). Finally, as industries' composition and interdependences tend to evolve over time, the evolution of the transmission of these shocks is an interesting topic for further research. Furthermore, I have argued throughout this thesis that technologies are intertwined and largely complementary, both between and within industries and even sectors. For this reason, an important area of future research is the integration of fixed capital in the input-output analysis along with intermediate consumption. 


\section{References}

Acemoglu, D., V. M. Carvalho, A. Ozdaglar, and A. Tahbaz-Salehi (2012). The network origins of aggregate fluctuations. Econometrica 80(5), 1977-2016.

Arrow, K. J. (1962a). The economic implications of learning by doing. The review of economic studies, $155-173$.

Arrow, K. J. (1962b). Economic welfare and the allocation of resources for invention. In The rate and direction of inventive activity: Economic and social factors, pp. 609-626. Princeton University Press.

Arthur, W. B. (2009). The nature of technology: What it is and how it evolves. Simon and Schuster.

Balassa, B. (1965). Trade liberalisation and "revealed" comparative advantage1. The Manchester School 33(2), 99-123.

Bolt, J. and J. L. Van Zanden (2014). The maddison project: collaborative research on historical national accounts. The Economic History Review 67(3), 627-651.

Broyden, C. G. (1970). The convergence of a class of double-rank minimization algorithms 1. general considerations. IMA Journal of Applied Mathematics 6(1), 76-90.

Byrd, R. H., P. Lu, J. Nocedal, and C. Zhu (1995). A limited memory algorithm for bound constrained optimization. SIAM Journal on Scientific Computing 16(5), 1190-1208.

Cadot, O., C. Carrère, and V. Strauss-Kahn (2011). Export diversification: What's behind the hump? Review of Economics and Statistics 93(2), 590-605.

Chenery, H. B. and T. Watanabe (1958). International comparisons of the structure of production. Econometrica: Journal of the Econometric Society, 487-521.

Cornwall, J. (1977). Modern capitalism: its growth and transformation. Martin Robertson London.

Cox, D. R. (1972). Regression models and life-tables. Journal of the Royal Statistics Society 34(2), $187-220$.

Dietzenbacher, E. (1997). In vindication of the ghosh model: a reinterpretation as a price model. Journal of regional science 37(4), 629-651.

Dietzenbacher, E. and B. Los (1998). Structural decomposition techniques: sense and sensitivity. Economic Systems Research 10(4), 307-324.

Dietzenbacher, E. and U. Temurshoev (2012). Input-output impact analysis in current or constant prices: does it matter? Journal of Economic Structures 1(1), 4.

Dosi, G. (1982). Technological paradigms and technological trajectories: a suggested interpretation of the determinants and directions of technical change. Research policy 11(3), 147-162.

Dosi, G., O. Marsili, L. Orsenigo, and R. Salvatore (1995). Learning, market selection and the evolution of industrial structures. Small Business Economics 7(6), 411-436.

Fagerberg, J. (2000). Technological progress, structural change and productivity growth: a comparative study. Structural change and economic dynamics 11(4), 393-411.

Fagerberg, J. and B. Verspagen (1999). "Modern capitalism" in the 1970s and 1980s. (1999002). 
Feenstra, R. C., R. E. Lipsey, H. Deng, A. C. Ma, and H. Mo (2005). World trade flows: 1962-2000. Technical report, National Bureau of Economic Research.

Fletcher, R. (1970). A new approach to variable metric algorithms. The computer journal 13(3), $317-322$.

Forrester, J. W. (1961). Industrial Dynamics. MIT Press.

Fortunato, S. (2010). Community detection in graphs. Physics Reports 486(3), 75-174.

Fortunato, S. and M. Barthélemy (2007). Resolution limit in community detection. Proceedings of the National Academy of Sciences 104(1), 36-41.

Foucher, Y., E. Mathieu, P. Saint-Pierre, J.-F. Durand, and J.-P. Daurès (2005). A semi-markov model based on generalized weibull distribution with an illustration for hiv disease. Biometrical Journal: Journal of Mathematical Methods in Biosciences 47(6), 825-833.

Frenken, K., F. Van Oort, and T. Verburg (2007). Related variety, unrelated variety and regional economic growth. Regional studies 41(5), 685-697.

Galindo-Rueda, F. and F. Verger. OECD taxonomy of economic activities based on R\&D intensity. OECD Science, Technology and Industry Working Papers 4.

Goldfarb, D. (1970). A family of variable-metric methods derived by variational means. Mathematics of computation 24(109), 23-26.

Good, B. H., Y.-A. De Montjoye, and A. Clauset (2010). Performance of modularity maximization in practical contexts. Physical Review E 81(4), 046106.

Guimerà, R., M. Sales-Pardo, and L. A. N. Amaral (2004). Modularity from fluctuations in random graphs and complex networks. Phys. Rev. E 70, 025101.

Hausmann, R. and C. A. Hidalgo (2011). The network structure of economic output. Journal of Economic Growth 16(4), 309-342.

Hausmann, R., L. Pritchett, and D. Rodrik (2005). Growth accelerations. Journal of Economic Growth 10(4), 303-329.

Hidalgo, C. A., B. Klinger, A.-L. Barabási, and R. Hausmann (2007). The product space conditions the development of nations. Science 317(5837), 482-487.

Hirschman, A. O. (1958). The strategy of economic development, Volume 10. Yale university Press New Haven.

Huffman, D. A. (1952). A method for the construction of minimum-redundancy codes. Proceedings of the IRE 40(9), 1098-1101.

Jacobs, J. (1969). The Economies of Cities. Random House, NewYork.

Jaffe, A. B., M. Trajtenberg, and R. Henderson (1993). Geographic localization of knowledge spillovers as evidenced by patent citations. the Quarterly journal of Economics 108(3), 577598.

Jerzmanowski, M. (2006). Empirics of hills, plateaus, mountains and plains: A markov-switching approach to growth. Journal of development economics 81(2), 357-385.

Jones, B. F. and B. A. Olken (2005). The anatomy of start-stop growth. NBER working paper.

Klinger, B. and D. Lederman (2004). Discovery and development: an empirical exploration of "new" products. The World Bank. 
Lall, S. (2000). The technological structure and performance of developing country manufactured exports, 1985-98. Oxford development studies 28(3), 337-369.

Lall, S., M. Albaladejo, and J. Zhang (2004). Mapping fragmentation: electronics and automobiles in east asia and latin america. Oxford Development Studies 32(3), 407-432.

Lancichinetti, A. and S. Fortunato (2009). Community detection algorithms: A comparative analysis. Phys. Rev. E 80, 056117.

Lancichinetti, A. and S. Fortunato (2012). Consensus clustering in complex networks. Scientific reports 2.

Leamer, E. E. (1984). Sources of international comparative advantage: Theory and evidence. MIT press Cambridge, MA.

Leicht, E. A., P. Holme, and M. E. Newman (2006). Vertex similarity in networks. Physical Review E 73(2), 026120.

Leontief, W. (1991). The economy as a circular flow. Structural change and economic dynamics 2(1), 181-212.

Lewis, W. A. (1954). Unlimited supplies of labour. Manchester school.

Lucas, R. E. (1977). Understanding business cycles. Carnegie-Rochester Conference Series on Public Policy 5, 7-29.

Lundvall, B.-A. (1992). National systems of innovation: Toward a theory of innovation and interactive learning. Pinter Publishers.

Malerba, F. (2002). Sectoral systems of innovation and production. Research policy 31(2), 247264.

Nelson, R. R. and G. Winter, Sidney (1982). An evolutionary theory of economic change. Cambridge, MA: Harvard University Press.

Newman, M. (2018). Networks. Oxford university press.

Newman, M. E. and M. Girvan (2004). Finding and evaluating community structure in networks. Physical review E 69(2), 026113.

OECD (2011). STAN database for structural analysis.

OECD (2017). Input-Output tables.

OECD (2019). Technology and R\&D statistics: Main science and technology indicators.

Olsson, O. (2005). Technological opportunity and growth. Journal of economic growth 10(1), $31-53$.

Pasinetti, L. L. (1981). Structural Change and Economic Growth. Cambridge University Press.

Pavitt, K. (1984). Sectoral patterns of technical change: towards a taxonomy and a theory. Research policy 13(6), 343-373.

Prebisch, R. (1950). The economic development of latin america and its principal problems.

Pritchett, L. (2000). Understanding patterns of economic growth: searching for hills among plateaus, mountains, and plains. The World Bank Economic Review 14(2), 221-250.

Rasmussen, P. N. (1956). Studies in inter-sectoral relations, Volume 15. North-Holland.

Reichardt, J. and S. Bornholdt (2006). Statistical mechanics of community detection. Phys. Rev. E 74, 016110. 
Ricardo, D. (1817). On The Principles of Political Economy and Taxation. John Murray.

Rodrik, D. (2008). One economics, many recipes: globalization, institutions, and economic growth. Princeton University Press.

Rosenberg, N. (1976). Perspectives on technology. Cambridge University Press.

Rosenberg, N. (1979). Technological interdependence in the american economy. Technology and Culture 20(1), 25-50.

Rosvall, M. and C. T. Bergstrom (2008). Maps of information flow reveal community structure in complex networks. PNAS 105(4), 1118-1123.

Rosvall, M. and C. T. Bergstrom (2010). Mapping change in large networks. PloS one 5(1), e8694.

Rosvall, M. and C. T. Bergstrom (2011). Multilevel compression of random walks on networks reveals hierarchical organization in large integrated systems. PloS one 6(4), e18209.

Salter, W. E. G. (1960). Productivity and technical change. Cambridge University Press.

Saviotti, P. P. and K. Frenken (2008). Export variety and the economic performance of countries. Journal of Evolutionary Economics 18(2), 201-218.

Schumpeter, J. A. (1934). The theory of economic development: An inquiry into profits, capital, credit, interest, and the business cycle. Cambridge: Harvard University Press.

Serrano, M. Á., M. Boguná, and A. Vespignani (2009). Extracting the multiscale backbone of complex weighted networks. PNAS 106(16), 6483-6488.

Shanno, D. F. (1970). Conditioning of quasi-newton methods for function minimization. Mathematics of computation 24(111), 647-656.

Singer, H. (1950). The distribution of gains between borrowing and investing nations. American Economic Review 40(2), 473-85.

Szirmai, A. and B. Verspagen (2015). Manufacturing and economic growth in developing countries, 1950-2005. Structural Change and Economic Dynamics 34, 46-59.

Timmer, M. P. and G. J. de Vries (2009). Structural change and growth accelerations in asia and latin america: a new sectoral data set. Cliometrica 3(2), 165-190.

Timmer, M. P., E. Dietzenbacher, B. Los, R. Stehrer, and G. J. Vries (2015). An illustrated user guide to the world input-output database: the case of global automotive production. Review of International Economics 23(3), 575-605.

Weitzman, M. L. (1998). Recombinant growth. Quarterly Journal of Economics, 331-360.

Winter, S. G. (1984). Schumpeterian competition in alternative technological regimes. Journal of Economic Behavior 8 Organization 5(3-4), 287-320. 


\section{Appendix A}

\section{Appendix to Chapter 2}

Table A.1: Evolution of the number of countries and product in the international trade network

\begin{tabular}{ccc}
\hline & Number of countries & Number of products \\
\hline $1962-1964$ & 110 & 517 \\
$1965-1969$ & 110 & 517 \\
$1970-1974$ & 111 & 696 \\
$1975-1979$ & 111 & 769 \\
$1980-1984$ & 111 & 783 \\
$1985-1989$ & 111 & 783 \\
$1990-1994$ & 111 & 783 \\
$1995-1999$ & 111 & 781 \\
2000 & 111 & 769 \\
\hline
\end{tabular}

Table A.2: Correlation between the similarity measures

\begin{tabular}{lccc}
\hline Period & $\begin{array}{c}\text { Cosine - } \\
\text { Proximity }\end{array}$ & $\begin{array}{c}\text { Proximity - } \\
\text { Jaccard }\end{array}$ & $\begin{array}{c}\text { Cosine - } \\
\text { Jaccard }\end{array}$ \\
\hline $1960-1964$ & 0.968 & 0.982 & 0.984 \\
$1965-1969$ & 0.967 & 0.981 & 0.986 \\
$1970-1974$ & 0.951 & 0.979 & 0.979 \\
$1975-1979$ & 0.942 & 0.977 & 0.967 \\
$1980-1984$ & 0.962 & 0.979 & 0.985 \\
$1985-1989$ & 0.965 & 0.980 & 0.986 \\
$1990-1994$ & 0.965 & 0.980 & 0.986 \\
$1995-1999$ & 0.963 & 0.980 & 0.985 \\
2000 & 0.960 & 0.979 & 0.986 \\
\hline
\end{tabular}

Table A.3: Interquartile range of each similarity measures

\begin{tabular}{lccc}
\hline Period & Cosine & Proximity & Jaccard \\
\hline $1960-1964$ & 0.25 & 0.21 & 0.15 \\
$1965-1969$ & 0.23 & 0.20 & 0.14 \\
$1970-1974$ & 0.22 & 0.19 & 0.13 \\
$1975-1979$ & 0.22 & 0.19 & 0.13 \\
$1980-1984$ & 0.22 & 0.19 & 0.14 \\
$1985-1989$ & 0.21 & 0.18 & 0.13 \\
$1990-1994$ & 0.20 & 0.17 & 0.13 \\
$1995-1999$ & 0.20 & 0.18 & 0.13 \\
2000 & 0.20 & 0.18 & 0.12 \\
\hline
\end{tabular}


Figure A.1: Weight distribution of the snapshots for each similarity measure

(a) 1975-1979

(b) 1980-1984



Cosine Proximity Jaccard



Cosine Proximity Jaccard (c) $1985-1989$



Cosine Proximity Jaccard (d) 1990-1994



Cosine Proximity Jaccard (e) 1995-1999



Cosine Proximity Jaccard (f) 2000



Cosine Proximity Jaccard 
Figure A.2: Simulation of two specific cases in which similarity measures differ

(a) Case 1: Product $A$ is exported by 16 countries and product $B$ by countries that also export product $A$



Number of common countries

(b) Case 2: Two products that are each exported by 12 countries



Number of common countries 
Figure A.3: Weight distribution of the snapshots of the product space

(a) $1975-1979$

(b) $1980-1984$



(c) $1985-1989$



w

(e) 1995-1999



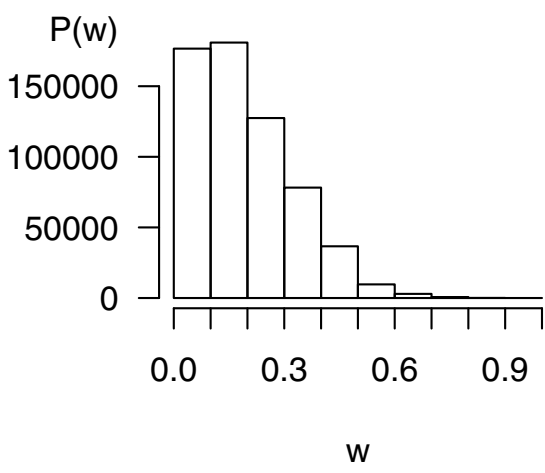

(d) 1990-1994



w

(f) 2000



w

$$
\text { W }
$$

Note: $w$ refers to edge weight. 


\section{A.1 Serrano et al. (2009)'s network reduction method}

Serrano et al. (2009) construct a threshold considering weight heterogeneity at the node level. This method selects the most significant neighbors of a node as determined by the disparity filter. This filter can be seen as a p-value for which the null hypothesis is the random case where the $k$ normalized weights $p_{i, j}$ of a node $i$ with degree $k$ are randomly assigned using a uniform distribution $U[0,1]$. The p-value (or disparity filter) $\alpha_{i, j}$ is formally described as:

$$
\alpha_{i, j}=1-(k-1) \int_{0}^{p_{i, j}}(1-x)^{k-2} d x<\alpha
$$

$p_{i, j}$ is the weight $w_{i j}$ between node $i$ and $j$ normalized by the strength $s_{i}$ of node $i$. It is formally defined as:

$$
p_{i j}=\frac{w_{i j}}{\sum_{j=1}^{N_{i}} w_{i j}}=\frac{w_{i j}}{s_{i}}
$$

where $N_{i}$ is the neighborhood of $i$.

The p-value $\alpha_{i, j}$ measures the probability of observing a normalized weight larger or equal to $p_{i j}$ if the null hypothesis is true. The significance of the edges increases as $\alpha_{i, j}$ decreases. Therefore, the edges with a low p-value are characterized by significant heterogeneities in the network that are not due to the strength sequence of the network but to other topological properties that are not accounted for in the null model.

Every edge involves two nodes $i$ and $j$, and so has two p-values $\left(\alpha_{i, j}\right.$ and $\left.\alpha_{j, i}\right)$. The value assigned to an edge is taken to be the maximum of the two. If this maximum value is inferior to the significance level $\alpha$, the corresponding link is kept. Formally, we obtain:

$$
\tilde{w}_{i j}= \begin{cases}w_{i j}, & \text { if } \alpha_{i, j} \leq \alpha \text { or } \alpha_{j, i} \leq \alpha . \\ 0, & \text { otherwise. }\end{cases}
$$


It can be simplified to:

$$
\tilde{w}_{i j}= \begin{cases}w_{i j}, & \text { if } \alpha_{i, j}^{\min }=\min \left\{\alpha_{i, j}, \alpha_{j, i}\right\} \leq \alpha . \\ 0, & \text { otherwise. }\end{cases}
$$

As one reduces the significance level, more edges are filtered out. However, below a critical level, the graph becomes disconnected. This provides a natural value at which to set the significance level $\alpha$. In what follows I define the critical value of $\alpha$ as the smallest value consistent with a connected network. For that condition to be fulfilled, each node should have at least one edge. For the degree of each node to be at least equal to one, the significant level should be higher than the p-value $\alpha_{i, j}$ corresponding to the most significant edge of the node that has the least significant edge among all the vertices. The lower bound of the significance level denoted $\alpha_{L B}$ is defined as follows:

$$
\alpha_{L B}=\max _{i}\left\{\min _{j}\left\{\alpha_{i, j}^{\min }\right\}\right\}
$$

For the graph to stay connected, the significance level should be superior or equal to $\alpha_{L B}$. I can then redefine the condition under which edges are kept using the lower bound of the significance level as ${ }^{1}$

$$
\tilde{w}_{i j}= \begin{cases}w_{i j}, & \text { if } \alpha_{i, j}^{\text {min }} \leq \alpha_{L B} \\ 0, & \text { otherwise }\end{cases}
$$

\footnotetext{
${ }^{1}$ In practice, because estimated values in the disparity filter matrix are automatically rounded by the software, I apply the following condition in order to insure that $\alpha_{L B} \geq \max _{i}\left\{\min _{j}\left\{\alpha_{i, j}^{\min }\right\}\right\}$ :

$$
\tilde{w}_{i j}= \begin{cases}w_{i j}, & \text { if } \alpha_{i, j}^{\min } \leq \alpha_{L B}+\epsilon . \\ 0, & \text { otherwise }\end{cases}
$$

with $\epsilon$ infinitesimally small.
} 
Figure A.4 shows the relationship between the values of the disparity filter, the significance level and the graph connectedness.

Figure A.4: The disparity filter and graph connectedness

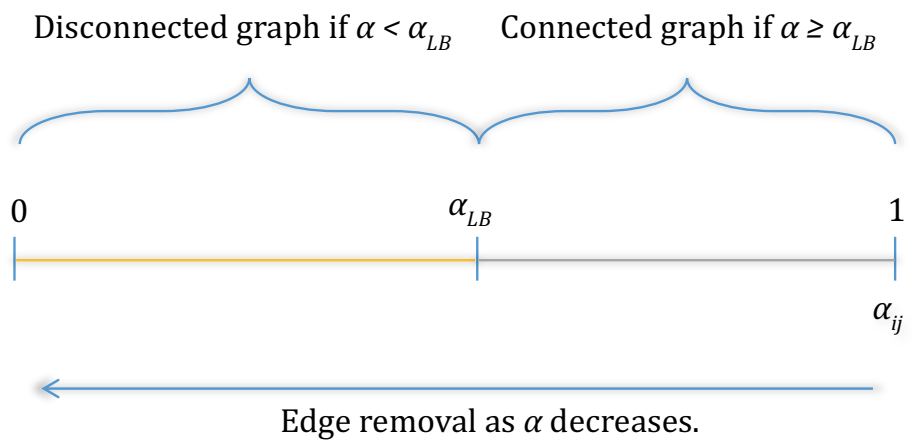

Note: $\alpha$ is the significance level and $\alpha_{L B}$ is the lower bound of the significance level.

\section{A.2 The Infomap algorithm}

The Infomap algorithm uses the dynamics of flow on the network to identify its community structure (Rosvall and Bergstrom, 2008, 2010, 2011) 2 Based on information theory, its aim is to compress the description of an infinitely long random walk on a network, which is considered to be a proxy for information flow. The first step of the procedure consists in computing the frequency with which a random walker visits a node ${ }^{3}$ Each vertex and cluster is given a coded name using a Huffman coding (Huffman, 1952). The steps of this method are detailed as follows (see Figure A.5):

1. First, vertices should be sorted in a decreasing order according to their probability of being visited.

2. Second, a recursive procedure is applied, in which the two smallest probabilities are added along a tree, until this summation is one.

3. Once the tree is created, each branch is attributed a binary code name $\{0,1\}$.

\footnotetext{
${ }^{2} \mathrm{An}$ interactive explanation of the algorithm is available at the address: http://www.mapequation.org/apps/MapDemo.html.

${ }^{3}$ The frequency to visit a node is measured by its PageRank.
} 
4. According to Huffman coding, the code name of each vertex $i$ corresponds to the combination of the code name of the branches leading to the same node $i$ from the bottom to the top of the tree.

This coding is optimal (i.e. it leads to a code of minimum length) because it enables most frequent nodes to have the smallest code name.

Figure A.5: Huffman coding

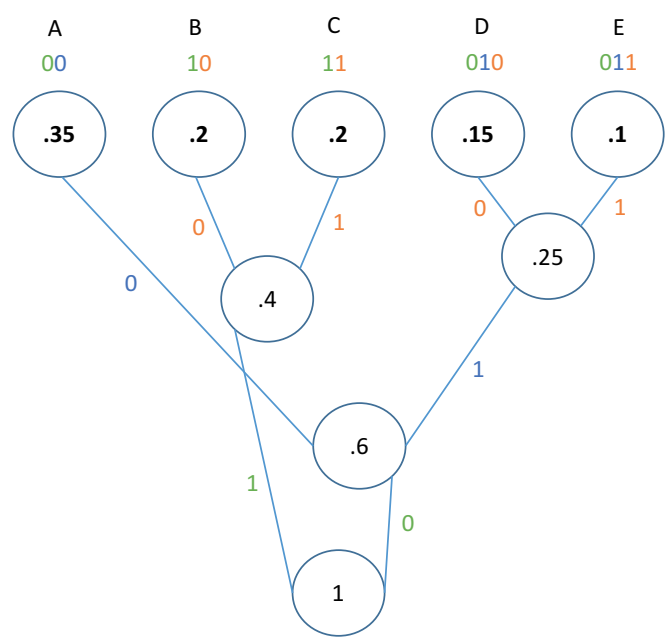

Note: The number contained inside each circle on the top row corresponds to the probability of being visited for each node $\mathrm{A}, \mathrm{B}, \mathrm{C}, \mathrm{D}$ and $\mathrm{E}$. The integers correspond to the binary code attributed to each branch. The Huffman code attributed to each node is the combination of the binary code of the branches leading to the node from the bottom to the top of the tree.

In the Infomap procedure, the coded names can be repeated for several vertices as long as they do not belong to the same cluster. This recycling procedure enables the compression of space that would otherwise be needed if each vertex were assigned a different name. The code length describes the path of the random worker. It consists in, first, indicating the codename of the cluster in which the random walker is, as well as the codename of the vertex. When the random walker goes to a vertex that belongs to a different cluster, the code describing the path must indicate the codename of the cluster the random walker is leaving, the codename of the cluster it is entering as well as the codename of the new vertex. It is assumed that when a random walker enters a cluster, it will spend a long period of time inside before leaving since nodes inside a cluster are more densely linked among each other than with the rest of the network. In a network with a strong community structure, recycling the codenames of vertices according to the parti- 
tion that reflects the best the dynamics on the network minimizes the description length. In other words, minimizing the code length of the random walker amounts to a trade off between having, on the one hand, a few community codenames along with longer node codenames and, on the other hand, many community codenames conjointly with short node codenames.

The objective function in this algorithm is not the modularity as in many other community detection algorithm but the map equation. This map equation which measures the code length of the random walker. Its minimization is used to detect the strongest community structure of the network. 


\section{A.3 Results}

Table A.4: Definition of the set of industries in terms of SITC Revision 2 at 2 digits

\begin{tabular}{cll}
\hline & Industry & SITC 2 digits \\
\hline 1 & Machinery & $71,72,73,74,78,79$ \\
2 & Controlling instruments & 87 \\
3 & Chemicals & $51,52,53,54,55,56,57,59$ \\
4 & Plastics & 58 \\
5 & Electronics & $75,76,77$ \\
6 & Optical goods & 88 \\
7 & Prints & 89 \\
8 & Textile - Manufacture & $83,84,85$ \\
9 & Textile - Material & 61,65 \\
10 & Textile - Crude & 21,26 \\
11 & Wood - Manufacture & 63 \\
12 & Wood - Crude & 24 \\
13 & Furniture & 81,82 \\
14 & Paper - Manufacture & 64 \\
15 & Paper - Crude & 25 \\
16 & Non-metal mineral - Manufacture & 66 \\
17 & Non-metal mineral - Crude & 27 \\
18 & Metal - Manufacture & 68,69 \\
19 & Metal - Crude & 28 \\
20 & Iron and steel & 67 \\
21 & Petroleum & 33 \\
22 & Coal & 32 \\
23 & Oils - Seed and fruit & 22 \\
24 & Oils - Manufacture & $41,42,43$ \\
25 & Food & $00,01,02,03,04,05,06,07,08,09$ \\
26 & Drinks and tobacco & 11,12 \\
\hline & &
\end{tabular}


Figure A.6: Share of products from each industry across communities (in \%)

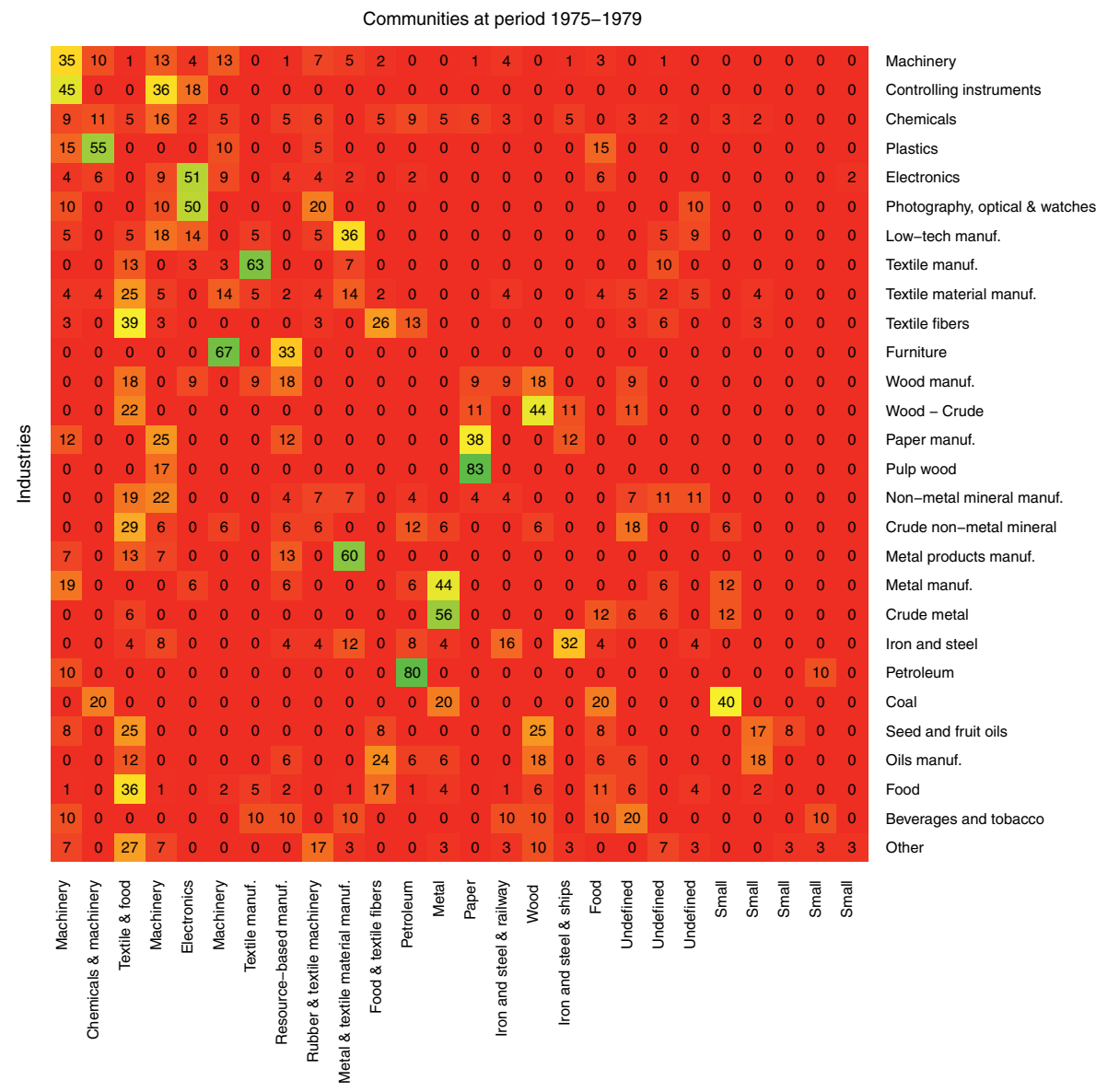


Communities at period 1980-1984

\begin{tabular}{|c|c|c|c|c|c|c|c|c|c|c|c|c|c|c|c|c|c|c|c|c|c|c|c|c|c|}
\hline 71 & 0 & 2 & 0 & 17 & 2 & 0 & 0 & 0 & 1 & 1 & 2 & 0 & 1 & 0 & 0 & 0 & 0 & 1 & 0 & 0 & 0 & 2 & 0 & 0 & Machinery \\
\hline 73 & 0 & 18 & 0 & 9 & 0 & 0 & 0 & 0 & 0 & 0 & 0 & 0 & 0 & 0 & 0 & 0 & 0 & 0 & 0 & 0 & 0 & 0 & 0 & 0 & Controlling instruments \\
\hline 22 & 8 & 2 & 9 & 2 & 8 & 5 & 0 & 3 & 2 & 0 & 11 & 2 & 2 & 3 & 3 & 8 & 5 & 5 & 0 & 0 & 0 & 2 & 2 & 0 & Chemicals \\
\hline 80 & 0 & 0 & 0 & 0 & 0 & 0 & 0 & 0 & 5 & 0 & 5 & 0 & 0 & 5 & 0 & 5 & 0 & 0 & 0 & 0 & 0 & 0 & 0 & 0 & Plastics \\
\hline 30 & 0 & 55 & 0 & 0 & 0 & 0 & 0 & 0 & 2 & 0 & 2 & 2 & 0 & 0 & 0 & 0 & 0 & 4 & 0 & 0 & 0 & 0 & 2 & 2 & Electronics \\
\hline 30 & 0 & 60 & 0 & 10 & 0 & 0 & 0 & 0 & 0 & 0 & 0 & 0 & 0 & 0 & 0 & 0 & 0 & 0 & 0 & 0 & 0 & 0 & 0 & 0 & Photography, optical \& watches \\
\hline 9 & 9 & 36 & 0 & 5 & 5 & 0 & 5 & 0 & 0 & 5 & 0 & 0 & 0 & 5 & 5 & 14 & 0 & 0 & 0 & 0 & 5 & 0 & 0 & 0 & Low-tech manuf. \\
\hline 0 & 97 & 3 & 0 & 0 & 0 & 0 & 0 & 0 & 0 & 0 & 0 & 0 & 0 & 0 & 0 & 0 & 0 & 0 & 0 & 0 & 0 & 0 & 0 & 0 & Textile manuf. \\
\hline 11 & 47 & 11 & 0 & 2 & 4 & 0 & 0 & 0 & 0 & 12 & 0 & 0 & 2 & 0 & 7 & 0 & 2 & 0 & 2 & 2 & 0 & 0 & 0 & 0 & Textile material manuf. \\
\hline 3 & 32 & 6 & 19 & 0 & 3 & 0 & 0 & 0 & 0 & 0 & 3 & 0 & 10 & 0 & 6 & 0 & 0 & 0 & 10 & 6 & 0 & 0 & 0 & 0 & Textile fibers \\
\hline 0 & 33 & 0 & 0 & 0 & 0 & 0 & 0 & 0 & 67 & 0 & 0 & 0 & 0 & 0 & 0 & 0 & 0 & 0 & 0 & 0 & 0 & 0 & 0 & 0 & Furniture \\
\hline 9 & 9 & 0 & 0 & 0 & 0 & 18 & 36 & 9 & 9 & 9 & 0 & 0 & 0 & 0 & 0 & 0 & 0 & 0 & 0 & 0 & 0 & 0 & 0 & 0 & Wood manuf. \\
\hline 0 & 0 & 0 & 0 & 0 & 0 & 0 & 56 & 22 & 11 & 11 & 0 & 0 & 0 & 0 & 0 & 0 & 0 & 0 & 0 & 0 & 0 & 0 & 0 & 0 & Wood - Crude \\
\hline 25 & 0 & 0 & 0 & 0 & 12 & 12 & 0 & 38 & 12 & 0 & 0 & 0 & 0 & 0 & 0 & 0 & 0 & 0 & 0 & 0 & 0 & 0 & 0 & 0 & Paper manuf. \\
\hline 0 & 0 & 0 & 17 & 0 & 17 & 0 & 0 & 67 & 0 & 0 & 0 & 0 & 0 & 0 & 0 & 0 & 0 & 0 & 0 & 0 & 0 & 0 & 0 & 0 & Pulp wood \\
\hline 19 & 19 & 4 & 0 & 7 & 0 & 4 & 0 & 4 & 0 & 15 & 4 & 0 & 4 & 4 & 11 & 4 & 0 & 0 & 0 & 0 & 4 & 0 & 0 & 0 & Non-metal mineral manuf. \\
\hline 12 & 24 & 0 & 6 & 0 & 6 & 6 & 0 & 12 & 0 & 0 & 12 & 6 & 6 & 0 & 0 & 6 & 6 & 0 & 0 & 0 & 0 & 0 & 0 & 0 & Crude non-metal mineral \\
\hline 20 & 27 & 13 & 0 & 0 & 0 & 7 & 0 & 0 & 7 & 7 & 0 & 0 & 0 & 20 & 0 & 0 & 0 & 0 & 0 & 0 & 0 & 0 & 0 & 0 & Metal products manuf. \\
\hline 19 & 0 & 6 & 38 & 0 & 6 & 6 & 12 & 6 & 6 & 0 & 0 & 0 & 0 & 0 & 0 & 0 & 0 & 0 & 0 & 0 & 0 & 0 & 0 & 0 & Metal manuf. \\
\hline 0 & 6 & 0 & 69 & 0 & 0 & 0 & 0 & 0 & 0 & 6 & 0 & 12 & 0 & 0 & 0 & 0 & 0 & 0 & 0 & 6 & 0 & 0 & 0 & 0 & Crude metal \\
\hline 8 & 4 & 4 & 8 & 4 & 0 & 0 & 0 & 4 & 48 & 4 & 0 & 0 & 0 & 8 & 0 & 0 & 0 & 0 & 4 & 4 & 0 & 0 & 0 & 0 & Iron and steel \\
\hline 0 & 50 & 0 & 0 & 0 & 0 & 20 & 10 & 0 & 0 & 0 & 0 & 0 & 0 & 0 & 0 & 20 & 0 & 0 & 0 & 0 & 0 & 0 & 0 & 0 & Petroleum \\
\hline 20 & 0 & 0 & 0 & 0 & 20 & 0 & 0 & 0 & 0 & 0 & 0 & 60 & 0 & 0 & 0 & 0 & 0 & 0 & 0 & 0 & 0 & 0 & 0 & 0 & Coal \\
\hline 8 & 58 & 0 & 0 & 0 & 8 & 0 & 8 & 0 & 0 & 0 & 8 & 8 & 0 & 0 & 0 & 0 & 0 & 0 & 0 & 0 & 0 & 0 & 0 & 0 & Seed and fruit oils \\
\hline 12 & 18 & 0 & 6 & 0 & 6 & 0 & 29 & 0 & 0 & 6 & 18 & 0 & 0 & 0 & 0 & 0 & 0 & 0 & 6 & 0 & 0 & 0 & 0 & 0 & Oils manuf. \\
\hline 0 & 51 & 0 & 13 & 0 & 13 & 1 & 5 & 1 & 0 & 1 & 2 & 6 & 1 & 0 & 0 & 0 & 5 & 0 & 0 & 0 & 0 & 0 & 0 & 0 & Food \\
\hline 10 & 40 & 0 & 0 & 0 & 0 & 30 & 0 & 0 & 0 & 10 & 0 & 0 & 0 & 0 & 0 & 0 & 0 & 0 & 0 & 0 & 10 & 0 & 0 & 0 & Beverages and tobacco \\
\hline 20 & 23 & 3 & 7 & 7 & 3 & 0 & 13 & 7 & 0 & 0 & 0 & 0 & 10 & 0 & 3 & 0 & 0 & 0 & 0 & 0 & 3 & 0 & 0 & 0 & Other \\
\hline 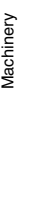 & 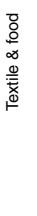 & 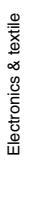 & $\frac{\bar{\pi}}{\frac{\bar{J}}{0}}$ & 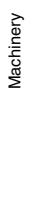 & 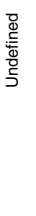 & 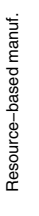 & 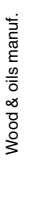 & 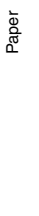 & 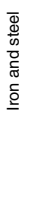 & 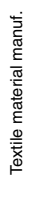 & 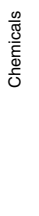 & 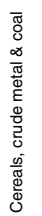 & 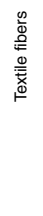 & 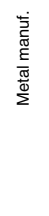 & 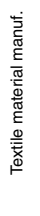 & 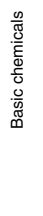 & 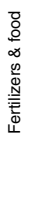 & $\begin{array}{l}\overline{\overline{\widetilde{\sigma}}} \\
\stackrel{\bar{\xi}}{\omega}\end{array}$ & $\begin{array}{l}\overline{\bar{\varpi}} \\
\text { ஸे }\end{array}$ & $\begin{array}{l}\overline{\bar{\varpi}} \\
\text { ڤ }\end{array}$ & $\begin{array}{l}\overline{\overline{\widetilde{\varpi}}} \\
\text { है }\end{array}$ & $\begin{array}{l}\overline{\overline{\widetilde{\varpi}}} \\
\text { ผ }\end{array}$ & $\begin{array}{l}\overline{\bar{\sigma}} \\
\text { है }\end{array}$ & $\begin{array}{l}\overline{\overline{\widetilde{\varpi}}} \\
\text { ळ }\end{array}$ & \\
\hline
\end{tabular}


Communities at period 1985-1989

\begin{tabular}{|c|c|c|c|c|c|c|c|c|c|c|c|c|c|c|c|c|c|c|c|c|c|c|c|c|c|c|}
\hline 0 & 66 & 4 & 6 & 0 & 2 & 0 & 0 & 1 & 0 & 0 & 0 & 0 & 9 & 0 & 0 & 0 & 6 & 1 & 1 & 0 & 2 & 0 & 0 & 0 & 3 & Machinery \\
\hline 0 & 64 & 18 & 0 & 0 & 0 & 0 & 0 & 0 & 0 & 0 & 0 & 0 & 9 & 0 & 9 & 0 & 0 & 0 & 0 & 0 & 0 & 0 & 0 & 0 & 0 & Controlling instruments \\
\hline 6 & 9 & 3 & 11 & 5 & 2 & 0 & 6 & 5 & 9 & 19 & 0 & 3 & 2 & 0 & 0 & 3 & 6 & 0 & 0 & 8 & 0 & 0 & 2 & 0 & 2 & Chemicals \\
\hline 0 & 10 & 0 & 40 & 5 & 5 & 0 & 0 & 0 & 5 & 5 & 0 & 0 & 0 & 0 & 0 & 0 & 5 & 5 & 5 & 0 & 0 & 10 & 5 & 0 & 0 & Plastics \\
\hline 0 & 9 & 66 & 9 & 0 & 4 & 0 & 0 & 2 & 0 & 0 & 4 & 0 & 0 & 0 & 0 & 0 & 0 & 2 & 0 & 0 & 4 & 0 & 0 & 0 & 0 & Electronics \\
\hline 0 & 20 & 50 & 20 & 0 & 0 & 0 & 0 & 0 & 0 & 0 & 0 & 0 & 0 & 0 & 0 & 0 & 10 & 0 & 0 & 0 & 0 & 0 & 0 & 0 & 0 & Photography, optical \& watches \\
\hline 9 & 14 & 59 & 0 & 0 & 0 & 0 & 0 & 5 & 0 & 0 & 5 & 0 & 5 & 0 & 5 & 0 & 0 & 0 & 0 & 0 & 0 & 0 & 0 & 0 & 0 & Low-tech manuf. \\
\hline 90 & 0 & 3 & 0 & 0 & 0 & 0 & 0 & 0 & 0 & 0 & 7 & 0 & 0 & 0 & 0 & 0 & 0 & 0 & 0 & 0 & 0 & 0 & 0 & 0 & 0 & Textile manuf. \\
\hline 33 & 5 & 18 & 4 & 2 & 5 & 0 & 0 & 0 & 0 & 4 & 18 & 4 & 0 & 0 & 2 & 0 & 0 & 0 & 0 & 0 & 2 & 0 & 5 & 0 & 0 & Textile material manuf. \\
\hline 32 & 0 & 3 & 0 & 19 & 0 & 0 & 0 & 3 & 0 & 3 & 6 & 19 & 3 & 3 & 0 & 0 & 0 & 0 & 0 & 0 & 6 & 0 & 0 & 0 & 0 & Textile fibers \\
\hline 33 & 0 & 0 & 0 & 0 & 0 & 0 & 0 & 0 & 0 & 0 & 0 & 0 & 0 & 0 & 0 & 0 & 0 & 0 & 67 & 0 & 0 & 0 & 0 & 0 & 0 & Furniture \\
\hline 9 & 0 & 0 & 9 & 0 & 0 & 45 & 0 & 9 & 0 & 0 & 9 & 0 & 0 & 0 & 0 & 0 & 0 & 0 & 18 & 0 & 0 & 0 & 0 & 0 & 0 & Wood manuf. \\
\hline 0 & 0 & 0 & 0 & 0 & 0 & 56 & 0 & 33 & 0 & 0 & 11 & 0 & 0 & 0 & 0 & 0 & 0 & 0 & 0 & 0 & 0 & 0 & 0 & 0 & 0 & Wood - Crude \\
\hline 0 & 0 & 0 & 0 & 0 & 38 & 0 & 0 & 50 & 0 & 0 & 0 & 0 & 0 & 0 & 12 & 0 & 0 & 0 & 0 & 0 & 0 & 0 & 0 & 0 & 0 & Paper manuf. \\
\hline 0 & 0 & 17 & 0 & 0 & 0 & 0 & 0 & 83 & 0 & 0 & 0 & 0 & 0 & 0 & 0 & 0 & 0 & 0 & 0 & 0 & 0 & 0 & 0 & 0 & 0 & Pulp wood \\
\hline 11 & 15 & 15 & 11 & 0 & 4 & 0 & 4 & 4 & 4 & 4 & 11 & 0 & 0 & 4 & 0 & 4 & 0 & 0 & 4 & 0 & 4 & 0 & 0 & 0 & 4 & Non-metal mineral manuf. \\
\hline 6 & 6 & 0 & 0 & 0 & 0 & 6 & 24 & 0 & 12 & 6 & 0 & 0 & 0 & 0 & 0 & 18 & 6 & 0 & 0 & 18 & 0 & 0 & 0 & 0 & 0 & Crude non-metal mineral \\
\hline 0 & 33 & 7 & 0 & 0 & 7 & 0 & 0 & 0 & 0 & 7 & 13 & 0 & 0 & 7 & 7 & 0 & 0 & 20 & 0 & 0 & 0 & 0 & 0 & 0 & 0 & Metal products manuf. \\
\hline 0 & 0 & 0 & 19 & 0 & 0 & 12 & 50 & 0 & 6 & 0 & 0 & 0 & 0 & 0 & 0 & 0 & 0 & 0 & 0 & 0 & 6 & 0 & 0 & 6 & 0 & Metal manuf. \\
\hline 12 & 0 & 0 & 0 & 0 & 0 & 6 & 56 & 0 & 12 & 0 & 0 & 0 & 0 & 0 & 0 & 12 & 0 & 0 & 0 & 0 & 0 & 0 & 0 & 0 & 0 & Crude metal \\
\hline 0 & 20 & 0 & 0 & 0 & 0 & 0 & 0 & 0 & 4 & 0 & 0 & 4 & 4 & 52 & 0 & 4 & 0 & 4 & 0 & 0 & 0 & 8 & 0 & 0 & 0 & Iron and steel \\
\hline 0 & 0 & 0 & 0 & 0 & 0 & 0 & 0 & 0 & 80 & 0 & 0 & 0 & 0 & 0 & 0 & 20 & 0 & 0 & 0 & 0 & 0 & 0 & 0 & 0 & 0 & Petroleum \\
\hline 0 & 0 & 0 & 0 & 0 & 0 & 0 & 0 & 0 & 0 & 0 & 0 & 0 & 0 & 0 & 0 & 100 & 0 & 0 & 0 & 0 & 0 & 0 & 0 & 0 & 0 & Coal \\
\hline 25 & 0 & 0 & 0 & 8 & 8 & 17 & 0 & 0 & 0 & 0 & 0 & 33 & 0 & 0 & 0 & 0 & 8 & 0 & 0 & 0 & 0 & 0 & 0 & 0 & 0 & Seed and fruit oils \\
\hline 12 & 0 & 0 & 6 & 6 & 0 & 35 & 6 & 0 & 0 & 0 & 6 & 24 & 0 & 0 & 0 & 0 & 0 & 0 & 0 & 0 & 6 & 0 & 0 & 0 & 0 & Oils manuf. \\
\hline 38 & 0 & 1 & 1 & 21 & 5 & 6 & 6 & 0 & 0 & 2 & 0 & 8 & 0 & 0 & 0 & 1 & 2 & 0 & 0 & 7 & 0 & 0 & 0 & 0 & 0 & Food \\
\hline 40 & 10 & 0 & 0 & 10 & 0 & 10 & 10 & 0 & 0 & 0 & 10 & 0 & 0 & 0 & 0 & 0 & 0 & 0 & 0 & 0 & 0 & 0 & 0 & 10 & 0 & Beverages and tobacco \\
\hline 23 & 10 & 7 & 10 & 0 & 3 & 10 & 10 & 3 & 3 & 3 & 0 & 0 & 0 & 7 & 0 & 3 & 0 & 0 & 3 & 0 & 3 & 0 & 0 & 0 & 0 & Other \\
\hline 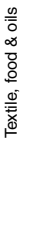 & 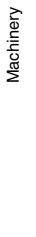 & 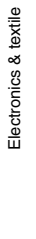 & 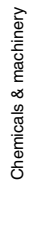 & 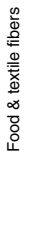 & 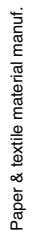 &  &  & $\begin{array}{l}\frac{\Phi}{\sigma} \\
\frac{0}{\sigma}\end{array}$ & 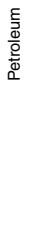 & 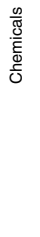 & 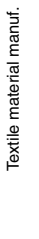 & 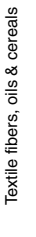 & 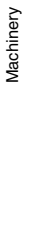 & $\begin{array}{l}\bar{\Phi} \\
\frac{\Phi}{\omega} \\
\text { o } \\
\text { ㅎ } \\
\text { 흐 }\end{array}$ & $\begin{array}{l}\overline{\overline{\widetilde{\varpi ్}}} \\
\text { ผे }\end{array}$ & 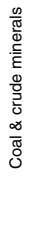 & $\frac{\frac{\pi}{\pi}}{\frac{\pi}{\frac{2}{2}}}$ & $\begin{array}{l}\overline{\overline{\widetilde{\sigma}}} \\
\text { ๘ } \\
\text { क }\end{array}$ & $\begin{array}{l}\overline{\bar{\varpi}} \\
\text { ळे }\end{array}$ & 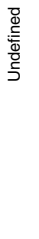 & 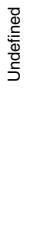 & 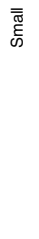 & $\begin{array}{l}\overline{\overline{\widetilde{\sigma}}} \\
\text { है }\end{array}$ & $\begin{array}{l}\overline{\overline{\widetilde{J}}} \\
\text { है }\end{array}$ & $\begin{array}{l}\overline{\overline{\bar{\sigma}}} \\
\text { हे }\end{array}$ & \\
\hline
\end{tabular}


Communities at period 1990-1994

\begin{tabular}{|c|c|c|c|c|c|c|c|c|c|c|c|c|}
\hline 88 & 0 & 6 & 6 & 0 & 0 & 0 & 0 & 0 & 0 & 0 & 0 & Machinery \\
\hline 82 & 0 & 9 & 0 & 0 & 9 & 0 & 0 & 0 & 0 & 0 & 0 & Controlling instruments \\
\hline 56 & 5 & 2 & 6 & 12 & 5 & 2 & 2 & 0 & 8 & 0 & 3 & Chemicals \\
\hline 70 & 0 & 5 & 15 & 0 & 0 & 10 & 0 & 0 & 0 & 0 & 0 & Plastics \\
\hline 28 & 4 & 66 & 0 & 0 & 0 & 0 & 2 & 0 & 0 & 0 & 0 & Electronics \\
\hline 40 & 0 & 60 & 0 & 0 & 0 & 0 & 0 & 0 & 0 & 0 & 0 & Photography, optical \& watches \\
\hline 23 & 23 & 50 & 0 & 0 & 0 & 0 & 0 & 0 & 0 & 0 & 5 & Low-tech manuf. \\
\hline 0 & 87 & 10 & 0 & 0 & 3 & 0 & 0 & 0 & 0 & 0 & 0 & Textile manuf. \\
\hline 16 & 42 & 30 & 2 & 0 & 4 & 5 & 2 & 0 & 0 & 0 & 0 & Textile material manuf. \\
\hline 10 & 35 & 19 & 10 & 0 & 23 & 0 & 3 & 0 & 0 & 0 & 0 & Textile fibers \\
\hline 0 & 100 & 0 & 0 & 0 & 0 & 0 & 0 & 0 & 0 & 0 & 0 & Furniture \\
\hline 9 & 45 & 0 & 9 & 0 & 0 & 0 & 9 & 27 & 0 & 0 & 0 & Wood manuf. \\
\hline 0 & 44 & 0 & 0 & 44 & 0 & 0 & 11 & 0 & 0 & 0 & 0 & Wood - Crude \\
\hline 50 & 0 & 0 & 0 & 38 & 0 & 12 & 0 & 0 & 0 & 0 & 0 & Paper manuf. \\
\hline 17 & 0 & 0 & 0 & 83 & 0 & 0 & 0 & 0 & 0 & 0 & 0 & Pulp wood \\
\hline 33 & 22 & 11 & 4 & 4 & 4 & 0 & 7 & 0 & 0 & 7 & 7 & Non-metal mineral manuf. \\
\hline 18 & 12 & 0 & 12 & 41 & 6 & 0 & 0 & 0 & 12 & 0 & 0 & Crude non-metal mineral \\
\hline 40 & 13 & 13 & 20 & 0 & 0 & 0 & 0 & 0 & 0 & 13 & 0 & Metal products manuf. \\
\hline 25 & 0 & 12 & 12 & 50 & 0 & 0 & 0 & 0 & 0 & 0 & 0 & Metal manuf. \\
\hline 0 & 31 & 0 & 0 & 62 & 0 & 0 & 0 & 0 & 0 & 0 & 6 & Crude metal \\
\hline 24 & 0 & 0 & 60 & 8 & 0 & 0 & 8 & 0 & 0 & 0 & 0 & Iron and steel \\
\hline 0 & 0 & 10 & 80 & 0 & 0 & 0 & 0 & 0 & 0 & 10 & 0 & Petroleum \\
\hline 0 & 0 & 0 & 0 & 80 & 0 & 0 & 0 & 0 & 0 & 20 & 0 & Coal \\
\hline 17 & 42 & 8 & 0 & 0 & 8 & 0 & 8 & 8 & 0 & 8 & 0 & Seed and fruit oils \\
\hline 6 & 12 & 6 & 0 & 6 & 18 & 0 & 6 & 35 & 0 & 12 & 0 & Oils manuf. \\
\hline 8 & 40 & 2 & 0 & 1 & 26 & 4 & 7 & 2 & 8 & 0 & 0 & Food \\
\hline 30 & 30 & 0 & 0 & 0 & 10 & 20 & 10 & 0 & 0 & 0 & 0 & Beverages and tobacco \\
\hline 23 & 27 & 7 & 17 & 7 & 3 & 3 & 0 & 3 & 0 & 0 & 10 & Other \\
\hline 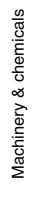 &  & 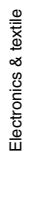 & 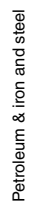 & 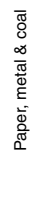 & $\begin{array}{l}\frac{\infty}{0} \\
\infty \\
\delta \\
\delta \\
\varnothing\end{array}$ & 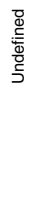 & 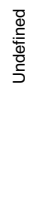 & 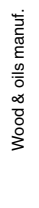 & 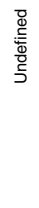 & 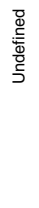 & 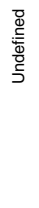 & \\
\hline
\end{tabular}


Communities at period 1995-1999

\begin{tabular}{|c|c|c|c|c|c|c|c|c|c|c|c|c|c|c|c|c|c|c|c|c|c|c|}
\hline 84 & 0 & 5 & 0 & 4 & 4 & 2 & 0 & 0 & 0 & 0 & 0 & 0 & 0 & 1 & 0 & 0 & 0 & 1 & 0 & 0 & 0 & Machinery \\
\hline 73 & 0 & 18 & 0 & 0 & 0 & 0 & 0 & 0 & 0 & 0 & 0 & 0 & 0 & 0 & 0 & 0 & 0 & 9 & 0 & 0 & 0 & Controlling instruments \\
\hline 42 & 5 & 3 & 5 & 8 & 0 & 14 & 0 & 2 & 0 & 9 & 0 & 0 & 0 & 3 & 3 & 0 & 6 & 0 & 0 & 0 & 0 & Chemicals \\
\hline 70 & 0 & 5 & 0 & 0 & 10 & 5 & 0 & 0 & 0 & 5 & 0 & 0 & 5 & 0 & 0 & 0 & 0 & 0 & 0 & 0 & 0 & Plastics \\
\hline 19 & 4 & 72 & 0 & 0 & 2 & 0 & 0 & 0 & 0 & 0 & 0 & 0 & 0 & 2 & 0 & 0 & 0 & 0 & 0 & 0 & 0 & Electronics \\
\hline 30 & 0 & 60 & 0 & 0 & 0 & 0 & 0 & 0 & 0 & 0 & 0 & 0 & 0 & 0 & 0 & 10 & 0 & 0 & 0 & 0 & 0 & Photography, optical \& watches \\
\hline 5 & 18 & 59 & 0 & 0 & 0 & 0 & 0 & 0 & 0 & 0 & 0 & 0 & 5 & 0 & 0 & 5 & 0 & 5 & 0 & 5 & 0 & Low-tech manuf. \\
\hline 0 & 83 & 7 & 3 & 0 & 0 & 0 & 0 & 0 & 0 & 0 & 0 & 3 & 0 & 0 & 0 & 0 & 3 & 0 & 0 & 0 & 0 & Textile manuf. \\
\hline 12 & 33 & 21 & 4 & 0 & 2 & 0 & 5 & 2 & 0 & 0 & 0 & 12 & 0 & 2 & 0 & 2 & 0 & 0 & 2 & 4 & 0 & Textile material manuf. \\
\hline 10 & 32 & 6 & 19 & 3 & 10 & 0 & 0 & 0 & 0 & 3 & 0 & 0 & 0 & 3 & 0 & 0 & 0 & 0 & 13 & 0 & 0 & Textile fibers \\
\hline 0 & 67 & 0 & 0 & 0 & 0 & 0 & 0 & 0 & 33 & 0 & 0 & 0 & 0 & 0 & 0 & 0 & 0 & 0 & 0 & 0 & 0 & Furniture \\
\hline 0 & 9 & 0 & 0 & 0 & 0 & 0 & 0 & 0 & 64 & 0 & 0 & 27 & 0 & 0 & 0 & 0 & 0 & 0 & 0 & 0 & 0 & Wood manuf. \\
\hline 11 & 22 & 0 & 0 & 11 & 0 & 0 & 0 & 0 & 44 & 0 & 0 & 11 & 0 & 0 & 0 & 0 & 0 & 0 & 0 & 0 & 0 & Wood - Crude \\
\hline 25 & 12 & 0 & 0 & 50 & 0 & 0 & 0 & 0 & 12 & 0 & 0 & 0 & 0 & 0 & 0 & 0 & 0 & 0 & 0 & 0 & 0 & Paper manuf. \\
\hline 0 & 0 & 0 & 0 & 83 & 0 & 0 & 0 & 17 & 0 & 0 & 0 & 0 & 0 & 0 & 0 & 0 & 0 & 0 & 0 & 0 & 0 & Pulp wood \\
\hline 37 & 22 & 15 & 0 & 4 & 0 & 0 & 0 & 4 & 0 & 0 & 0 & 11 & 0 & 0 & 0 & 4 & 0 & 0 & 0 & 4 & 0 & Non-metal mineral manuf. \\
\hline 12 & 12 & 0 & 0 & 12 & 0 & 12 & 0 & 0 & 0 & 29 & 0 & 0 & 0 & 12 & 0 & 6 & 0 & 6 & 0 & 0 & 0 & Crude non-metal mineral \\
\hline 33 & 0 & 20 & 0 & 0 & 13 & 7 & 0 & 0 & 0 & 0 & 0 & 0 & 7 & 13 & 0 & 0 & 0 & 0 & 0 & 7 & 0 & Metal products manuf. \\
\hline 25 & 0 & 12 & 6 & 19 & 6 & 6 & 0 & 0 & 0 & 0 & 0 & 0 & 0 & 0 & 25 & 0 & 0 & 0 & 0 & 0 & 0 & Metal manuf. \\
\hline 0 & 19 & 0 & 6 & 44 & 0 & 0 & 0 & 0 & 0 & 0 & 0 & 0 & 0 & 0 & 31 & 0 & 0 & 0 & 0 & 0 & 0 & Crude metal \\
\hline 20 & 0 & 0 & 0 & 4 & 64 & 0 & 0 & 0 & 0 & 0 & 0 & 0 & 4 & 0 & 4 & 0 & 4 & 0 & 0 & 0 & 0 & Iron and steel \\
\hline 0 & 0 & 0 & 0 & 10 & 10 & 80 & 0 & 0 & 0 & 0 & 0 & 0 & 0 & 0 & 0 & 0 & 0 & 0 & 0 & 0 & 0 & Petroleum \\
\hline 0 & 0 & 0 & 0 & 80 & 20 & 0 & 0 & 0 & 0 & 0 & 0 & 0 & 0 & 0 & 0 & 0 & 0 & 0 & 0 & 0 & 0 & Coal \\
\hline 8 & 42 & 0 & 17 & 0 & 0 & 0 & 0 & 0 & 0 & 0 & 17 & 0 & 0 & 0 & 0 & 8 & 0 & 0 & 8 & 0 & 0 & Seed and fruit oils \\
\hline 0 & 0 & 0 & 29 & 0 & 0 & 0 & 6 & 12 & 0 & 0 & 35 & 6 & 0 & 0 & 0 & 0 & 0 & 0 & 12 & 0 & 0 & Oils manuf. \\
\hline 4 & 39 & 0 & 29 & 1 & 0 & 0 & 1 & 7 & 0 & 8 & 7 & 1 & 0 & 0 & 0 & 0 & 0 & 0 & 1 & 0 & 1 & Food \\
\hline 10 & 30 & 0 & 10 & 0 & 0 & 0 & 10 & 10 & 0 & 0 & 10 & 10 & 0 & 10 & 0 & 0 & 0 & 0 & 0 & 0 & 0 & Beverages and tobacco \\
\hline 17 & 30 & 7 & 0 & 3 & 10 & 7 & 3 & 0 & 0 & 0 & 7 & 0 & 3 & 0 & 0 & 3 & 3 & 3 & 0 & 0 & 3 & Other \\
\hline 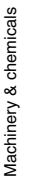 & 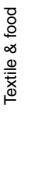 & 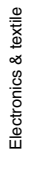 & 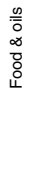 &  &  &  & $\begin{array}{l}\overline{\overline{\widetilde{\sigma}}} \\
\text { ๘े }\end{array}$ & 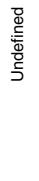 & $\begin{array}{l}\text { 우 } \\
\vdots\end{array}$ & 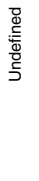 & $\frac{\omega}{\bar{\partial}}$ &  & $\begin{array}{l}\overline{\overline{\widetilde{\sigma}}} \\
\bar{E} \\
\omega\end{array}$ &  & $\begin{array}{l}\overline{\frac{\sigma}{0}} \\
\frac{0}{2}\end{array}$ & 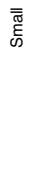 & $\begin{array}{l}\overline{\overline{\widetilde{\varpi}}} \\
\bar{E}\end{array}$ & $\begin{array}{l}\overline{\overline{\bar{\varpi}}} \\
\text { है }\end{array}$ & 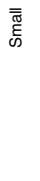 & $\begin{array}{l}\overline{\bar{\varpi}} \\
\text { है }\end{array}$ & $\begin{array}{l}\overline{\overline{\widetilde{\varpi}}} \\
\text { है }\end{array}$ & \\
\hline
\end{tabular}


Communities at period 2000

\begin{tabular}{|c|c|c|c|c|c|c|c|c|c|c|c|c|c|c|c|c|c|c|c|c|c|c|c|c|c|c|}
\hline 69 & 0 & 5 & 1 & 12 & 2 & 0 & 1 & 0 & 0 & 0 & 0 & 2 & 0 & 1 & 0 & 0 & 1 & 0 & 0 & 0 & 2 & 4 & 0 & 0 & 1 & Machinery \\
\hline 73 & 0 & 18 & 0 & 0 & 0 & 0 & 0 & 0 & 0 & 0 & 0 & 0 & 0 & 0 & 0 & 0 & 0 & 0 & 9 & 0 & 0 & 0 & 0 & 0 & 0 & Controlling instruments \\
\hline 38 & 3 & 3 & 2 & 3 & 0 & 3 & 2 & 6 & 2 & 2 & 3 & 0 & 12 & 0 & 0 & 6 & 0 & 0 & 0 & 9 & 0 & 0 & 6 & 0 & 0 & Chemicals \\
\hline 50 & 0 & 10 & 5 & 0 & 0 & 0 & 0 & 10 & 0 & 0 & 5 & 0 & 5 & 0 & 0 & 5 & 5 & 0 & 0 & 0 & 0 & 0 & 5 & 0 & 0 & Plastics \\
\hline 21 & 4 & 66 & 6 & 2 & 0 & 0 & 0 & 0 & 0 & 0 & 0 & 0 & 0 & 0 & 0 & 0 & 0 & 0 & 0 & 0 & 0 & 0 & 0 & 0 & 0 & Electronics \\
\hline 40 & 0 & 40 & 10 & 0 & 0 & 0 & 0 & 0 & 0 & 0 & 0 & 0 & 0 & 0 & 10 & 0 & 0 & 0 & 0 & 0 & 0 & 0 & 0 & 0 & 0 & Photography, optical \& watches \\
\hline 9 & 18 & 36 & 18 & 9 & 0 & 0 & 0 & 0 & 0 & 0 & 0 & 0 & 0 & 9 & 0 & 0 & 0 & 0 & 0 & 0 & 0 & 0 & 0 & 0 & 0 & Low-tech manuf. \\
\hline 0 & 80 & 3 & 10 & 0 & 0 & 0 & 0 & 0 & 0 & 0 & 0 & 0 & 0 & 0 & 0 & 0 & 7 & 0 & 0 & 0 & 0 & 0 & 0 & 0 & 0 & Textile manuf. \\
\hline 12 & 30 & 2 & 23 & 2 & 0 & 2 & 0 & 0 & 5 & 0 & 4 & 0 & 0 & 2 & 0 & 0 & 5 & 9 & 2 & 0 & 4 & 0 & 0 & 0 & 0 & Textile material manuf. \\
\hline 3 & 23 & 10 & 3 & 0 & 6 & 16 & 3 & 0 & 3 & 0 & 6 & 0 & 0 & 0 & 0 & 3 & 0 & 13 & 3 & 0 & 6 & 0 & 0 & 0 & 0 & Textile fibers \\
\hline 0 & 33 & 0 & 0 & 0 & 0 & 0 & 0 & 0 & 0 & 0 & 0 & 67 & 0 & 0 & 0 & 0 & 0 & 0 & 0 & 0 & 0 & 0 & 0 & 0 & 0 & Furniture \\
\hline 9 & 9 & 0 & 0 & 0 & 0 & 0 & 0 & 0 & 0 & 0 & 0 & 55 & 0 & 0 & 0 & 0 & 9 & 0 & 9 & 0 & 9 & 0 & 0 & 0 & 0 & Wood manuf. \\
\hline 0 & 0 & 0 & 0 & 0 & 33 & 0 & 0 & 0 & 0 & 0 & 0 & 33 & 0 & 0 & 11 & 0 & 11 & 0 & 0 & 0 & 11 & 0 & 0 & 0 & 0 & Wood - Crude \\
\hline 0 & 0 & 0 & 12 & 38 & 38 & 0 & 0 & 0 & 0 & 0 & 0 & 12 & 0 & 0 & 0 & 0 & 0 & 0 & 0 & 0 & 0 & 0 & 0 & 0 & 0 & Paper manuf. \\
\hline 0 & 0 & 0 & 0 & 0 & 83 & 0 & 17 & 0 & 0 & 0 & 0 & 0 & 0 & 0 & 0 & 0 & 0 & 0 & 0 & 0 & 0 & 0 & 0 & 0 & 0 & Pulp wood \\
\hline 22 & 19 & 15 & 4 & 4 & 4 & 0 & 4 & 0 & 7 & 0 & 0 & 0 & 0 & 4 & 0 & 4 & 4 & 0 & 0 & 4 & 0 & 0 & 0 & 7 & 0 & Non-metal mineral manuf. \\
\hline 24 & 12 & 0 & 0 & 6 & 18 & 0 & 0 & 6 & 18 & 0 & 0 & 0 & 0 & 0 & 0 & 6 & 0 & 6 & 0 & 0 & 0 & 0 & 6 & 0 & 0 & Crude non-metal mineral \\
\hline 33 & 0 & 0 & 33 & 0 & 0 & 0 & 7 & 7 & 0 & 7 & 7 & 0 & 0 & 7 & 0 & 0 & 0 & 0 & 0 & 0 & 0 & 0 & 0 & 0 & 0 & Metal products manuf. \\
\hline 31 & 0 & 12 & 0 & 0 & 12 & 6 & 0 & 6 & 0 & 0 & 0 & 0 & 31 & 0 & 0 & 0 & 0 & 0 & 0 & 0 & 0 & 0 & 0 & 0 & 0 & Metal manuf. \\
\hline 12 & 19 & 0 & 0 & 0 & 38 & 6 & 0 & 0 & 0 & 0 & 0 & 0 & 25 & 0 & 0 & 0 & 0 & 0 & 0 & 0 & 0 & 0 & 0 & 0 & 0 & Crude metal \\
\hline 8 & 0 & 0 & 0 & 8 & 8 & 0 & 0 & 0 & 0 & 4 & 28 & 8 & 4 & 0 & 0 & 0 & 12 & 12 & 0 & 4 & 0 & 0 & 4 & 0 & 0 & Iron and steel \\
\hline 0 & 0 & 0 & 0 & 0 & 0 & 0 & 0 & 80 & 0 & 0 & 0 & 0 & 0 & 0 & 0 & 0 & 10 & 0 & 0 & 0 & 0 & 10 & 0 & 0 & 0 & Petroleum \\
\hline 20 & 0 & 0 & 0 & 0 & 0 & 0 & 0 & 0 & 0 & 0 & 0 & 0 & 0 & 0 & 0 & 0 & 0 & 0 & 0 & 0 & 0 & 20 & 0 & 60 & 0 & Coal \\
\hline 8 & 25 & 0 & 0 & 0 & 0 & 8 & 0 & 0 & 8 & 0 & 8 & 0 & 0 & 0 & 17 & 0 & 17 & 8 & 0 & 0 & 0 & 0 & 0 & 0 & 0 & Seed and fruit oils \\
\hline 12 & 0 & 0 & 0 & 0 & 0 & 12 & 6 & 0 & 6 & 0 & 18 & 0 & 0 & 0 & 35 & 0 & 0 & 6 & 0 & 0 & 6 & 0 & 0 & 0 & 0 & Oils manuf. \\
\hline 1 & 33 & 0 & 1 & 0 & 2 & 18 & 11 & 0 & 10 & 1 & 2 & 0 & 0 & 0 & 6 & 0 & 7 & 0 & 4 & 2 & 0 & 0 & 0 & 0 & 1 & Food \\
\hline 10 & 30 & 0 & 0 & 0 & 10 & 30 & 0 & 0 & 0 & 0 & 0 & 0 & 0 & 0 & 0 & 0 & 0 & 0 & 20 & 0 & 0 & 0 & 0 & 0 & 0 & Beverages and tobacco \\
\hline 13 & 37 & 7 & 0 & 0 & 3 & 0 & 0 & 7 & 7 & 0 & 7 & 0 & 3 & 0 & 3 & 0 & 3 & 0 & 3 & 0 & 0 & 0 & 0 & 0 & 7 & Other \\
\hline 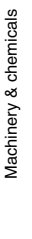 & 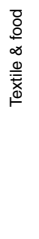 & 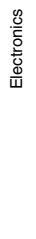 & 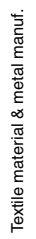 &  & 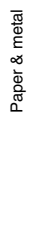 & 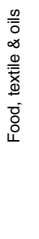 & $\begin{array}{l}\text { D } \\
\text { ¿ }\end{array}$ & 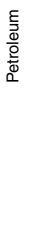 & 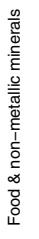 & 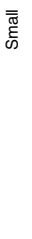 &  & 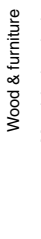 & 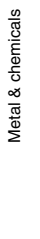 & $\begin{array}{l}\overline{\overline{\widetilde{J}}} \\
\text { ผ }\end{array}$ & $\begin{array}{l}\bar{\delta} \\
\frac{0}{\infty} \\
\frac{0}{\overline{0}} \\
\frac{\bar{\sigma}}{0}\end{array}$ & $\begin{array}{l}\overline{\overline{\widetilde{\varpi}}} \\
\text { लॉ }\end{array}$ & 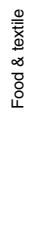 & 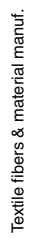 & 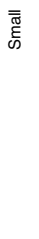 & 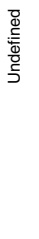 & $\begin{array}{l}\overline{\overline{\widetilde{\sigma}}} \\
\text { ๘ }\end{array}$ & $\begin{array}{l}\overline{\overline{\bar{\varpi}}} \\
\text { Eั }\end{array}$ & $\begin{array}{l}\overline{\overline{\bar{\varpi}}} \\
\text { Е }\end{array}$ & ठّ̊ & $\begin{array}{l}\overline{\overline{\bar{\varpi}}} \\
\text { है }\end{array}$ & \\
\hline
\end{tabular}




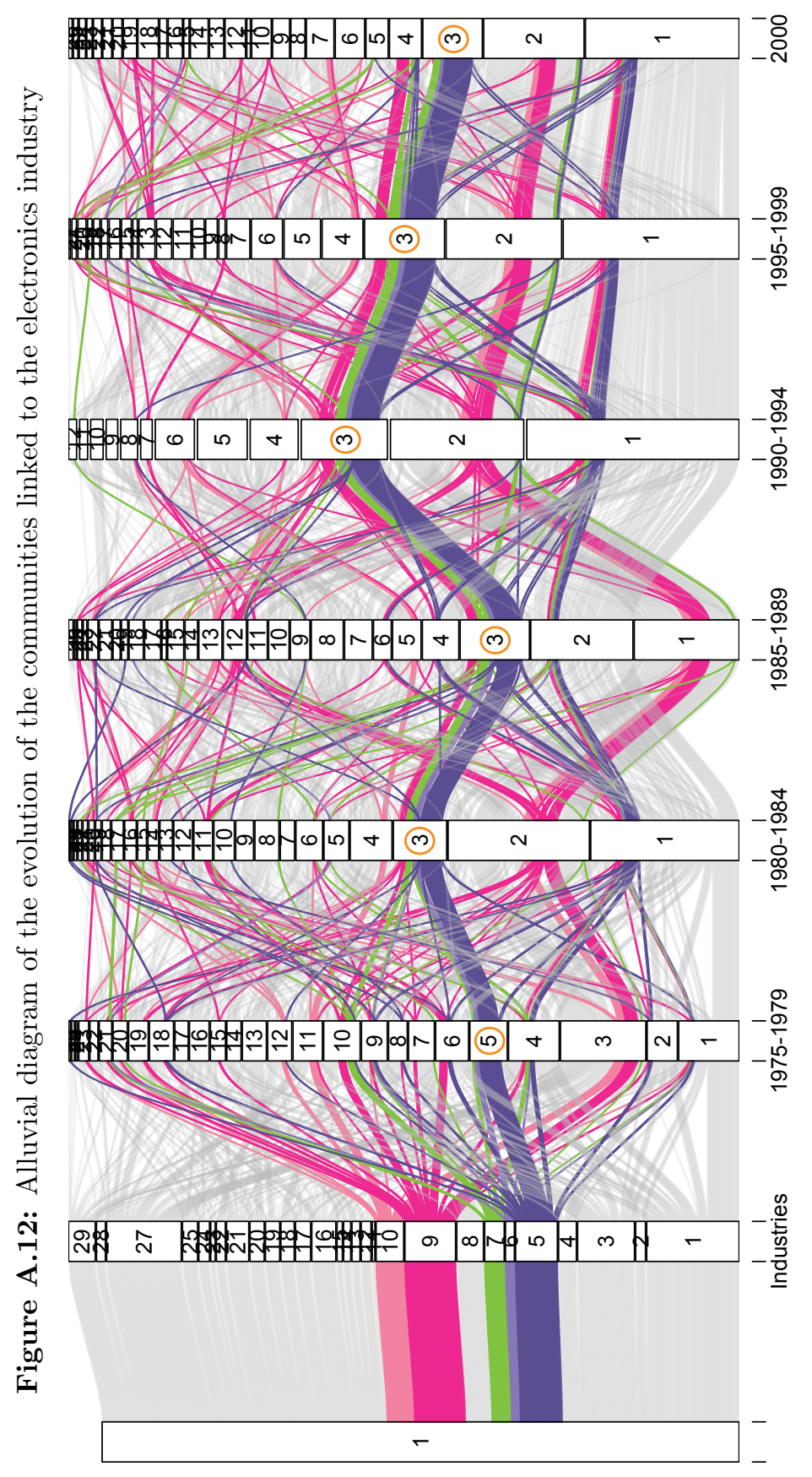

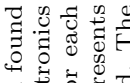

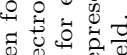

एँ

บ

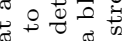

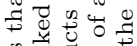

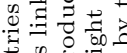

की

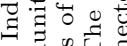



능

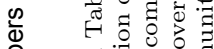

$\exists$.



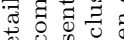

च

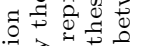

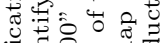

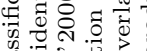

$\approx 0=\frac{\pi}{0}$

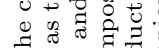

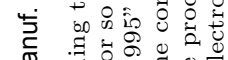

ह ह गुण

क त्र

茂

ป ह

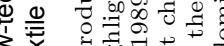

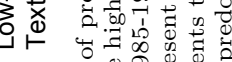

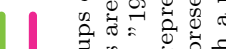

क्ष

$+700$

\& 0000

吃

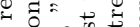

$\infty$ कि

तु



क ते

은 잉

志 음

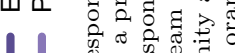

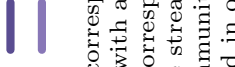

उ 0 o

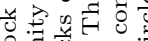

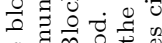

Q








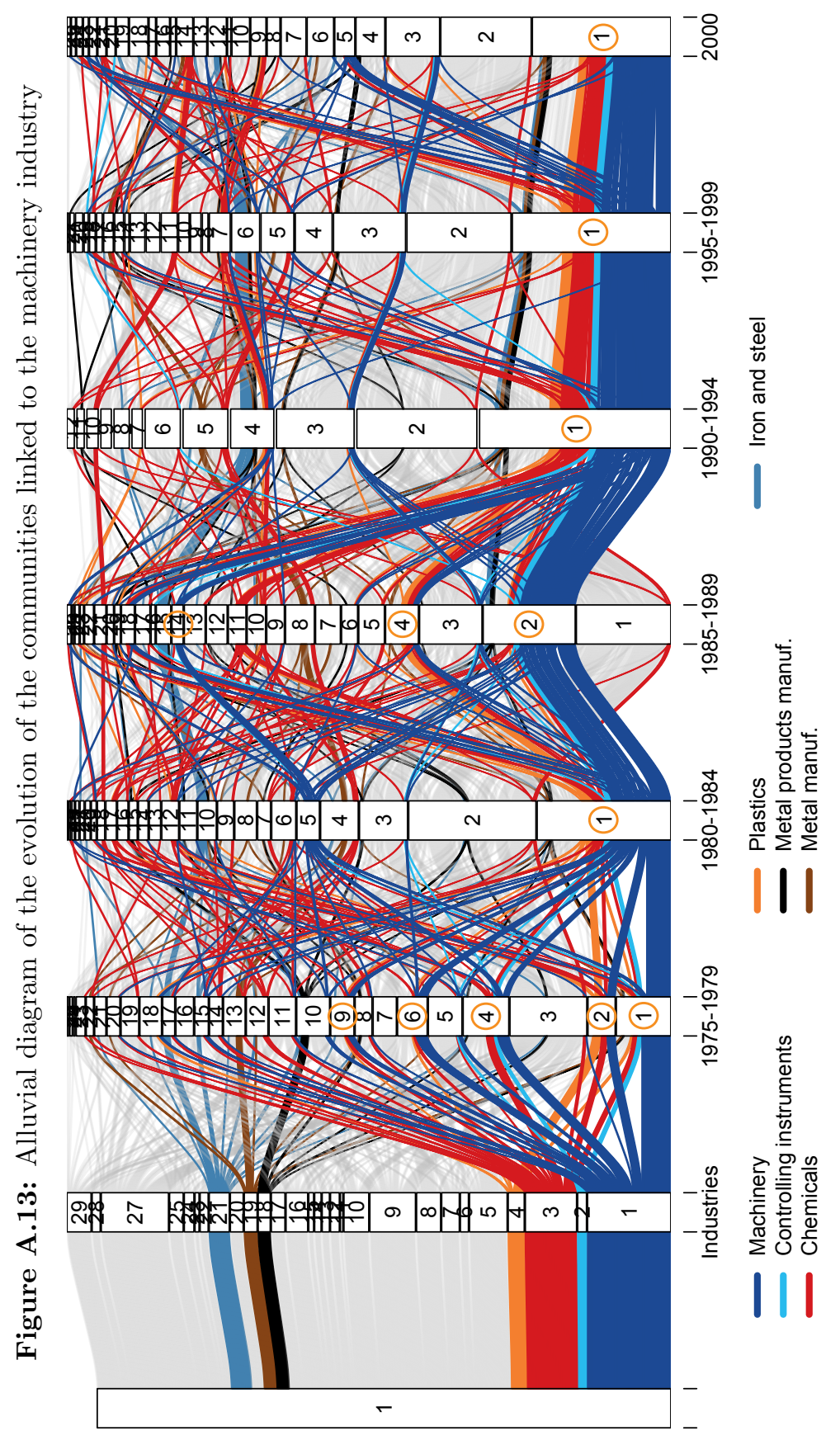

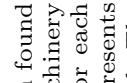



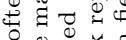

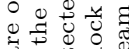

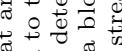

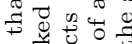

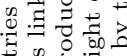

की



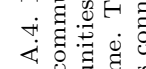

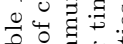

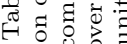

$\exists$ 击 $巳$

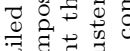

สี हี ठ

$\checkmark$.

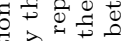

苞言出范

जี

ส 0 .

نे

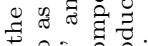

so on is 0 i :

$\exists$ 음 웜

ठํㅖ

교요

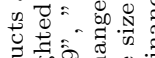

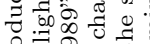



$0-\infty$ o

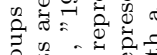

की

귱 $ᄋ$

क

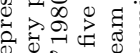



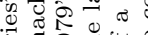

다의 궁



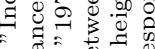

$\circ \stackrel{\Xi}{\circ} \circ$.

我



की

0000



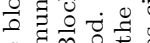

进范

o

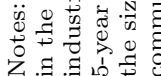




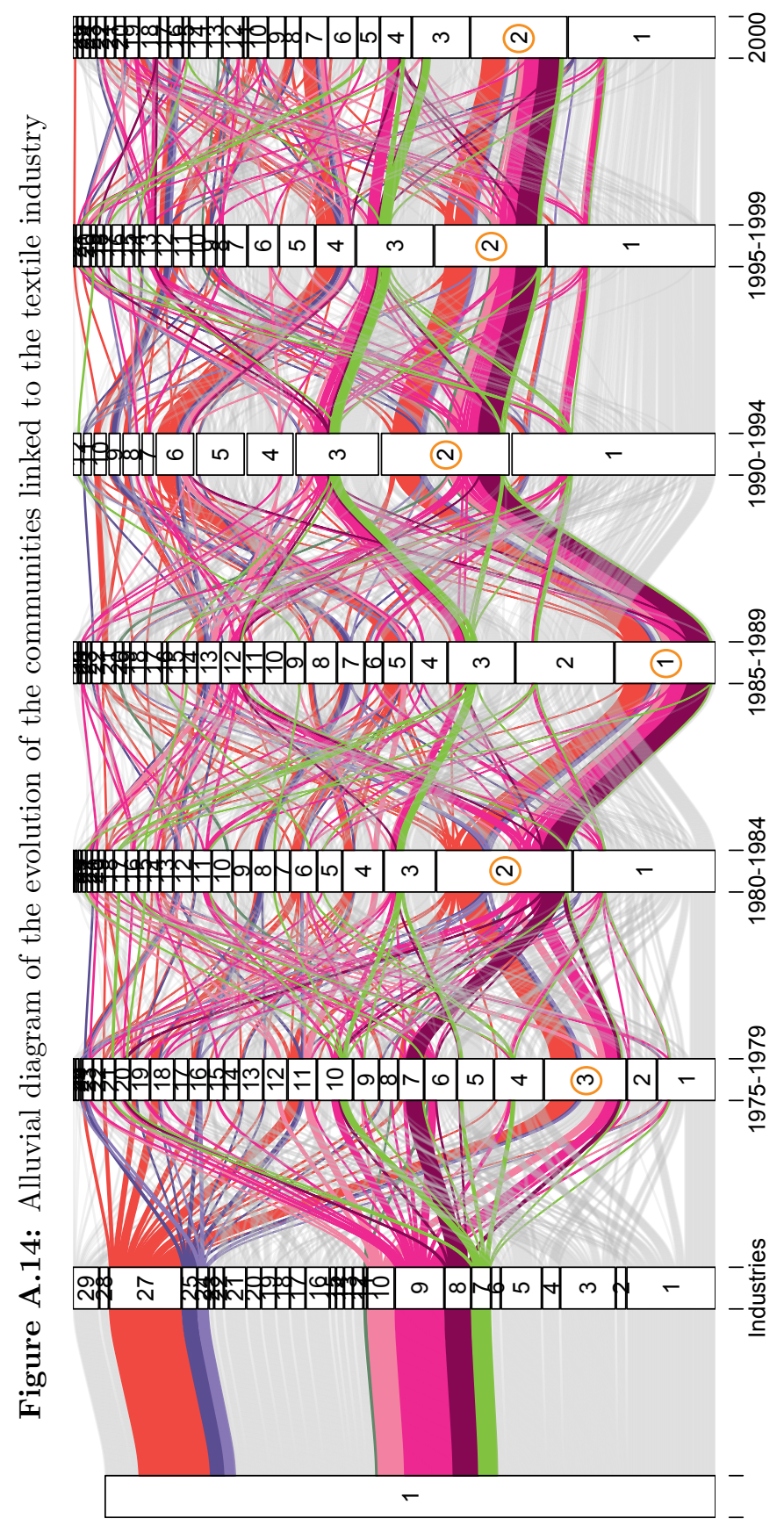

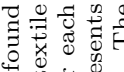

†

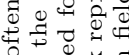

원웡

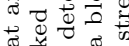

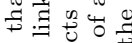

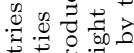

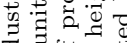

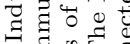

0
0
0
0
0
\pm
0
$\frac{0}{\pi}$
0
0
0
$\frac{\pi}{0}$
0
0
0
10
1

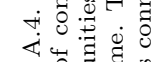

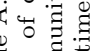

으몀.

.

द

$\stackrel{0}{\sigma} 00$

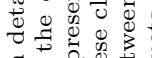

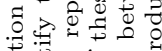

范㟧岇

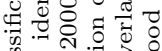

$\frac{\pi}{1} \circ=$

๑) สิ สี

on in 0

क

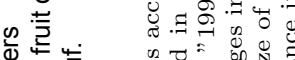

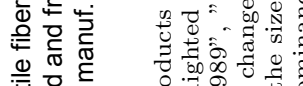

車

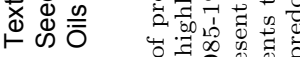

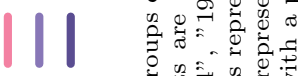

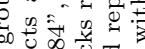

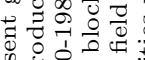

艹

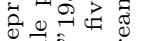

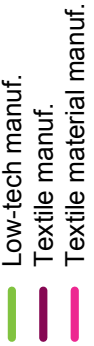

in $\begin{gathered}-10 \\ 0\end{gathered}$

0

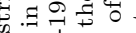

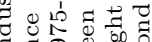

羯

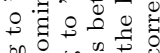

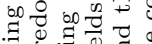

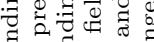

๙ 0 है

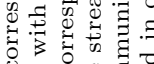

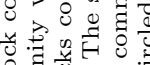

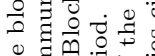

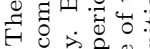

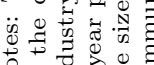

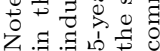




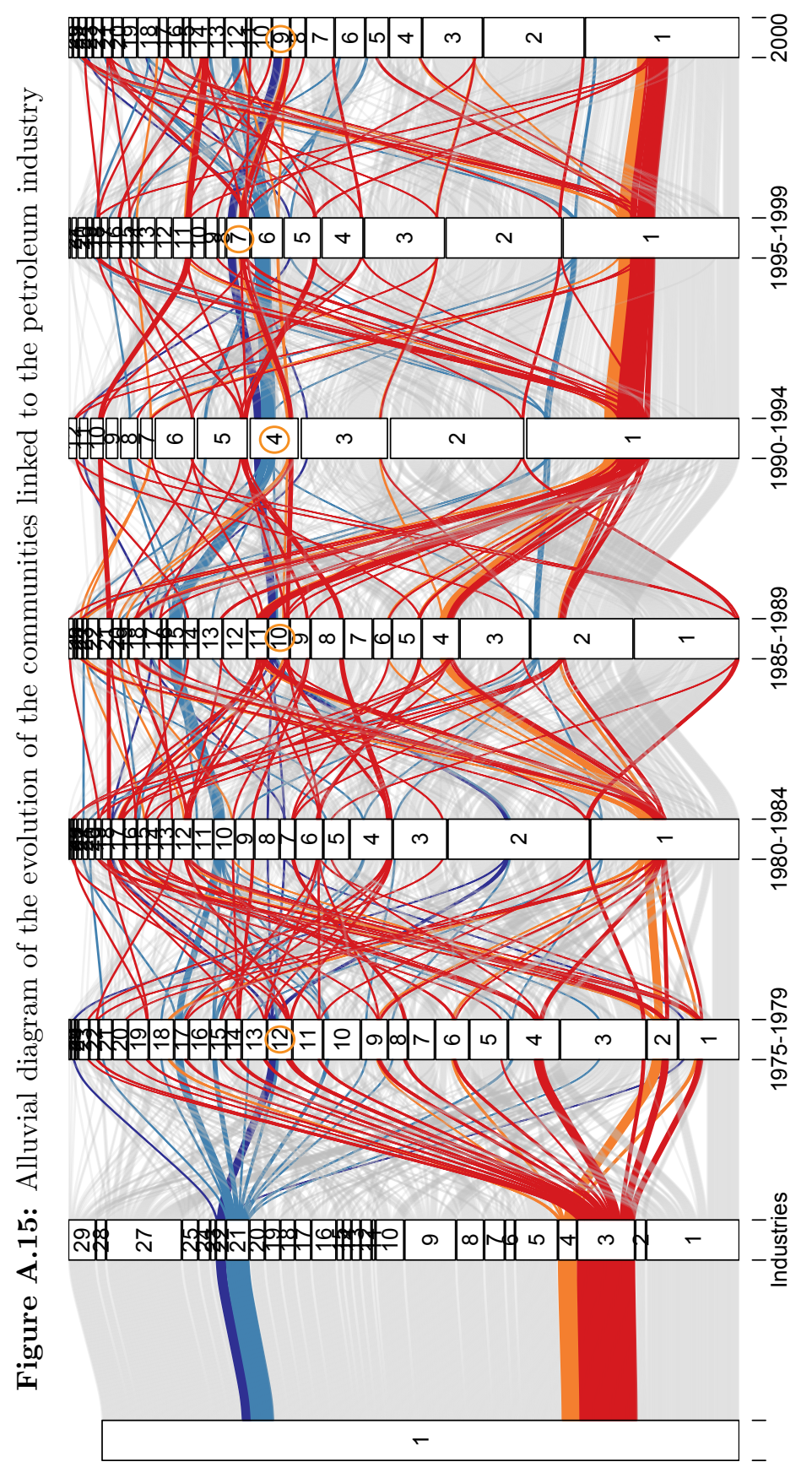

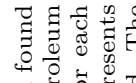

ஸ

屯ี

엄 売

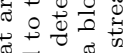

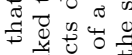

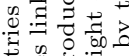

落

可嵌。

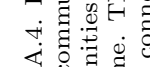

$\varangle{ }^{\circ} \Xi$

녕

स

$\exists$.

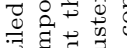

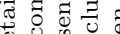

$\checkmark$ \&

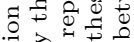

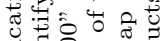

ज्ञ

$\approx 0.40$

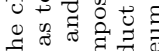

कo on is 000

范

일

ब

क

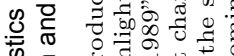

क

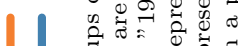

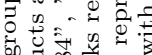

$+\exists \stackrel{0}{0} 0$

प्र

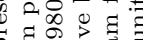

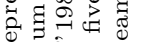

is

की

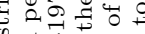

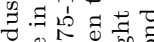

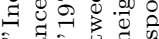

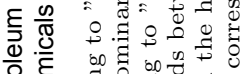

인

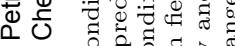

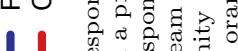

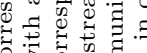

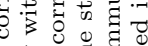

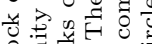

을

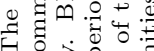

- 0 通

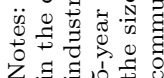




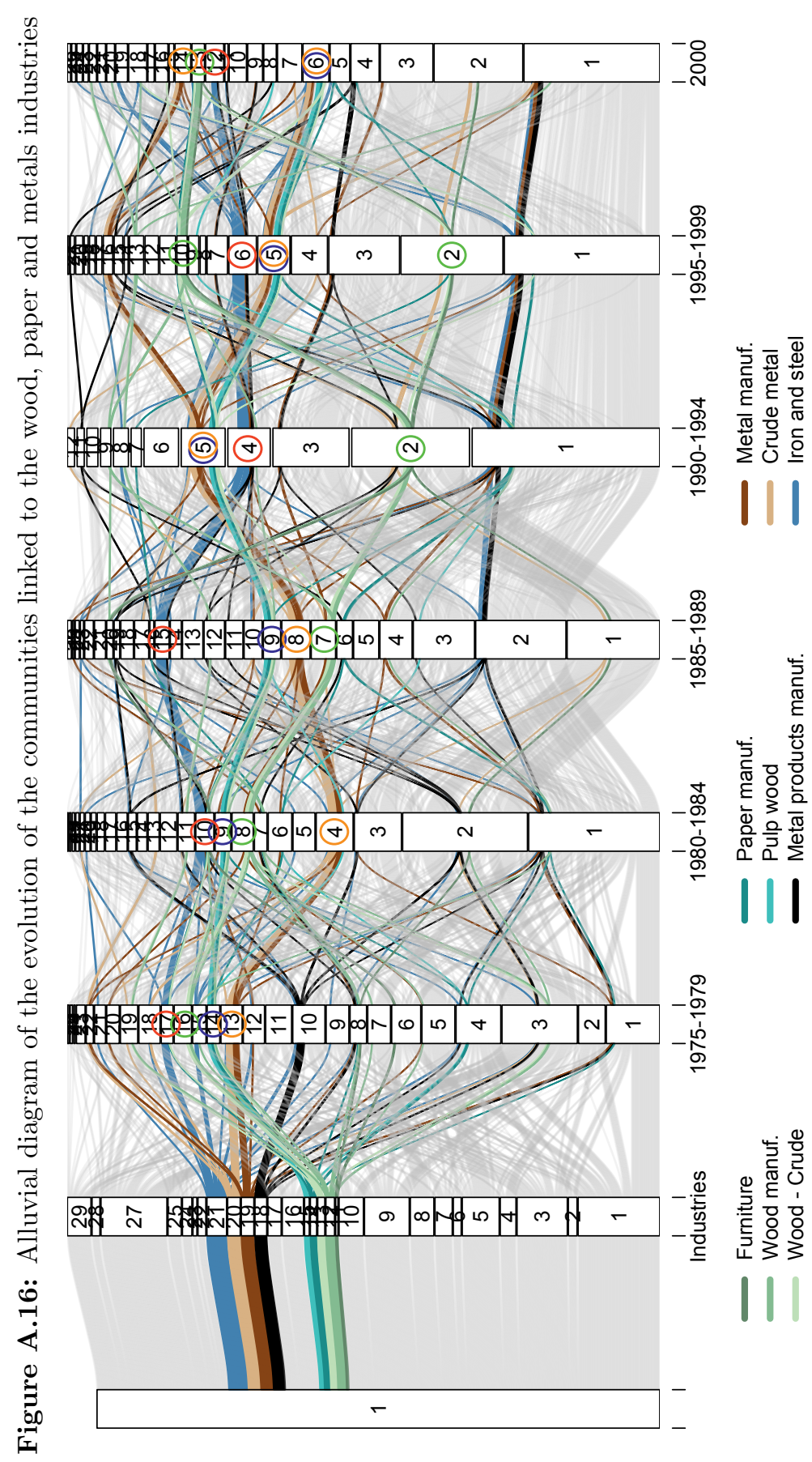

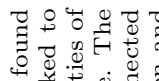

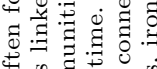

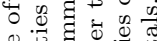

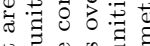

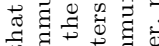

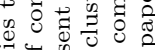

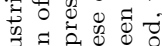

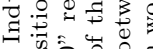

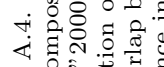

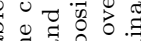

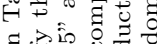

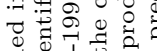

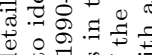

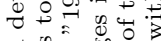

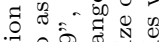

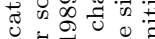

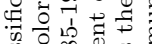

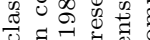

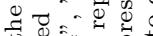

so $\begin{gathered}0 \\ \text { n }\end{gathered}$

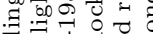

궁

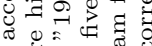

क సं

的向要

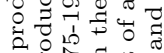

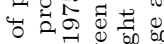

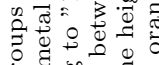

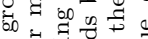

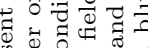

品命

至

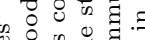

.

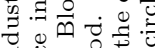

就

Z

$\circ: \exists: \mathbb{N}$

b :

$\exists: \exists 1+$

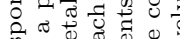

我

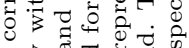

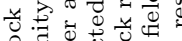

응 范总응

๑ छี

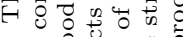

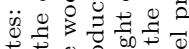

足. 
Figure A.17: Product overlap between communities across time (in \%)

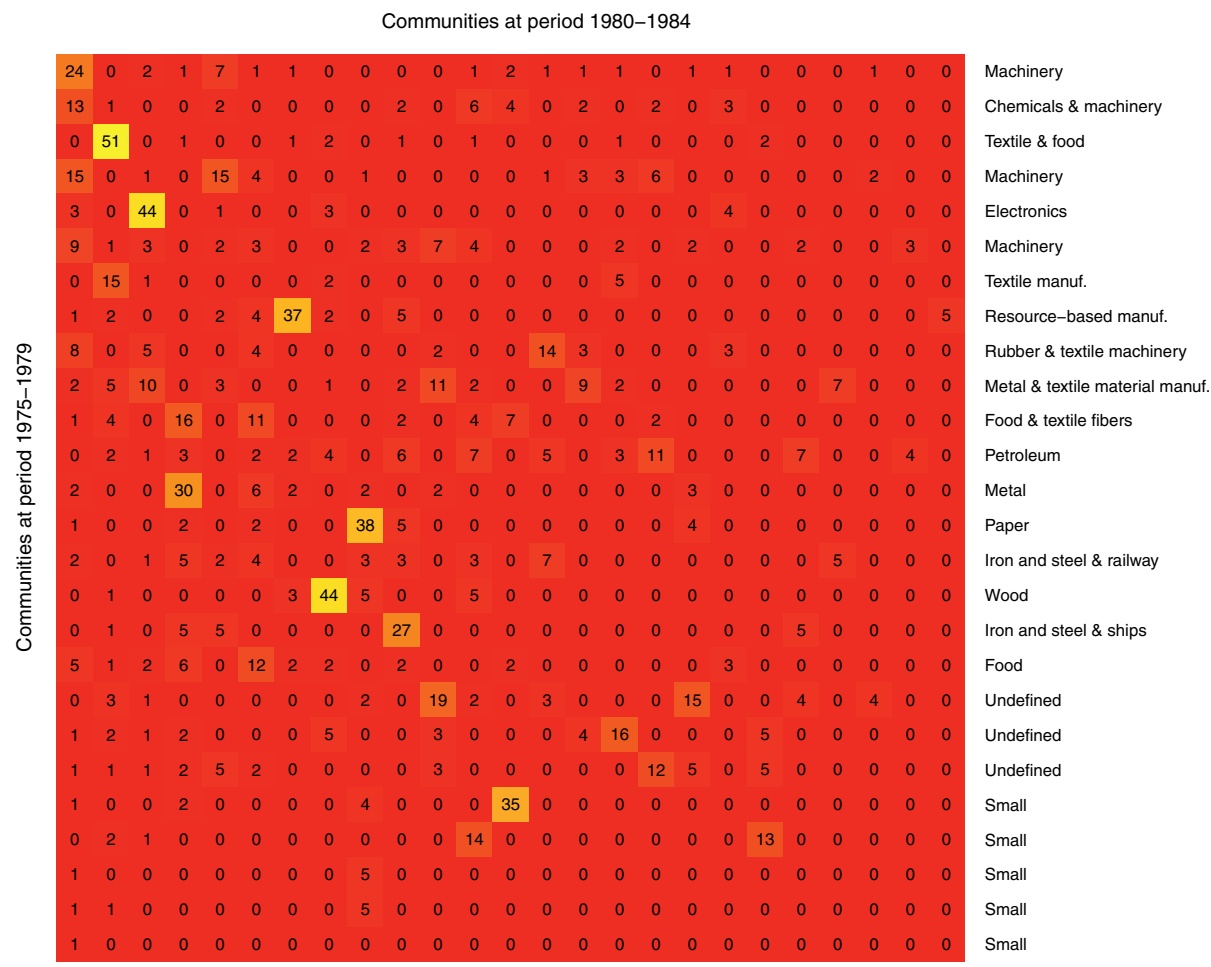

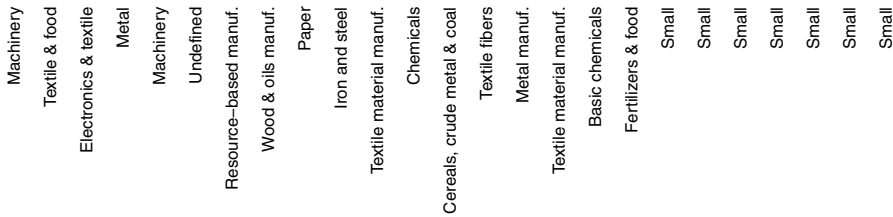


Communities at period 1985-1989

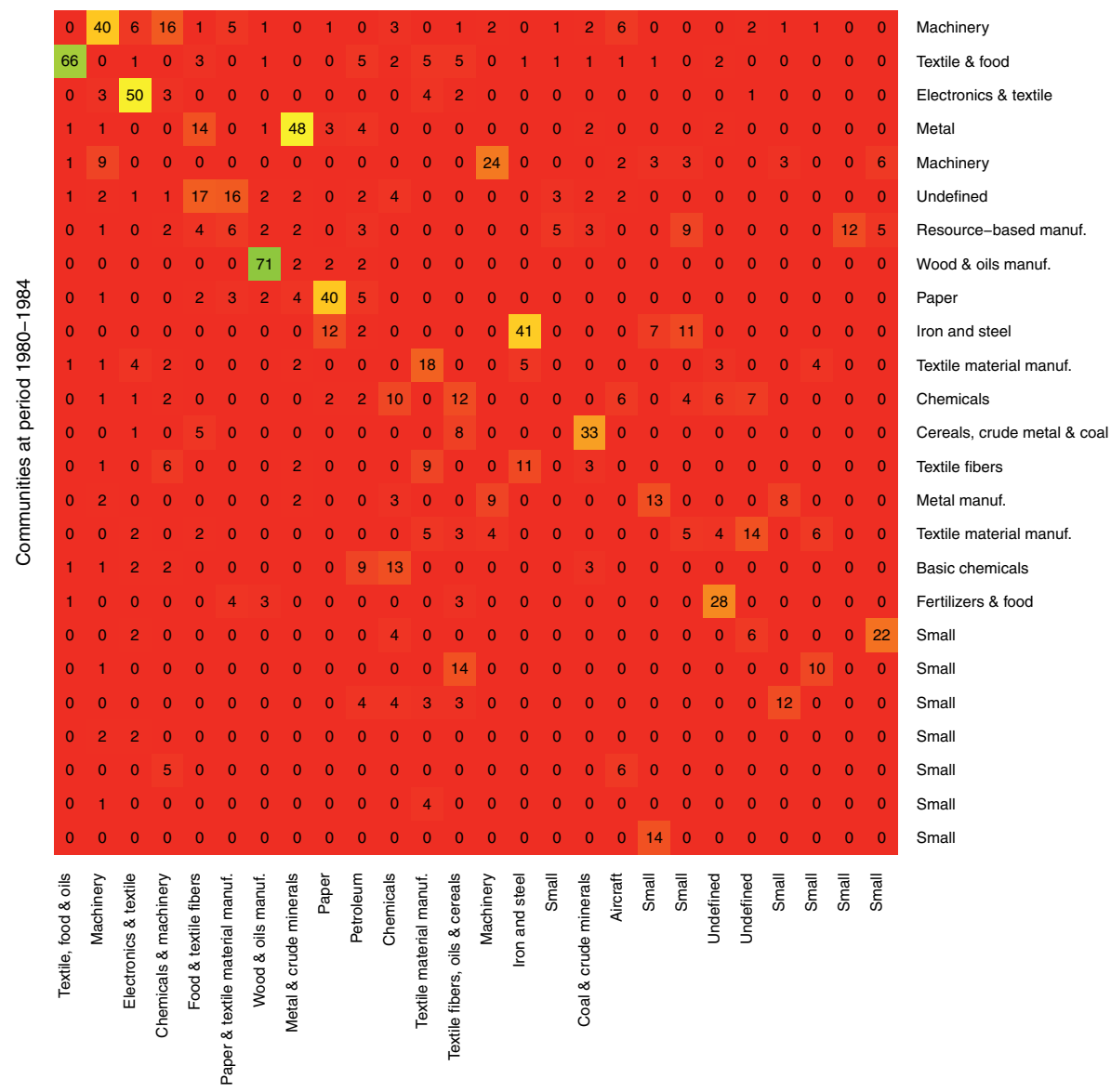


Communities at period 1990-1994

\begin{tabular}{|c|c|c|c|c|c|c|c|c|c|c|c|c|}
\hline 0 & 64 & 2 & 1 & 0 & 3 & 0 & 1 & 0 & 2 & 0 & 0 & Textile, food \& oils \\
\hline 42 & 0 & 1 & 1 & 0 & 1 & 0 & 0 & 0 & 0 & 0 & 3 & Machinery \\
\hline 4 & 3 & 50 & 0 & 0 & 0 & 0 & 0 & 0 & 0 & 0 & 2 & Electronics \& textile \\
\hline 12 & 0 & 5 & 1 & 1 & 0 & 0 & 3 & 2 & 0 & 0 & 0 & Chemicals \& machinery \\
\hline 2 & 0 & 0 & 0 & 1 & 41 & 7 & 0 & 0 & 0 & 2 & 0 & Food \& textile fibers \\
\hline 7 & 0 & 0 & 0 & 1 & 0 & 0 & 0 & 0 & 0 & 4 & 0 & Paper \& textile material manuf. \\
\hline 1 & 6 & 2 & 0 & 4 & 0 & 0 & 0 & 33 & 2 & 0 & 0 & Wood \& oils manuf. \\
\hline 1 & 3 & 0 & 1 & 33 & 3 & 2 & 0 & 0 & 0 & 0 & 2 & Metal \& crude minerals \\
\hline 2 & 0 & 0 & 3 & 20 & 0 & 0 & 2 & 0 & 0 & 0 & 3 & Paper \\
\hline 0 & 2 & 0 & 28 & 1 & 0 & 0 & 0 & 0 & 0 & 0 & 0 & Petroleum \\
\hline 5 & 1 & 0 & 3 & 0 & 3 & 9 & 2 & 0 & 0 & 0 & 0 & Chemicals \\
\hline 0 & 5 & 5 & 3 & 0 & 1 & 5 & 12 & 0 & 0 & 3 & 0 & Textile material manuf. \\
\hline 1 & 1 & 6 & 1 & 0 & 13 & 0 & 12 & 0 & 0 & 3 & 0 & Textile fibers, oils \& cereals \\
\hline 4 & 0 & 2 & 1 & 0 & 0 & 0 & 3 & 0 & 0 & 0 & 5 & Machinery \\
\hline 0 & 1 & 0 & 24 & 1 & 0 & 0 & 3 & 0 & 0 & 4 & 0 & Iron and steel \\
\hline 1 & 0 & 0 & 0 & 0 & 0 & 6 & 0 & 0 & 0 & 8 & 0 & Small \\
\hline 0 & 1 & 2 & 0 & 17 & 2 & 0 & 0 & 0 & 0 & 8 & 0 & Coal \& crude minerals \\
\hline 5 & 0 & 1 & 1 & 0 & 0 & 0 & 0 & 0 & 3 & 0 & 0 & Aircraft \\
\hline 1 & 1 & 1 & 3 & 0 & 0 & 0 & 0 & 0 & 0 & 0 & 0 & Small \\
\hline 0 & 3 & 0 & 3 & 0 & 0 & 0 & 0 & 5 & 0 & 0 & 0 & Small \\
\hline 0 & 0 & 0 & 0 & 0 & 2 & 0 & 6 & 0 & 56 & 0 & 0 & Undefined \\
\hline 1 & 0 & 4 & 2 & 2 & 2 & 0 & 0 & 0 & 0 & 5 & 0 & Undefined \\
\hline 1 & 0 & 0 & 2 & 0 & 0 & 6 & 0 & 0 & 0 & 0 & 0 & Small \\
\hline 1 & 0 & 1 & 2 & 0 & 0 & 6 & 0 & 0 & 0 & 0 & 0 & Small \\
\hline 0 & 0 & 0 & 0 & 0 & 0 & 7 & 0 & 0 & 0 & 0 & 0 & Small \\
\hline 1 & 0 & 0 & 5 & 0 & 0 & 0 & 0 & 0 & 0 & 0 & 0 & Small \\
\hline 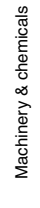 & 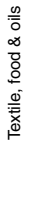 & 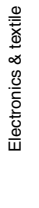 & 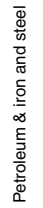 & 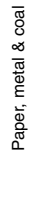 & 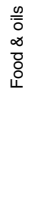 & 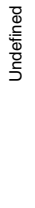 & 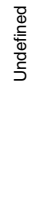 & 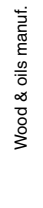 & 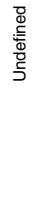 & 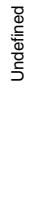 & 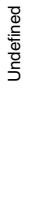 & \\
\hline
\end{tabular}


Communities at period 1995-1999

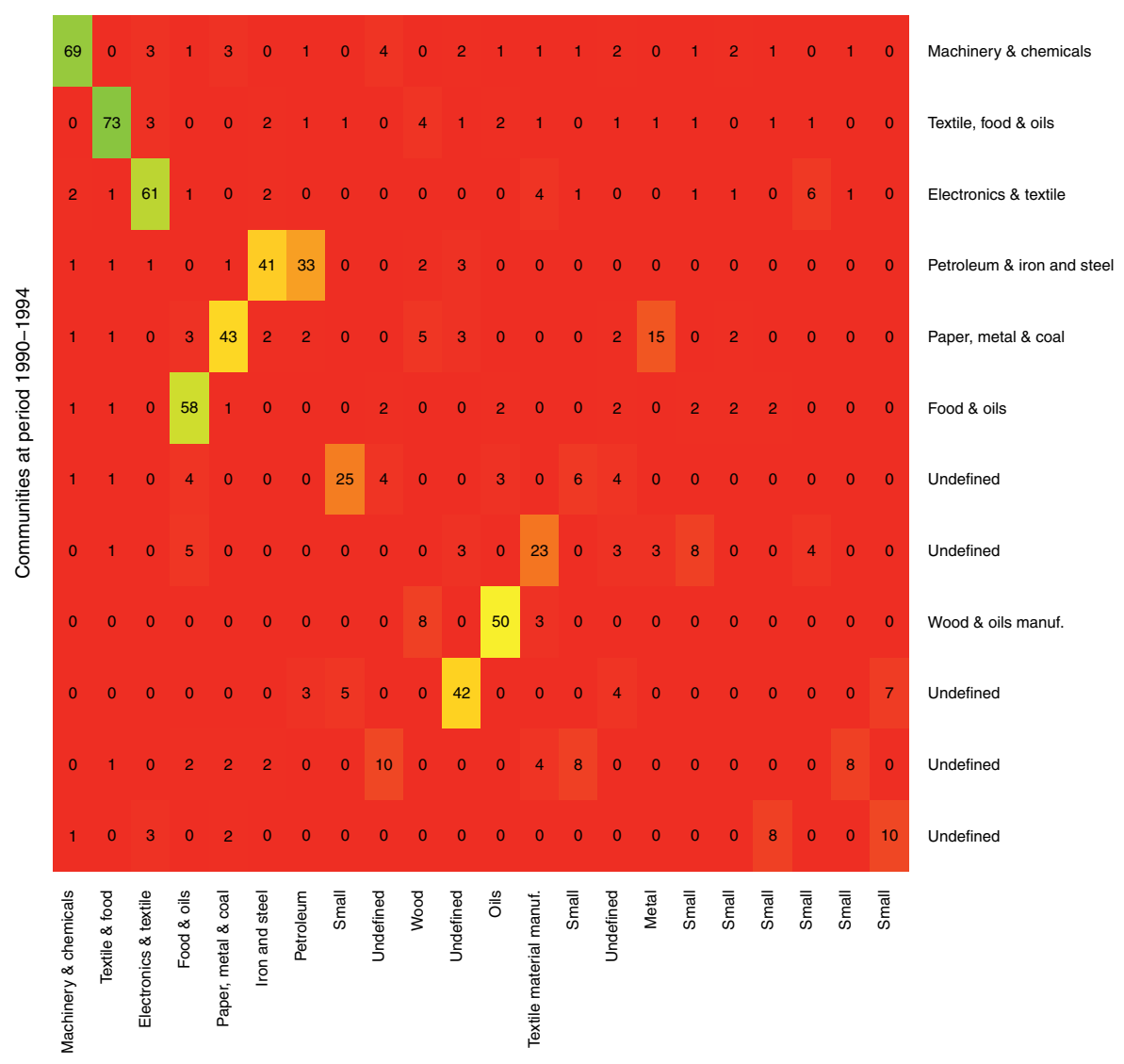


Communities at period 2000

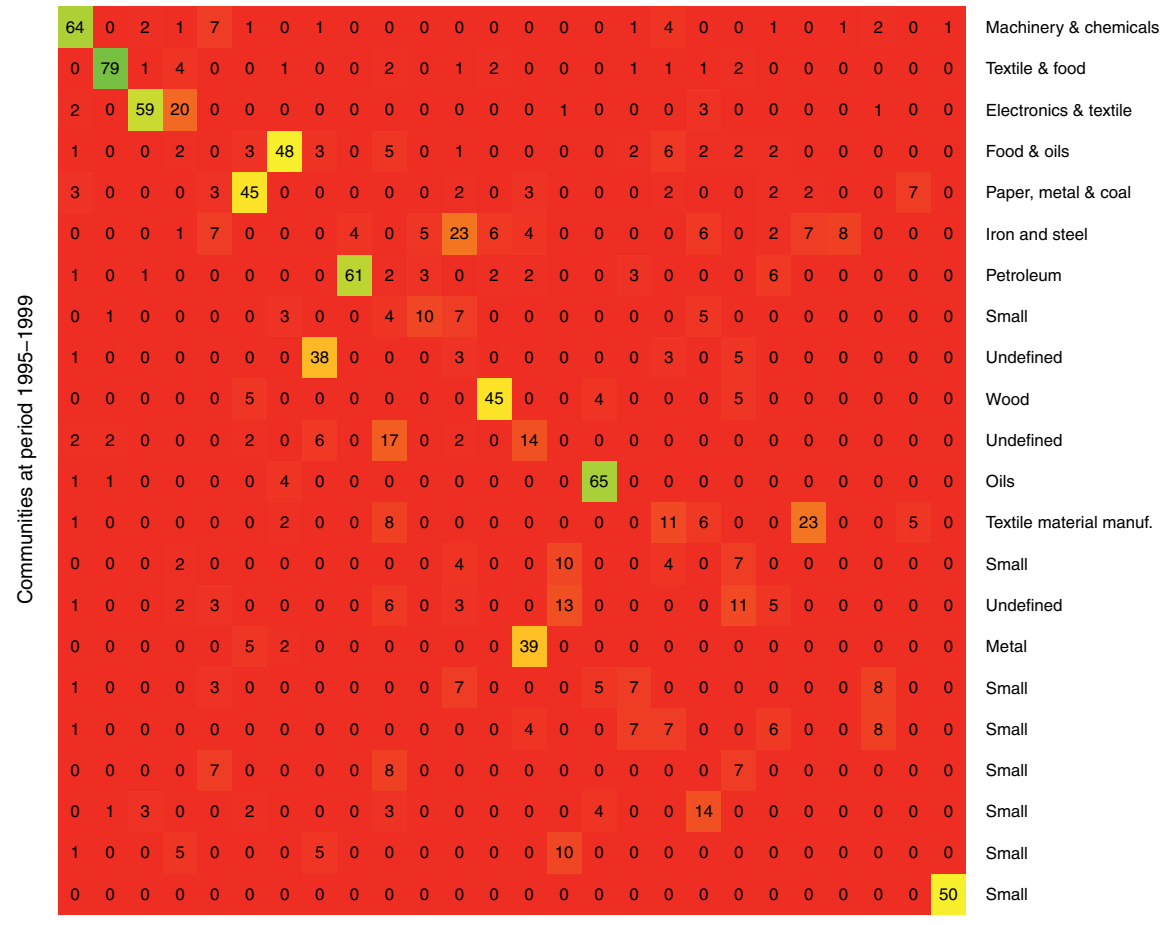

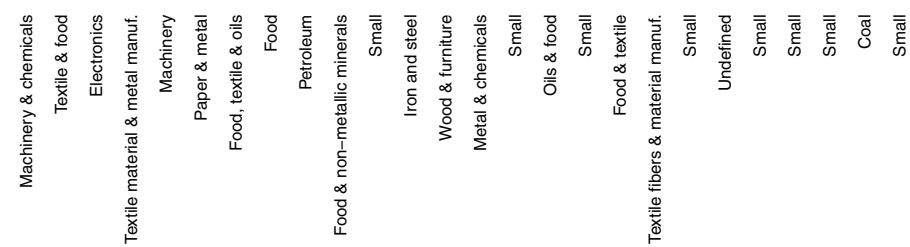


Figure A.22: Entropy of industry shares across communities

\begin{tabular}{|c|c|c|c|c|c|c|}
\hline 0.64 & 0.31 & 0.41 & 0.14 & 0.22 & 0.38 & Machinery \\
\hline 0.31 & 0.23 & 0.31 & 0.18 & 0.23 & 0.23 & Controlling instruments \\
\hline 0.83 & 0.81 & 0.79 & 0.48 & 0.58 & 0.66 & Chemicals \\
\hline 0.38 & 0.23 & 0.61 & 0.27 & 0.32 & 0.51 & Plastics \\
\hline 0.52 & 0.36 & 0.38 & 0.25 & 0.25 & 0.29 & Electronics \\
\hline 0.41 & 0.27 & 0.37 & 0.2 & 0.27 & 0.36 & Photography, optical \& watches \\
\hline 0.58 & 0.64 & 0.42 & 0.35 & 0.41 & 0.49 & Low-tech manuf. \\
\hline 0.36 & 0.04 & 0.12 & 0.14 & 0.2 & 0.21 & Textile manuf. \\
\hline 0.75 & 0.54 & 0.62 & 0.44 & 0.6 & 0.64 & Textile material manuf. \\
\hline 0.5 & 0.59 & 0.56 & 0.48 & 0.57 & 0.68 & Textile fibers \\
\hline 0.19 & 0.19 & 0.19 & 0 & 0.19 & 0.19 & Furniture \\
\hline 0.6 & 0.53 & 0.46 & 0.41 & 0.26 & 0.42 & Wood manuf. \\
\hline 0.43 & 0.34 & 0.28 & 0.29 & 0.43 & 0.44 & Wood - Crude \\
\hline 0.44 & 0.44 & 0.29 & 0.29 & 0.36 & 0.37 & Paper manuf. \\
\hline 0.14 & 0.26 & 0.14 & 0.14 & 0.14 & 0.14 & Pulp wood \\
\hline 0.66 & 0.71 & 0.78 & 0.57 & 0.52 & 0.7 & Non-metal mineral manuf. \\
\hline 0.63 & 0.69 & 0.62 & 0.48 & 0.59 & 0.62 & Crude non-metal mineral \\
\hline 0.36 & 0.55 & 0.57 & 0.45 & 0.53 & 0.5 & Metal products manuf. \\
\hline 0.48 & 0.53 & 0.43 & 0.36 & 0.53 & 0.47 & Metal manuf. \\
\hline 0.4 & 0.31 & 0.38 & 0.25 & 0.36 & 0.44 & Crude metal \\
\hline 0.63 & 0.56 & 0.45 & 0.32 & 0.34 & 0.66 & Iron and steel \\
\hline 0.19 & 0.37 & 0.15 & 0.19 & 0.19 & 0.19 & Petroleum \\
\hline 0.4 & 0.29 & 0 & 0.15 & 0.15 & 0.29 & Coal \\
\hline 0.54 & 0.4 & 0.49 & 0.5 & 0.47 & 0.59 & Seed and fruit oils \\
\hline 0.62 & 0.57 & 0.54 & 0.56 & 0.47 & 0.56 & Oils manuf. \\
\hline 0.64 & 0.48 & 0.56 & 0.49 & 0.5 & 0.62 & Food \\
\hline 0.65 & 0.43 & 0.52 & 0.45 & 0.59 & 0.45 & Beverages and tobacco \\
\hline 0.69 & 0.64 & 0.71 & 0.57 & 0.66 & 0.63 & Other \\
\hline 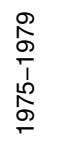 & 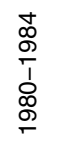 & 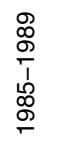 & 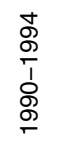 & 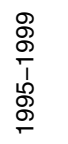 & ঃ & \\
\hline
\end{tabular}

Note: Industry shares correspond to the number of products in each community relative to the total number of products within the industry.

Table A.5: Leamer (1984) classification (pp. 62-63)

\begin{tabular}{lll}
\hline Id & Leamer classification & SITC Rev. 2 $(2$ digits $)$ \\
\hline 1 & Petroleum & 33 \\
2 & Raw materials & $27 ; 28 ; 32 ; 34 ; 35 ; 68$ \\
3 & Forest products & $24 ; 25 ; 63 ; 64$ \\
4 & Tropical agriculture & $05 ; 06 ; 07 ; 11 ; 23$ \\
5 & Animal products & $00 ; 01 ; 02 ; 03 ; 21 ; 29 ; 43 ; 94$ \\
6 & Cereals, etc. & $04 ; 08 ; 09 ; 12 ; 22 ; 26 ; 41 ; 42$ \\
7 & Labor intensive & $66 ; 82 ; 83 ; 84 ; 85 ; 89 ; 91 ; 93 ; 96$ \\
8 & Capital intensive & $61 ; 62 ; 65 ; 67 ; 69 ; 81$ \\
9 & Machinery & $71 ; 72 ; 73 ; 86 ; 95$ \\
10 & Chemicals & $51 ; 52 ; 53 ; 54 ; 55 ; 56 ; 57 ; 58 ; 59$ \\
\hline
\end{tabular}


Table A.6: Lall (2000) classification

\begin{tabular}{|c|c|c|}
\hline Id & Lall classification & SITC Rev. 2 (3 digits) \\
\hline 1 & Primary & $\begin{array}{l}001 ; 011 ; 022 ; 025 ; 034 ; 036 ; 041 ; 042 ; 043 ; 044 ; 045 ; 054 ; \\
057 ; 071 ; 072 ; 074 ; 075 ; 081 ; 091 ; 121 ; 211 ; 212 ; 222 ; 223 \text {; } 232 ; 244 ; 245 ; 246 ; 261 ; 263 ; 268 ; 271 ; 273 ; 274 ; 277 ; 278 ; \\
291 ; 292 ; 322 ; 333 ; 341 ; 681 ; 682 ; 683 ; 684 ; 685 ; 686 ; 687\end{array}$ \\
\hline 2 & Agro-based & $\begin{array}{l}012 ; 014 ; 023 ; 024 ; 035 ; 037 ; 046 ; 047 ; 048 ; 056 ; 058 ; 061 ; \\
062 ; 073 ; 098 ; 111 ; 112 ; 122 ; 233 ; 247 ; 248 ; 251 ; 264 ; 265 ; \\
269 ; 423 ; 424 ; 431 ; 621 ; 625 ; 628 ; 633 ; 634 ; 635 ; 641\end{array}$ \\
\hline 3 & Others resource-based & $\begin{array}{l}281 ; 282 ; 286 ; 287 ; 288 ; 289 ; 323 ; 334 ; 335 ; 411 ; 511 ; 514 ; \\
515 ; 516 ; 522 ; 523 ; 531 ; 532 ; 551 ; 592 ; 661 ; 662 ; 663 ; 664 ; \\
667 ; 688 ; 689\end{array}$ \\
\hline 4 & Textile (low-tech) & $\begin{array}{l}611 ; 612 ; 613 ; 651 ; 652 ; 654 ; 655 ; 656 ; 657 ; 658 ; 659 ; 831 ; \\
842 ; 843 ; 844 ; 845 ; 846 ; 847 ; 848 ; 851\end{array}$ \\
\hline 5 & Others low-tech & $\begin{array}{l}642 ; 665 ; 666 ; 673 ; 674 ; 675 ; 676 ; 677 ; 679 ; 691 ; 692 ; 693 ; \\
694 ; 695 ; 696 ; 697 ; 699 ; 821 ; 893 ; 894 ; 895 ; 897 ; 898 ; 899\end{array}$ \\
\hline 6 & $\begin{array}{l}\text { Medium-tech: Automo- } \\
\text { tive }\end{array}$ & $781 ; 782 ; 783 ; 784 ; 785$ \\
\hline 7 & Medium-tech: Process & $\begin{array}{l}266 ; 267 ; 512 ; 513 ; 533 ; 553 ; 554 ; 562 ; 572 ; 582 ; 583 ; 584 ; \\
585 ; 591 ; 598 ; 653 ; 671 ; 672 ; 678 ; 786 ; 791 ; 882\end{array}$ \\
\hline 8 & $\begin{array}{l}\text { Medium-tech: Engineer- } \\
\text { ing }\end{array}$ & $\begin{array}{l}711 ; 713 ; 714 ; 721 ; 722 ; 723 ; 724 ; 725 ; 726 ; 727 ; 728 ; 736 ; \\
737 ; 741 ; 742 ; 743 ; 744 ; 745 ; 749 ; 762 ; 763 ; 772 ; 773 ; 775 ; \\
793 ; 812 ; 872 ; 873 ; 884 ; 885 ; 951\end{array}$ \\
\hline 9 & $\begin{array}{l}\text { High-tech: Electronics } \\
\text { and electrical }\end{array}$ & $716 ; 718 ; 751 ; 752 ; 759 ; 761 ; 764 ; 771 ; 774 ; 776 ; 778$ \\
\hline 10 & Other high-tech & $524 ; 541 ; 712 ; 792 ; 871 ; 874 ; 881$ \\
\hline
\end{tabular}

\section{A.4 Robustness checks}

\section{A.4.1 Network reduction method}

When using the multi-scale backbone network reduction method, there are several ways to proceed to select the edges to keep and the ones to remove. One possibility is to keep an edge between two nodes $i$ and $j$ only if it is significant for either one of the two nodes. In other words, an edge between two nodes $i$ and $j$ can be kept if the p-value associated with this edge is inferior to the significance level for either one of the two nodes. This is the condition used in the original paper of Serrano et al. (2009). Another possibility to reduce the density of the network is by only keeping an edge between $i$ and $j$ if it is significant for both nodes.

The inconsistency in the network reduction method has more to do with the determination of the optimal significance level than with the condition to keep or remove the edges according to the p-values of each node (although the choice of the condition obviously leads to different outcomes as well). $\leftarrow$ I should have a look at the backbone when using the first condition and the second optimal significance level (that is less strict than the first (i.e. higher), and therefore remove less edges) and compare the community structure I obtain with the same first condition and two different significance levels. 
In order to reduce the density of the network, I establish an optimal threshold which corresponds to the lowest significance level, that is the one leading to the lowest network density, while maintaining the network connected. The determination of the optimal significance level depends on the choice between the two possibilities exposed above. Under the first condition, the optimal significance level consists in choosing the lowest p-value of each edge. The optimal significance level corresponds to the maximum value among these p-values. By construction, there exists situations in which the set of edges kept are not the most significant ones for a given node $i$ (that is the ones with the lowest alpha). The edge is still part of the network only because it corresponds to the adjacent node's most significant edges. These inconsistencies are the result of the asymmetry in the edges significance between adjacent nodes. This problem is avoided in the second case. Under the second condition, the optimal significance level is determined by first identifying the p-value of the most significant edge of each node in the network. The optimal significance level is equal to the maximum value among these p-values. While under this method, at least the most significant edge of the network can be kept, the network density cannot be reduced as much, which results in a less precise community structure. The differences in the density of the network resulting from these two methods leads to different community structures. It seems that the first method enables the community structure to be more precise than the first one. This shows that there is a clear trade-off between keeping the significant edges and obtaining a precise and relevant community structure.

Another limit of this method is that it does not deal well with network for which nodes have different levels of weight heterogeneity since the method is constructed for network with high levels of weight heterogeneity at the node level. 


\section{Appendix B}

\section{Appendix to Chapter 3}

\section{B.1 Dataset}

Table B.1: Variables

\begin{tabular}{|c|c|c|c|}
\hline Variable & Definition & Source & Period \\
\hline \multirow[t]{2}{*}{$\begin{array}{l}\text { GDP per } \\
\text { capita growth }\end{array}$} & See methodology in section 3.3 .1 & 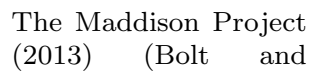 & \multirow[t]{2}{*}{$\begin{array}{l}1950-2010 \\
\text { (yearly) }\end{array}$} \\
\hline & & Van Zanden, 2014) & \\
\hline $\begin{array}{l}\text { Structural } \\
\text { change }\end{array}$ & See section 3.3 .2 & Feenstra et al. (2005) & $\begin{array}{l}1962-2000 \\
\text { (yearly) }\end{array}$ \\
\hline
\end{tabular}

\section{B.2 Static community structure of the manufac- turing exports}

I identify the static community structure of manufacturing products as described below ${ }^{1}$ I first construct a static bipartite export network, $W_{c, p}$, as follows:

$$
\tilde{W}_{c, p}=\sum_{t} W_{c, p, t}
$$

where $W_{c, p, t}$ corresponds to the value of product $p$ exported by country $c$ at time $t$.

The unweighted bipartite network becomes:

$$
\tilde{M}_{c p}= \begin{cases}1, & \text { if } R \tilde{C} A_{c p}>1 . \\ 0, & \text { otherwise. }\end{cases}
$$

\footnotetext{
${ }^{1}$ The manufacturing sector corresponds to 513 products.
} 
where $R \tilde{C} A_{c p}$ corresponds to the revealed comparative advantage of country $c$ in product $p$ over the period of analysis (1962-2000).

The static product space is defined as:

$$
\tilde{P}_{p p^{\prime}}=\frac{\sum_{c} \tilde{M}_{c p} \tilde{M}_{c p^{\prime}}}{\max \left\{\sum_{c} \tilde{M}_{c p}, \sum_{c} \tilde{M}_{c p^{\prime}}\right\}}
$$

I then extract the backbone of the static product space $\tilde{P}_{p p^{\prime}}$ (see Table B.2) and subset the network to account only for manufacturing products and apply Infomap algorithm.

Table B.2: Network statistics of the product space aggregate (1962-2000) reduced using Serrano (2009)'s multiscale backbone technique

\begin{tabular}{lccccc}
\hline & $\% \mathrm{TW}$ & $\% \mathrm{~N}$ & $\% \mathrm{E}$ & $\mathrm{D}(\%)$ & $\mathrm{C}$ \\
\hline 1 & 100.00 & 100.00 & 100.00 & 93.17 & 1.00 \\
0.2 & 35.89 & 100.00 & 19.05 & 17.75 & 1.00 \\
0.09258 & 6.55 & 100.00 & 2.78 & 2.59 & 1.00 \\
0.05 & 1.80 & 66.67 & 0.67 & 0.63 & 279.00 \\
0.01 & 0.12 & 13.28 & 0.04 & 0.03 & 706.00 \\
\hline
\end{tabular}

Edge removed if weight $<\alpha$; TW (\%), the percentage of total weights left; $\mathrm{N}(\%)$, the percentage of nodes left; $\mathrm{E}(\%)$, the percentage of edges left; D, the density of the network; $\mathrm{C}$, the number of components. The third row corresponds to the optimal threshold.

As shown in Table B.4, I obtain 17 communities of which 8 contain at least 10 products (community id 1-8). I analyze the effect of structural change associated to these 8 communities (470 products), which correspond to more than $90 \%$ of the total of manufacturing products. I label each community according to the type of product (based on SITC) they include as described in Table B.3. 
Table B.3: Results of the static community structure: number of products in each community by SITC

\begin{tabular}{c|l|l}
\hline $\begin{array}{c}\text { Community } \\
\text { id }\end{array}$ & Description & Label \\
\hline 1 & Machinery, controlling instruments and chem- & Machinery \\
& icals (mostly plastics) & \\
2 & Electronics and textile (fabric) & Electronics \\
3 & Textile (garment) & Textile \\
4 & Iron and steel & Iron and steel \\
5 & Miscellaneous natural resource-based manu- & Natural resources-based \\
& facturing & Chemicals \\
6 & Organic chemicals & Machinery II \\
7 & Machinery and metal-based manufacturing & Wood \\
\hline 8 & Wood & \\
\hline
\end{tabular}


Table B.4: Results of the static community structure: number of products in each community by SITC

\begin{tabular}{|c|c|c|c|c|c|c|c|c|c|c|c|c|c|c|c|c|c|}
\hline \multirow{2}{*}{ SITC } & \multicolumn{17}{|c|}{ Community id } \\
\hline & 1 & 2 & 3 & 4 & 5 & 6 & 7 & 8 & 9 & 10 & 11 & 12 & 13 & 14 & 15 & 16 & 17 \\
\hline 5 & 31 & 3 & 5 & 7 & 7 & 26 & 1 & 0 & 0 & 8 & 0 & 3 & 0 & 0 & 1 & 2 & 0 \\
\hline 51 & 2 & 1 & 0 & 2 & 0 & 13 & 0 & 0 & 0 & 0 & 0 & 1 & 0 & 0 & 1 & 2 & 0 \\
\hline 52 & 3 & 0 & 0 & 2 & 1 & 0 & 0 & 0 & 0 & 4 & 0 & 1 & 0 & 0 & 0 & 0 & 0 \\
\hline 53 & 4 & 0 & 2 & 0 & 1 & 1 & 0 & 0 & 0 & 0 & 0 & 0 & 0 & 0 & 0 & 0 & 0 \\
\hline 54 & 2 & 0 & 0 & 0 & 2 & 3 & 0 & 0 & 0 & 0 & 0 & 0 & 0 & 0 & 0 & 0 & 0 \\
\hline 55 & 0 & 0 & 2 & 0 & 1 & 3 & 0 & 0 & 0 & 0 & 0 & 0 & 0 & 0 & 0 & 0 & 0 \\
\hline 56 & 1 & 0 & 1 & 0 & 0 & 0 & 0 & 0 & 0 & 2 & 0 & 0 & 0 & 0 & 0 & 0 & 0 \\
\hline 57 & 0 & 1 & 0 & 0 & 0 & 0 & 0 & 0 & 0 & 2 & 0 & 0 & 0 & 0 & 0 & 0 & 0 \\
\hline 58 & 15 & 1 & 0 & 3 & 2 & 1 & 0 & 0 & 0 & 0 & 0 & 1 & 0 & 0 & 0 & 0 & 0 \\
\hline 59 & 4 & 0 & 0 & 0 & 0 & 5 & 1 & 0 & 0 & 0 & 0 & 0 & 0 & 0 & 0 & 0 & 0 \\
\hline 6 & 35 & 23 & 33 & 27 & 16 & 2 & 4 & 11 & 6 & 0 & 3 & 4 & 4 & 3 & 2 & 0 & 1 \\
\hline 61 & 0 & 0 & 8 & 0 & 0 & 1 & 0 & 0 & 1 & 0 & 0 & 0 & 0 & 0 & 0 & 0 & 1 \\
\hline 62 & 1 & 1 & 0 & 1 & 1 & 0 & 0 & 0 & 0 & 0 & 0 & 0 & 2 & 3 & 0 & 0 & 0 \\
\hline 63 & 1 & 0 & 1 & 0 & 0 & 0 & 0 & 8 & 0 & 0 & 0 & 0 & 1 & 0 & 0 & 0 & 0 \\
\hline 64 & 6 & 0 & 1 & 0 & 4 & 0 & 0 & 2 & 0 & 0 & 0 & 0 & 0 & 0 & 0 & 0 & 0 \\
\hline 65 & 10 & 12 & 18 & 0 & 3 & 0 & 0 & 0 & 1 & 0 & 2 & 3 & 0 & 0 & 0 & 0 & 0 \\
\hline 66 & 10 & 6 & 5 & 2 & 3 & 0 & 2 & 0 & 1 & 0 & 1 & 1 & 1 & 0 & 0 & 0 & 0 \\
\hline 67 & 3 & 1 & 0 & 19 & 0 & 0 & 0 & 0 & 2 & 0 & 0 & 0 & 0 & 0 & 0 & 0 & 0 \\
\hline 69 & 4 & 3 & 0 & 5 & 5 & 1 & 2 & 1 & 1 & 0 & 0 & 0 & 0 & 0 & 2 & 0 & 0 \\
\hline 7 & 94 & 43 & 0 & 8 & 0 & 0 & 9 & 0 & 1 & 0 & 1 & 0 & 1 & 0 & 0 & 0 & 0 \\
\hline 71 & 15 & 1 & 0 & 3 & 0 & 0 & 0 & 0 & 0 & 0 & 0 & 0 & 0 & 0 & 0 & 0 & 0 \\
\hline 72 & 24 & 1 & 0 & 0 & 0 & 0 & 3 & 0 & 0 & 0 & 0 & 0 & 0 & 0 & 0 & 0 & 0 \\
\hline 73 & 8 & 0 & 0 & 0 & 0 & 0 & 0 & 0 & 0 & 0 & 0 & 0 & 0 & 0 & 0 & 0 & 0 \\
\hline 74 & 20 & 2 & 0 & 0 & 0 & 0 & 3 & 0 & 1 & 0 & 0 & 0 & 0 & 0 & 0 & 0 & 0 \\
\hline 75 & 2 & 8 & 0 & 0 & 0 & 0 & 0 & 0 & 0 & 0 & 0 & 0 & 0 & 0 & 0 & 0 & 0 \\
\hline 76 & 0 & 12 & 0 & 0 & 0 & 0 & 0 & 0 & 0 & 0 & 0 & 0 & 0 & 0 & 0 & 0 & 0 \\
\hline 77 & 6 & 17 & 0 & 1 & 0 & 0 & 0 & 0 & 0 & 0 & 1 & 0 & 0 & 0 & 0 & 0 & 0 \\
\hline 78 & 8 & 2 & 0 & 0 & 0 & 0 & 2 & 0 & 0 & 0 & 0 & 0 & 1 & 0 & 0 & 0 & 0 \\
\hline 79 & 11 & 0 & 0 & 4 & 0 & 0 & 1 & 0 & 0 & 0 & 0 & 0 & 0 & 0 & 0 & 0 & 0 \\
\hline 8 & 16 & 24 & 30 & 0 & 6 & 2 & 3 & 4 & 1 & 0 & 1 & 0 & 0 & 0 & 0 & 0 & 1 \\
\hline 81 & 1 & 0 & 1 & 0 & 0 & 0 & 1 & 0 & 0 & 0 & 0 & 0 & 0 & 0 & 0 & 0 & 0 \\
\hline 82 & 0 & 0 & 0 & 0 & 0 & 0 & 1 & 2 & 0 & 0 & 0 & 0 & 0 & 0 & 0 & 0 & 0 \\
\hline 83 & 0 & 0 & 1 & 0 & 0 & 0 & 0 & 0 & 0 & 0 & 0 & 0 & 0 & 0 & 0 & 0 & 0 \\
\hline 84 & 0 & 3 & 24 & 0 & 0 & 0 & 0 & 0 & 0 & 0 & 0 & 0 & 0 & 0 & 0 & 0 & 1 \\
\hline 85 & 0 & 0 & 1 & 0 & 0 & 0 & 0 & 0 & 0 & 0 & 0 & 0 & 0 & 0 & 0 & 0 & 0 \\
\hline 86 & 0 & 0 & 0 & 0 & 0 & 0 & 0 & 0 & 0 & 0 & 0 & 0 & 0 & 0 & 0 & 0 & 0 \\
\hline 87 & 9 & 2 & 0 & 0 & 0 & 0 & 0 & 0 & 0 & 0 & 0 & 0 & 0 & 0 & 0 & 0 & 0 \\
\hline 88 & 4 & 5 & 0 & 0 & 0 & 0 & 0 & 0 & 1 & 0 & 0 & 0 & 0 & 0 & 0 & 0 & 0 \\
\hline 89 & 2 & 14 & 3 & 0 & 6 & 2 & 1 & 2 & 0 & 0 & 1 & 0 & 0 & 0 & 0 & 0 & 0 \\
\hline Total & 176 & 93 & 68 & 42 & 29 & 30 & 17 & 15 & 8 & 8 & 5 & 7 & 5 & 3 & 3 & 2 & 2 \\
\hline
\end{tabular}




\section{B.3 Collinearity Diagnostics}

Figure B.1: Correlation coefficients

(a) Export value

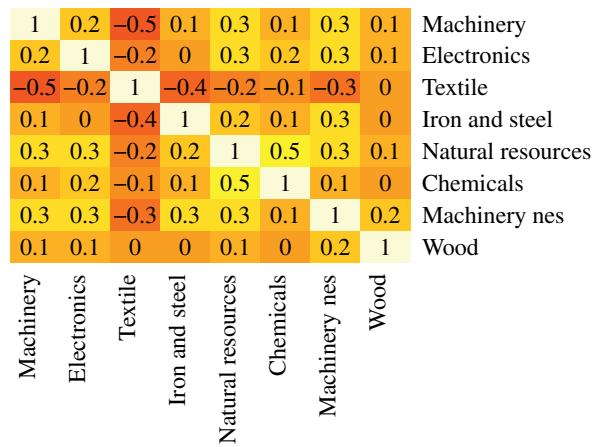

(b) Diversity

Notes: In this figure, the values contained in the correlation coefficient matrix are represented as colors. Variables are in $\log$.

Variance inflation factors are calculated in the following way:

$$
\operatorname{VIF} F_{k}=\frac{\operatorname{Var}\left(\hat{\beta}_{k}\right)}{\operatorname{Var}\left(\hat{\beta}_{k}\right)_{\min }}=\frac{\frac{\sigma^{2}}{\sum_{i=1}^{n}\left(x_{i k}-\bar{x}_{k}\right)^{2}}}{\frac{\sigma^{2}}{\sum_{i=1}^{n}\left(x_{i k}-\bar{x}_{k}\right)^{2}} \frac{1}{1-R_{k}^{2}}}=\frac{1}{1-R_{k}^{2}}
$$

where $\operatorname{Var}\left(\hat{\beta}_{k}\right)_{\min }$ corresponds to the variance of the coefficient $\hat{\beta}_{k}$ estimated with no other explanatory variables and $\operatorname{Var}\left(\hat{\beta}_{k}\right)$ the variance of this same coefficient estimated with other explanatory variables. $R_{k}^{2}$ is the value of the $R^{2}$ obtained by regressing the $k^{\text {th }}$ explanatory variable on the remaining variables. The higher the variance of the $k^{\text {th }}$ explanatory variable explained by the remaining variables, the greater the multicollinearity problem. 
Table B.5: Variance inflation factor tests

\begin{tabular}{lcc}
\hline \multirow{2}{*}{ Variable } & \multicolumn{2}{c}{ VIF } \\
\cline { 2 - 3 } & $\begin{array}{c}\text { Export } \\
\text { value }\end{array}$ & $\begin{array}{c}\text { Export } \\
\text { diversity }\end{array}$ \\
\hline Machinery & 1.76 & 6.15 \\
Electronics & 1.25 & 3.60 \\
Textile & 1.71 & 2.26 \\
Iron and steel & 1.33 & 3.22 \\
Natural Resources-based & 1.68 & 4.39 \\
Chemicals & 1.27 & 2.69 \\
Machinery nes & 1.57 & 4.09 \\
Wood & 1.06 & 2.20 \\
\hline Mean VIF & 1.45 & 3.57 \\
\hline
\end{tabular}

Note: Variables are in log.

\section{B.4 Tests for the choice of the model}

\section{B.4.1 Testing the distribution of the hazard rate of waiting times}

The LR tests are used to evaluate the goodness of fit of the Semi-Markov model and in particular the distribution of the hazard rate of waiting times. The statistic of the test and its asymptotic behavior are as follows:

$$
L R S=-2 \log \frac{L_{0}}{L_{1}} \rightarrow \chi^{2}(d f)
$$

Where $L_{0}$ is the likelihood of the reduced model (the null hypothesis) and $L_{1}$ is the likelihood of the full model (the alternative hypothesis), $d f$ is the difference in the degrees of freedom between the two models. In this setting, the null hypothesis is a model in which parameters are estimated assuming an exponential distribution for the transition $2 \rightarrow 3$ and a Weibull distribution of waiting times for the rest, and the alternative hypothesis is a model parameters are estimated assuming a Weibull distribution of waiting times for all transitions. According to the results, presented in table B.6. the null hypothesis cannot be rejected for any year lag of the explicative variables. 
Table B.6: Likelihood-ratio tests for different number of lags of the economic structure variables

\begin{tabular}{cc}
\hline LRS & $\mathrm{p}$-value \\
\hline-0.375 & 1.000 \\
\hline
\end{tabular}

\section{B.4.2 Testing the number of the lag of the economic struc- ture variables}

The Akaike Information Criterion (AIC) is used to select the model that best fits the data in terms of the number of lags of the economic structure variables. This criterion is based on information theory and measures the relative information lost by a given model to reproduce an unknown process (which generates the data). The preferred model is the one that minimized the information loss (i.e. the AIC). It is calculated as follows:

$$
A I C=2 k-2 \ln (\hat{L})
$$

with $\ln (\hat{L})$ the maximum of the log-likelihood function for the estimated model.

This criterion evaluates the trade-off between goodness of fit according to the maximum of likelihood function and overfitting of the model given by the number of parameters estimated. I select the model with 2-year lag for the interpretation of the results since it is the one that best explains the data, i.e with the lowest AIC.

Table B.7: AIC for different number of lags of the economic structure variables

\begin{tabular}{ccc}
\hline Lag & Export value & Export diversity \\
\hline 1-year & 1726.117 & 1740.823 \\
2-year & 1697.837 & 1698.182 \\
3-year & $\mathbf{1 6 9 3 . 2 3 4}$ & $\mathbf{1 6 8 8 . 7 3 1}$ \\
\hline
\end{tabular}




\section{Appendix C}

\section{Appendix to Chapter 4}

\section{C.1 Measuring weight disparity}

Weight disparity measures the concentration of the weights (inputs) from and towards a given industry $i$. It is defined following Serrano et al. (2009). The disparity of the supply of intermediate consumption is measured as follows:

$$
\operatorname{disp}_{i, c}^{\text {out }}\left(k_{i}^{\text {out }}\right)=k_{i}^{\text {out }}\left(\sum_{j} \frac{z_{i j}}{\sum_{i} z_{i j}}\right)^{2}
$$

where $z_{i j}$ are the value of inputs supplied by industry $i$ and used in the production of industry $j, k_{i}^{\text {out }}$ corresponds to the out-degree. The degree is the number of connections an industry has with other industries (including itself) due to inputoutput exchanges. When the disparity of industry $i$ is equal to 1 , the normalized weight associated to an industry is shared equally among the industries of the network. When the disparity is equal to $k_{i}$, the normalized weight associated to an industry is concentrated on one node. The disparity is high in presence of local heterogeneity, that is when the weights associated to an industry peak on a small number of industries. Because the disparity depends on the degree, I normalize it by the value expected in the null model for a given degree. The value expected in the null mode $\bigsqcup^{1}$ is (I drop in and out superscripts to simplify):

$$
\tilde{d i s p}_{i, c}\left(k_{i}\right)=\frac{\operatorname{disp}_{i, c}\left(k_{i}\right)}{\mu\left(\operatorname{disp}_{\text {null }}\left(k_{i}\right)\right)+2 \sigma\left(\operatorname{disp}_{\text {null }}\left(k_{i}\right)\right)}
$$

where $\mu$ and $\sigma$ correspond to the mean and standard deviation of the null model respectively. They are defined below as (see Serrano et al. (2009) for more details):

$$
\begin{gathered}
\mu\left(\operatorname{disp}_{\text {null }}\left(k_{i}\right)\right)=\frac{2 k_{i}}{k_{i}+1} \\
\sigma^{2}\left(\operatorname{disp}_{\text {null }}\left(k_{i}\right)\right)=k_{i}^{2}\left(\frac{20+4 k_{i}}{\left(k_{i}+1\right)\left(k_{i}+2\right)\left(k_{i}+3\right)}-\frac{4}{\left(k_{i}+1\right)^{2}}\right)
\end{gathered}
$$

\footnotetext{
${ }^{1}$ I consider here a confidence interval of two standard deviations from the mean.
} 
When $\tilde{i s s}_{i, c}^{i n}>1$, there is local heterogeneity and the higher the value the more concentrated are the weights on a few industries, accounting for the number of connections each industry has. The results of this measure are displayed in Figure C.1. It shows that most industries have local heterogeneity, that is a large share of their input-output exchanges are focused on a limited number of industries. Local heterogeneity tends to be present when looking at the distribution of weights of supplier industries, and in particular, construction, trade and transport services as well as food and textile manufacturing industries.

Figure C.1: Distribution of the normalized disparity of the demand for intermediate consumption, by industry

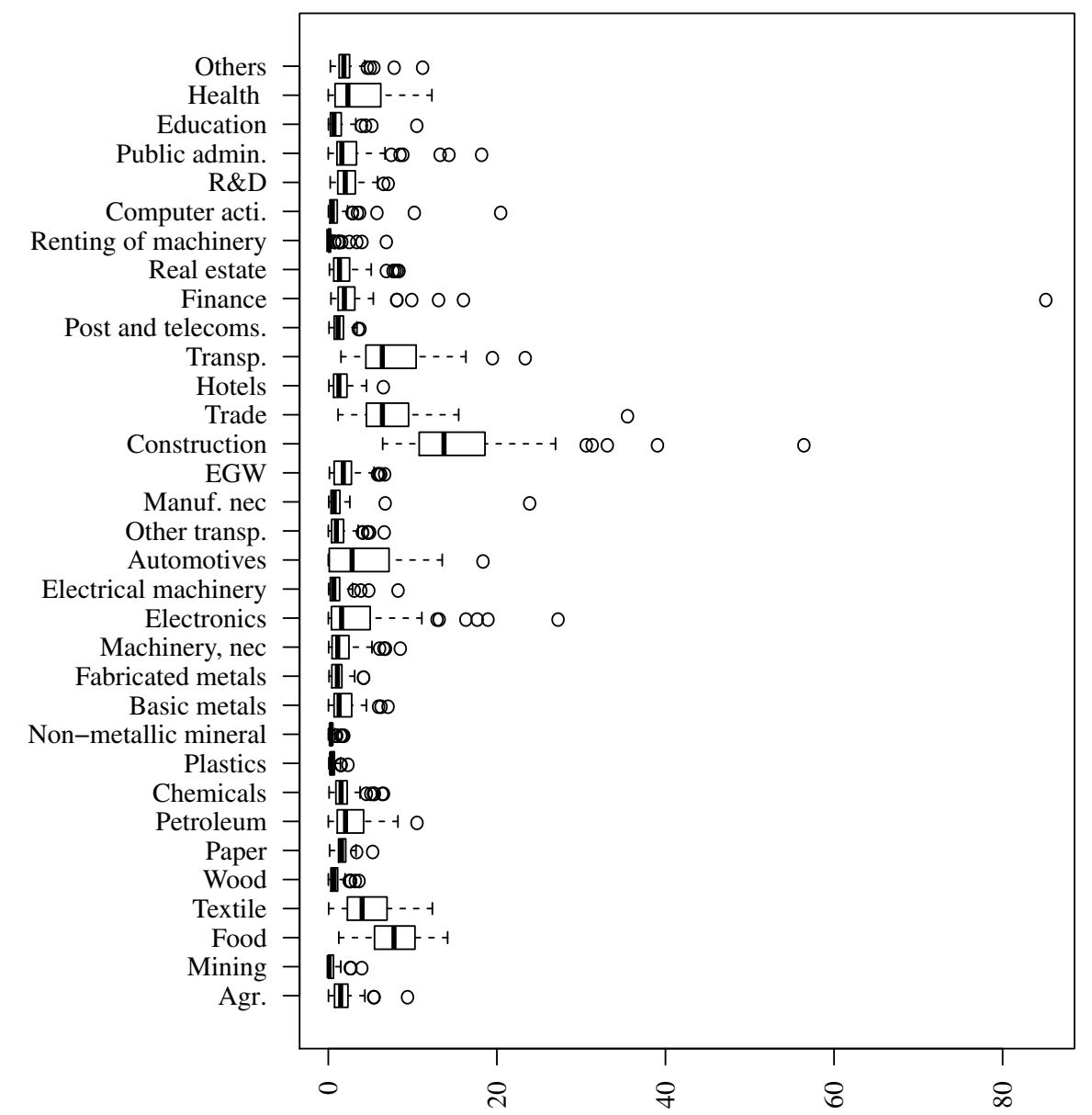

Notes: Within each industry, each observation corresponds to a country. The set of observations is described by the boxplot. 


\section{C.2 IOT data}

Table C.1: IOT country list

\begin{tabular}{|c|c|}
\hline $\begin{array}{l}\text { Country } \\
\text { code }\end{array}$ & Country name \\
\hline $\mathrm{ARG}$ & Argentina \\
\hline AUS & Australia \\
\hline AUT & Austria \\
\hline BEL & Belgium \\
\hline BGR & Bulgaria \\
\hline BRA & Brazil \\
\hline BRN & Brunei Darussalam \\
\hline $\mathrm{CAN}$ & Canada \\
\hline $\mathrm{CHE}$ & Switzerland \\
\hline CHL & Chile \\
\hline $\mathrm{CHN}$ & China \\
\hline $\mathrm{COL}$ & Colombia \\
\hline CRI & Costa Rica \\
\hline CYP & Cyprus \\
\hline $\mathrm{CZE}$ & Czech Republic \\
\hline DEU & Germany \\
\hline DNK & Denmark \\
\hline ESP & Spain \\
\hline $\mathrm{EST}$ & Estonia \\
\hline FIN & Finland \\
\hline FRA & France \\
\hline GBR & United Kingdom \\
\hline GRC & Greece \\
\hline $\mathrm{HKG}$ & Hong Kong, China \\
\hline HRV & Croatia \\
\hline HUN & Hungary \\
\hline IDN & Indonesia \\
\hline IND & India \\
\hline IRL & Ireland \\
\hline ISL & Iceland \\
\hline ISR & Israel \\
\hline ITA & Italy \\
\hline
\end{tabular}

\begin{tabular}{ll}
\hline Country & Country name \\
code & \\
\hline JPN & Japan \\
KHM & Cambodia \\
KOR & Korea \\
LTU & Lithuania \\
LUX & Luxembourg \\
LVA & Latvia \\
MAR & Morocco \\
MEX & Mexico \\
MLT & Malta \\
MYS & Malaysia \\
NLD & Netherlands \\
NOR & Norway \\
NZL & New Zealand \\
PER & Peru \\
PHL & Philippines \\
POL & Poland \\
PRT & Portugal \\
ROU & Romania \\
RUS & Russian Federation \\
SAU & Saudi Arabia \\
SGP & Singapore \\
SVK & Slovak Republic \\
SVN & Slovenia \\
SWE & Sweden \\
THA & Thailand \\
TUN & Tunisia \\
TUR & Turkey \\
TWN & Chinese Taipei \\
USA & United States \\
VNM & Viet Nam \\
ZAF & South Africa \\
ROW & Rest of the world \\
\hline
\end{tabular}


Table C.2: IOT industry list

\begin{tabular}{|c|c|c|}
\hline ISIC (Rev. 3) & Description & Label \\
\hline $01,02,05$ & $\begin{array}{l}\text { Agriculture, hunting, forestry and fish- } \\
\text { ing }\end{array}$ & Agr. \\
\hline $10,11,12,13,14$ & Mining and quarrying & Mining \\
\hline 15,16 & Food products, beverages and tobacco & Food \\
\hline $17,18,19$ & $\begin{array}{l}\text { Textiles, textile products, leather and } \\
\text { footwear }\end{array}$ & Textile \\
\hline 20 & Wood and products of wood and cork & Wood \\
\hline 21,22 & $\begin{array}{l}\text { Pulp, paper, paper products, printing } \\
\text { and publishing }\end{array}$ & Paper \\
\hline 23 & $\begin{array}{l}\text { Coke, refined petroleum products and } \\
\text { nuclear fuel }\end{array}$ & Petroleum \\
\hline 24 & Chemicals and chemical products & Chemicals \\
\hline 25 & Rubber and plastics products & Plastics \\
\hline 26 & Other non-metallic mineral products & Non-metallic minerals \\
\hline 27 & Basic metals & Basic metals \\
\hline 28 & Fabricated metal products & Fabricated metals \\
\hline 29 & Machinery and equipment, nec & Machinery, nec \\
\hline $30,32,33$ & $\begin{array}{l}\text { Computer, Electronic and optical } \\
\text { equipment }\end{array}$ & Electronics \\
\hline 31 & $\begin{array}{l}\text { Electrical machinery and apparatus, } \\
\text { nec }\end{array}$ & Electrical machinery \\
\hline 34 & $\begin{array}{l}\text { Motor vehicles, trailers and semi- } \\
\text { trailers }\end{array}$ & Automotives \\
\hline 35 & Other transport equipment & Other transp. \\
\hline 36,37 & Manufacturing nec; recycling & Manuf. Nec \\
\hline 40,41 & Electricity, gas and water supply & EGW \\
\hline 45 & Construction & Construction \\
\hline $50,51,52$ & Wholesale and retail trade; repairs & Trade \\
\hline 55 & Hotels and restaurants & Hotels \\
\hline $60,61,62,63$ & Transport and storage & Transp. \\
\hline 64 & Post and telecommunications & Post and telecoms. \\
\hline $65,66,67$ & Financial intermediation & Finance \\
\hline 70 & Real estate activities & Real estate \\
\hline 71 & Renting of machinery and equipment & Renting of machinery \\
\hline 72 & Computer and related activities & Computer acti. \\
\hline 73,74 & R\&D and other business activities & $\mathrm{R} \& \mathrm{D}$ \\
\hline 75 & $\begin{array}{l}\text { Public admin. and defence; compul- } \\
\text { sory social security }\end{array}$ & Public admin. \\
\hline 80 & Education & Education \\
\hline 85 & Health and social work & Health \\
\hline $90,91,92,93$ & $\begin{array}{l}\text { Other community, social and personal } \\
\text { services }\end{array}$ & Others \\
\hline
\end{tabular}


Figure C.2: Distribution of the share of output of industry $i$ that is used as intermediate consumption, by industry

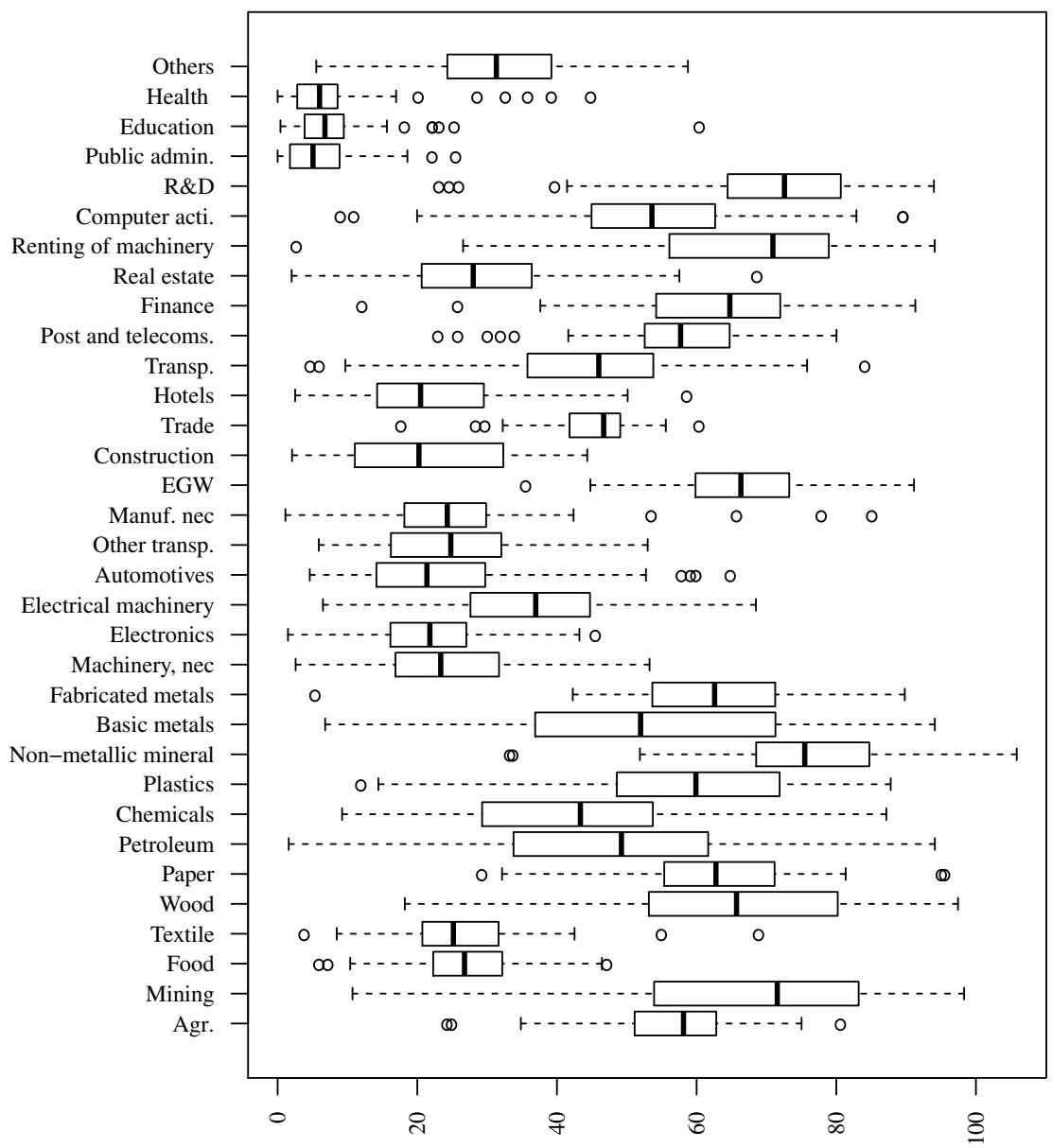

Notes: Within each industry, each observation corresponds to a country. The set of observations is described by the boxplot. Variations in inventory are deducted from total output to account for effective production. 
Figure C.3: Share of output of industry $i$ in total output, by industry and country

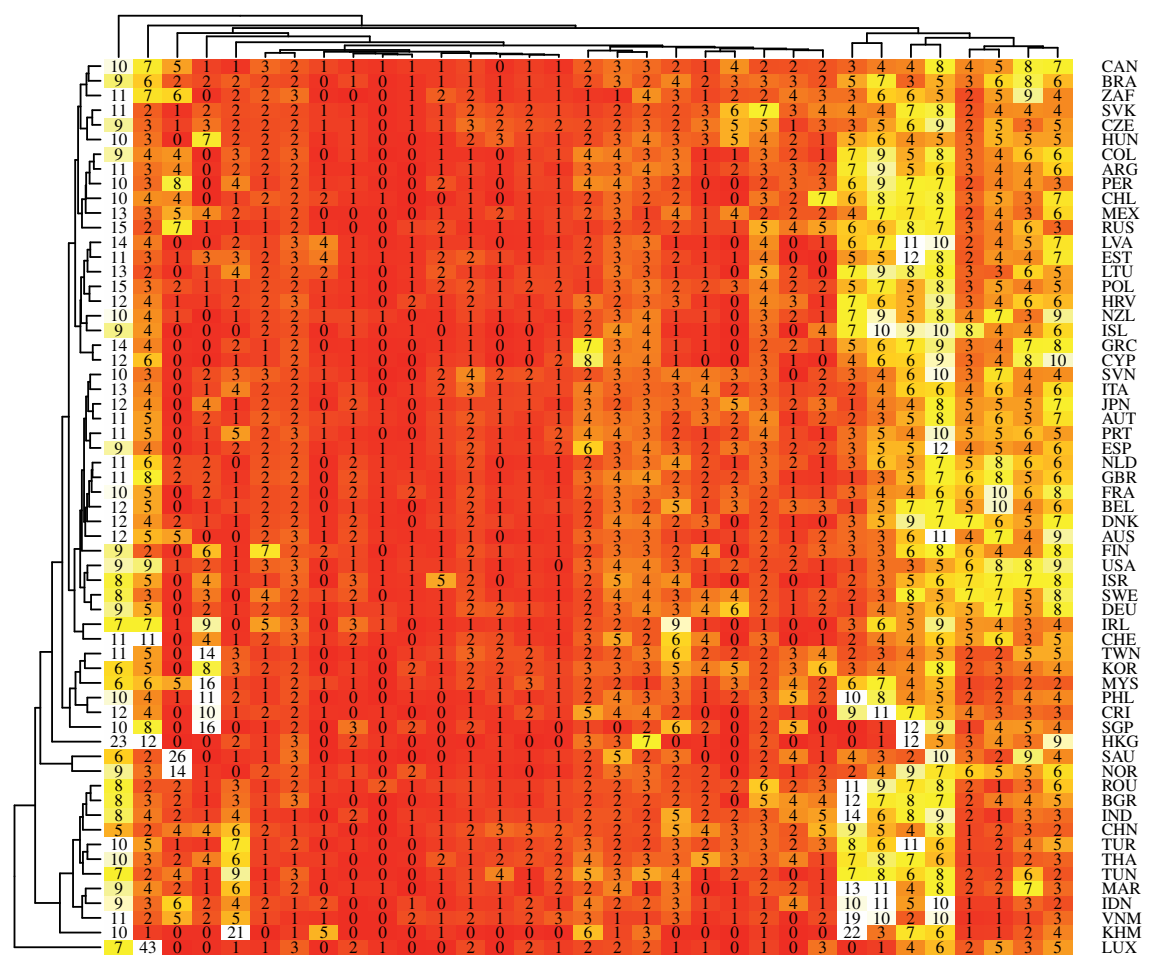

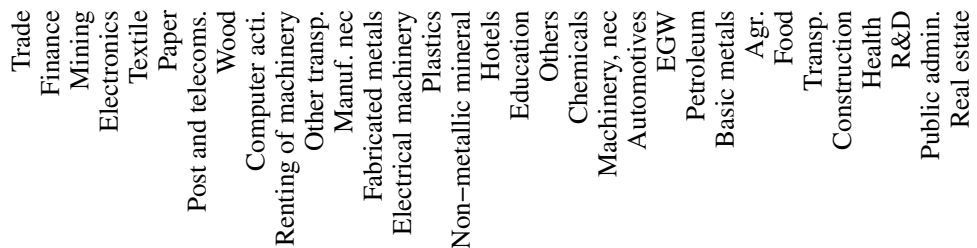

Notes: The darker the color the lower the value of $\alpha$ is. The dendrogram represent hierarchical clusters of countries and industries according to the values of the share of output in total output. The hierarchical clustering analysis is done as follows: "Initially, each object is assigned to its own cluster and then the algorithm proceeds iteratively, at each stage joining the two most similar clusters, continuing until there is just a single cluster. At each stage distances between clusters are recomputed by the LanceWilliams dissimilarity update formula according to the particular clustering method being used." (for more details see R function "hclust"). 
Figure C.4: Coefficient $\alpha^{k}$ in the revised Leontief matrix, $\tilde{L}$, for different values of $\alpha$ and $k$

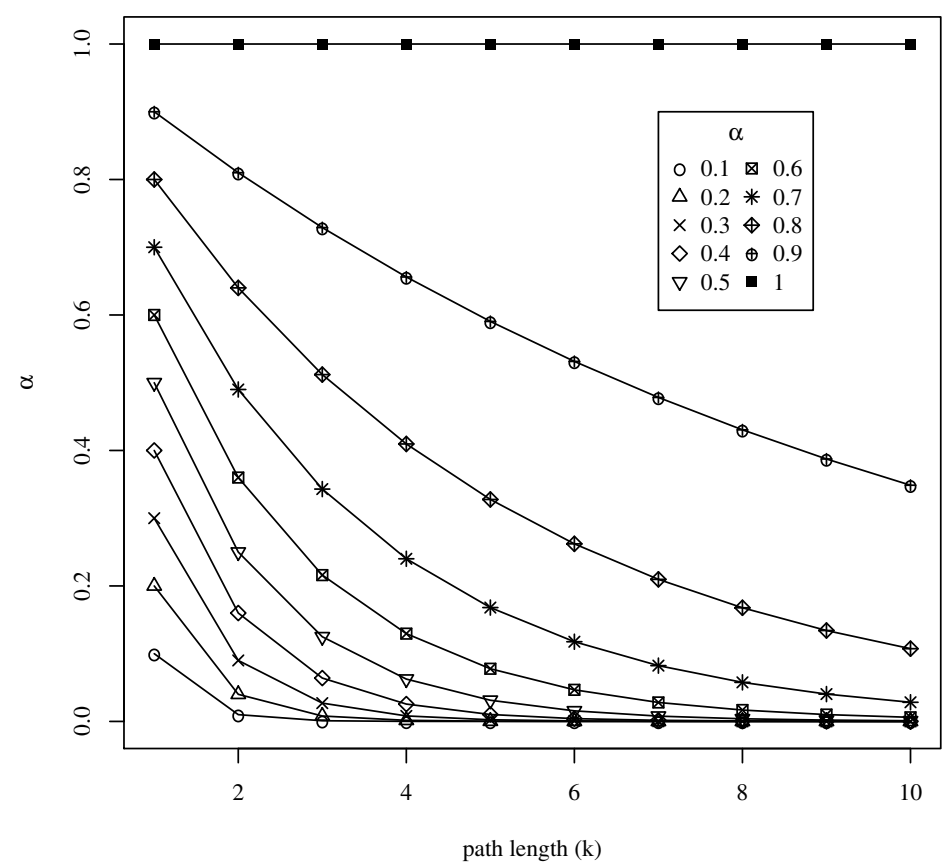

Note: The revised Leontief matrix is: $\tilde{L}=(I-\alpha A)^{-1}=I+\sum_{k=1}^{K} \alpha^{k} A^{k}$, where $k$ represents the path length and $\alpha$ the attenuation factor. 


\section{Valorization}

In accordance with article 23.5 of the "Regulation governing the attainment of doctoral degrees at Maastricht University" decreed by resolution of the Board of Deans, dated 3 July 2013, an addendum must be added about valorization opportunities presented by this PhD thesis.

In recent years, there has been a renewed interest in industrial policy to face increasing competition and promote economic growth. The industrial policy of a country consists in its strategic effort to encourage the development and growth of all or part of the economy. Furthermore, the different activities that form the economy of a country are connected through inputs in terms of skills, technological capabilities and knowledge, input-output relations and value chains (either global or local). With this in mind, understanding the characteristics of such a system and the way its different parts interact and create synergies is essential. This is precisely the type of knowledge this thesis aims at providing. For obvious reasons, such knowledge is highly relevant to inform policy makers, both in the developed and developing world, in order for them to better shape their industrial policy. This thesis is also scientifically relevant in that it largely contributes to the literature on the economics of technological and structural change, on the economics of growth and to the methodology for input-output analysis. In particular, chapter 2 aims at redefining the boundaries of production/export empirically with a focus on economic activities rather than predefined sectors. This is done by diverting away from traditional economic analysis and adopting a network perspective. More specifically, I combine economic data with community detection to map clusters of products for several time windows. This exercise enables to identify bottlenecks and opportunities for economic development and its changes over time. In particular, results indicate that the formation of clusters do not always depend on the traditional divide between high/medium and low-tech products. Such patterns are strongly dependent on other factors such as the domain of knowledge and technology as well as value chains, the stage of production, the type of production process and product characteristics. As argued throughout the thesis, this is essential because the development is gradual and path dependent. A better characterization of the boundaries between economic activities informs policy makers of the bottlenecks that might arise in implementing a given industrial strategy.

In chapter 3. I adopt a measure of economic growth so as to capture medium- 
term growth rather that growth volatility that represent business cycles. This measure improves upon traditional measures in two ways. First, countries care about factors of sustainable growth rather than those making the growth rate vary from one year to the next. Second, structural change is a rather slow process and its effect on growth is only relevant when looking at medium-term growth. I innovate in adapting a semi-Markov model, which has been used so far in medical studies, to growth analysis. I also estimate an extension of this model using the Cox-proportional model to analyze the effect of the economic structure on growth transitions. This model improves upon the literature by focusing on growth transitions rather than simply on growth variation or on the probability to move towards a growth regime (logit or probit models). Furthermore, I find that the growth process is gradual and so a simple Markov model would be limited in terms of the information that it could provide (transition probabilities). Instead, in the semiMarkov model, transitions from one growth regime to another depend on the growth regime a country is in, the time spent in this state as well as the economic structure of the country (Cox-proportional model extension). Such an analysis provides information on the characteristics of each growth transition conditional on the time spent in a state and quantifies the effect of the economic structure on each of them. The definition of the economic structure relies on chapter 2 , but focusing on manufacturing activities. The model is estimated in two-steps in order to test several measures of economic structure. I look at two dimensions of the participation of countries in each cluster: specialization and diversification. Results show that the way the economic structure is measure has different policy implication, i.e. being diverse in a cluster doesn't bring about the same changes as being specialized in the same cluster.

Lastly, the production of countries can be decomposed in terms of the destination of output: as input in the production (i.e. intermediary consumption), as investment or as final good ready to be consumed. Since intermediary consumption accounts for more than half of the value of total production in most countries (OECD), it is important to know how the value is distributed across the supply chain, especially when shocks arise. In particular, the increasing division of tasks within and across borders has contributed to a growing and more and more complex interconnectedness between industries. In this context, the answer to the question "How are shocks from one industry distributed throughout the economy?" is particularly relevant for industrial policy. While industrial policy usually targets a specific group of industries, its effect can be amplified since it can affect indus- 
tries outside of the targeted group through input-output linkages. In chapter 4 , I improve upon the traditional methodology to estimate more accurately the output multiplier from the demand side, i.e. backward linkages, for each country in the sample including both developed and developing economies. The traditional measure of backward linkages relies on several strong assumptions. When an inputoutput link is present between supplier industry $i$ and user industry $j$, the shock from user industry $j$ is fully transmitted to its supplier industry $i$. That is, as long as there is a link, the shock is transmitted and the strength of this shock is proportional to the importance of the supplier industry for the user industry. In addition, it is assumed that a direct shock is considered to be as important as an indirect one. Otherwise said, the effect does not fade away along the supply chain. I modify the Leontief matrix in order to test the validity of these assumptions. This change is inspired by a well-known measure in network analysis, called Katz centrality. I extend it to adapt it the measurement of the output multiplier. The new measure enables to quantify the response to demand shock by industry and country (until now considered constant and equal to 1), by comparing estimated and actual output variation. I find that the assumptions are in many cases not valid. In particular, there are differences between sectors and between countries (especially between developed and developing countries). These results are critical when shaping an industrial strategy as it provides information on the effective possibility of a particular industry to disrupt the supply chain and thereby leads to a more accurate measure of the output multiplier.

As for the outcome of this thesis, it consists of three research papers that I aim at publishing shortly. These papers have also been presented in several international conferences and workshops including the workshop on The future of industrial work at UNIDO (Austria) in September 2019; The 3rd UNU-MERIT Internal Conference (The Netherlands) in June 2019; Druid Academy (France) in January 2016; the European Meeting on Applied Evolutionary Economics (EMAEE): Globalisation, Innovation and Economic Change (The Netherlands) in June 2015; Conference on Governance, Innovation and Development (The Netherlands.) in November 2014 and the Conference on Micro Evidence on Innovation in Developing Economies MEIDE (Chile) in November 2013. 


\section{About the author}

Charlotte Guillard was born in France in 1987. She holds a Master degree in Development and international economics (Magna Cum Laude) from Auvergne University and a Master degree in Project Analysis (Magna Cum Laude) from the same institution. Charlotte joined Strasbourg University and UNU-MERIT in 2011. Her research focuses on understanding the mechanisms of economic development and structural change using methods and theories from network analysis, complex systems and evolutionary economics. During her $\mathrm{PhD}$, she has also worked as an economic consultant in the Competitiveness, Technology and Innovation division of the Inter-American Development Bank (IDB) in Washington DC. Within the IDB, she contributed to several research projects on productivity and innovation, focusing on Latin America and the Caribbean, including the development of several innovation surveys and indicators. She later worked at Imperial College on the estimation of knowledge spillovers using patent data (under a European Union Horizon 2020 project).

Charlotte recently joined the Institute for Innovation and Public Purpose at University College London as a research fellow to explore ways of improving the measurement of public value, with a focus on the space economy. 



\section{UNU-MERIT/MGSoG Dissertation Series}

2019

\section{Charlotte Guillard}

Rethinking economic growth

and structural change.

The role of boundaries and linkages

between industries

UNU-MERIT/MGSoG Dissertation

Series № 237

\section{Nicolas Echarti}

Employment Effects or Vocational

Rehabilitation in Germany:

A quantitative analysis

UNU-MERIT/MGSoG Dissertation

Series № 236

\section{Shellie E. Solomon}

Neighborhoods Matter:

Crime, collective efficacy and

foreclosures in Miami

UNU-MERIT/MGSoG Dissertation

Series № 235

\section{Michał Kazimierczak}

Regional Innovation and

Entrepreneurship

Patents, trade marks, entry and

entrants' growth in European

manufacturing industries

UNU-MERIT/MGSoG Dissertation

Series № 234

\section{Fernanda Soares}

The Influence of Within School and Across Schools' Collaborative Practices on Student Learning and Teaching

Outcomes in West Afrika

UNU-MERIT/MGSoG Dissertation

Series № 233

\section{Mira Bierbaum}

New Mindsets to Innovate Activation UNU-MERIT/MGSoG Dissertation Series № 232

\section{Norman Dytianquin}

Technology in the Asian Miracle and Crisis Debates: Applications of and Insights from the Field of Influence Approach to Input-Output Analysis UNU-MERIT/MGSoG Dissertation Series № 231

\section{Nga Le}

The implications of health insurance for the labour market and patient satisfaction with medical care in Vietnam

UNU-MERIT/MGSoG Dissertation Series № 230

\section{Jinhyuck Park}

Intellectual Property right protection and cross-border RED investments by multinational enterprises

UNU-MERIT/MGSoG Dissertation Series № 228 


\section{Richard de Groot}

Show me the Money:

Essays on the Impact of Cash Transfers on Child Nutrition and the Role of Intra-Household Dynamics

UNU-MERIT/MGSoG Dissertation

Series № 228

\section{Catie Lott}

Diamonds are a Women's Best Friend

Broadening Measures of Women's

Access to Formal Political Decision-

Making

UNU-MERIT/MGSoG Dissertation

Series № 227

\section{Ana Cristina Calderon Ramirez}

Public Management Reforms

Three stories about public procurement agencification in Latin America

UNU-MERIT/MGSoG Dissertation Series № 226

\section{Camilo Nicanor Carrillo Purin}

Teachers' in-service training and student achievement:

The effect of in-service training of

Peruvian teachers on student

achievement

UNU-MERIT/MGSoG Dissertation

Series № 225

\section{Hugo Confraria}

Developing scientific capacity in the

Global South

UNU-MERIT/MGSoG Dissertation

Series № 224

\section{Alison Cathles}

Educational Pathways and Skills:

Past, Present, and Future

UNU-MERIT/MGSoG Dissertation

Series № 223

\section{Ibrahima Sory Kaba}

Aggregate Fluctuations and

Development: Essays on

Macroeconomic Volatility and

Economic Growth

UNU-MERIT/MGSoG Dissertation

Series № 222

\section{Charlotte Keijser}

Firm Participation, Learning and

Innovation in Heterogenous Value

Chains of IT-enabled Services

UNU-MERIT/MGSoG Dissertation

Series № 221

\section{Salih Çevikarslan}

Innovation Strategies and Their

Implications for Technological Change and Market Outcomes:

An Evolutionary Multi-Agent Based

Modelling Approach

UNU-MERIT/MGSoG Dissertation

Series № 220

\section{Wondimagegn Mesfin Tesfaye}

Essays on the Impacts of Climate-

Smart Agricultural Innovations on

Household Welfare

UNU-MERIT/MGSoG Dissertation

Series № 219 
Tatevik Poghosyan

How Board Networks Affect Firm

Performance and Innovation Incentives

in Transition Economies: The Case of

Armenia

UNU-MERIT/MGSoG Dissertation

Series № 218

\section{Arip Muttaqien}

Essays on Inequality and Polarization:

Empirical Studies in Developing Asia

UNU-MERIT/MGSoG Dissertation

Series № 217

2018

\section{Katrin Marchand}

Essays on Forced Migration and

Labour Market Participation in

Developing Countries

UNU-MERIT/MGSoG Dissertation

Series № 216

\section{Ortrun Merkle}

The Myth of Gender Neutral Power:

Corruption and Gender Norms

UNU-MERIT/MGSoG Dissertation

Series № 215

\section{Biljana Meshkovska}

Life after Trafficking:

(re)integration processes of women that have been trafficked for the purpose of sexual exploitation in Europe

UNU-MERIT/MGSoG Dissertation

Series № 214

\section{Vincenzo Vinci}

The Relevance of Institutions and

People's Preferences for Social

Protection

UNU-MERIT/MGSoG Dissertation

Series № 213

\section{Silke Heuser}

The Effectiveness of Environmental

Policies on Reducing Deforestation in

the Brazilian Amazon

UNU-MERIT/MGSoG Dissertation

Series № 212

\section{Jennifer Waidler}

Social Assistance and Remittances and

Their Role in the Fight Against

Poverty

UNU-MERIT/MGSoG Dissertation

Series № 211

\section{Choolwe Muzyamba}

The role of community mobilization in the promotion of maternal health of women living with HIV in Zambia UNU-MERIT/MGSoG Dissertation Series № 210

\section{Juan Carlos A. Castillo Sánchez}

Assessing the Role of the Export Sector in Mexican Economic

Development,1965-2014

UNU-MERIT/MGSoG Dissertation

Series № 209

\section{Tareq Abuelhaj}

Food Security Policy Impact Analysis:

The Econometrics of Cash and Food

Assistance Cost Effectiveness

UNU-MERIT/MGSoG Dissertation

Series № 208 
Marta Férnandez de Arroyabe Arranz

Essays on MEAS and Innovation UNU-MERIT/MGSoG Dissertation Series № 207

\section{Clotilde Mahé}

Essays on Migration and Occupational Choice

UNU-MERIT/MGSoG Dissertation Series № 206

\section{Simone Sasso}

Talent on the move. Essays on Human Capital, Graduate Mobility and

Economic Development

UNU-MERIT/MGSoG Dissertation

Series № 205

\section{Khaled Walid Rajab}

Strategic Planning under Fragility UNU-MERIT/MGSoG Dissertation Series № 204

\section{Mutinta Hambayi Nseluke}

A Tall Order: Improving Child Linear Growth

UNU-MERIT/MGSoG Dissertation Series № 203

\section{Elvis Korku Avenyo}

Innovations and Firm Performance

in sub-Saharan Africa: Empirical

Analyses

UNU-MERIT/MGSoG Dissertation

Series № 202

\section{Ni Zhen}

Employment Dynamics, Firm

Performance and Innovation

Persistence in the Context of

Differentiated Innovation Types:

Evidence from Luxembourg

UNU-MERIT/MGSoG Dissertation

Series № 201

\section{Caroline Wehner}

Too Scared to Achieve: The Relation

Between Neuroticism,

Conscientiousness

and Socioeconomic Outcomes

UNU-MERIT/MGSoG Dissertation

Series № 200

\section{Stefania Innocenti}

On Institutional Persistence

UNU-MERIT/MGSoG Dissertation

Series № 199

\section{Hassen Abda Wako}

Economic Globalization, Institutions and Development: Essays on Aid, Foreign Direct Investment and Trade UNU-MERIT/MGSoG Dissertation Series № 198

\section{7}

\section{Hans-Erik Edsand}

Winds of Change

UNU-MERIT/MGSoG Dissertation

Series № 197

Ana Patricia Silva Vara

Redressing the Gender Gap

UNU-MERIT/MGSoG Dissertation

Series № 196 


\section{Andrés Iván Mideros Mora}

Essays on the Economic Effects of Noncontributory Social Protection

UNU-MERIT/MGSoG Dissertation

Series № 195

\section{Tobias Broich}

New Actors in the Global Economy

UNU-MERIT/MGSoG Dissertation

Series № 194

\section{Bernard Nikaj}

From No-government to E-government

UNU-MERIT/MGSoG Dissertation

Series № 193

\section{Ali Safarnejad}

Prioritizing the HIV Response

UNU-MERIT/MGSoG Dissertation

Series № 192

\section{Clovis Freire}

Diversification and Structural

Economic Dynamics

UNU-MERIT/MGSoG Dissertation

Series № 191

\section{Michael Verba}

Innovation and Knowledge Dynamics:

Essays on the Knowledge Economy

UNU-MERIT/MGSoG Dissertation

Series № 190

\section{Pui Hang Wong}

The Hearts and Minds in Conflict and

Peace: The Economics of

Counterinsurgency and the Psychology of Reconstruction

UNU-MERIT/MGSoG Dissertation

Series № 189

\section{Brenda Yamba}

Schooling Despite All Odds: Evidence from Lesotho on Female Child Carers who Stayed in School

UNU-MERIT/MGSoG Dissertation Series № 188

\section{Sheng Zhong}

Moving towards An Energy Efficient

Future: Essays on Energy Efficiency,

Technology and Development

UNU-MERIT/MGSoG Dissertation

Series № 187

\section{Julieta Marotta}

Access to Justice and Legal

Empowerment of Victims of Domestic

Violence through Legal Organizations

in the City of Buenos Aires: A

Qualitative Empirical Legal Study

UNU-MERIT/MGSoG Dissertation

Series, № 186

\section{Andrea Franco-Correa}

On the Measurement of

Multidimensional Poverty as a Policy Tool: Empirical Applications to Chile, Colombia, Ecuador and Peru

UNU-MERIT/MGSoG Dissertation Series, № 185

\section{6}

\section{Yesuf Awel}

Insurance for Growth: Empirical

Essays on Insurance Demand and

Impacts in Africa

UNU-MERIT Dissertation Series,

№ 108 
Tigist Mekonnen Melesse

Grow More Food using Fewer

Resources: Agricultural Technology

Adoption and Innovation Practices for

Inclusive and Sustainable

Development

UNU-MERIT Dissertation Series, № 107

\section{Eleni Yitbarek}

Getting Ahead or left Behind? Essays

on Poverty Dynamics and Social

Mobility in Africa

UNU-MERIT Dissertation Series,

№ 106

\section{Thuy Dieu Nguyen}

Firm-Level Theory and Evidence of

Corruption

UNU-MERIT Dissertation Series,

№ 105

\section{Raquel Tsukada Lehman}

Essays on Household Production with

Labor-Saving Technology

UNU-MERIT Dissertation Series,

№ 104

\section{Eva Barteková}

Multi-Problem Challenges for a

Renewable Future: Empirical Studies

on Competitive Disadvantages from

Electricity Price Differentials and

Mineral Supply Risk in an Open

Economy

UNU-MERIT Dissertation Series, № 103

\section{Jocelyn Olivari}

Entrepreneurial Traits and Innovation:

Evidence from Chile

UNU-MERIT Dissertation Series,

№ 102

\section{Muhammad Shafique}

Essays on the role of knowledge, RED, and Technology-based Firms in the

Evolution of Socio-techno-economic

System

UNU-MERIT Dissertation Series,

№ 101

\section{Serdar Türkeli}

Governance of Innovation Policy:

Empirical Studies on Applied Political

Economy by Multi-Methods Analysis

UNU-MERIT Dissertation Series,

№ 100

\section{Ayokunu Adedokun}

Pathways to Sustainable Peace

building in Divided Societies: Lessons

and Experiences from Mozambique

MGSoG Dissertation Series, № 75

\section{Luiz Rothier Bautzer}

Organizing Concurrent Engineering

through ICT Platforms

Blueprinting Product Lifecycle

Management Platforms across

Disciplinary Agencies

MGSoG Dissertation Series, № 74 


\section{Natalia Popova}

Migration in the Periphery of the

European Union:

Determinants of Successful and

Sustainable Labour Market Integration of Return Migrants in Albania, Egypt, Moldova and Tunisia

MGSoG Dissertations Series, № 73

Richard A. Martina

Uncertainty and Resource Constraint in the Small Island Developing States: Essays in Entrepreneurial Cognition

MGSoG Dissertations Series, № 72

\section{Cécile Cherrier}

The Expansion of Basic Social

Protection in Low-income Countries:

An Analysis of Foreign Aid Actors'

Role in the Emergence of Social

Transfers in Sub-Saharan Africa

MGSoG Dissertations series, № 71

\section{Paul Caldron}

The Tacit Bargain in Short-Term

Medical Missions: Why U.S.

physicians go and what it costs

MGSoG Dissertation Series, № 70

\section{Mahmut Kobal}

Customs \& Excellence: A Comparative

Approach on Administrative and

Regulatory Compliance Perspectives of the EU-Turkey Customs Union

MGSoG Dissertation Series, № 69

\section{Craig Loschmann}

Essays on Conflict-related Migration

and Development in the Case of

Afghanistan

MGSoG Dissertations Series, № 68

\section{Andrea Milan}

Rural Livelihoods, Location and

Vulnerable Environments: Approaches to Migration in Mountain areas of

Latin America

MGSoG Dissertation Series, № 67

\section{Farida Lada}

On Guarding the Welfare of Clinical

Trial Subjects While Promoting Novel

Drug Innovation

A Game Theoretical Approach

MGSoG Dissertation Series, № 66

\section{5}

\section{Hibret Belete Maemir}

Dissecting Aggregate Productivity:

International Integration and Growth

with Heterogeneous Firms

UNU-MERIT Dissertation Series,

№ 96

\section{Giorgio Triulzi}

Looking for the Right Path: Technology

Dynamics, Inventive Strategies and

Catching-up in the Semiconductor

Industry

UNU-MERIT Dissertation Series, № 95
Abdul Baseer Qazi
Knowledge flows and networks in the
ICT sector: The case of Pakistan
UNU-MERIT Dissertation Series,
№ 94 


\section{Ajay Thutupalli}

Technology Paradigm Shifts in

Agriculture: Drivers of Sustainability

and Catch up

UNU-MERIT Dissertation Series, № 93

\section{Eduardo Urias}

Improving access to HIVIAIDS

treatment in Brazil: When are

Compulsory Licenses effective in Price

Negotiations?

UNU-MERIT Dissertation Series,

№ 92

\section{Francesca Guadagno}

Why have so few Countries

Industrialised?

UNU-MERIT Dissertation Series, № 91

\section{Daniel Opolot}

The Evolution of Beliefs and Strategic

Behaviour

UNU-MERIT Dissertation Series, № 90

\section{Alejandro Lavopa}

Structural Transformation and

Economic Development: Can

Development Traps be Avoided

UNU-MERIT Dissertation Series, № 89

\section{Jinjin Zhao}

Urban water management reform: The

Case of China

UNU-MERIT Dissertation Series, № 88

\section{Simona Vezzoli}

Borders, Independence and Post-

colonial Ties: the Role of the State in

Caribbean Migration

MGSoG Dissertation Series, № 65

\section{Silvia Consuelo Gómez Soler}

Civil Conflict and Education: How

Does Exposure to Civil Conflict Affect

Human Capital Accumulation?

Evidence from Standardized Exit

Exams in Colombia

MGSoG Dissertation Series, № 64

\section{Paula Nagler}

Occupational Choice in the Developing

World

MGSoG Dissertation Series, № 63

\section{Jasmin Kientzel}

Determinants of Professional

Commitment to Environmental

Sustainability

MGSoG Dissertation Series, № 62

\section{Mehmet Güney Celbiş}

Regional Policies: Convergence, Trade, and the Allocation of Public Capital MGSoG Dissertation Series, № 61

\section{Florian Henning}

Living Up to Standard:

Interoperability Governance and

Standards Adoption in Government

Information Networks

MGSoG Dissertation Series, № 60 
Niels P. Groen

2014

The Never-Ending Project

Understanding E-Government Project

Escalation

MGSoG Dissertation Series, № 59

\section{Derek Copp}

Teacher-Based Reactivity to Provincial

Large-scale Assessment in Canada

MGSoG Dissertation Series, № 58

\section{Michaella Vanore}

Family-Member Migration and the

Psychosocial Health Outcomes of

Children in Moldova and Georgia

MGSoG Dissertation Series, № 57

\section{Sonja Fransen}

The Economic and Social Effects of

Remittances and Return Migration in

Conflict-Affected Areas: The Case of

Burundi

MGSoG Dissertation Series, № 56

\section{Ibrahim Khalil Conteh}

The Impact of Floods on Primary

School Education in Zambia

MGSoG Dissertation Series, № 55

\section{Richard Bluhm}

Growth Dynamics and Development

Essays in Applied Econometrics and

Political Economy

MGSoG Dissertation Series, № 54

\section{Nevena P. Zhelyazkova}

Work-Family Reconciliation and Use of Parental Leave in Luxembourg:

Empirical Analysis of Administrative Records

MGSoG Dissertation Series, № 53

\section{Dirk Crass}

The Impact of Brands on Innovation and Firm Performance: Empirical Evidence from Germany

UNU-MERIT Dissertation Series, № 87

\section{Samyukta Bhupatiraju}

The Geographic Dimensions of Growth and Development

UNU-MERIT Dissertation Series, № 86

\section{François Lafond}

The Evolution of Knowledge Systems UNU-MERIT Dissertation Series, № 85

\section{Annalisa Primi}

Promoting Innovation in Latin America: What Countries Have Learned (and What They Have Not) in Designing and Implementing Innovation and Intellectual Property Policies

UNU-MERIT Dissertation Series, № 84

\section{Fatoumata Lamarana Diallo}

Evaluation of Meal and Deworming Programs for Primary Schools in Rural Senegal

UNU-MERIT Dissertation Series, № 83 
Sachin Kumar Badkas

Metachoice and Metadata: Innovating with Environmental Policy Analysis in Europe

MGSoG Dissertation Series, № 52

\section{Irina S. Burlacu}

An Evaluation of Tax-Benefit Systems Impact on the Welfare of Frontier

Worker:

The Case of Luxembourg and Belgium MGSoG Dissertation Series, № 51

\section{Özge Bilgili}

Simultaneity in Transnational

Migration Research: Links Between

Migrants' Host and Home Country

Orientation

MGSoG Dissertation Series, № 50

\section{Yulia Privalova Krieger}

Reshaping the Big Agenda:

Transnational Politics and Domestic

Resistance Financial crisis and social

protection reform in Bosnia and

Herzegovina

MGSoG Dissertation Series, № 49

\section{Marieke van Houte}

Moving Back or Moving Forward?

Return migration after Conflict

MGSoG Dissertation Series, № 48

\section{Oxana Slobozhan}

Global Governance in the Management of Natural Resources: The Case of the Extractive Industries Transparency Initiative (EITI)

MGSoG Dissertation Series, № 47

\section{Luis Bernardo Mejia Guinand}

The Changing Role of the Central

Planning Offices in Latin America: A

Comparative Historical Analysis

Perspective (1950-2013)

MGSoG Dissertation Series, № 46

\section{Cheng Boon Ong}

Ethnic Segregation in Housing,

Schools and Neighbourhoods in the

Netherlands

MGSoG Dissertation Series, № 45

\section{Luciana V. Cingolani}

Bureaucracies for Development:

Oxymoron or Reality? Studies on State

Capacity in Challenging Governance

Contexts

MGSoG Dissertation Series, № 44

\section{Carlos Cadena Gaitán}

Green Politics in Latin American

Cities - Sustainable Transport Agendas

MGSoG Dissertation Series, № 43

\section{Katie Kuschminder}

Female Return Migration and

Reintegration Strategies in Ethiopia

MGSoG Dissertation Series, № 42

\section{Metka Hercog}

Highly-Skilled Migration and New

Destination Countries

MGSoG Dissertation Series, № 41

\section{Margaret Agaba Rugadya}

Can Remittances Influence the Tenure and Quality of Housing in Uganda?

MGSoG Dissertation Series, № 40 


\section{Ilire Agimi}

New Governance Under Limited

Statehood: The Case of Local

Government Reform in Kosovo

MGSoG Dissertation Series, № 39

2013

Anant Kamath

Information Sharing through Informal

Interaction in Low-Tech Clusters

UNU-MERIT Dissertation Series, № 82

\section{Flavia Pereira de Carvalho}

What we talk about when we talk about

Brazilian Multinationals: An

Investigation on Brazilian FDI,

Economic Structure, Innovation and

the Relationship between them

UNU-MERIT Dissertation Series, № 81

\section{Jun Hou}

Complementarity in Innovation and

Development: A Cross-country

Comparison

UNU-MERIT Dissertation Series, № 80

\section{Rufin Baghana}

Impacts of Government Incentives to $R \mathcal{E D}$, Innovation and Productivity: A Microeconometric Analysis of the Québec Case

UNU-MERIT Dissertation Series, № 79

\section{Lilia I. Stubrin}

High-Tech Activities in Emerging

Countries: A Network perspective on

the Argentinean Biotech Activity

UNU-MERIT/MGSoG Dissertation

Series, № 78

\section{Kristine Farla}

Empirical Studies on Institutions,

Policies and Economic Development

MGSoG Dissertation Series, № 38

\section{Marina Petrovic}

Social Assistance and Activation in the

Pursuit of Happiness: Shedding New

Light on Old Policy Solutions to Social

Exclusion

MGSoG Dissertation Series, № 37

\section{Laura Torvinen}

Assessing Governance Assessments:

The Case of Mozambique: Governance

Assessments in the Context of Aid

Effectiveness Discourse

MGSoG Dissertation Series, № 36

\section{Biniam Egu Bedasso}

Institutional Change in the Long

Shadow of Elite: Essays on

Institutions, Human Capital and

Ethnicity in Developing Countries

MGSoG Dissertation Series, № 35

\section{Sepideh Yousefzadeh Faal}

Deghati

Childhoods Embargoed: Constructing

and Reconstructing Multidimensional

Child Poverty in Iran 1984-2009

MGSoG Dissertation Series, № 34 


\section{Robert Bauchmüller}

Investing in Early Childhood Care and

Education: The Impact of Quality on

Inequality

MGSoG Dissertation Series, № 33

\section{Martin Rehm}

Unified Yet Separated: Empirical

Study on the Impact of Hierarchical

Positions within Communities of

Learning

MGSoG Dissertation Series, № 32

2012

\section{Abdul Waheed \\ Innovation Determinants and}

Innovation as a Determinant: Evidence

from Developing Countries

UNU-MERIT Dissertation Series,

№ 77

\section{Bilal Mirza}

Energy Poverty and Rural Energy

Markets in Pakistan

UNU-MERIT Dissertation Series,

№ 76

\section{Benjamin Engelstätter}

Enterprise Software and Video Games:

An Empirical Analysis

UNU-MERIT Dissertation Series, № 75

\section{Fulvia Farinelli}

Natural Resources, Innovation and

Export Growth: The Wine Industry in

Chili and Argentina

UNU-MERIT Dissertation Series

\section{Rodolfo Lauterbach}

Innovation in Manufacturing: From

Product Variety and Labor

Productivity Growth to Economic

Development in Chile

UNU-MERIT Dissertation Series

\section{Kirsten Wiebe}

Quantitative Assessment of

Sustainable Development and Growth in Sub-Saharan Africa

UNU-MERIT Dissertation Series,

№ 74

\section{Julio Miguel Rosa}

Organizational Strategies, Firms'

Performance and Spatial Spillovers:

The Canadian Case in Research and

Development.

UNU-MERIT Dissertation Series, № 73

Johannes Wilhelmus Marie Boels

Joseph Schumpeter, Honderd Jaar

Economische Ontwikkeling: Een

Historisch-theoretische Beschouwing.

UNU-MERIT Dissertation Series

\section{Dorcas Mbuvi}

Utility Reforms and Performance of the

Urban Water Sector in Africa

MGSoG Dissertation Series, № 31

\section{Lina Salanauskaite}

Distributional Impacts of Public

Policies: Essays in Ex-Ante and Ex-

Post Evaluation

MGSoG Dissertation Series, № 30 


\section{Esther Schüring}

To Condition or not - is that the

Question?

An Analysis of the Effectiveness of ExAnte and Ex-Post Conditionality in

Social Cash Transfer Programs

MGSoG Dissertation Series, № 29

\section{Joe Abah}

Strong Organisations in Weak States:

Atypical Public Sector Performance in

Dysfunctional Environments

MGSoG Dissertation Series, № 28

\section{Zina Samih Nimeh}

Social Citizenship Rights: Inequality and Exclusion

MGSoG Dissertation Series, № 27

2011

\section{Daniel Vertesy}

Interrupted Innovation: Emerging

Economies in the Structure of the

Global Aerospace Industry

UNU-MERIT Dissertation Series,

№ 72

\section{Tina Saebi}

Successfully Managing Alliance

Portfolios: An Alliance Capability

View

UNU-MERIT Dissertation Series, № 71

\section{Nora Engel}

Tuberculosis in India: A Case of

Innovation and Control

UNU-MERIT/MGSoG Dissertation

Series, № 70

\section{Evans Mupela}

Connectivity and growth in Sub-

Saharan Africa: The Role of

Communication Satellites

UNU-MERIT Dissertation Series, № 69

\section{Nantawan Kwanjai}

Cross Cultural Intelligence amid

Intricate Cultural Webs: A Tale of the

UnDutchables in the Land of 1002

Smiles

UNU-MERIT Dissertation Series,

№ 68

\section{Lina Sonne}

Innovation in Finance to Finance

Innovation: Supporting Pro-poor

Entrepreneur-based Innovation

UNU-MERIT Dissertation Series,

№ 67

\section{Lenka Eisenhamerová}

Legitimacy of 'Humanitarian Military

Intervention'

MGSoG Dissertation Series, № 26

\section{Sonila Tomini}

Informal Payments for Health Care

Services in Albania

MGSoG Dissertation Series, № 25

\section{Jinjing Li}

Dynamic Microsimulation in Public

Policy Evaluation

MGSoG Dissertation Series, № 24 


\section{Aziz Atamanov}

Rural Nonfarm Employment and

International Migration as

Alternatives to Agricultural

Employment: The Case of Kyrgyzstan

MGSoG Dissertation Series, № 23

\section{Frieda Vandeninden}

Poverty Alleviation: Aid and Social

Pensions

MGSoG Dissertation Series, № 22

\section{Juliana Nyasha Tirivayi}

The Welfare Effects of Integrating

AIDS Treatment with Food Transfers:

Evidence from Zambia

MGSoG Dissertation Series, № 21

\section{Agnieska Ewa Sowa}

Who's Left Behind? Social Dimensions of Health Transition and Utilization of Medical Care in Poland

MGSoG Dissertation Series, № 20

\section{Emmanaouil Sfakianakis}

The Role of Private Actors in the

Provision of Public Goods with

Applications to Infrastructure and

Financial Stability

MGSoG Dissertation Series, № 19

\section{Siu Hing Lo}

White Collars Green Sleeves: An Interorganizational Comparison of

Determinants of Energy-Related

Behaviors among Office Workers

MGSoG Dissertation Series, № 18

\section{Treena $\mathrm{Wu}$}

Constraints to Human Capital

Investment in Developing Countries:

Using the Asian Financial Crisis in

Indonesia as a Natural Experiment

MGSoG Dissertation Series, № 17

\section{Henry Espinoza Peña}

Impact Evaluation of a Job-Training

Programme for Disadvantaged Youths:

The Case of Projoven

MGSoG Dissertation Series, № 16

2010

\section{Fernando Santiago}

Human Resources Management

Practices and Learning for Innovation

in Developing Countries:

Pharmaceutical Firms in Mexico

UNU-MERIT Dissertation Series,

№ 66

\section{Zakaria Babutsidze}

Essays on Economies with

Heterogeneous Interacting Consumers

UNU-MERIT Dissertation Series,

№ 65

\section{Bertha Vallejo}

Learning and Innovation Under Changing Market Conditions: The Auto Parts Industry in Mexico UNU-MERIT Dissertation Series, № 64 


\section{Donatus Ayitey}

Technical Change, Competitiveness and Poverty Reduction: A Study of the Ghanaian Apparel Industry UNU-MERIT Dissertation Series, № 63

\section{Sergey Filippov}

Multinational Subsidiary Evolution:

Corporate Change in New EU Member States

UNU-MERIT Dissertation Series, № 62

\section{Asel Doranova}

Technology Transfer and Learning under the Kyoto Regime: Exploring the Technological Impact of CDM Projects in Developing Countries

UNU-MERIT Dissertation Series, № 61

\section{Florian Tomini}

Between Family and Friend:

Understanding the Interdependency of Private Transfers

MGSoG Dissertation Series, № 15

\section{Michał Polalowski}

The Institutional Transformation of Social Policy in East Central Europe: Poland and Hungary in Comparative and Historical Perspective

MGSoG Dissertation Series, № 14

\section{Maha Ahmed}

Defining, Measuring and Addressing

Vulnerability: The Case of Post

Conflict Environments

MGSoG Dissertation Series, № 13

\section{Pascal Beckers}

Local Space and Economic Success: The Role of Spatial Segregation of Migrants in the Netherlands MGSoG Dissertation Series, № 12

\section{Victor Cebotari}

Conflicting Demands in Ethnically

Diverse Societies: Ethno political

Contention and Identity Values in

Europe

MGSoG Dissertation Series, № 11

\section{Dennis Gyllensporre}

Competing and Complementary Perspectives on the EU as a Crisis Management Actor:

An Examination of the Common Security and Defence Policy through the Lenses of Idealism and Realism MGSoG Dissertation Series, № 10

\section{Judit Vall Castello}

Business Cycle and Policy Effects on Labour Market Transitions of Older and Disabled Workers in Spain MGSoG Dissertation Series, № 9

\section{Keetie Roelen}

False Positives or Hidden Dimensions:

The Definition and Measurement of

Child Poverty

MGSoG Dissertation Series, № 8

\section{Denisa Maria Sologon}

Earning Dynamics in Europe

MGSoG Dissertation Series, № 7 


\section{Melissa Siegel}

Money and Mobility: Migration and

Remittances

MGSoG Dissertation Series, № 6

Jessica S. Hagen-Zanker

Modest Expectations: Causes and

Effects of Migration on Migrant

Households inSource Countries

MGSoG Dissertation Series, № 5

2009

\begin{abstract}
Alexis Habiyaremye
From Primary Commodity Dependence to Diversification and Growth:

Absorptive Capacity and Technological Catch Up in Botswana and Mauritius.

UNU-MERIT Dissertation Series, № 60
\end{abstract}

\section{Yoseph Getachew}

The Role of Public Capital in Economic Development

UNU-MERIT Dissertation Series, № 59

\section{Sandra Leitner}

Embodied Technological Change and

Patterns of Investment in Austrian

Manufacturing

UNU-MERIT Dissertation Series, № 58

\section{Semih Akçomak}

The Impact of Social Capital on

Economic and Social Outcomes

UNU-MERIT Dissertation Series, № 57

\section{Abraham Garcia}

The Role of Demand in Technical

Change

UNU-MERIT Dissertation Series, № 56

\section{Saurabh Arora}

Coherence in Socio-technical Systems:

A Network Perspective on the

Innovation Process

UNU-MERIT Dissertation Series, № 55

\section{Mirtha R. Muniz Castillo}

Human Development and Autonomy in Project Aid: Experiences from four bilateral projects in Nicaragua and El Salvador

MGSoG Dissertation Series, № 4

\section{Christiane Arndt}

Governance Indicators

MGSoG Dissertation Series, № 3

\section{Britta Augsburg}

Microfinance: Greater Good or Lesser Evil?

MGSoG Dissertation Series, № 2

\section{8}

\section{Rutger Daems}

Medicines for the Developing World UNU-MERIT Dissertation Series, № 54 


\section{Johannes Hanel}

Assessing Induced Technology:

Sombart's Understanding of Technical

Change in the History of Economics

UNU-MERIT Dissertation Series,

№ 53

\section{Rifka Weehuizen}

Mental Capital: the Economic

Significance of Mental Health

UNU-MERIT Dissertation Series, № 52

\section{Danielle Cloodt}

The Relationship between R\&D

Partnership Formation, Social

Embeddedness and Innovative

Performance

UNU-MERIT Dissertation Series, № 51

\section{Sabine Fuss}

Sustainable Energy Development under Uncertainty

UNU-MERIT Dissertation Series, № 50

\section{Geranda Notten}

Measuring and Managing Poverty

Risks

MGSoG Dissertation Series, № 1

2007

\section{Tobias Kronenberg}

Reconciling Environmental

Conservation with Economic

Prosperity: The Feasibility of Double

Dividends in the Short and Long Run

UNU-MERIT Dissertation Series, № 49

\section{Viktoria Kravtsova}

Assessing the Impact of Foreign Direct Investment in Transition Economies UNU-MERIT Dissertation Series, № 48

\section{Suhail Sultan}

The Competitive Advantage of Small and Medium Sized Enterprises: The Case of Jordan's Natural Stone Industry

UNU-MERIT Dissertation Series, № 47

2006

\section{Bulat Sanditov}

Essays on Social Learning and Imitation

UNU-MERIT Dissertation Series, № 46

\section{Mamata Parhi}

Dynamics of New Technology

Diffusion: A Study of the Indian

Automotive Industry

UNU-MERIT Dissertation Series, № 45

\section{Andreas Reinstaller}

Social Structures and the Innovation Process: Their Role in the Demand of Firms and Consumers

UNU-MERIT Dissertation Series, № 44 


\section{Rose Kiggundu}

Innovation systems and Development:

The Journey of a Beleaguered Nile

Perch Fishery in Uganda

UNU-MERIT Dissertation Series,

№ 43

\section{Thomas Pogue}

The Evolution of Research

Collaboration in South African Gold

Mining: 1886-1933

UNU-MERIT Dissertation Series,

№ 42

\section{Geoffrey Gachino}

Foreign Direct Investment, Spillovers and Innovation: The Case of Kenyan

Manufacturing Industry

UNU-MERIT Dissertation Series, № 41

\section{Önder Nomaler}

Technological Change, International

Trade and Growth: An Evolutionary,

Multi-Agents-Based Modeling

Approach

UNU-MERIT Dissertation Series, № 40

2005

\section{Samia Satti Osman Mohamed-}

Nour

Change and Skill Development in the Arab Gulf Countries

UNU-MERIT Dissertation Series, № 39

\section{Elad Harison}

Intellectual Property Rights:

Economics and Policy Analysis

UNU-MERIT Dissertation Series, № 38

\section{Daniel Dalohoun}

Learning to innovate: agricultural innovation and entrepreneurship: the case of Songhaï farmers in Benin UNU-MERIT Dissertation Series, № 37

\section{Müge Ozman}

Networks, Organizations and

Knowledge

UNU-MERIT Dissertation Series, № 36

\section{Bas Straathof}

Product Variety and Economic

Growth: The Counteracting Effects of

Scale and Idiosyncrasy

UNU-MERIT Dissertation Series, № 35

\section{Wilfred Schoenmakers}

Knowledge Flows between

Multinational Companies: A Patent

Data Analysis

UNU-MERIT Dissertation Series,

№ 34

\section{Myriam Cloodt}

Mergers and Acquisitions ( $M$ and As) in High-Tech Industries: Measuring the Post- $M$ and $A$ Innovative

Performance of Companies

UNU-MERIT Dissertation Series, № 33 
2004

\section{Paola Criscuolo}

$R \mathcal{E D}$ Internationalisation and

Knowledge Transfer: Impact on MNEs and their Home Countries

UNU-MERIT Dissertation Series, № 32

\section{Maarten Verkerk}

Trust and Power on the Shop Floor UNU-MERIT Dissertation Series, № 31

\section{Gottfried Leibbrandt}

Adoption, Harmonization and Succession of Network Technologies across Countries

UNU-MERIT Dissertation Series, № 30

\section{Mark Sanders}

Skill Biased Technical change: Its Origins, the Interaction with the Labour Market and Policy Implications UNU-MERIT Dissertation Series, № 29

2003

\section{Nadine Roijakkers}

Inter-firm Cooperation in High-tech Industries: a Study of RED

Partnerships in Pharmaceutical

Biotechnology

UNU-MERIT Dissertation Series, № 28
Viki Sonntag

Speed, Scale and Sustainability

UNU-MERIT Dissertation Series, № 27

\section{Masaru Yarime}

From End-of-Pipe Technology to Clean Technology

UNU-MERIT Dissertation Series, № 26

\section{Stéphane Malo}

The Combinatorial Chemistry

Revolution: Sustaining a Superior

Performance Position through

Technological Learning

UNU-MERIT Dissertation Series, № 25

2002

\section{Annelies Hogenbirk}

Determinants of Inward Foreign

Direct Investment: the Case of the

Netherlands

UNU-MERIT Dissertation Series, № 24

\section{Bastiaan Johan terWeel}

The Computerization of the Labour Market

UNU-MERIT Dissertation Series 


\section{Marjolein Caniëls}

Regional Growth Differentials: The

\section{John Adeoti}

Technology Investment in Pollution Control in Sub-Saharan Africa: The

Case of the Nigerian Manufacturing Industry

UNU-MERIT Dissertation Series, № 23

\section{Edward Huizenga}

Innovation Management: How

Frontrunners Stay Ahead: An

Empirical Study on Key Success

Factors in the ICT sector

UNU-MERIT Dissertation Series, № 22

2000

\section{Machiel van Dijk}

Technological Change and the

Dynamics of Industries: Theoretical Issues and Empirical evidence from

Dutch Manufacturing

UNU-MERIT Dissertation Series, № 21

1999

\section{Jan Cobbenhagen}

Managing Innovation at the Company Level: A Study on Non-Sector-Specific Success Factors

UNU-MERIT Dissertation Series, № 20
Impact of Locally Bounded Knowledge

Spillovers

UNU-MERIT Dissertation Series, № 19

1998

\begin{abstract}
Aldo Geuna
Resource Allocation and Knowledge production: Studies in the Economics of University Research UNU-MERIT Dissertation Series, № 18
\end{abstract}

1996

\section{Reinoud Joosten}

Dynamics, Equilibria, and Values UNU-MERIT Dissertation Series, № 17

\section{Hugo Kruiniger}

Investment, $R \mathcal{E} D$, and the Financing Decisions of the Firm

UNU-MERIT Dissertation Series, № 16

1995

\section{Hans van Meijl}

Endogenous Technological Change:

The Case of Information Technology, Theoretical Considerations and Empirical Results UNU-MERIT Dissertation Series, № 15 


\section{René Kemp}

Environmental Policy and Technical

Change: A Comparison of the

Technological Impact of Policy

Instruments

UNU-MERIT Dissertation Series, № 14

\section{Rohini Acharya}

The Impact of New Technologies on

Economic Growth and Trade: A Case

Study of Biotechnology

UNU-MERIT Dissertation Series,

№ 13

\section{Geert Duysters}

The Evolution of Complex Industrial Systems: The Dynamics of Major IT Sectors

UNU-MERIT Dissertation Series, № 12

\section{Marjan Groen}

Technology, Work and Organisation: A Study of the Nursing Process in Intensive Care Units

UNU-MERIT Dissertation Series, № 11

1994

\section{Huub Meijers}

On the Diffusion of Technologies in a Vintage Framework: Theoretical Considerations and Empirical Results UNU-MERIT Dissertation Series, № 10

\section{Theon van Dijk}

The Limits of Patent Protection: Essays on the Economics of Intellectual

Property Rights

UNU-MERIT Dissertation Series, № 9

\section{Hans Voordijk}

Naar Integrale Logistiek in

Bedrijfsketens: Ontwikkelingen in de Bouw

UNU-MERIT Dissertation Series, № 8

\section{3}

\section{Paul Diederen}

Technological Progress in Enterprises and Diffusion of Innovation:

Theoretical Reflections and Empirical Evidence

UNU-MERIT Dissertation Series, № 7

\section{Ben Dankbaar}

Economic Crisis and Institutional Change: The Crisis of Fordism from the Perspective of the Automobile Industry UNU-MERIT Dissertation Series, № 6

\section{Hanno Roberts}

Accountability and Responsibility: The Influence of Organisation Design on Management Accounting UNU-MERIT Dissertation Series, № 5 


\section{Bart Verspagen}

Uneven Growth between

Interdependent Economies: An

Evolutionary View on Technology

Gaps, Trade and Growth

UNU-MERIT Dissertation Series,

№ 4

\section{Sjoerd Romme}

A Self-organization Perspective on

Strategy Formation

UNU-MERIT Dissertation Series,

№ 3

1989

John Spangenberg

Economies of Scale, and Atmosphere in

Research Organisations

UNU-MERIT Dissertation Series,

№ 2

1988

John Hagedoorn

Evolutionary and Heterodox

Innovation Analysis: A Study of

Industrial and Technological

Development in Process Control and

Information Technology

UNU-MERIT Dissertation Series, № 1 
